\title{
JAPAN'S SUBNATIONAL GOVERNMENTS IN INTERNATIONAL AFFAIRS
}

Purnendra Jain

SHEFFIELD CENTRE FOR JAPANESE STUDIES/ROUTLEDGE SERIES

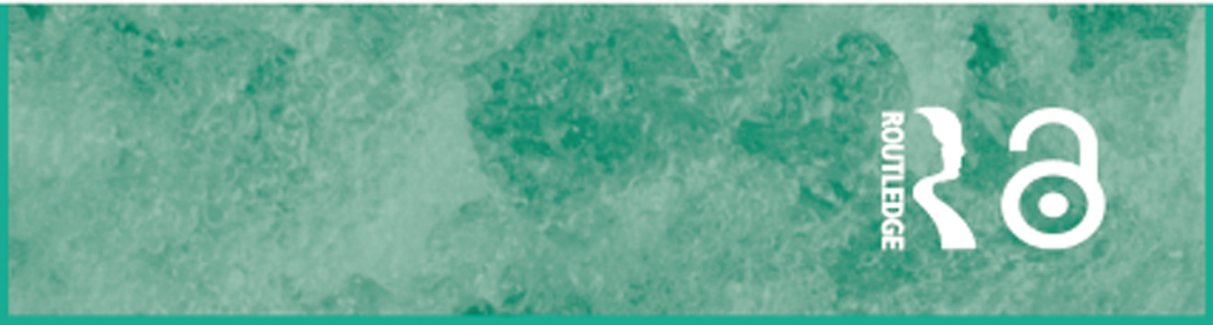




\section{Japan's Subnational Governments in International Affairs}

It is a common understanding that Japan's international relations are firmly the preserve of the national government within a highly centralized political system. This book dispels this belief by examining examples of subnational governments (SNGs) which are highly instrumental in foreign affairs. It shows how SNGs are operating as largely independent bodies in the international arena. This activity is demonstrated through their involvement in trade, aid and economic cooperation as well as cultural and educational programmes.

Drawing on extensive fieldwork and interviews, this book shows the valuable role that SNGs fulfil operating largely outside of national government in pursuit of both domestic and international goals. How, why and where these SNGs operate in Japan's international relations is explored alongside a comparative discussion of other Asian examples, including China and India.

In this seminal work, Jain brings to light the scope and consequences of the international actions of Japan's SNGs. By doing so, he provides a more accurate and nuanced understanding of Japan's foreign policy and international actions at a time when Japan is pursuing a broader and more active profile in international affairs.

Purnendra Jain is Professor of Japanese Studies at the Centre for Asian Studies, University of Adelaide, Australia. He specializes in the domestic and international politics of contemporary Japan with other Asia-Pacific nations. 


\section{Sheffield Centre for Japanese Studies/Routledge Series Series editor: Glenn D. Hook \\ Professor of Japanese Studies, University of Sheffield}

This series, published by Routledge in association with the Centre for Japanese Studies at the University of Sheffield, both makes available original research on a wide range of subjects dealing with Japan and provides introductory overviews of key topics in Japanese Studies.

\section{The Internationalization of Japan}

Edited by Glenn D. Hook and Michael Weiner

\section{Race and Migration in Imperial Japan}

Michael Weiner

Japan and the Pacific Free Trade Area

Pekka Korhonen

\section{Greater China and Japan}

Prospects for an economic partnership?

Robert Taylor

The Steel Industry in Japan

A comparison with the UK

Hasegawa Harukiyo

Race, Resistance and the Ainu of Japan

Richard Siddle

\section{Japan's Minorities}

The illusion of homogeneity

Edited by Michael Weiner

\section{Japanese Business Management}

Restructuring for low growth and globalization

Edited by Hasegawa Harukiyo and Glenn D. Hook 
Japan and Asia Pacific Integration

Pacific romances 1968-1996

Pekka Korhonen

Japan's Economic Power and Security

Japan and North Korea

Christopher W. Hughes

Japan's Contested Constitution

Documents and analysis

Glenn D. Hook and Gavan McCormack

Japan's International Relations

Politics, economics and security

Glenn D. Hook, Julie Gilson, Christopher Hughes and Hugo Dobson

Japanese Education Reform

Nakasone's legacy

Christopher P. Hood

The Political Economy of Japanese Globalisation

Glenn D. Hook and Hasegawa Harukiyo

Japan and Okinawa

Structure and subjectivity

Edited by Glenn D. Hook and Richard Siddle

Japan and Britain in the Contemporary World

Responses to common issues

Edited by Hugo Dobson and Glenn D. Hook

Japan and United Nations Peacekeeping

New pressures, new responses

Hugo Dobson

Japanese Capitalism and Modernity in a Global Era

Re-fabricating lifetime employment relations

Peter C. D. Matanle

Nikkeiren and Japanese Capitalism

John Crump

Production Networks in Asia and Europe

Skill formation and technology transfer in the automobile industry

Edited by Rogier Busser and Yuri Sadoi 
Japan and the $G 7 / 8$

1975-2002

Hugo Dobson

The Political Economy of Reproduction in Japan

Between nation-state and everyday life

Takeda Hiroko

Grassroots Pacifism in Post-War Japan

The rebirth of a nation

Mari Yamamoto

Interfirm Networks in the Japanese Electronics Industry

Ralph Paprzycki

Globalisation and Women in the Japanese Workforce

Beverley Bishop

Contested Governance in Japan

Sites and issues

Edited by Glenn D. Hook

Japan's International Relations

Politics, economics and security

Second Edition

Glenn D. Hook, Julie Gilson, Christopher Hughes and Hugo Dobson

Japan's Changing Role in Humanitarian Crises

Yukiko Nishikawa

Japan's Subnational Governments in International Affairs

Purnendra Jain 


\title{
Japan's Subnational Governments in International Affairs
}

\author{
Purnendra Jain
}


First published 2005 by Routledge

Published 2017 by Routledge

2 Park Square, Milton Park, Abingdon, Oxon OX14 4RN

711 Third Avenue, New York, NY 10017, USA

Routledge is an imprint of the Taylor \& Francis Group, an informa business

Copyright (C) 2005 Purnendra Jain

Typeset in Times New Roman by

Newgen Imaging Systems (P) Ltd, Chennai, India

The Open Access version of this book, available at www.tandfebooks.com, has been made availableunder a CreativeCommonsAttribution-Non CommercialNo Derivatives 4.0 license.

British Library Cataloguing in Publication Data

A catalogue record for this book is available from the British Library

Library of Congress Cataloging in Publication Data

Jain, Purnendra.

Japan's subnational governments in international affairs /

by Purnendra Jain.

p. cm. - (Sheffield Centre for Japanese studies/Routledge series)

Includes bibliographical references and index.

1. Subnational governments-Japan-Foreign relations.

2. Japan-Foreign relations-1989- I. Title. II. Series.

JZ4059.J35 2005

$327.52-\mathrm{dc} 22$

2005005627

ISBN 978-0-415-33367-2 (hbk) 


\section{Contents}

Preface ix

List of acronyms xiii

An outline of local government in Japan Xv

Introduction 1

1 Contexts: conceptual, comparative and Japanese 12

2 Japanese SNGs as international actors: domestic dimensions 39

3 International exchanges: SNGs lead with a soft approach 63

4 International cooperation: a strategic edge 87

$\begin{array}{lll}5 & \text { Economic diplomacy } & 113\end{array}$

6 Hard diplomacy: SNGs and national security 139

$\begin{array}{ll}\text { Conclusion } & 166\end{array}$

$\begin{array}{ll}\text { Notes } & 173\end{array}$

References $\quad 193$

Index 205 


\section{Preface}

From the early 1990s, my interest in Japanese local government and Japan's foreign affairs has continued to intersect for me, begging a comprehensive study of Japan's local governments as international actors in their own right. This book is the result, a product of about a decade of thinking, questioning and researching on this relatively unexplored subject. I could more fully focus my attention on this study after I was awarded a large grant from the Australian Research Council for a three-year period, 2001-03. This enabled me to pursue systematic research with the help of part-time research assistants, and undertake empirical work through fieldtrips in Japan and elsewhere. Without this grant, the book would have been impossible, especially as the project needed frequent research trips to Japan to collect information through interviews in localities across the country and library research. The grant also provided me with teaching relief for one semester, which greatly facilitated my writing and timely completion of the project. My sincere thanks to the Australian Research Council.

As with any research project, support from a number of people became crucial. Numerous national and local-level officials and politicians in Japan generously set aside time to talk with me, share their ideas and insights and answer my specific questions. Some also offered materials or supplied the ones that I requested. It is impossible to list all of their names and some, anyway, preferred to remain anonymous. I certainly acknowledge here with deep appreciation their cooperation, time and patience in carefully explaining some of the very complex issues in this little-examined epistemic landscape. I especially mention CLAIR officials in the Tokyo, Sydney, Seoul and Singapore offices, who generously gave their time and valuable verbal information and printed materials. Several officials in the Ministry of Foreign Affairs, Ministry of Home Affairs (now Sōmushō Home Affairs), JETRO, JICA and JIAM readily agreed to answer my questions on the wide-ranging issues examined in this book. Officials of Hokkaido, Miyagi, Gifu, Hyogo, Niigata, Okinawa, Oita and Fukuoka Prefectures and Sapporo, Nagoya, Hiroshima, Kobe, Kitakyushu and Niigata Cities were particularly generous with their time. Staff at the Tokyo Municipal Research Library were very obliging, especially Mr Tamura Yasuhiro and Mr Yanagihara Hirohiko. Inoguchi Takashi, Shinohara Hajime, Menju Toshihiro, Yoshida Hitoshi, Nakamura Akira, Kanbara Masaru, Tsujiyama Takanobu and Mizukami Tetsuo have advised, helped and encouraged me throughout the project. I offer all of them my sincerest thanks. 


\section{x Preface}

During the course of writing this book, I published several papers on related topics, one of them with my colleague Yoshida Hitoshi. I have drawn on materials published in these papers and I would like to thank the apposite journal editors and my co-author for allowing me to reproduce some of the materials in various sections of the book. These journals are: Global Change, Peace \& Security, Asian Profile and Policy and Society.

Several research assistants helped me with this project from time to time in cataloguing materials, translating and advising on several aspects of this project. First and foremost I owe my deep gratitude to Maureen Todhunter for helping me with this project in many ways - as research assistant, critic and editor. I thank her for her crucial support, invaluable assistance and professional attention at every stage of this work. Carol Lawson, Midori Kagawa-Fox, Hidaka Tomoko and Mahara Akiko also assisted me at various stages with research support and I thank them accordingly.

While researching and writing drafts of this book, I presented seminars at various institutions and received valuable feedback for which I am grateful. These institutions include Meiji University, Bukkyo University, Rikkyo University, University of Birmingham, University of Melbourne, University of Hawaii and the University of Adelaide. Discussions at the Local Government Centre in Birmingham University and Warwick, especially with Professor Mike Geddes, were very useful for the conceptual and comparative analysis in Chapter 1.

Alan Rix, Ellis Krauss, Terry MacDougall, Lam Peng Er, Akaha Tsuneo, Glenn Hook, Arthur Stockwin, Felix Patrikeeff and Gerry Groot generously gave me useful comments on one or several draft chapters of the book and I thank you all very much. I also thank Glenn Hook for encouraging me to consider the Sheffield Centre for Japanese Studies Routledge Series for publishing my work and sincere thanks to the Routledge staff, especially Stephanie Rogers, for their cooperation and support at every stage of producing this book.

Finally, I want to acknowledge my family for their support and patience. I especially appreciate their understanding during my frequent absences from home on overseas trips for fieldwork for this book and during the many late nights/early mornings when the annoying tap of my fingers on keyboard resonated through an otherwise quiet home. I owe special thanks to Sam for his help as research assistant, critic and especially for much-needed computer assistance.

My list of people to thank is long. But it is I alone who accept full responsibility for the content and interpretation I offer in this book.

\section{Conventions}

\section{Japanese names}

In Japan, family name precedes given name and I respect that convention in this book. However, in most English-language books, Japanese authors' names appear in the Western order, with their given name followed by family name. I retain the order presented in the original publication. 


\section{Japanese words}

Long vowels in Japanese words are marked, but there are some exceptions for place name such as Tokyo, Hyogo, Hokkaido that are recognized in English without these marks. I am responsible for translation of all Japanese texts and titles. In translating titles I have used sentence case, for example, Menju Toshihiro (1998) 'Jichitai gaikō no susume' (local diplomacy), Chūō Kōron, October. I have retained original translations where they are provided and these are indicated through title case as in Menju Toshihiro (2002) 'Jichitai gaikō no kadai to tenbō' (International Policies of Japanese Local Governments), Toshi Mondai, 93: 1, January. 


\section{Acronyms}

$\begin{array}{ll}\text { ALT } & \text { Assistant Language Teacher } \\ \text { APEC } & \text { Asia-Pacific Economic Cooperation } \\ \text { ASEAN+3 } & \begin{array}{l}\text { Association of Southeast Asian Nations plus Japan, China and } \\ \text { South Korea }\end{array} \\ \text { CDI } & \text { Community Development Initiative } \\ \text { CIRs } & \text { Coordinators for International Relations } \\ \text { CLAIR } & \text { Council of Local Authorities for International Relations } \\ \text { COCOM } & \text { Coordinating Committee for Export Control } \\ \text { DAC } & \text { Development Assistance Committee } \\ \text { EC } & \text { European Commission } \\ \text { ERINA } & \text { Economic Research Institute for Northeast Asia } \\ \text { EU } & \text { European Union } \\ \text { FCM } & \text { Federation of Canadian Municipalities } \\ \text { FDI } & \text { Foreign direct investment } \\ \text { FMCU } & \text { World Federation of United Cities } \\ \text { GATT } & \text { General Agreement on Tariffs and Trade } \\ \text { GDP } & \text { Gross domestic product } \\ \text { ICETT } & \text { International Centre for Environmental Technology Transfer } \\ \text { ICLE } & \text { International Council for Local Enviromental Initiatives } \\ \text { IULA } & \text { International Union of Local Authorities } \\ \text { JAMLIF } & \text { Japan Municipal League for International Friendship } \\ \text { JAMP } & \text { Japan Academy for Municipal Personnel } \\ \text { JBIC } & \text { Japan Bank for International Cooperation } \\ \text { JET } & \text { Japan Exchange and Teaching } \\ \text { JETAA } & \text { JET Alumni Association } \\ \text { JETRO } & \text { Japan External Trade Organization } \\ \text { JEXIM } & \text { Export-Import Bank of Japan } \\ \text { JIAM } & \text { Japan Intercultural Academy of Municipalities } \\ \text { JICA } & \text { Japan International Cooperation Agency } \\ \text { JOCV } & \text { Japan Overseas Cooperation Volunteers } \\ \text { JPP } & \text { JICA Partnership Programme } \\ \text { JSEG } & \text { Japan Sea Economic Group } \\ \text { KICC } & \text { Kobe International Cooperation Center } \\ & \end{array}$


KITA Kitakyushu International Techno-cooperative Association

KLAFIR Korean Local Authorities Foundation for International Relations

LAL Local Autonomy Law

LAT Local allocation tax

LDP Liberal Democratic Party

MAFF Ministry of Agriculture, Forestry and Fisheries

ME Ministry of Education

METI Ministry of Economy, Trade and Industry

MEXT Ministry of Education, Culture, Sports, Science and Technology

MITI Ministry of International Trade and Industry

MOFA Ministry of Foreign Affairs

MOHA Ministry of Home Affairs

NAFTA North American Free Trade Agreement

NEAR Association of Northeast Asia Regional Governments

NET Natural economic territories

NGO Nongovernmental organization

NIMBY Not in my backyard

O-BIC Osaka Business and Investment Centre

OCHA Office for the Coordination of Humanitarian Affairs (UN)

ODA Official Development Assistance

OECD Organization for Economic Cooperation and Development

OECF Overseas Economic Cooperation Fund

PBEC Pacific Basin Economic Council

PECC Pacific Economic Cooperation Council

PRC People's Republic of China

RFE Russian Far East

SACO Special Action Committee on Okinawa

SASJ Situations in Areas Surrounding Japan (Law Concerning

Measures to Ensure the Peace and Security of Japan)

SDF Self Defence Force

SEA Sports Exchange Advisor

SHA Sōmushō Home Affairs (Ministry of Public Management, Home Affairs, Posts and Telecommunications)

SNG Subnational Government

TRADP Tumen River Area Development Programme

UCLG United Cities and Local Governments

WHO World Health Organization

WTC World Trade Centre

WTO World Trade Organization 
Prefectures, Prefectural Capitals, and Number of Municipalities by Prefecture

- Prefectural capital

$\star$ Designated city

- Designated city and prefectural capital

- Core city

- Core city and prefectural capital

(n) 


\section{Introduction}

In Japan today, local or subnational governments (SNGs) together with many non-state organizations have joined national authorities to become important actors in international affairs. ${ }^{1}$ This is a result of profound changes in the domestic and international contexts of Japan's external relations that have rendered a ball game rather different from earlier times among the players on Japan's foreign affairs field. The forces of globalization and technological advancement continue to erode the authority of national borders as defining mechanisms and regulators of international flows. Inside Japan, the traditional capacity of the national government to regulate international flows is also weakening. It is not just the nature, the extent, the style and the goals of Japan's international relations that are transforming. Inevitably, the actors who initiate, participate in, and influence these relationships are also changing. Conducting international relations and influencing foreign policy are no longer the sole preserve of Japan's central government through its Ministry of Foreign Affairs (MOFA) and other Tokyo-centred actors. New actors are becoming significant in conducting and influencing - indeed redefining - Japan's international relations. SNGs are key agents in this new context.

This book opens the window on these hitherto unexplored political developments by examining the role of Japan's SNGs as important new types of players in Japan's foreign affairs. It also considers the domestic and international political implications of this move by SNGs into the international arena. SNG involvement in international issues relates to two key transformations under way in most nations, known in Japan as uchinaru kokusaika (domestic internationalization of, and from inside, the nation) and sotonaru kokusaika (transborder internationalization of, and from outside, the nation). The focus of this book is on the latter as we explore the role of SNGs as actors pursuing their own interests through international engagements and the political consequences of this development.

The broad-ranging international initiatives of SNGs include not just promoting cultural and educational programmes, technological and scientific cooperation or trade and other commercial activities, but also providing foreign aid, a local version of official development assistance (ODA) and importantly, carrying out diplomacy by extension, as an arms-length vehicle for the national government. All of these have significant implications for Japan's international affairs. 


\section{Introduction}

Furthermore, SNGs are also increasingly involved in hard-core diplomatic issues (such as war, security and international peace) through their policies, pronouncements and actions. Some of these involvements may have simply symbolic significance but others certainly have major implications for Japan's foreign policy since SNGs are government bodies, after all. These actions are being pursued by an increasing number of Japanese SNGs in various configurations: across different levels of government (prefecture, city and town), bilaterally between Japanese SNGs and their counterparts overseas, multilaterally between groups of Japanese SNGs and external partners, and in partnership with or independently of the central government. Very few SNGs are involved in activities that have explicit political impact on national diplomacy or deliberately draw international political or strategic relations into the domestic political arena. Generally, international activity rewards the locality through economic and/or socio-cultural benefit and may also reward the SNG through stronger domestic political leverage. Therefore as the national level shifts more and more administrative responsibility without adequate finances to the subnational level in the name of decentralization, there may be a widening gap in performance between SNGs that pursue international affairs successfully and those that focus narrowly on domestic issues.

This book reaches beyond the questions of who, what, when and where, to address the crucial issue of 'why'. We explore international and domestic factors that have promoted SNGs' rising activism in international affairs and consider how SNG motivations influence the types of international programmes and where/with whom these programmes are conducted. The political implications of these locally initiated international actions are considered in two contexts - the management of Japan's international affairs and foreign policy, and relations between the national and subnational levels of government - as national-government actors tenaciously defend their political turf. We see that some SNGs use international activities to increase their leverage and their autonomy in domestic politics.

That SNGs are taking initiatives in response to profound structural change under way in Japan is not of itself an unprecedented development. Although conventional wisdom has generally cast the role of SNGs as narrowly limited to repairing streetlights, paving roads, collecting garbage and other community services, their role expanded significantly several decades ago and as a result of their own initiatives. From the late 1960s, as the consequences of rapid post-war industrialization and urbanization began to confront local communities with unforeseen problems, many progressive SNGs took steps ahead of the central government to address these new challenges.

They responded effectively to the need for appropriate housing, childcare and health-care facilities and for protecting people's lives from new industrial by-products such as noxious industrial wastes and other industrial pollution. ${ }^{2}$ SNGs have actively pursued the cause of human and political rights such as those of Korean residents in Japan and voting rights of foreign residents. ${ }^{3}$ Japan's SNGs have played a pioneering role in these policy areas - not only in association with the national government but also, importantly, at times in opposition to it. 
Japanese SNGs have long been unsung pacesetters in the nation's political life and now in response to complex domestic and international challenges, they are again demonstrating innovative capacities, practical abilities and political acumen by moving into the international arena. Although they are certainly driven by developments in the national and international arenas, SNGs are not simply reacting; some have moved proactively on many of the issues affecting Japan's international diplomacy. The end of the Cold War, the forces of globalization and rapid technological advancement in the final quarter of the twentieth century have served as vital enabling forces.

The entrance of SNGs and other bodies as increasingly active international actors is an international trend; Japan is not exceptional. Across the world, these developments have drawn into the policy arena new players, interests, concerns and strategies. They have set in motion a shift in power relationships not just between key players on the national and international stages, but at all levels of government within the state, from national level down to towns and villages. The changing international context has created situations that compel lower levels of governments, nongovernmental organizations (NGOs), citizens and others formerly excluded from the narrow realm of foreign policy to pursue their own interests and priorities at the international level in partnership with or independently of the central government and with or without the centre's approbation. ${ }^{4}$

Some observers have referred to Japan's response to these international developments as Japan's 'third' opening up. ${ }^{5}$ International challenges and central government responses to them have been felt nationwide particularly from the 1980s, and have sometimes prompted independent action, remedial or retaliatory, by Japanese citizens and their representative bodies. As a post-war trading giant, Japan needed to accept new, often dislocating rules of global trade, including opening protected domestic markets, making currency adjustments and opening national borders to an inflow of people from abroad. The impact was felt most severely at the grassroots level, sometimes even in remote communities. Globalization of the distribution process in trade forced the central government to open protected domestic agricultural markets to overseas suppliers and began to erode the livelihoods of rural producers and their communities, forcing them to search for alternative means of economic, social and political survival. Internationalization of production encouraged many of Japan's industries to move offshore for cheaper labour to remain competitive in the free market environment, taking a raft of manual jobs outside Japan and exposing Japanese expatriates to new parts of the world.

The flow of people and ideas was inward as well as outward. In the labour-scarce booming economy of the 1980s, workers from developing countries found Japan an attractive destination for work in construction and industry. Foreign business professionals and working-holiday visa holders, 'foreign brides' and international students gave visible human presence to internationalization. This was the beginning of Japan's kokusaika (internationalization) at the grassroots level, as people from outside Japan came to live within Japanese neighbourhoods. Local communities and their governments faced unparalleled challenges as most Japanese, until then, had remained relatively isolated from the outside world. ${ }^{6}$ 


\section{Introduction}

For their part, many SNGs realized that they could not address the challenges of globalization by continued reliance on the national government in Tokyo for policy advice and financial support. Some national-government policies damaged local economies, employment structures and communities, and the largely top-down central government was not in the habit of consulting SNGs on policy decisions. Central authorities also continued to reduce financial support for SNGs to meet constraints upon the national budget arising from the long-standing economic recession.

Some SNGs recognized in these circumstances not just the need for innovative action but also opportunities for self-advancement through greater autonomy from within Japan's centralized unitary system of government. These opportunities are possible if SNGs can build financial autonomy and form new strategic alliances. To this end, SNGs have pursued some opportunities to build the strength of their local economy through innovative policies that include international economic relations independent of the central government. These enhance SNGs' financial autonomy from the central government and help to strengthen their position in relations with the centre, as the principal source of SNG income and direction. SNGs recognize that the new politico-economic conditions have served to further unhinge the tenuous alignment of interests between themselves and the central government. The centre's management of local economies through vertical, top-down administration has proven to be increasingly inefficient and ineffective. ${ }^{7}$ SNGs have discovered more useful partners in their counterparts nationally and internationally, that share similar concerns and experiences and can engage meaningfully with them in tackling new challenges, for mutual learning and support. 'Horizontal linkages' between localities inside Japan were formed in the past for nationwide policy coordination and such linkages still exist. $^{8}$ Now some linkages cross national borders, as SNGs seek to develop ways to address their problems with their counterparts outside Japan.

\section{Deficit of attention to SNGs' international reach}

Today in Japan there is much greater recognition than before that Japanese SNGs are genuine players in international affairs. But the full import of this development and its potentially far-reaching consequences is as yet not appreciated. There has been little discussion and analysis of this phenomenon in mainstream literature, either Japanese or foreign, that deals with Japan's subnational government, national-subnational relations, or Japan's foreign affairs. ${ }^{9}$ The issue of Japanese SNGs in international affairs has not registered in the analytical frameworks used by Japan scholars. It appears that outdated assumptions about Japan's highly centralized state have helped to block recognition of emerging actors like SNGs. Some academic studies are available, ${ }^{10}$ but most accounts have appeared in semi-official publications or from practitioners such as governors, mayors and local officials, ${ }^{11}$ or have focussed on a few distinctive SNGs or a particular subregion of Japan. ${ }^{12}$ Meantime the comparative literature on SNGs as international actors remains largely Western-centric with limited analysis of Asian examples. ${ }^{13}$ 
This book is therefore an attempt to fill a significant void in the literature on three important issues concerning contemporary Japan: first, the changing role of Japan's SNGs as they pursue their interests beyond Japan's national borders; second, the influence upon SNG relationships with central government actors, which are surely affected by the SNGs' newfound leverage from international activities; and third, the conduct of Japan's international relations and management of foreign policy as SNGs extend their international reach. Many studies have argued cogently that SNGs have considerable autonomy in certain domestic policy matters. This study explains how SNGs are gaining autonomy in international matters, and alongside other relatively new players such as NGOs and citizens' groups, SNGs are making an impact on Japan's foreign policy. ${ }^{14}$ These developments indicate that the world's second largest economy - industrialized, modernized and internationalized Japan - has joined the frontline of this phenomenon that began to flourish in the West some decades back.

It is important at this point to acknowledge the need to maintain a sense of proportion about what is under the lens here. This study confirms increasing pluralization in the conduct of Japan's international affairs, but it does not by any means deny the role of the central government as the main player with primary responsibility in the country's international affairs. Rather, this study asserts that the national-level actors' monopoly on foreign affairs has been broken by the emergence of a range of other actors including 'governments' at lower levels. The national ministries and agencies can no longer control all aspects of foreign affairs. These bodies no longer have the capacity, the expertise, and the resources to fulfil the functions required of national foreign policy under the new global circumstances and other actors such as SNGs are willing and able to become involved. SNGs now have the precedents set by their counterparts outside and inside Japan, and some are keen to pursue opportunities now available. They also recognize the need to help shape proactively the course of international relations rather than to retreat behind the central government and live with the consequences of the centre's actions or inaction. SNGs see that the interests of national and subnational governments conflict more and more, and only through their own direct actions, sometimes transborder, can SNGs seek the outcomes best suited to their local interests. The evidence presented here therefore suggests that in future we are likely to see more pluralism and less centralization in Japan's approach to managing foreign relations. The central government has, willingly or not, taken an accommodative stance rather than being stubbornly exclusive in foreign affairs issues, recognizing that it has no better alternative. Nevertheless, it does not necessarily follow that the central government generally takes an inclusive stance on foreign affairs matters. And as ironic as it might be, the national government still treats SNGs acting internationally as part of the private sector (minkan) and NGOs. ${ }^{15}$

A second caveat concerns the extent to which SNGs are involved in international pursuits. Although this study produces wide-ranging evidence of SNGs' international activities, I do not claim that all Japanese SNGs are involved in international affairs or that they are involved to the same degree. Quite the contrary. The level of interest among SNGs varies considerably, as do their motivations, strategies 


\section{Introduction}

and wherewithal. Some still hold the conventional view that 'foreign affairs' is a national matter and SNGs should not intrude. Yet some local leaders, policy advisors and think-tank staff believe strongly that SNGs have a distinctive and significant role to play in international relations. ${ }^{16}$ They believe that the era when SNGs were concerned only with local issues has passed and as globalization has reached into even the smallest corners of localities, it is time for SNGs not simply to 'think globally and act locally' but also to 'think locally and act globally'. Here, the message of their advocacy is unambiguous.

\section{Theoretical and comparative issues}

Much of this book's discussion is empirical and proceeds from discussion in Chapter 1 of two broad theoretical concerns, one in international politics and the other in domestic politics. I discuss these from a comparative perspective, with examples from industrialized and developing countries. The first takes us to the debate in the International Relations literature between the state-centric realist and pluralistic complex-interdependence approaches to understanding relationships across national borders. This study identifies the emergence of a pluralistic interdependent framework in Japan's foreign affairs. This pluralism is consistent with the trend noted as far back as at the start of the 1970s by pre-eminent International Relations scholars Robert Keohane and Joseph Nye, with sub-state and non-state actors playing a crucial role in initiating, maintaining and shaping the nation's international relationships. ${ }^{17}$ The Japanese case illustrates how in the present era of internationalization and increasing global interdependence, transborder relationships are less and less between 'nations', and boundaries between domestic and international policy appear ever more indeterminate. Even so, this does not signal the end of the nation state, or the complete redundancy of national governments in framing foreign policies and attempting to commandeer international diplomacy, as the Japanese case illustrates clearly.

The second theoretical concern relates to how the rise of SNGs as international actors is shaped by, and itself shapes, Japan's highly centralized political structure. It takes us to the power struggle between levels of government as the centre tries to maintain its firm grip on policy and administrative authority in the face of increasing demands from localities for policy autonomy, flexibility and decentralization of functions. The capacity of SNGs to conduct some international activities more effectively than the centre, and the centre's own internecine conflicts, serve to accentuate this struggle. A related issue that feeds directly into the first, concerns the increasing conflict of interest between national and subnational governments. Gradually, the central government has relinquished some of its authority and is willing to work with SNGs in partnership, at least where the interests of both coalesce.

\section{The evolution of SNGs as international actors in Japan}

By comparison with SNGs in North America, western Europe and in some other countries, Japanese SNGs have been slow to extend their reach internationally. 
Even so, SNGs' involvement in Japan's international affairs is by no means new. It is, and always has been, shaped by the administrative constraints of Japan's centralized system of government that restrict what SNGs can do. Historical accounts record how some centuries ago, a few cities tried to pursue their own interests by opening their territories to foreigners and pursuing activities overseas. ${ }^{18}$ However, as Meiji leaders centralized national administration and increased their control during the second half of the nineteenth century, national level actors came to monopolize most areas of public policy. In the post-war period, SNGs were granted some autonomy under the new 1947 constitution, but the 'centralized' unitary structure remained at least partially intact. ${ }^{19}$

Taking advantage of this new constitutional status granted to SNGs, local leaders and bureaucrats took time to try to assert some autonomy in policy development. Sometimes they acted in consultation and cooperation with the national government but at times some SNGs acted contrary to the wishes of the national government. ${ }^{20}$ SNGs' initial steps internationally from the mid-1950s were through sister-city relationships, a so-called 'soft' area of foreign policy where the aims and interests of both levels of government were mutual.

The rise of progressive mayors and governors in the 1960s and 1970s politicized some local issues that had a direct bearing on Japan's foreign affairs. Tension set in as local-national interests slowly began to diverge. For example, in the early 1970s Mayor Asukata Ichio of Yokohama City refused to grant permission for Japan-based US tanks to pass along the city's roads on their way to the Vietnam War. Some SNGs began to form ties with SNGs in countries from which Japan's diplomatic relations were estranged because of Cold War ideological differences. The Japan-Soviet Coastal Mayors' Association (now the Japan-Russia Mayors' Association of the Sea of Japan Coastal Cities) established in 1970 and the 1972 Conference of Japan Sea Coastal Cities for Japan-North Korea Friendship and Trade Promotion are two main examples. Here SNGs aimed to demonstrate how governments below the national level could sustain productive ties even while Cold War animosities ruptured 'official contacts' at the national level. These actions demonstrated that SNGs could do what the central government, because of diplomatic baggage and concerns for national security, could not.

During the 1960s and 1970s, some SNG leaders involved their administrations in international relations simply by expressing opinion on critical issues such as war and peace and by making policies or pronouncements that were directly against Japan's official position. Yet, these acts remained on the periphery of SNG activities and were largely symbolic except in a few localities such as Hiroshima where the legacy of the atom bomb is pushed nationally and internationally. Until the early 1980s, SNGs generally confined themselves primarily to the symbolic aspects of sister-city relationships. Only a few pursued initiatives with clear political overtones and even these were mostly consistent with the centre's diplomatic planning and did not indicate an irreconcilable clash of interests. Except for a few prominent localities, SNGs did not seriously consider themselves in the role of conducting international relations since they had very little opportunity, motivation, precedent, political willingness or know-how to do so. The national authorities also had no need to acknowledge or co-opt SNGs in the policy domain. 


\section{Introduction}

Recognition that SNGs could play a vital role in international relations gained significant currency with the end of the Cold War. SNGs now recognize they have both the need and the capacity to pursue this avenue. Even the national government now accepts that SNGs constitute an important part of the team in selected areas of foreign affairs, largely because they have the practical ability but sometimes precisely because they do not have the diplomatic baggage of the central government bodies.

What differentiates the recent upsurge of SNGs as international actors from the earlier, much smaller-scale pursuits? It is not just the expansion in programmes and numbers of SNGs involved. Part of the difference is the institutionalization of SNGs as international actors. New institutions with the necessary administrative arrangements have been established at local, regional and national levels to initiate and sustain SNG international activities. For example, all prefectures and large cities have established international affairs departments or sections (kokusai-bu or ka) and third-sector organizations (kyōkai) - often a collaborative structure between SNGs and local private organizations - for administering activities related to issues of international relations. To some extent these institutions enable the central government to coordinate and regulate SNGs' international actions.

The Council of Local Authorities for International Relations (CLAIR), a national body representing SNG interests, has branch offices throughout Japan and even overseas. The Ministry of Home Affairs (MOHA) in particular has supported and promoted SNGs' international role. ${ }^{21}$ Other ministries such as the Ministry of International Trade and Industry (MITI, now METI), Ministry of Education (ME, now MEXT) and central agencies like Japan External Trade Organization (JETRO) and Japan Bank for International Cooperation (JBIC) have recognized the crucial role of SNGs in a range of foreign affairs issues. Even the MOFA, stridently protective of its bureaucratic turf, is coming to terms with a new status quo where other actors including SNGs pursue actions outside Japan beyond the Ministry's full control. These central government players accept SNG involvement and see SNGs as potential partners in situations where interests are shared, such as generating economic benefit and creating goodwill abroad. However, central government players try to restrict and even curtail SNG activities when the centre sees SNGs as competing with it or pursuing initiatives and policies that intrude on the centre's bureaucratic turf or that the centre thinks may adversely affect national interests, illustrated particularly in Chapter 6 .

'The international' has become new policy turf for bureaucratic battles between government actors. It is well known that Japanese ministries and central agencies do not speak with one voice in policy matters; they compete for power, prestige, authority and budget. ${ }^{22} \mathrm{MOHA}$ has been the ministry with least influence in foreign affairs given its responsibility for domestic issues, local-level governments and local concerns. However, with development of SNGs as international actors in their own right, MOHA has come to discover that it can compete with MOFA in some areas by using SNGs. Thus MOHA as the supervising ministry of SNGs has acted as their strongest ally in supporting their international ventures. 
MOFA, which assumed for itself the mantle of exclusively conducting Japan's international diplomacy and has very little interest in domestic development, has proved to be the weakest link in nurturing SNGs' international role. These themes of rivalry and alliances at various levels of government, and conflicting or shared interests in issues beyond Japan's borders, are discussed in detail in later chapters. What we need to recognize is that SNGs have attempted to use this situation to their own advantage. Recognizing this helps to shed light on how SNGs are also influenced by the interests and politicking of individuals, other SNGs and central governments both inside and outside Japan.

\section{The changing debate and language}

The discussion above suggests how official perceptions of SNGs' international engagements have changed from politically benign to somewhere between diplomatically useful and potentially or actually polemical and threatening to some central authorities. With the arrival of increasing inflows of foreigners as longterm residents in the late 1970 s and 1980s, government actors were instrumental in popularizing a new discourse of kokusaika (internationalization). One dimension of this discourse concerns uchinaru kokusaika (domestic internationalization), a sub-discourse setting out the role and responsibility of Japanese government actors at national and subnational levels in addressing the new international challenges inside Japan. To be sure, SNGs' actions towards foreigners inside Japan are related to SNGs' actions outside Japan and towards foreigners outside Japan. However, as indicated earlier, this book explores the other subdiscourse - sotonaru kokusaika (transborder internationalization).

In the late $1970 \mathrm{~s}$ and $1980 \mathrm{~s}$, discussion of SNGs' interactions with the international community mainly concerned the various types of exchanges and collaborative arrangements then under way. In the 1990s, the style of these activities was linguistically recast: from $k \bar{o} r y \bar{u}$ (exchange) to kyōryoku (cooperation). ${ }^{23}$ This shift symbolized the expansion of SNGs' international programmes and highlighted the programmes' mutually beneficial nature. It was also part of SNGs' move to increase their independence as international actors. 'Kokusai yakuwari' (international role) and 'kokusai seisaku' (international policy) referring to SNGs' limited international engagements were replaced with 'kokusai kyōryoku' (international cooperation), 'chihō gaikō' (municipal diplomacy) and 'toshi gaiko' (urban diplomacy) to accommodate the diplomatic import and overall importance of these actions. ${ }^{24}$

\section{Structure of this book}

This study progresses from the 'big picture' to specific details of the Japanese case. Chapter 1 sets the context by exploring three strands of discussion. First is conceptual, turning to the International Relations literature to identify how the forces broadly understood as 'globalization' have (1) profoundly transformed and expanded relations across national borders; and (2) forced new approaches to 
managing these relations through various types of 'domestic' and 'foreign' policy. The second strand is comparative and here we turn to studies of the increasingly active, diverse and politicized role of SNGs in many countries. These works help to contextualize the Japanese case with insights into: (1) how and why SNGs in other countries pursue international action in their own right; and (2) the domestic consequences of these SNGs' actions for foreign policy and intra-governmental relations. The third strand considers Japanese context as a prelude to empirical discussion that follows.

Chapter 2 contextualizes the actions of Japanese SNGs in international affairs by considering developments inside Japan. Here, we overview the complex mix of international, national and subnational factors at work. We consider how these factors promote, constrain and ultimately shape the SNGs' international actions through influencing SNGs' capacity, ability and willingness to pursue these actions.

Chapter 3 is the first of four chapters that focus on the specific types of international activities and programmes that the SNGs pursue. Analysis in all four chapters is guided by questions of what, where, how and why. I illustrate with examples gleaned during fieldwork in specific locations in Japan, each location chosen carefully for capacity to reveal the diversity, extent and impact of SNGs' international pursuits. The chapters follow the evolutionary path of the SNGs' overseas pursuits, beginning in Chapter 3 with international exchange programmes that have been in place since the early 1950s. Here the major focus is on the key vehicles of international exchange, which are sister-city relationships and the Japan Exchange and Teaching (JET) programme.

Chapter 4 highlights a new era of international relations in Japan initiated the grassroots level. As noted earlier, in the 1990s MOHA and some SNGs put forward the slogan Kōryū kara kyōryoku e (from exchange to cooperation). Here, I look particularly at SNGs' involvements in their principal types of international cooperation: (1) cooperative problem-solving with foreign counterparts; and (2) foreign-aid delivery. We find that in some cases SNGs are doing what the centre cannot do because SNGs have the practical capacity, experience and useful networks. As a result, some central authorities are keen to involve SNGs in international collaboration, but the central government still attempts to control them through new institutional arrangements.

One of the most important motivations for SNGs pursuing international activities at present is to maximize the economic interests of their locality. This is a relatively new approach in Japan by comparison with its Western counterparts. Here, the national government shares with SNGs a keen interest in positive outcomes, appreciating the potential for national economic benefit. Chapter 5 examines the various types of economic and commercial relationships that SNGs are pursuing independently or collectively as regions, the strategic motivations behind these relationships, and what they produce.

Japanese SNGs do not have the legal and constitutional power of their counterparts in the United States, and administratively and traditionally they are bound quite firmly to the central government. These circumstances by design and 
in practice weaken SNGs' political will to pursue international actions that contravene the stance of the central government. Yet, there are strong indications that as the elected representatives of local constituents, some SNGs are keenly interested in hard-core diplomatic matters that impinge on their locality, including national security and territorial conflicts. Some matters inspire resistance by local leaders and communities that are affected by the treaties and arrangements that the national government puts in place in the name of the national interest. Some localities have articulated their own 'local interest' on security issues and other matters of conscience and have worked wholeheartedly to resist the centre's unilateral behaviour. In Chapter 6 we consider the role of SNGs in matters of security and other political concerns. We find that in some ways, for example through protests at the central government's laxity on non-nuclear principles and its support for the US invasion of Iraq in 2003, SNGs function as a vent supporting popular grievances against the central government.

In a brief concluding section, I draw together observations and findings discussed in the previous chapters. Here, we consider the domestic and international political implications of SNGs' move into the international arena, particularly how the role of Japan's SNGs as important new players in Japan's international affairs influences three areas. One is the overall role of SNGs as administrative bodies that are responsible primarily for meeting local concerns. The second is the relationship between SNGs and the national government, questioning whether SNGs' newly won international clout strengthens their leverage vis-à-vis the central government by increasing their fiscal and administrative autonomy on domestic issues and international issues. The third area is management of Japan's international relations, considering how the central government's ministries that are responsible for foreign affairs respond to the wanted and unwanted contributions of SNGs as interests synchronize, collide or are in some other relationship across and within the different levels of government. The overall picture that emerges casts Japanese SNGs as increasingly active international actors within a highly regulated unitary state, in ever more globalized international and domestic environments. 


\section{Contexts}

\section{Conceptual, comparative and Japanese}

In this chapter I consider the context for the analysis in this book. I take up three strands of discussion: conceptual, comparative and Japanese. The first presents a conceptual framework for explaining SNGs as international actors, drawing principally from International Relations literature. The second strand considers the international activities of SNGs in other countries to provide comparative examples for examining Japanese SNGs. Most experienced are North American and European SNGs where the trend has been under way for some time. Examples from Asia help to focus our lens for understanding the Japanese case. The third discussion strand concerns the Japanese context. I explain the key developments in Japan's political and foreign affairs environments, especially post-Cold War, that have enabled and encouraged the emergence of Japanese SNGs as international actors. These developments have opened up space for new actors to act in what was previously the sole preserve of central government actors. The developments also gave rise to the limited decentralization of foreign policy that is rendering SNGs - and non-government actors - an increasingly important role in Japan's foreign affairs.

This book takes us to an evolving area at the intersection of Japan's international and domestic politics, through a new prism and a new context. Although most studies of Japan's foreign affairs have been largely through the prism of nationalgovernment actors, this study concerns the role of subnational governments. And whereas the locus for analysing relations between different levels of government in Japan has been principally the domestic context, this study extends the context to the international arena where players derive and exert power that can influence relations inside the arena of domestic politics. This new approach begs two central questions, which this book seeks to address. First, how are Japan's international relations being penetrated by SNGs and what are the implications of this development for understanding Japan's international relations? Second, what is the impact of the expanding role of SNGs as international actors on national-subnational government relations in Japan?

The entry of lower levels of government into Japan's foreign affairs arena has brought a new dimension to the territorial fragmenting of public policy and government functions. Such 'fragmentation' now also needs to be considered in the much broader international context, where SNGs are increasingly active 
players given the partial decentralization of function and responsibility in national foreign policy. By their very nature SNGs have an ambiguous status in the international arena as neither 'state' nor 'non-state' bodies. In the International Relations lexicon, the noun 'state' is usually understood as nation (nation state) and the adjective 'state' refers specifically and exclusively to national government. The SNGs' 'neither/nor' status allows them to take some international actions that neither 'government' (read central or national government) nor non-government bodies can. Let us turn here to that arena and the conceptual understanding we need for this study.

\section{SNGs as actors in international relations}

Complex theories of International Relations explain actions across national borders and their consequences, as observers seek to identify who (or what), does what, how, and for whom (or what) in the international arena and why so. Since the end of the Cold War, a period when divisions and alliances seemed to be more clearly drawn, a 'new world order' or disorder, creating structures that sustain predictable behaviour among international actors, is still evolving. The end of Cold War structural alliances and the advent of 'globalization' and its ubiquitous forces have stimulated a steady output of scholarship that is transforming earlier understandings - not just of how international relations are conducted and to what end, but also of the nature of the actors, their motivations, their processes and consequences. Schools of thought have been established, diversified, or 'neo'-ed as a result.

Yet observers have generally failed even to recognize, let alone examine, subnational governments as international actors. The primary shortcoming appears to be an oversight that locates official governance exclusively at the national and supranational levels and thus fails to recognize the lower 'sub' levels of government that legitimately govern administrative units within the nation and are international actors themselves.

The general theoretical assumption of mainstream International Relations theories is that even after the Cold War, the world is still comprised of nations represented officially only by a unitary national government whose mandate and responsibility align with the nation's border. This government is ultimately responsible for overseeing the international affairs of those whom the national government is elected to serve - the citizens of the nation. The national government may form part of higher levels of governance internationally through supranational bodies (e.g. the European Union (EU), United Nations, Association of Southeast Asian Nations). But that is where 'government' stops in most of this theorizing; governments of administrative units within the nation are largely ignored. Failure to recognize lower levels of government blinds observers to the huge bulk of SNGs that have some autonomy and capacity to act internationally, in ways that are not expressly through national government fiat and are with a certain degree of independence. We then cannot take account of the consequences of SNGs' international engagements for domestic political life. 
Realists endow primacy and exclusive regulatory capacity in the international arena to nation states led by national governments. Other observers extend their vision beyond the state to non-state actors and their ever more diverse international roles. But the status of SNGs as neither state (national government) nor non-state (non-government) has left them generally outside the viewing lenses. Various factors may help to explain how SNGs seem to have fallen through the cracks, as observers try to take note of unprecedented, perhaps revolutionary, global change. One is the sudden proliferation of new international actors with the advent of globalization, which has overstretched observers' attention. A second is that even though SNGs are becoming more significant as international players, their international engagements generally have neither clout nor cachet as media-grabbing developments. A third is the lingering dominance of Cold War theorizing that upheld national government as the predominant and unitary player.

These oversights mean that a conceptual appreciation of SNGs as international actors (what they do, how they do it, and the domestic and international consequences of this) is yet to register seriously in scholarship. Our discussion of practical examples of SNGs in various countries in this chapter helps answer these questions. Yet a review of International Relations scholarship is nevertheless conceptually helpful here. First, it reveals how traditional international power structures involving nations, national borders and unified national-government control over international affairs have gradually weakened, creating space for non-government and other government actors (including SNGs) to operate on this terrain. ${ }^{1}$ International engagement links domestic with international politics to influence power arrangements inside as well as outside national borders. Second, contrasting with national government and non-government actors enables us to identify some distinctive qualities of SNGs as international actors.

The realist school that established and still dominates the academic discipline of International Relations sees international relationships purely through the prism of power politics, Realpolitik. ${ }^{2}$ It proceeds from recognizing the primacy of the nation state in an anarchical international society where 'law and order' can be maintained only through balancing power between nation states. ${ }^{3}$ In this view, the nation state is a singular entity and its capacity as sovereign actor and its internal and external politics are in separate realms. A unitary national government conducts and controls foreign policy exclusively and is compelled to speak with a single voice. There is no room for other actors to compete with the national government in this arena. Some variants such as neo-realists, neo-liberals and structural realists recognize the importance of economic actors that are not national governments, but see the role of these economic actors as subordinate within a tightly defined state-centric system.

Other observers acknowledge the sovereignty of nations and the role of national government in both maintaining order and acting as the final adjudicator in many areas of international life. But they see that international traffic has become too complex to be managed by national governments as unitary actors, if indeed it ever was so managed. They marshal mountains of evidence attesting to 
complex interdependence between a multiplicity of actors, including national governments, that cross national borders to pursue their own interests, which may include helping to address international concerns independently or collaboratively. National borders are crossed incessantly by tourists, business people, students, refugees and migrants; by international organizations for aid, environmental protection and other humanitarian concerns, and the list goes on, including a hugely significant non-human element. Revolutionary technological development has facilitated these international flows. Moreover, for many actors, self-interest dominates over national interest.

The growing load of international concerns now stretching the global agenda, such as communicable disease, poverty, climate change, pollution, environmental destruction, refugees, human rights abuses and terrorism, require collaborative responses from multiple types of actors working with and beyond national governments. ${ }^{4}$ In this milieu the scale of national governments' international engagements has mushroomed such that national governments need cooperation of other entities, particularly to perform the practical work that their foreign ministries and foreign offices are not equipped to handle. This point is crucial in conceptualizing our study; it means that there is legitimate space for new types of actors, relationships and outcomes to reshape international relations. The vast and diverse flow of people, goods, capital and information gives rise to complex interdependence between people, nations and governments and effectively weakens national boundaries and national governments' singular capacity to 'maintain international law and order' through 'balancing power' between adversarial nations.

Observers who work outside the realist paradigm therefore argue that national security and power politics are not the only defining elements of international relations as realists emphasize, especially since socio-economic factors have become so significant in the global context. ${ }^{5}$ They also argue that domestic and international politics are becoming inextricably linked, rather than taking the quite separate and divisible paths that realists claim to observe. In arguing that international relations can be explained more accurately if actors other than national governments are also considered, the broad offering of perspectives sheds light on many types of state and non-state actors including at supranational, regional and local levels. But they do not illuminate the SNGs.

Keohane and Nye were among the original proponents of the complex interdependence model, which sees multiple channels of transborder contact between societies through transgovernmental and transnational organizations that bring various government and non-government actors into the equation. These multiple channels of contact blur the distinction between domestic and international politics, so that 'politics does not stop at the waters' edge'. ${ }^{6}$ Rosenau, another key proponent of the interdependence model, points to a variety of authority structures other than national government that play a role in world affairs. But his attention is on the dynamics of bureaucratic politics, since 'much of what transpires in world affairs derives from the initiatives and activities of governmental sub-units, of bureaucratic agencies that work independently with counterparts abroad as well as through their superiors'? 
Mathews speaks of a 'power shift', with the end of the steady concentration of power in the hands of states that began with the Peace of Westphalia in 1648. With different types of power and ability dispersed across a range of non-state as well as state actors, Mathews speculates that 'nation states may simply no longer be the natural problem-solving unit' ${ }^{8}$ Camilleri and Falk also observe the erosion of monolithic national power structures. They see that continuing penetration of national boundaries through the growing role of subnational, international and transnational actors has made the earlier preserve of the sovereign state (i.e. the national domain) 'a contested territory'. ${ }^{9}$ The primacy of sovereign national government is therefore now out of place in a world shaped by 'shifting allegiances, new forms of identity and overlapping tiers of jurisdiction', ${ }^{10}$ but SNGs are not identified among the new international actors that challenge, support or serve national government in this contested territory.

Sapping of the traditional power structure of the state has also been noted in contexts beyond the mainstream International Relations literature. For example, Strange advances the thesis of the state's retreat in a globalized world in the context of market forces and the increasing role of corporations. ${ }^{11}$ Willetts proceeds from this ground in claiming that two of the most fundamental attributes of sovereignty, control over both currency and foreign trade, have been substantially diminished. ${ }^{12}$ Willetts also points to pluralization of international policy, observing that in any area of global policy-making, developments need to be understood in terms of 'complex systems containing governments, companies, and NGOs interacting in a variety of international organizations'. ${ }^{13}$

Horsmann and Marshall offer a more comprehensive view, recognizing multiple forces that curtail the role of the nation state ranging from the changing nature and reach of capitalism, economic liberalization and technological revolution, to the changing relationship between citizens and their governmental structure, and instability in the international system. ${ }^{14}$ They identify how the emergence of two opposing forces, integration (e.g. the European Union and the North American Free Trade Association) and fragmentation (e.g. the demand for new states based on ethnic identity and greater autonomy for constituent units), directly threaten the identity of the classically constituted nation state. ${ }^{15}$ Horsmann and Marshall come close to the terrain of our discussion in this book in recognizing the demand for greater autonomy for 'constituent units' of nations, but there is no mention of SNGs even though they are some of the influential 'constituent units' that help to fragment policy while not seeking to create new states.

Here it is useful to note that although some observers point to erosion of traditional international structures that include national government, since they have not acknowledged SNGs as levels of government below the national level, their analyses cannot point to decentralization of international 'work' - practice or responsibility - by the national government to SNGs. There is no acknowledgement of governments below the centre to which international affairs can be decentralized. Hence such observers fail to recognize decentralization as another force that weakens but does not erode national government hold on international affairs, even though it is vital to our understanding of the evolving international relations picture. 
This observation can also be made of Nicholson, who presents a pluralist 'complex interdependence' model based on the Rosenau schema. Here 'the billiard-ball state has ceased to be solid' and sub-state actors (cities and regions) penetrate as international actors. ${ }^{16}$ Yet Nicholson offers no discussion of SNGs in the context of levels of government that administer cities and regions as sub-state, that is, subnational actors, whose international penetration helps to make the billiard-ball state less solid. ${ }^{17}$

Other observers come close to identifying SNG involvement in international affairs by recognizing the importance of international grassroots activity as the world becomes more complex and national governments are unable to respond effectively on their own. We can recognize 'grassroots' as the terrain of SNGs since they work much more closely than national government with 'the people' and with grassroots communities. Still, SNGs remain unnoticed as internationally involved grassroots actors. Clough, for example, has noted the growth of grassroots actors in international affairs and their influence on national foreign policy without mention of the levels of government that work at society's grassroots. ${ }^{18}$

Overall, the literature outside the Realist school favours a pluralist paradigm that acknowledges the broad diversity of non-government actors and their considerable and increasing influence on international politics and on the global system in general. ${ }^{19}$ This literature does not deny that national government plays a crucial role in international affairs, but argues that the involvement of multiple actors inside and outside national government, with conflicting interests and contradictory positions on international affairs, makes nations and national governments anything but unitary actors. This multiple involvement also makes for complex interdependence between players. It means that sources of power and influence cross over between the domestic and international domains such that domestic politics cannot be hermetically sealed from international conditions.

Most observers who argue for a pluralist approach to understanding international relations appear to have conceptually subsumed the subnational level of government within national government or have failed to recognize subnational governments as bodies capable of independent international involvement, and so do not per se see SNGs as international actors. Some rare exceptions have identified SNGs' international activity but, like Breslin and Hook, categorize the SNGs themselves as non-state actors. This distorts our understanding of SNGs' capacity and their political potency. ${ }^{20}$ Overall, SNGs have not been allowed to stand alone conceptually, as the 'neither/nor' actors they actually operate as in contemporary international affairs.

\section{Features of SNGs as international actors}

Being neither national governments nor non-government gives SNGs a unique position in international affairs. Their quasi-diplomatic status can allow them to play a valuable role that sometimes neither of the other two types of actors can play, as the Japanese case attests most clearly in Chapter 6. In this book we can most constructively examine SNGs as a subset of the national government distinct 
from the national level and its departments and agencies but ultimately still answerable to it.

As a subset of government, SNGs are responsible for administering public services to their constituency as effectively as possible, and for serving the interests of their constituents collectively. To some extent they must answer to the national government and carry out its instructions because the national government is largely their paymaster and their position is circumscribed by law and/or the national constitution that set down SNG responsibilities. Because they are governments, irrespective of their level they are usually elected bodies returned to or ousted from office through the electoral system. This makes their actions domestic or international - inherently political, however small-scale or innocuous these actions may appear to be. Most importantly, the SNG subset is not the same as the full national set, and the subset itself comprises a diverse array of SNGs with distinctive local features that we consider in the next section. Their distinctiveness and diversity mean that the interests, concerns and priorities of the 'local' members of the subset may or may not always align internally or with those of the full national set of which it is part. It also means that SNGs as international actors present a very diverse picture. There is no one-size-fits-all model that reveals similar experiences for SNGs across the board.

To identify some defining features of SNGs as 'neither/nor' international actors with their own capacities, objectives and limitations, it is useful to compare SNGs with the types of international actors that they are not: national government and non-government organizations. SNGs resemble the national government in some ways because they are, primarily, government, with the distinctive features of government discussed earlier and which come into effect when SNGs engage internationally. They do not comprise privately organized citizens. They are mostly elected representatives of the public and as such often have easier access to the corridors of power nationally and internationally. Their purpose is not to generate profit for themselves, although it is certainly to cultivate the economic climate for profit-making within their constituency, ${ }^{21}$ and in contemporary times when labour supply exceeds demand in many nations, there is a strong compulsion for both national governments and SNGs to bring jobs (often seen as votes) as well as profit-making opportunities to their constituency through international channels. Like national governments - and unlike most non-state actors that are issue-oriented and act in the interest of a specific-purpose group - SNGs have a complex, internally competing set of public interests to serve in their international engagements.

In other ways SNGs resemble non-government actors. Most significantly, although they must accept the consequences of their international actions, they do not have the ultimate responsibility for the national ramifications since this rests with the national government. Although they have a complex set of public interests to serve, they are not responsible for the nation's economic well-being, cohesion and protection. Their international actions do not have the full diplomatic import of national-government action. The scale of their international involvements is limited and nothing like the worldwide reach of national government. 
Nor are they bound by the domestic and international conventions that apply to the national government such as official diplomatic standing and procedure. Moreover, inside and outside their national context, SNGs have 'liberating', non-national government qualities in their roles as international actors. This is important because perception matters enormously in international affairs.

Because the international interests of this subset of government may synchronize with or depart from the interests pursued by the national government, SNGs can work hand-in-hand with the national government, independently of it, or sometimes in opposition to it. They can be policy supporters or policy spoilers. SNGs may be divided or united by political party and other expected domestic loyalties and these can also influence their international behaviour. While SNGs are not 'sovereignty-bound' like national governments, neither are they 'sovereignty free' like non-government actors. Yet, SNGs usually have some policy autonomy even in foreign affairs.

The gradual weakening of national-government control over international affairs and national governments' growing dependence on new international actors has given the SNGs greater leeway, especially in the post-Cold War period to act on the international scene, once a coveted area of national policy firmly held by the national government alone. To understand more fully what SNGs are doing internationally, let us turn to practical examples of SNGs in various countries that have responded to this international climate now open to a much wider collection of actors.

\section{SNGs in comparative perspective}

There is an expanding and eye-opening literature on the practical roles and consequences of internationally active SNGs from specific countries or regions. ${ }^{22}$ It serves to puncture the silence in the theoretical literature discussed earlier. This literature is rich with neologies for SNGs' involvement in international affairs, acknowledging both diplomatic and policy dimensions and its non-national-government source. Observers use terms such as 'multilayered diplomacy', ${ }^{23}$ 'plurinational diplomacy', ${ }^{24}$ 'proto-diplomacy', ${ }^{25}$ 'para-diplomacy', ${ }^{26}$ and 'micro diplomacy', ${ }^{27}$ and speak of 'perforated sovereignty', ${ }^{28}$ 'foreign policy localization', ${ }^{29}$ or simply 'local foreign policy'.

The examples discussed in these studies reveal the extent and diversity of SNGs' and their increasingly important international role. We see the diversity of their approaches to international engagement, the types of relationships SNGs have with other actors, and how these relationships can serve to shift leverage among the government players at different levels in national and regional contexts. Engaging with these studies enables us to see the localized consequences of the international transformation discussed in the section above in countries across Europe, North America and Asia-Pacific, as globalization has drawn multiple new actors and new sources of power or influence into the international field. The new international relations dynamic is changing power relations between national and subnational governments on the ground, while both increasing national 
government dependence on SNGs and increasing SNG autonomy through international contact.

The comparison also reveals other features that distinguish SNGs as international actors. The SNGs can serve as a valuable arm of their nation or region for outsiders such as national governments, commercial interests, or others who want this access. They have formed strong global networks that offer useful support and opportunities for collaborative arrangements that national governments, with inescapable diplomatic baggage, are sometimes unable to make. Often, they form clusters of similar actors with shared interests, which present opportunities for alliances and other strategic action. They are also realigning strategically across and within the national/subnational divide as pressures and opportunities from globalization reconfigure SNG interests. New competitions among all involved actors seeking to satisfy their interests as effectively and efficiently as possible require SNGs to be politically expedient both nationally and internationally. In both contexts, a view is gaining currency that national government is less efficient than SNGs in representing the localized interests of individual SNGs within the global economy. ${ }^{30}$

The international scale of this dynamic change for SNGs means that we find examples in countries with domestic political systems as different from each other as communist China's unitary system and democratic India's federal system. Conventional wisdom would suggest that federal structures (such as in the United States, Australia and Canada) that allow more autonomy to federated units would enable SNGs to take active roles in international affairs and influence national foreign policy through their actions. Yet European and other national examples (such as Japan) show that even in centralized unitary systems, SNGs are actively involved in international affairs. Hocking has noted that in looser federations and in highly centralized states, SNGs have been equally motivated to operate outside their national environment. ${ }^{31}$ Pursiainen's study points to the increasingly 'independent' stance of Russian regional SNGs (particularly through self-declared freedom) in their external relations, but also through international policies that are generally in line with the Russian government's official position. ${ }^{32}$

The comparative literature reveals multiple factors other than the unitary/federal nature of the political system that are instrumental in shaping who does what, where, why and how. Some are contingent on the nation, including whether its legal/constitutional framework confirms SNGs' roles or offers an ambiguity that SNGs can tap into to pursue international roles. Other factors are contingent on the SNG. These include its location, size and importance (e.g. Japan's capital metropolis of Tokyo with its concentration of human, financial and political resources has an international role very different from that of rural Tottori on the Japan Sea side); the political and personal will of SNG leaders, and the geostrategic location of the SNG's locality in relation to other domestic and international actors. The capacity to work with the national government and its agencies, corporations, NGOs, counterparts and others in pursuing international relations is also central.

The pace of development has also differed. Starting in the 1970s, SNGs in Europe and the United States were earlier starters and models than their 
counterparts elsewhere. Forces of globalization leading to new international economic norms around market liberalization for example the General Agreement on Tariffs and Trade (GATT) and World Trade Organization (WTO) and regionalization (in bodies with supranational frameworks such as the European Union and North American Free Trade Agreement, NAFTA) have intensified pressures on SNGs and lubricated, or for some compelled, their international engagements. The comparative literature reveals how this development has emboldened the SNGs in their quest for greater autonomy, while shifting the levels at which citizens identify their loyalties - not just up from national level to supranational bodies but also down from national level to localities.

Overall, the message from the comparative literature is that there is real diversity but also enough similarity to recognize some more general trends. The goal of SNGs as international actors is usually far from having grand aspirations to establish an international identity for their locality. It is to manage local issues as efficiently as possible and pursue constituents' collective interests internationally, whether directly, with national governments, or with supranational and international organizations. There is a compelling overall reason why this goal draws SNGs increasingly towards international action: local issues are increasingly internationally conditioned. Let us turn here to consider the domains where SNGs are most active internationally - economics, diplomatic action and international cooperation and networking. We can then consider the impact of their actions upon the national-subnational government relationship.

\section{Key areas of SNGs' international engagement}

\section{Economics}

Trade, investment and other economic relations pursued by SNGs with partners overseas are the most common and least controversial aspect of SNG involvement in foreign affairs. Most SNGs are to some extent responsible for the economic conditions in their locality, so they are keen to pursue commercial and other arrangements that will enhance the economic climate of their locality and ideally bring jobs, technology and other commercial operations. National governments' failure to protect local markets and cuts to SNG budgets have forced SNGs to take more responsibility for the economic welfare of their locality and for managing local budgets prudently. Seeking economic opportunities internationally is also a means to a particularly important political end: greater financial independence usually also means greater SNG autonomy from their nationalgovernment masters.

SNGs take a number of approaches to stimulate and maintain overseas economic linkages: trade missions seeking new markets for local products and help local industry establish linkages overseas, and overseas offices that facilitate commercial linkages and support trade missions. Overseas offices have been common for some European, US, Canadian and Australian SNGs for the past two or three decades. Even before the end of the Cold War when SNGs' international 
actions were more firmly regulated, 43 US states maintained 132 offices overseas. By the late 1990s, US states maintained almost as many offices overseas as the US federal government operated embassies. ${ }^{33}$ Some economically oriented regions in Europe operate overseas offices that function as quasi-embassies to negotiate regional trade agreements. France's Rhone-Alpes region centred in Lyon reaches into Switzerland and Italy and so maintains overseas 'embassies' in Geneva in Switzerland and in Turin in Italy. ${ }^{34}$

Quantified data suggest that the Canadian province of Quebec is the world's most active SNG in international economic activity. Around the mid-1990s, Quebec spent more money in this activity and operated more overseas offices than Canada's nine other provinces combined. Its expenditure and staff were also more than for all 50 US states combined. Quebec recognizes responsibility for independent action as a Canadian province since 40 per cent of the country's gross domestic product (GDP) and one-third of jobs in the private sector depend directly on export activity. ${ }^{35}$

Other approaches to stimulating international economic linkages are carried out within the locality or the region that a group of localities form, to create local conditions attractive to specific types of commerce or industry. One of these is establishing infrastructure such as transport and communication that supports commercial activity. Some European cities have linked themselves in state-of-the-art transportation networks and have been largely successful in attracting the foreign businesses they solicit. ${ }^{36}$ Another approach is financial incentives through inducement packages, tax breaks and other financial enticements. These competitive packages are put together to attract high-profile companies that would bring jobs and attract other economic stimulation. For example, SNGs in Alabama in the United States offered nearly $\$ 300$ million in incentives to draw Mercedes-Benz to the state. Fry's study presents many similar examples across the United States. ${ }^{37}$

Most SNGs have very limited financial resources compared to their central governments and need to operate judiciously when seeking business opportunities; they are not private corporations. However, despite being publicly accountable government bodies, the SNGs strive to develop market advantages on whatever basis they can: geographic, demographic or through other sources of local strength or distinctiveness. An important consideration is how they can maximize their interests: through bilateral relations, domestic regional groupings or multilateral regional groupings or some combination of these. Citing developments in Germany, northern Italy, the Rhone-Alpes in France, and Catalonia in Spain, Newhouse argues that regionalism involving local actors is the coming dynamic, especially in Europe. ${ }^{38}$

SNGs use multilateral regional groups to establish webs of alliances at the micro-regional level to create opportunities for trade and other economic activities in their localities. Breslin and Hook's volume, for example, presents several cases of micro-regional collaborations. ${ }^{39}$ In the Chinese case, SNGs in the Shandong and Liaodong peninsulas and in the Tianjin area have promoted the idea of building an economic region around the Bo-Hai Sea to harness their traditional ties with European countries such as France, Britain and Germany, and 
also seek investment from new players such as Japan and Korea. The aim is to make the area a centre of heavy industry, technology, finance and transportation in Northeast Asia. ${ }^{40}$ Some observers claim that many of these initiatives fail to meet these aims, but here it is important to recognize that SNGs and other local actors recognize they must supplement their bilateral economic networks externally with multilateral linkages.

Since geographic proximity, regional orientation and other considerations orientate Japanese SNGs towards China, it is useful here to further consider the Chinese example. The decline of central planning and pursuit of marketization in the post-Mao era have made foreign investment a significant source of capital, employment and technology for China's provinces, so it is not surprising that action to expand foreign economic relations has become the most important aspect of provincial external affairs. ${ }^{41}$ Some Chinese provinces are actively pursuing their commercial interests overseas independently and doing so with central government encouragement. ${ }^{42}$ For international relationships where there are unresolved diplomatic issues between the national governments, the Chinese national government has encouraged provinces to seek commercial links that it is unable to pursue bilaterally at the national level. For example, the central government approved special arrangements to facilitate economic contacts between Shandong and South Korea even before formal diplomatic ties were established in 1992. Shandong has since used its ties with South Korea extensively to accelerate its own development. South Korean investment in Shandong was insignificant in the 1980s, but increased dramatically in the 1990s while South Korea replaced Hong Kong as Shandong's second most important export market and overtook Taiwan as the second most significant source of foreign direct investment (FDI) in 1995. ${ }^{43}$

India provides another interesting example. Although India has a federal political system, Indian states have had few contacts overseas. Until very recently, even their trade and other economic matters were dealt with via the national government in New Delhi. However, economic liberalization from the early 1990s has given states greater autonomy to pursue external economic relations independently. Central authorities such as the Ministry of Finance now encourage state governments to negotiate directly with multilateral agencies such as the World Bank and the Asian Development Bank. Sridharan's study offers examples from the southern and central states of Tamil Nadu, Andhra Pradesh, Kerala, Karnataka and Maharashtra, showing the increasing efforts by these state SNGs seeking commercial opportunities overseas and attracting foreign investment in high-tech industry, tourism and even in providing municipal services. Although she sees that in the early $2000 \mathrm{~s}$, the international role of Indian states is 'nascent', discussion of trends under way makes it clear that India's national government will increasingly share the commercial dimension of foreign policy with SNGs. ${ }^{44}$

Russia also provides an interesting example, as a former communist regime that established a federal system in the early 1990s. Many of the larger Russian SNGs now actively pursue trade and commercial interests overseas. ${ }^{45}$ Pursianen regards them as 'foreign policy players in their own right', since at least in some 
issues they have their own distinctive policies towards the outside world. ${ }^{46}$ Regions are becoming important centres for international contact and the preferred route for approaches from external parties is increasingly via the regions directly rather than via Moscow. INTERREG (the EU-based Inter-regional Initiative programme), which aims to promote cooperation between the border regions in Europe, now includes the Russian regions. And as with the Chinese example, the Russian government is keen to have SNGs pursue economic linkages that it feels it cannot so pursue, where unresolved diplomatic issues curtail national-government capacity. We see this in the economic cooperation between Russian regions and Japanese SNGs on the Kuril Islands, Sakhalin and the Maritime Province, despite the territorial dispute and absence of a peace treaty at the national level. ${ }^{47}$

\section{Diplomatic action}

SNGs in some European nations and particularly in the United States have pursued political activity for a few decades, with both covert and overt involvement in national diplomacy. As with international economic action, national circumstances shape the ability and the will of SNGs to take international action that is explicitly political. Federal government systems generally present SNGs with greater structural capacity than unitary government systems for taking independent international political action. Capacity to act is usually legitimated in the legal system and the constitution, with restrictions that ensure that SNGs do not have a free reign in international politics. In the United States, for example, the constitution expressly forbids SNGs from making treaties, engaging in war, exchanging ambassadors or negotiating with foreign governments on matters vital to the nation, such as national security. States may enter into international 'agreements or compacts' with the approval of Congress. But the main consideration is this: 'whatever power is not expressly assigned to the national government [through the constitution] belongs in the state governments and the people. ${ }^{48}$ This clear allocation of power to SNGs in the United States - notably to US states rather than lower levels - contrasts with the Japanese and many other cases where SNGs have had to carve out a niche for their international political actions in the gaps of ambiguity between imprecise power allocations within the constitution.

SNGs engage in various types of political action with diverse consequences both nationally and internationally. Sometimes their actions are consistent with national-government policy and may support or reinforce the national level's diplomatic efforts by default. Sometimes these supportive actions are more deliberate, by national-government design or at least in collaboration, with SNGs seeking to carry out the work of the national government at arms length since diplomatic or other policy considerations prevent the national government from taking direct action. At other times, however, the political actions of SNGs have been in direct opposition to the stance of their national government and pose challenges to the national government's supremacy in foreign affairs. Here the national government has little choice but to work around these challenges, although it may try to obtain a more cooperative arrangement with SNGs through domestic policy levers. 
Most cases where SNGs imposed their own sanctions on oppressive foreign regimes and on others who systematically abused human rights were in direct opposition to their national government's stated policy. Oppositional action like this has been rare in Asian countries and is most common in the United States, where some have oppugned 'the worrisome foreign policies' of SNGs. ${ }^{49}$

Some US states have made independent policies seeking to oppose oppressive regimes, promote democracy and protect human rights by imposing sanctions on foreign nations. In the 1970s, to protest the apartheid regime in South Africa and the US government's stance on it, the state of Washington passed measures to divest pension and portfolios of securities in corporations doing business in South Africa. Other SNGs enacted anti-apartheid sanctions that caused some two-thirds of their companies to leave South Africa or sell their equity, which helped force the US government to drop its policy of 'constructive engagement' towards South Africa. ${ }^{50}$ Similar resistance actions came from various states' referenda and support for measures against the Vietnam War in the 1970s, and their diverse acts of opposition to Washington's policies against Iran and the former Soviet Union, including embargos in the aftermath of the Soviet 1983 downing of a KAL passenger jet. ${ }^{51}$ More recently, in 1996, the state of Massachusetts introduced the 'Burma Law' that effectively bans state agencies from signing contracts with companies doing business with Myanmar. ${ }^{52}$ Some efforts have opposed national policy stances on other than specific bilateral concerns. For example, at the height of the Cold War, more than 50 localities, including the city of Chicago, selectively banned research, manufacture, transhipment or deployment of nuclear weapons within their jurisdiction.

Other acts of opposition are constructive. In the 1970s, Idaho sponsored trade missions to and from Libya when the country was out of favour at the federal level and various SNGs over time provided sanctuary for illegal immigrants and refugees. SNGs' move to establish sister-city relations with municipalities in Nicaragua at the height of conflict between the Reagan and Sandinista administrations were clearly to oppose Washington foreign policy and the 86 US cities with Nicaraguan 'sisters' sent more humanitarian support to Nicaraguan towns than all of the aid that the US government provided to the anti-Sandinista Contras that these SNGs opposed. Their move also helped to keep US public opinion two-to-one against US aid to the Contras. ${ }^{53}$

Some European SNGs have also pursued independent policies seeking to oppose oppressive regimes, promote democracy and protect human rights by imposing sanctions on foreign nations. For example, in the mid-1970s, several Dutch cities forced Stevin, a major dredging and building firm, to cancel its projects for the repressive regime of General Augusto Pinochet in Chile. SNGs in Europe have also mounted cases for decent treatment of refugees. ${ }^{54}$ Furthermore, some local authorities in Britain and the Netherlands have mounted special programmes to absorb refugees in their localities, while others have even challenged their national-government policies of deportation. ${ }^{55}$

Although national governments try to dissuade or prevent SNG political action opposing national policy, they support SNGs taking political action that upholds 
national diplomatic objectives or indeed substitutes for, or enables, formal diplomacy. SNGs can conduct de facto diplomacy as a conduit for national government because of their ambiguous neither/nor status; they are free of the full diplomatic baggage that attaches to national government in the name of sovereignty but still have representative status and formal connection to the national level. Provinces in China, for example, have been active in 'informal diplomacy', as discussed above in Shandong Province's economic connections with South Korea. In the wake of the 1989 Tiananmen incident, when China's national leaders were unwelcome in some national capitals, especially those that staunchly criticized the Chinese leadership's quashing of freedoms of assembly and speech, some SNG leaders made trips to these countries. No high-ranking national politicians were invited to Canada, but eight senior local leaders visited Canada in 1991. The then Shanghai Mayor Zhu Rongji (later China's prime minister) visited the United States and a number of European capitals, paving the way for a diplomatic breakthrough between Beijing and Western nations. Similarly, before the establishment of formal diplomatic relations between the PRC and South Africa in 1997, contacts with post-apartheid South Africa were maintained mainly at the provincial level. ${ }^{56}$

In recent years, India's national government has acknowledged the political utility of SNGs in international affairs with governments of Indian states involved in diplomatic discussions with India's neighbouring countries. Sridharan notes awareness at the national level that regional leaders can help facilitate negotiations because of common cultural ties between the people of their province and people across the border. ${ }^{57}$ The chief ministers of West Bengal in the east and Tamil Nadu in the south have often been involved in negotiations with Bangladesh and Sri Lanka because of their linguistic and cultural connections to these countries.

Although SNGs are commended for their role as supporter, their spoiler role draws mixed appraisal. Some observers believe strongly that SNGs should not involve themselves in matters of foreign policy. In the 1980s, when more than 800 US localities passed nuclear-freeze resolutions, some critics dismissed these as 'hortatory measures' that had little influence on US nuclear policy despite their intention to incite policy change. Realist scholar Spiro has criticized such actions of opposition or resistance as 'local interference in foreign policy' ${ }^{58}$ Yet others see these actions as a sign of healthy democracy. Some have argued that SNG action against repressive regimes such as in pre-Mandela South Africa and Myanmar should not be seen as central government losing control over the foreign policy agenda but as a legitimate function of democratic government in a federal system. ${ }^{59}$ Former Los Angeles Mayor, Tom Bradley, claimed that because SNGs are closer to the people than the federal government, they are better placed to register popular dissent expressed through locally elected representatives, especially since many national policies are felt initially and most profoundly at the local level. Guay stridently claims, for reasons such as these, that SNGs cannot be dismissed as political actors in the international arena. ${ }^{60}$ Some prominent public figures in the United States have moved further, encouraging 
SNGs to pursue their own foreign policy. For example, some have exhorted California to orient itself towards the Asia-Pacific region and rediscover its old relationships with Mexico, especially while Washington focuses on trans-Atlantic policies. $^{61}$

Some SNG international engagements are not overtly political but can have political consequences. One area is SNG involvement in international development issues through assisting SNGs and communities in developing countries. Donor SNGs use their own resources and financial support from the development assistance budgets of their national governments. SNGs in Germany, France, Belgium, the United Kingdom and Spain were early actors in this field through support for NGO projects. Shuman notes many cases of involvement in northsouth assistance programmes by European SNGs that have provided money, volunteers and technology to build schools, hospitals, roads and bridges. The German city-state of Bremen is exemplary here, providing technical assistance through biogas projects in China, India and Africa that created local jobs as well as energy for cooking. ${ }^{62}$

As Shuman has noted, SNGs' capacity to assist in international development programmes is not just in the practical areas of technical expertise for road building, water systems and so forth but also in public administration and 'good governance' including sound planning, efficient administration and effective leadership. ${ }^{63}$ Since the 1980 s, the Federation of Canadian Municipalities (FCM) has been involved in this area. ${ }^{64}$ These examples show that SNGs in some countries are becoming important players in delivery of international aid, labelled by some as 'local ODA' or 'mini ODA' programmes. The precedent of European and Canadian SNGs has been followed by Japanese SNGs that are responding with enthusiasm to the opportunity to contribute to international development programmes, as discussed in Chapter 4.

\section{Networking and international cooperation}

It is widely recognized that the nation state does not have the capacity to look after the distinctive interests of all of its many diverse SNGs. In an environment where many non-state actors are gaining significance in foreign policy through national and international networks, SNGs have also recognized the value of establishing formal linkages bilaterally, regionally and multilaterally. Sister-city linkages are the most common formal ties between SNGs bilaterally and are largely outside the auspices of any central government involvement. ${ }^{65}$ Thousands of American cities and states have established sister-city ties with foreign counterparts, as have SNGs in many European and Asian countries (especially Northeast Asia). SNGs in Australia and New Zealand have also pursued this path enthusiastically.

Sister linkages were designed initially in the wake of the Second World War to promote mutual understanding through cultural and educational exchanges, but have now evolved into vehicles for pursuing a wide range of shared interests including commercial opportunities. These formal linkages include educational 
exchanges, staff visits, cultural celebrations, pursuit of shared interests or concerns, exchange of trade missions and mutual assistance at times of disaster. O'Toole has explained the transformation of SNG linkages from an 'associative phase' of cultural and educational ties to the 'commercial phase' involving various economic connections. ${ }^{66}$

There is no single template that sister-city relationships follow. As noted earlier, in the United States, some sister-city links have been used for expressly political purposes. These include promotion of democracy abroad, helping to train elected foreign officials of nascent democracies in Eastern Europe, and as Spiro notes of many US sister-city relationships, 'more to send a foreign policy message to Washington than merely to cement subnational ties' ${ }^{67}$ We certainly see signs of Japanese SNGs expanding sister linkages into commercial arrangements, however the political aims of US counterparts are not at all evident in the Japanese case.

Some SNGs use sister and other formal or semi-formal bilateral linkages as mutual problem-solving mechanisms, especially with geographically adjacent counterparts. Several US state governments have environmental accords with Canadian provinces or Mexican states, and have hosted these neighbouring SNGs in discussing solutions to acid rain and other shared problems concerning environment and climate. This type of cooperation at SNG level increased pressure on the US government to enter into formal negotiations with the Canadian government over bilateral approaches to some problem solving and prompted new legislation by the US government. ${ }^{68}$

Recognizing the logic of strength in numbers, SNGs are also moving beyond bilateral relationships into multilateral organizations to fortify both their national and international networking and their capacity to influence decision-making on global concerns. A number of international associations represent SNG interests at international forums and transnational and supranational organizations. Three international bodies - the International Union of Local Authorities (IULA), the World Federation of United Cities (FMCU-UTO) and Metropolis (the international association of major metropolises) - combined in 2004 to form a new organization called United Cities and Local Governments (UCLG), to present SNGs as an internationally coordinated body. The UCLG is driven by lofty goals of pursuing international cooperation, fostering city diplomacy in all realms concerning local life, particularly peace efforts, building a formal role for SNGs as a pillar of the international system and working in partnership with the UN to meet Millennium Development goals. ${ }^{69}$ Another body, the International Council for Local Environmental Initiatives (ICLE) helps several hundred municipalities worldwide to share state-of-the-art technologies and policies for environmental protection. ${ }^{70}$ My interviews with Japanese local leaders and officials revealed a reasonable level of interest in membership in these international associations.

Recognizing sustainable development and ecological management as prime areas where SNGs can contribute internationally, associations representing the interests of SNGs across the world have participated in high-level international meetings such as the Rio Earth Summit in 1992 and the World Summit on 
Sustainable Development in Johannesburg in 2002. At Johannesburg the message from SNGs was clear: 'Nation states cannot, on their own, centrally manage and control the complex, fast moving, cities and towns of today and tomorrow - only strong decentralized local governments, in touch with and involving their citizens, and working in partnership with national governments, are in a position to do so. ${ }^{\text {71 }}$

The terms 'decentralized' and 'partnership' appear to be crucial for understanding the nexus between the two levels of government in contributing to effective management of local and global issues. This is true of the Japanese case where the national government has decentralized to SNGs, some tasks and responsibilities in foreign affairs, recognizing that SNGs work more closely with citizens and so are placed ideally to work in partnership with the national government. But this message at the Johannesburg Summit was to resonate not just in national contexts but in an international context where institutional arrangements reflect this philosophy. Regionalization gives this message a particular resonance as we see manifest in the EU.

SNGs have generally worked hard to establish their place - and their voice - in the EU. Literature on local government in Europe features considerable discussion of the move by SNGs to bypass national governments and represent their own interests at the European Commission (EC) in Brussels, where many SNGs have set up offices. Here some SNGs have been motivated to secure much-needed funding directly from Brussels, as well as to influence policy made in Brussels through direct communication with policymakers. Eurocities, an SNG organization founded in 1986 with headquarters in Brussels, pushes the agenda of a pan-Europe urban policy that recognizes cities as significant centres of subnational governance and mobilizes city administrations to work collaboratively in this direction. ${ }^{72}$

The push to collaborate is linked to political imperatives that are locally defined but influenced by increasing economic internationalization. ${ }^{73}$ Yet as we may expect, the interests of all EU SNGs are not always in sync with each other, so that some political battles must be waged and compromise reached. And while many SNGs establish links directly with counterparts abroad, they have not completely bypassed the nation state in favour of a Europe of regions; regional lobbies are still more powerful in Brussels when they work with national governments than when they act on their own. ${ }^{74}$ The EU Commission has itself promoted partnerships with local authorities to learn what is happening at local levels directly since central governments have acted as barriers and gatekeepers. Many initiatives for SNGs have come from Brussels and were later approved by national governments. $^{75}$

The EU example highlights the absence of concerted action by SNGs in any Asian regional grouping to collaboratively register their capacity, their voice and their potential clout within the group. Japanese SNGs have not moved proactively like European counterparts to institutionalize SNG contributions to the regional organizations of which Japan is a member such as the Association of Southeast Asian Nations plus Japan, China and South Korea (ASEAN+3), the Pacific 
Basin Economic Council (PBEC), the Pacific Economic Cooperation Council (PECC) and Asia-Pacific Economic Cooperation (APEC). Failure to take initiative, build momentum among Asian counterparts or flex their own political muscle may contribute to the apparent inertia on the part of Japanese SNGs vis-à-vis regional groupings. The EU example presents not necessarily a model but a guide to the types of collaborative arrangements that Japanese SNGs could forge if they perceive that circumstances will sustain their efforts. Also, the preferred political style of many Japanese and other Asian SNGs may simply differ from that of their Western counterparts.

\section{The national-subnational government relationship}

The entry of SNGs into the international arena extends the strategic space in which SNGs relate to national government as one of a multitude of new types of international actors. It provides SNGs with further opportunities for political voice and action, as the transformative processes of globalization render foreign policy a contested territory. In this environment there is room, indeed compulsion, for new alliances and divisions that cut across national-subnational government barriers and create new sources of leverage on both sides of the government divide and both sides of national borders. This is true of centralized unitary systems of government (like Japan's) and looser federal systems (like those of the United States and Canada). Expressed plainly, national governments need what some SNGs are well placed to contribute to managing international affairs. Under these conditions, the earlier structures of dependence between government players within nations, and the relative unity of their interests in international matters, have both begun to adjust.

Structures of dependence between national and subnational governments are still institutionalized through financing, legal, constitutional and practical administrative arrangements. But as the discussion above suggests, the complex interdependence that now marks relations between a vast array of international actors is increasing national governments' reliance on their subnational ranks to support or actually do what national governments cannot do given the bulk of work and responsibilities and at times unwanted diplomatic incursions in managing international affairs. Central governments are inundated with issues of trade and globally generated pressures, and are unable to satisfactorily handle these without the cooperation of SNGs. Simultaneously, this very process of 'going international' makes SNGs in some ways less dependent on their national government for financing and for practical advice on problems and policies. SNGs have more confidence in their capacity to operate as international actors and increasingly more experience to do so. Importantly, many SNGs regard themselves as valuable players in the policy process, no longer dutifully policy-compliant or subservient policy-followers in relation to national policy.

Here, we can recognize how this gradual shift in dependence between the two government levels serves to weaken the underlay for top-down intergovernmental relations and can help to strengthen the capacity for SNG autonomy inside and 
outside the nation. This does not mean that SNGs are becoming independent political entities at home and abroad. But it does mean that national governments must share some foreign-policy territory with SNGs through partnerships and other co-operative arrangements. This is the source of decentralization of foreignpolicy tasks. Our comparative overview above suggests some decentralization of foreign policy is under way in all nations, at least partly in response to global forces. Its nature and extent are shaped by multiple factors that derive from local, national and international contexts.

Incongruity of interests with national government helps firm the will of SNGs to reach beyond national borders. If there was ever unity of interests between national and subnational governments, it no longer exists as the underlay for relations between and within levels of government inside the nation. We have noted above that the local ramifications of global transformation have created new competitions, particularly economic, between government actors such that the interests or at least the priorities of the national government in foreign relations at times conflict with the interests of competing localities. While SNGs internationally pursue their explicitly local political interests or priorities that diverge from the national governments' big-picture interests in national economic strength, national security/ defence, national image and regional stability, cleavages sometimes appear.

What are the consequences of these developments for national-subnational government relations as SNGs begin to share the national government's foreign policy space, albeit in a limited way? National governments have recognized the emerging role of SNGs in foreign affairs and generally welcome SNGs' valuable contribution to the national economy through local efforts. However, national governments firmly resist relinquishing what they regard as the dedicated 'national' turf of foreign policy, which is a vital source of their representative capacity and authority over the nation. This turf particularly involves national defence and security and other areas of explicitly national interest. Even here, in some countries such as the United States (and in Chapter 6 we see this in Japan) SNGs have implemented policies that challenge their national government's foreign-policy stance. Such posturing suggests that although national governments allocate to SNGs some responsibility for practical action to which both sides agree, national governments will not relinquish their capacity to regulate the actions of any actors, including SNGs, that influence those outside their nation, particularly other national governments. Retaining this regulatory capacity appears to be crucial. This is why we see limited decentralization of foreign policy that allows national government to retain overall regulatory capacity and thus ultimate authority for international affairs.

China provides us a useful comparative basis as a highly centralized nation where the central government still has a relatively tight hold on all national policies. Even in China, SNGs are no longer involved in foreign affairs only to promote the central government's interests; they now conduct external relations to pursue their own economic interests and enhance their own international image. ${ }^{76}$ And by pulling together, SNGs as international actors may have capacity to shift national policy. Segal claims that the Chinese central government could lose some 
of its hold over human rights and defence spending if a bulk of Chinese SNGs respond collectively against the central government to embargoes by foreign suppliers and major importers on goods produced in Chinese prisons. ${ }^{77}$ In other words, SNGs pursuing local interests could force Beijing to do what it would not have done of its own volition. In a 'centralized federal structure' like India, this has already happened. States in India have been able to force the central government to be more transparent and inclusive when dealing with external entities that have implications for states' economies. As Sridharan observes, in India 'the states have served notice on the Centre's monopolistic behaviour'. ${ }^{78}$

The comparative examples discussed in the previous section indicate variation in SNGs' roles in foreign policy, influenced by national context and differences between SNGs even within the same national context. It is unwise and impossible to speak conclusively of this trend. But overall, we can say that national governments are beginning to treat SNGs as an integral part of foreign policy that supplement rather than replace the efforts of the central authorities. Whereas some observers speak of 'local foreign policies', ${ }^{79}$ SNGs are acting with some autonomy from their national governments but by no means as independent actors whose policies could supplant those of their national governments in the international arena. The involvement engages SNGs with multiple domestic and international actors including counterparts at home and abroad. They may be able to use these connections practically and strategically to gain leverage in their relations with the central government. But the fundamental structures of unitary and federal systems remain in place to help sustain the formal power relations between levels of government even as globalization transforms much of the international landscape.

\section{The case of Japan}

How does the above discussion relate to Japan as a unitary state with a strong tradition of centralization? Japanese SNGs are firmly restricted even in the domestic policy arena and we might expect that central control would also limit SNGs' reach into the external arena and their capacity to influence foreign affairs independently, except where acting on the central government's behalf. Yet as we see throughout this book, although SNGs sometimes operate externally in partnership with the national government, they have shown a surprising degree of independence in the international arena. Some have successfully devised and implemented their own policies for international engagement, without central government guidance or support. Some have also spoken and acted against central government policy on foreign issues, and where interests have collided a few have carried out policies that have embarrassed the central government on such 'hard core' diplomatic matters as Japan-US security arrangements.

Some Japanese SNGs have actively engaged themselves on an array of issues in the international arena despite operating within a centralized unitary system. They are later starters than counterparts in Europe and North America, whose precedents and international networks have to some degree facilitated Japanese action. 
But now Japanese SNGs sit comfortably beside their Western peers with unitary or federal governments, and in the Asian context they are pioneers. Japanese prefectures and cities are much further advanced with strategy and initiative than are their counterparts in China's still authoritarian unitary system and in India's 'liberalizing' federal system. However their constitutional status and institutionally subordinate relationship to the central government mean that Japanese SNGs cannot be as assertive in their approach as US counterparts (enabled by a more liberal political system) or European counterparts (enabled and encouraged by the supranational body of the EC in Brussels). Japanese SNGs have responded strongly as international actors particularly since the early 1990 s, despite constitutional and legal restrictions and a centralized political tradition that long debarred SNGs from international engagement. It is useful, then, to consider the circumstances inside Japan that have enabled, prompted and pushed SNGs into this position.

\section{Actors in Japan's foreign affairs}

The national government through its principal representative organ, the MOFA, has long been seen as the main player in Japan's foreign affairs. Other ministries such as the METI have played critical roles in some foreign affairs issues and MOFA has seen these ministries as rivals competing for influence. MOFA's vigorous struggle to protect its 'international' bureaucratic domain indicates that Japan's foreign policy has long been produced on contested turf rather than being the product of a united national government. In these defensive struggles the constitutional or legal authority of other ministries to establish links overseas and negotiate agreements and treaties on behalf of the state has never been challenged. The involvement of various central government actors is itself a type of pluralism in foreign affairs, one that Alger observed in the early $1980 \mathrm{~s} .{ }^{80}$

Japan's foreign policy arena remained largely untouched by actors other than those at the national-government level, with minimal involvement by non-state actors especially until the end of the Cold War. Aggressive economic expansion through trade and other commercial activities from the 1970s prompted some observers to see Japanese corporations as transnational actors, ${ }^{81}$ but it is only with the appearance of other non-state actors that the term 'pluralism' was applied to Japan's foreign policy actors. ${ }^{82}$ In the late 1990s, an issue of Gaikō Fuoramu, which is MOFA's official printed mouthpiece ran a collection of articles on tayōka (pluralization) in Japanese diplomacy. Officially translating the theme as 'diversifying Japan's diplomatic actors', the feature considered mainly 'diplomatic' actors from the private sector. The few cases of SNGs presented reveal that MOFA understands the status of SNGs as private or non-state actors, rather than other, lower-level, government actors. Recognizing MOFA's highly defensive approach to its bureaucratic patch we may appreciate this somewhat dismissive disposition towards SNGs. ${ }^{83}$ Other recent studies such as Tanaka's have analysed the influence of a number of different types of domestic actors on Japan's foreign policy in the context of domestic and international transition. ${ }^{84}$ However, none of these studies treats SNGs as foreign-policy actors. 


\section{Concepts, comparison and Japanese context}

One particularly noteworthy type of entrant into Japan's foreign-policy arena is NGOs. NGOs were for a long time on the periphery of social and political spheres in Japan, but they have come to play a diverse and valuable international role through involvement in a range of major international concerns. Mekata has analysed their successful role in the international campaign against landmines, Hirata has explored their role in delivery of Japan's ODA and Jain has offered an overall assessment of the growing influence of Japanese NGOs through a range of international matters. ${ }^{85}$

When we recognize that tayōka is a recent and still incipient trend in Japan's international affairs, we can appreciate that theoretical and empirical studies are yet to keep pace with the plethora of new international actors. The seminal nature of this very book on Japanese SNGs highlights the present circumstances while observers try to adjust their viewing lens to a more diverse foreign-policy spectrum. As our theoretical and comparative discussion reveals, inside and outside Japan a powerful mix of pressures domestically and internationally provides new space, new capacity and new need for players beyond the national government to supplement the 'business' of foreign affairs. SNGs are one of many types of new international actors. Across Japan, all levels of government, NGOs, the private sector and citizens individually and collectively try to respond most effectively as local and national matters are inescapably internationally conditioned. Let us turn here to consider these developments that have pushed and pulled Japanese SNGs into the international arena and enabled them to play a greater role in international affairs.

\section{The international context}

Post-war Japan kept a low-profile internationally - active in low politics (trade and other economic matters) but passive in high politics (diplomatic and other political issues). Japan's 'peace constitution' and security blanket provided by the United States allowed Japan to focus on national economic development and become the world's second largest economy over approximately four decades. During the Cold War period, Japan operated largely in the shadow of the United States and supported US strategic designs. The end of the Cold War, however, saw growing expectations from within the international community that Japan would play an international role commensurate with its economic status. This expectation intensified with the Gulf War in 1990-91 when Japan was accused of cheque-book diplomacy by contributing only money to an international crisis. Many observers expected Japan to lift its veil of caution on international involvement, as the looming security threat formerly presented by the former Soviet Union in the north dissipated and the attention Japan had focussed on security matters during the Cold War could be directed to other international concerns.

A number of observers claim that the first Gulf War generated the most serious discussion inside Japan since the end of the Second World War about the nation's international role, ${ }^{86}$ with the relative speed of responses by the Ministry of Finance and the Defence Agency highlighting the inertia and inadequacies of the MOFA. ${ }^{87}$ Ensuing debate highlighted a serious foreign policy dilemma: international pressure 
and domestic consensus affirmed that contributing to the international community made good foreign-policy sense for Japan, but the nation appeared to lack the wherewithal to make these contributions in a practical form other than money. Japan's contributions to the international community were limited to non-military engagement given the constraints of the Japanese 'peace' constitution.

In what some described as a 'civilian role', Japan contributed financially to a number of emerging global concerns including environmental management, fighting diseases such as AIDS, building social capital, protecting human rights, promoting democracy and advancing global peace. But through most of the 1990s Japan's national government had neither capacity nor experience for practical involvement; the national contribution was still largely pecuniary - writing cheques or supporting new projects from ever-increasing ODA budgets. One response was reform of the ODA programme that had been geared to large infrastructure projects and criticized as primarily helping Japanese businesses, with little regard for either local communities or the environment in recipient nations. ${ }^{88}$ Policy reform saw the national government introduce new philosophy and practice to the ODA programme to meet the new demands of the international community more effectively, but assessments of the reformed programme have not been positive. ${ }^{89}$ Through the $1990 \mathrm{~s}$, then, we observe the mounting challenge to Japan's foreign policy to respond to complex demands. ${ }^{90}$ MOFA, as the responsible national-government actor, lacked the resources, expertise, experience and connections to sustain multi faceted 'international contributions' (kokusai kōken) that were cast, at least rhetorically, as the hallmarks of Japan's foreign policy.

Here was the practical and conceptual space for new, capable international actors to contribute domestically to Japan's international contributions. Until this time, actors other than those at the national level were kept on the periphery, their contributions not fully recognized and their full potential untapped. As noted earlier, MOFA as the ministry responsible for the nation's foreign affairs has been reluctant to share conduct of public policy with new non-state actors and has struggled to hold the reins of power over this policy area. MOFA worked with business for decades while the renowned 'iron-triangle' of big business, bureaucracy and the ruling Liberal Democratic Party (LDP) operated as the lynchpin of Japan's postwar trading success. But it resisted rather than embraced new entrants to the field, with reports of its attempts to thwart initiatives by non-state actors such as NGOs. Developments from the early 1990s have therefore forced a different understanding and a different approach on MOFA's part. Despite its self-conscious bid to continue to protect bureaucratic turf, imperatives from external and internal pressures are forcing MOFA to accept new types of international actors as valuable members of Japan's foreign-affairs community. These actors include NGOs and SNGs, with which MOFA has begun to form constructive partnerships to achieve mutual objectives.

\section{The domestic context}

Since the end of the Cold War, significant domestic developments have worked in tandem with international developments to open the way for new actors to join 
the cast involved in Japan's foreign affairs. The economic and political turbulence that struck Japan from the early 1990s are the two main drivers of change. The so-called bursting of the economic bubble that was an overheated national economy in the late 1980s induced a decade of recession through the nineties with some inconsistent signs of growth in the early 2000s. While the economy remained stagnant, some of the key organizing principles of the Japanese economic and political systems came under scrutiny. The 1993 defeat of the LDP, the party that ruled Japan continuously for 38 years, marked an important transition in Japan. This was despite the fact that the LDP was out of power for less than a year and has been returned as the dominant party in coalition governments ever since. The short period when non-LDP coalitions took the national helm triggered changes that made room for involvement by actors other than national-government bureaucracies even in foreign affairs. ${ }^{91}$ A crucial move in this direction was the 1995 Decentralization Promotion Act and subsequent changes in laws that legally increased SNGs' autonomy through transfer of central responsibility and devolution of power in designated areas. ${ }^{92}$

The consequences of these developments have enhanced the zeal of SNGs to pursue international engagements to bolster their local economies. Reform and devolution of functions increased SNGs' responsibilities to serve their constituents but without financial support to do so. Cuts in budgetary allocations from the central government reduced SNGs' financial capacity to deliver these services and an aging population stretched demand for services even further. SNGs' financial shortages increased drastically in the 1990s to the point where borrowing for the shortfall was no longer a viable option.

This situation is vitiated by the national government's failure to consult with SNGs in developing responses to globalization, which has hit every nook and corner of localities. The national government has moved independently in policymaking, even though it is the SNGs that come face to face with the consequences of these policies much more closely than national-government bodies, because SNGs are in the localities and physically on the ground with the people and the problems they experience. One example is the Large-scale Retail Stores Law passed in the early 1990s as a result of US pressure. The law had a huge and deleterious impact on small retailers in local areas but SNGs could not introduce ordinances to address the problem since ordinances would violate the international agreements made by the national government. The national government did not consult with SNGs before introducing this law. ${ }^{93}$ Similar circumstances have surfaced on matters of land use, environmental regulations and many other policy areas. Abe and Shindō have spoken up for SNGs claiming, 'This is an era where SNGS can no longer be treated as the bottom administrative organizations (mattan gyōsei kikan). For international agreements to be effective, SNGs and national government must reach agreement. ${ }^{94}$ But the national government does not appear to have heard. SNGs are left to bear the burdens of decentralization that increase SNG responsibility for practical policy implementation but give them little or no voice in policy decision-making. SNGs are also left with both the debt and the dilemma of how to solve their local problems. International 
relationships are thus surely attractive to SNGs for their potential to remedy both the debt and the local-problem dilemmas.

The situation of Japanese SNGs has mirror images in countries worldwide as they experience dislocation from globalization's ubiquitous reach. Little wonder that SNGs have formed cooperative international bodies for mutual support and collaboration. Many share problems of addressing local issues and virtually all are bound by budget cutbacks while needing to increase the services they provide. Hobbs's observation of city SNGs in the United States is true of Japanese SNGs and presumably SNGs in other nations when she claims, 'these policies, concurrent with the cutbacks on federal and local assistance funds and the promotion of free trade, pushed cities into the international arena economically'. ${ }^{95}$ Since sufficient national-government support is not forthcoming and since remedial options are limited, we may well say that domestic and global forces have 'pushed' SNGs into the international arena economically. But while they are there, many SNGs recognize other opportunities for pursuing their interests and in the Japanese case, they now have a national government more willing to accept their roles rather than resist or reject as in earlier times.

\section{Conclusion}

SNGs across the globe are today on the rise as active players in international affairs. They have been pushed, pulled and have launched themselves into the international arena as evolutionary developments reconfigure the landscape of international relations. This has been particularly so since the end of the Cold War, as globalization and other forces are eroding earlier international power structures formalized through the concept of 'sovereignty' in nations and national governments. These forces open the international arena to multiple types of actors whose interests and motivations are not attached to a nation and who behave to a considerable extent independently of national attachment. SNGs are one of many types of government and non-government actors that have pluralized the line-up of international actors and helped to create complex interdependence between them.

This has brought significant consequences for relationships between national and subnational levels of government and comparative examples show similarity across national experiences. In Japan and other national contexts, the national government and its ministry responsible for international matters are keen (perhaps desperate) to retain the regulatory capacity that sustains their hold on levers of power in the national and international domains. They have cautiously decentralized some practice and responsibility to the lower government levels since they now need what SNGs can contribute to managing an ever more demanding foreign policy. Limited decentralization is therefore a useful management strategy in foreign policy, as the national government still has some control over SNGs. For Japan as elsewhere, complex interdependence therefore runs not just across national boundaries but also within them, across the divide between levels of government within the nation. SNGs are supplementing though certainly not replacing the efforts of national government in foreign affairs and are gradually 
helping to weaken, but by no means erode, national government's overall responsibility for foreign policy.

In our discussion of conceptual and comparative contexts we have seen how this picture plays out in both unitary government systems and the somewhat looser federal systems. In the Japanese case these big-picture developments do not signify that the national government is losing control over foreign affairs but it is 'loosening the reins' to the lower levels. Japan's national government is decentralizing some practical work and responsibilities through partnership and other cooperative arrangements with SNGs and Japanese SNGs are strengthening their autonomy from the centre in the process, at times taking a course that conflicts with that of the national government when national and subnational interests diverge.

The ambiguous status of SNGs as being neither national government nor non-government gives them a distinctive position within the line-up of international actors. They have quasi-diplomatic 'government' status to rely on when useful, but because these are not elements of national government they do not have diplomatic baggage that can at times be a hindrance in their international pursuits. Their duties and experience at home equip them well to connect at grassroots levels with other nations. Many now have informal and well institutionalized formal connections with counterparts across the globe. And ever more SNGs are developing stronger political will to explore opportunities to satisfy local interests in the world outside their national border.

Today while the spotlight still shines on national governments and other international actors, from multinational corporations, to NGOs, to private individuals, SNGs are quietly building an international profile, largely beyond the spotlight. Present trends suggest that we are likely to see SNGs continue to develop their international profiles as important international actors alongside, but separate from, national governments. Japanese SNGs are today working actively as the strongest national example in Asia. Surely it is time that we pay more careful attention to what they are doing and what are the consequences of their actions for Japanese and regional political life. 


\title{
2 Japanese SNGs as international actors
}

\author{
Domestic dimensions
}

Forces at work inside and outside Japan have helped to propel the reach of Japanese SNGs beyond the administrative borders of their locality and the sovereign borders of nation, into the international arena. In this chapter we turn first to the domestic arena to contextualize SNGs' international actions. Inside Japan, the reach by more and more SNGs for international engagement is driven largely by the complex rub of the nation's political economy as it responds to the domestic consequences of globalization, prolonged economic recession and pressures to decentralize government and conduct political reform. These powerful forces have continued to rearrange the nation's political turf as well as its institutional players, their interests, and the alliances and divides between them. The process has encouraged - in some cases compelled - SNGs to pursue the interests of their local constituencies beyond central government directives and beyond the national border, usually with central government acceptance but sometimes without it.

New institutions, legislation and policies have been established to strengthen the role of SNGs in international affairs. The central government has been forced to recognize the potential for national benefit from SNGs' reach outside the nation's borders, particularly since SNGs have some wherewithal to achieve internationally what central bodies cannot achieve. MOHA (now Sōmushō Home Affairs, SHA) is responsible for SNGs and has been one of the chief advocates of SNGs' more active international life. Growing international activism at the SNG level since the late 1980s and throughout the 1990s led MOHA to create new institutions to both assist SNGs with their grassroots contacts overseas and extend its jurisdictional capacity from the purely domestic domain to the international arena.

Resistance has come mainly from the MOFA as it struggles to assert its responsibility for national foreign policy and in so doing to regulate SNGs' 'local' foreign policies. MOFA has begun to decentralize certain aspects of foreign policy by allocating some responsibility for practical functions to SNGs, while retaining its overall authority on foreign policy. However, neither the SNGs nor the central government are monolithic. Differences in the interests and capacities of players within the two layers of government have produced competitions and allegiances that cut across these layers and are also played out through extra-ministerial bodies. SNGs' international pursuits therefore complicate national-subnational relationships, particularly since some international activities give SNGs valuable 
leverage in their relationships with other government actors inside and outside Japan and in their quest for greater autonomy from the national government.

I begin with discussion of the key actors - Japanese SNGs, the central government ministries and extra-ministerial bodies involved here - and then consider the evolving relationships between these players. Next, I explore policies, legislation, funding and personnel as official mechanisms used to promote SNGs as officially sanctioned international actors by helping to shape their actions, motivations and capacities. I also discuss other measures explicitly for building the capacity of SNGs in their international pursuits, and the intellectual and political lobbies that support these developments. Overall we find that while a complex political terrain generates and sustains these developments, the domestic environment has become far more conducive for SNGs to conduct activities in the international arena. The foreign policy context is of pluralizing actors and decentralizing to SNGs. Here we see the reorientation and creation of institutions trying to bring together 'the local' and 'the international' through the actions of SNGs. We could describe this as a distinctive approach seeking to 'institutionalize internationalization' through 'internationalizing SNGs'.

\section{Japanese subnational governments}

As explained in this book's introduction, I use the term 'subnational government' rather than the term 'local government' that is often used in English language discourse. ${ }^{1}$ Both words in the term I have chosen require some attention before we proceed further. 'Subnational' includes all layers of governments below the central government in Japan. This enables cross-country comparison since in some national contexts such as the United States, Canada and Australia, 'local government' does not include state governments even though they are below the national level.

'Government' is also a slippery term. In the Japanese constitution, the title of Chapter VIII is Chihō jichi in Japanese and Local Self-government in English, but the word 'government' appears nowhere in the text of the English-language chapter (Articles 92-95); instead the term 'local public entities' is used. The term 'seifu' (government) is not used in the Japanese title of Chapter VIII and 'jichitai' (local public entities) rather than 'seifu' is used throughout the text of this chapter. In Japanese the term 'seifu' is usually used to refer exclusively to the national government.

During the 1960s and 1970s when a number of progressive local administrations were elected to subnational governments, a debate ensued about whether or not 'seifu' (government) was an appropriate term for elected units below the national level. Progressive Tokyo Governor Minobe Ryōkichi fuelled this debate in 1970 when he announced in the assembly that the Tokyo Metropolis (Tokyo-to) was a 'chihō no seifu' (local 'government'). Critics denounced Minobe's statement as an exaggeration, claiming that 'government' (seifu) by definition includes power and authority on matters of defence, diplomacy and law. ${ }^{2}$ But nowadays, the administrations of many prefectures and other municipalities speak of themselves 
at least in the English-language version of their websites as 'government', instead of 'authority'. ${ }^{3}$ To be sure, in Japan's centralized unitary form of government, SNGs are not officially authorized to conduct what are seen to be the national matters of defence, diplomacy and law, as are some of their counterparts overseas. Yet Japanese SNGs have influenced policies in these areas, particularly through finding space for action inside their officially sanctioned regulatory capacity, such as in streets and ports as we find in Chapter 6.

The introduction of a centralized system of government in the Meiji period (1868-1912) firmly restricted the role of Japanese localities in domestic and international arenas. The Meiji constitution made no mention of the role of local administrations which were completely under central government control. Postwar, the 1947 constitution enshrined a new status for Japan's SNGs. A new chapter on Local Self-government (Chapter VIII) sets out the role and responsibilities of SNGs, as does the 1947 Local Autonomy Law (LAL). But neither legal framework mentions international functions, leaving SNGs legally unimpeded to follow the examples of European and American SNGs in pursuing their own interests overseas and to innovate with their own international initiatives.

Administratively and legally, the types of government below the national government vary considerably (see p. xv): prefectures (to, dō, fu, ken), cities (shi) and municipalities that include towns and villages (chō and son). Then there are varying divisions within levels of government. For example, wards $(k u)$ within the Tokyo Metropolis (Tokyo-to) have functional responsibilities different from those of other wards as, for example, in Yokohama City. As for cities, there are 13 designated cities (seirei shitei toshi) that operate on the same level as prefectures in selected policy areas, and other exceptions are core cities (chūkaku toshi) and special-case cities (tokurei-shi). ${ }^{4}$

Variations in type, status and functional responsibility only begin to signal the diversity of Japan's SNGs. They are made much more diverse by differences between them in size, geography, history, constituency, political colour of the governing administration and other aspects. Two strands that unify these diverse administrations are their position as 'subnational' with all that it entails and their responsibility to exercise local governance through elected representatives. Subnational governments do not share the same interests and do not agree collectively as a united front on most policy issues. Indeed, government restructuring in the 1990s has forced SNGs to compete increasingly against each other for resources and policy initiatives, so as in other countries, cooperation and competition shape relations between SNGs in Japan. Hence, while some are keen to pursue international linkages, others have scant regard for any international pursuits.

In moving into the international arena, Japanese SNGs are reaching well beyond what was long seen as specifically 'local' business conducted within their locality. This is a reach onto external political turf where there are potential ramifications for national policy, which makes SNGs' international actions contested by some, especially within the Foreign Ministry as I discuss later in this chapter. In fact, the constitutional and legal status of SNGs gives them the opportunity to expand their jurisdictional territory into the international arena by failing to even 
mention this action as a possibility - or impossibility - for SNGs. They have been able to take on roles as international actors by regulatory default.

Discussion throughout this book gives us continuing reminders that in pursuing their 'local' international policies and actions, the SNGs do not constitute a unified body that speaks with a single voice that can be used to assert their position in the national political context. Some SNGs see the international arena as potentially rich with opportunities for financial gain, problem solving, and developing political leverage. But since SNGs have been pressured ever more to produce their own sources of funding and their will for greater autonomy strengthens, competition between some SNGs is inevitable as they seek to share the bounty of international activities - from cooperation, trade, and investment, to membership of regional SNG associations and delivery of the nation's official aid programme. We see that SNGs cooperate with each other to form regional and policy alliances (e.g. the Japan Sea Group) to support their international pursuits, but they also compete against each other for the rewards that flow from these pursuits. This denies them the clout they could derive vis-à-vis the national government if they were able to present a united front on the issue of SNGs as international actors. However, as we see in the next section, the national government too is not a monolithic body with unity of interests and a unified voice in this area. This disunity within both levels creates space for competition, shared interest and allegiance to create new alliances and divides that cut across the national and subnational levels.

\section{National-government ministries}

A number of government ministries support SNGs in their international activities. For example, the Ministry of Economy, Trade and Industry (METI) lends considerable support through its extensive networks across regional Japan. However, as mentioned above, divisions run through central government players on this issue, essentially because ministries use it to strengthen their own turf against each other, as well as to achieve their own ends. So the landscape is marked by cooperation and conflict, especially between the two ministries that are most involved. MOHA which is responsible for managing SNGs, has been the strongest advocate and most active promoter of SNGs in their international pursuits. MOFA, on the other hand, which is responsible for managing the nation's international diplomacy, has generally recognized SNGs' international actions as an intrusion on its ministerial terrain, especially where diplomatic matters are involved. Thus, while MOFA would like to regulate SNGs as much as it can to protect its own jurisdiction, MOHA supports SNGs in their international relations to increase its own power and its authority vis-à-vis MOFA.

Inter-ministerial rivalry is a well-known phenomenon within the Japanese bureaucracy. Various bureaucratic battles indicate that Japan's international diplomacy is hotly contested ministerial turf and MOFA has struggled with an iron-fist to control it. ${ }^{5}$ Yet in this instance of SNGs on the nation's diplomatic turf, circumstances have forced MOFA to temper its apprehension and outright 
opposition and to take a more accommodating stance. MOFA has come to recognize that SNGs as international actors can make valuable contributions that MOFA itself is unable to and that these have created some dependence on SNGs' international contributions by MOFA. MOHA has helped to create new institutional arrangements that facilitate and maintain its hold on SNGs' actions as international actors and help to mediate potentially damaging power struggles between the players. Through these new arrangements - institutional and legal - that we explore later in this chapter, MOFA has begun to work with MOHA and SNGs to influence, if not fully regulate, SNGs' international actions. Nevertheless, asserting control where they can, MOFA staff still refuse to recognize SNGs as actors in Japan's foreign policy and as noted in the previous chapter cast SNGs as 'non-government' actors in international affairs. ${ }^{6}$

SHA has immense financial control over SNGs. It manages a large bulk of SNG funding including the local allocation tax (LAT) (chihō kōfuzei) for general equalization that constitutes over 20 per cent of SNG income, and it controls SNGs' capacity to issue local bonds (chihōsai) that are an important component of SNGs' budgets. SHA has strong influence on and regulatory power over SNGs through administrative and legal controls. It also exerts influence through political channels, particularly prefectural governors, many of whom have moved from Home Affairs into these positions. ${ }^{7}$ Muramatsu and Iqbal acknowledge the potential tension in this ministry's role, noting how, 'The Ministry of Home Affairs is supposed to be a national spokesman for local interests vis-à-vis the other central ministries, while it also tries to control local governments'. ${ }^{8}$ The examples discussed in the following chapters illustrate this tension well.

MOFA is the weakest of all the ministries in Japan since it does not have an influential domestic constituency. In this case MOFA had to transmute its initial resistance to SNGs. It was forced to realize that unless it became involved in coordination and guidance, the Ministry would be left behind while some SNGs launched further with their own international policies. MOFA effectively saw that through new intermediary institutions it could become involved in connecting the local level with the international, rather than simply allowing the local level, through SNGs and other domestic bodies, to make its own international connections.

When SNG international activities began to intensify in the 1980s, MOFA saw some merit in liaising with SNGs and supporting their actions. In 1986, MOFA established the Internationalization Consultation Centre (Kokusaika Sōdan Sentaa) within its Domestic Public Relations Section (Kokunai Kōhōka), ${ }^{9}$ offering assistance to SNG officials in charge of international exchanges. ${ }^{10}$ From 1989, it offered subsidies to regional international associations (chiiki kokusaika kyōkai). ${ }^{11}$ MOFA's Economic Cooperation Bureau had subsidized prefectural administrations to train foreign aid recipients as part of the Ministry's official aid budget since the early 1970s. From 1991, it began to offer subsidies to dispatch experts from SNGs on overseas aid-delivery assignments and for recruitment as Japan Overseas Cooperation Volunteers (JOCV) personnel for the Ministry. These moves were part of what MOFA saw as 'internationalization of local communities' (chihō no kokusaika). But MOFA did not have a long-term strategy in place to engage SNGs on this issue. 
Here MOHA saw an opportunity to strengthen its ties with SNGs which it was well placed to engage because of its extensive networks with SNGs at all levels. MOHA has used various legal and extra-legal instruments to promote, coordinate and steer SNGs in their international role. Organizations such as the Japan Municipal League for International Friendship (JAMLIF) (Kokusai Shinzen Toshi Renmei) established in 1962 and the Japan Center for Local Autonomy (Jichi Sōgo Sentaa) established in 1977, had served as external arms of MOHA, even though established through private funding, since both have been headed by retired or seconded MOHA officials. ${ }^{12}$ In April 1993, MOHA established an international section (kokusai shitsu) within the Ministry to coordinate SNGs' international activities. It declared 1995 'the first year of local government international cooperation' ( jichtai kokusai kyōryoku gannen), symbolizing a landmark shift in SNGs' involvement in the international arena from cultural activities to comprehensive relationships that have a more profound impact on the nation's foreign policy.

But most important for MOHA is its involvement in CLAIR (Jichitai Kokusaika Kyōkai), which has overall responsibility for SNGs in their international relations as discussed below. MOHA was instrumental in establishing CLAIR in the late 1980 s in response to phenomenal growth in the international activities of SNGs during this period. Through CLAIR, MOHA plays a significant role in the JET programme (discussed in Chapter 3) that CLAIR was established to implement. The JET programme was the product of high-level diplomatic negotiations between Japanese and American leaders, ${ }^{13}$ but MOFA recognized that it could not take charge since MOHA's role was crucial in implementing the programme. Support from MOHA was essential in convincing SNGs that they needed to accept JET participants in their schools and offices and MOHA quickly became a key player in administering the JET programme, especially through CLAIR.

\section{SNG-centre relations}

The account above indicates two major undercurrents of the political and bureaucratic power that shapes SNGs' actions, especially through new cleavages and alliances between all layers of government. First, some in the central government resent SNGs' moving onto the international turf that they claim is the prerogative of national rather than subnational policy. Second, some ministerial actors enthusiastically respond to these developments as an opportunity to flex muscle or gain further control. The divide appears to be essentially between those who support SNGs and those who support MOFA, but the interests and loyalties of all players on this scene weave through this divide and create a complex scenario that is by no means bi-polar. It is therefore useful to appraise the relationship between the national and subnational levels.

Here national-subnational relations are more complex than general literature suggests. Conventional accounts of Japanese government explain that because of a centralized structure, the national government's provision of finances, policy and fiat in general, as certified in the constitution and law, makes SNGs highly 
dependent on the national government and compelled to comply with its directives. External observers speak of 30 per cent autonomy (sanwari jichi) and numerous officials who I interviewed, especially in smaller SNGs, used this term when explaining the restricted action that SNGs can take, considering their limited autonomy. This simplistic term derives from the understanding that SNGs raise about 30 per cent of their total budget income through local taxes and the other 70 per cent is provided by the national government in various forms. But this is a misreading. Local taxes comprise some 35 per cent of SNGs' total revenue and the Local Allocation Tax (chihō kōfuzei) that is transferred automatically from national to subnational governments as a general equalization grant calculated on a set of prescribed measures, constitutes another 22 per cent of SNG revenue. ${ }^{14}$ So more than half of subnational revenue ( 57 per cent) has no direct strings attached to the national government. Even more importantly, financial dependence does not necessarily and proportionately translate into policy dependence. ${ }^{15}$ And in this instance, the results of the vast bulk of SNGs' international actions are of great value to the national government, which gives SNGs considerable purchase in this domain.

The central government's control on what SNGs can and cannot do overall is exercised by several ministries and defined by law, such as the LAL. But none of this has completely prevented SNGs from taking independent action domestically or internationally. At times, some SNGs have been more proactive than the central government in policy matters, and have even set the lead that the national government followed. Many SNGs resisted the centre to pursue innovative policies on minority rights, health care and pollution control. Progressive (kakushin) administrations in the 1960s and 1970s implemented bold policy initiatives in areas such as social welfare, medical services and child-care facilities. ${ }^{16}$ Some among the current group of reformist chief executives (kaikaku-ha) from the 1980s have again implemented innovative policies long before the central government. For example, the small town of Kaneyama in rural Yamagata Prefecture was the first to establish an ordinance on information disclosure in 1982, some 17 years before the national government passed legislation on the matter. ${ }^{17}$

The second round of reformist local chief executives was elected to office through the 1980s and 1990s, backed by a broader mix of political parties (ainori). These leaders have tried to pursue explicitly 'local interests' through local policies, putting into practice the increasingly palpable recognition among some at the subnational level that 'national' and 'subnational' interests do not always coincide. These SNG leaders have rejected their conservative predecessors' strategies of simply following their party headquarters or establishing a direct pipeline to the central government (chīo chokketsu), for reciprocal flows of favour and compliance. They are well placed and have the political will to take independent action rather than wait for instruction from central bureaucrats who self-interestedly perpetuate the system's tight centralization. ${ }^{18}$ The progressives' tradition of policy initiative and struggle for greater autonomy is now manifest in SNGs' international activities. The cases examined throughout this book reveal how, as in other administrative areas, the philosophy, innovative capacity and 
leadership of both levels of government influence SNGs' relations with central government actors.

Yet as noted above, we should not imagine that this aspect of nationalsubnational relations is riven with conflict. On the contrary, parties at both levels have compelling reasons to cooperate with each other in many of the SNGs' international endeavours. Both levels share an interest in (1) building the strength of local economies; (2) effectively addressing issues that concern the welfare of residents and; (3) SNGs carrying out effectively the responsibilities that the national government can no longer maintain, such as some types of aid delivery and involvement in a broad range of international programme like environmental protection and community development. As discussion in later chapters reveals, actors from the same and different levels of government work together cooperatively in a number of areas for national and subnational benefit.

\section{Extra-ministerial and quasi-government institutions: old and new}

The national government's response to the flourishing of SNG international activities particularly from the 1980 s has involved a steady institutionalization to maximize the ministries' capacity for assistance, regulation and influence. This has enabled the concerned ministries to provide advice, guidance and coordination, through an accretion of government and quasi-government bodies that have come to recognize SNGs as valuable partners. Let us consider these bodies that now work with SNGs and enhance their capacity to contribute positively to the nation's foreign affairs. I begin with the three central agencies that have existed for some time - Japan International Cooperation Agency (JICA), JETRO and JBIC - and then turn to two newer institutions - CLAIR and JIAM.

\section{Japan International Cooperation Agency}

JICA was established in 1974 as a central agency under the direct supervision of MOFA to manage Japan's ODA in the area of technical cooperation, one of the three core areas of Japan's official bilateral aid programme. ${ }^{19}$ In October 2003, JICA's status was changed from special public institution (tokushu hōjin) to independent administrative institution (dokuritsu gyōsei hōjin), with a great deal more budgetary and management autonomy from its supervising ministry. ${ }^{20}$ Under its former status, ministries such as the Ministry of Agriculture, Forestry and Fisheries (MAFF) and MITI had vested interests in JICA's work. ${ }^{21}$ MOHA and its SNG constituents were not part of this scene - until SNGs' increasing involvement in technical ODA delivery prompted significant change in JICA arrangements now reflected in JICA's new official status.

JICA has 14 regional training centres across Japan that provide technical and other developmental training to trainees from developing countries. MOFA has little direct interaction with SNGs, but JICA has worked in ever-closer association with SNGs for some time to conduct technical aid programmes. In Hyogo 
Prefecture, for example, in 2002 SNGs ran 20 of the 30 different programmes conducted by the JICA Hyogo Centre, with huge contributions from the SNGs of Kobe City and Hyogo Prefecture. ${ }^{22}$ JICA staff recognize clearly that SNGs have the technical know-how that national-government agency staff simply do not have to pass on through the training programmes. ${ }^{23}$ Sumita Kiyoshi of Sapporo City Office who has worked on secondment with the Foreign Ministry's Economic Cooperation Bureau agrees firmly, lauding the bulk of expertise and know-how 'yakusho (local government office) technology' - within city governments on matters such as sewerage, water supply, road construction, emergency services and environmental management. ${ }^{24}$ Officials who I interviewed in JICA centres in Hokkaido, Kobe and Tokyo all claimed that the cooperation and assistance from SNGs is indispensable to effective conduct of their diverse training programmes.

Yet the benefits are not one way from SNGs to JICA. Some SNGs compete to attract JICA centres to their areas. These are usually the SNGs that provide technical training through their own international cooperation programmes, and JICA centres in their areas offer these SNGs opportunities to share resources.

JICA began a new partnership programme, JICA Partnership Programme (JPP) in 2002 with SNGs and NGOs, recognizing the growing importance of organizations beyond the central government. This is consistent with JICA's new objectives to draw on the expertise and experience of SNGs and local communities for international cooperation activities. One of the four pillars of the newly organized JICA is to promote public participation in its programmes, partly through SNGs. ${ }^{25}$ JICA's new domestic division is for liaising with domestic partners and identifying possibilities. Those interested in JICA's success hope that in its new position as an independent administrative institution, it can attract more partnership programmes with SNGs and NGOs that are attracted by JICA's more autonomous status. ${ }^{26}$

\section{Japan External Trade Organization}

JETRO was established in 1958 as a special public institution to promote Japanese exports and help build the Japanese economy. MITI was its supervisory ministry and even after the 2001 administrative restructuring and change in the status of JETRO, MITI's successor METI supervises JETRO. However, in response to profound changes in the Japanese economy, JETRO has been allocated new roles such as promoting imports and seeking domestic investment. JETRO was one of the SNGs' earlier supporters in their campaign to operate overseas. In the early 1980s when the central government, advised by MOFA, denied SNGs permission to open independent overseas offices, JETRO came to their rescue where it could by allowing SNG employees to work within JETRO overseas offices to gain experience and pursue business opportunities for their locality. ${ }^{27}$ JETRO has an extensive network domestically and internationally, with 80 offices in 60 countries abroad and 38 domestic offices, employing some 1600 people. $^{28}$

Like JICA, JETRO was made an independent administrative agency, which has given it more autonomy from its supervising ministry, METI. JETRO Chairman 
in 2003, Watanabe Osamu, noted the growing role of SNGs in attracting foreign investment and businesses to Japan, as well as in helping small and medium Japanese firms to expand their business overseas, especially in East Asia. ${ }^{29}$ JETRO has established a number of programmes by forming vertical alliances between itself and SNGs to promote two-way trade and investment as I discuss in Chapter 5. It has also promoted horizontal alliances with other national agencies to coopt SNGs in international activities. For example, JETRO and CLAIR overseas offices conduct joint seminars and forums to promote trade and investment, indicating a new era of cooperation between national agencies and SNG organizations. ${ }^{30}$

\section{Japan Bank for International Cooperation}

Whereas JICA is responsible for technical assistance or the 'soft infrastructure' side of the ODA programme, JBIC (Kokusai Kyōryoku Ginkō) is responsible for the 'hard infrastructure' side of this programme. ${ }^{31} \mathrm{JBIC}$ 's main task is to provide long-term low-interest loans to developing countries for large infrastructure projects such as railways, roads and bridges. In recent years, JBIC has also supported environmental projects in the fields of pollution control, cleaner production, energy conservation, mass transit, waste management and afforestation. JBIC now commits some 30-40 per cent of its yen loans to environment-related projects.

JBIC has worked for some time with NGOs for project design and implementation. Like JICA it has come to recognize the value of cooperation with SNGs given their expertise in the many areas of JBIC projects such as for the environment and in 2001 it commissioned a study into the possibilities of cooperation with SNGs for its yen loan programmes in developing countries. ${ }^{32}$ The study discussed the important contributions that SNGs can make to the success of JBIC projects, pointing to possibilities for SNGs to provide 'soft infrastructure' such as management, maintenance and technical support to complement the 'hard infrastructure' such as roads and highways provided through JBIC loans to Chinese cities and provinces. ${ }^{33}$

In February 2002, JBIC held a 'Local Government-JBIC Partnership Promotion Forum' to discuss prospects of collaboration and partnership since the two bodies have complementary capacities. About 40 representatives from 19 SNGs participated in the Forum held in Gifu Prefecture, with SNG presentations on the kinds of projects where they can be valuable partners with JBIC. ${ }^{34}$ These again point to the capacity and institutional need for SNGs to involve themselves further in various types of official aid delivery. Examples of actual and proposed collaborative projects are discussed in Chapter 4.

Recent changes introduced through legislation to the longer-standing institutions of JICA, JETRO and JBIC highlight the national level's changing perceptions of SNG capacity to make valuable contributions to international cooperation programmes. We have seen how ministries and central agencies have become more willing, even eager, to extend SNG involvement in certain types of activities such as international cooperation and exchange programmes since SNGs can do 
what these bodies cannot, especially since SNGs have personnel with experience and know-how from their own work at the grassroots level where these institutions' overseas programmes are directed. As well as changes to the existing institutions, several new institutions were established from the late 1980s to support, strengthen, guide and even equip SNGs in specific types of international activities. Here, we look at two of the most important bodies: CLAIR and JIAM. While both these institutions have strong connections with SHA because their senior management is drawn from senior ranks of SHA retired or serving bureaucrats, they also empower SNGs to promote their international activities.

\section{Council of Local Authorities for International Relations}

Jichitai Kokusaika Kyōkai, which is known widely inside and outside Japan as CLAIR, was established in July 1988 as a foundation (zaidan hōjin) with funding from SNGs and private bodies and no direct financial contribution from MOHA or any other ministry. ${ }^{35}$ CLAIR is perhaps the foremost institution behind SNGs' rapid rise as international actors from the late 1980s. It is devoted to promoting and facilitating the international role of SNGs, and networking for them domestically and internationally through continuously evolving, innovative programmes. As an organization expressly for this purpose, CLAIR is unparalleled internationally in its size and capacity. CLAIR's original purpose was to set up and implement the JET programme (discussed later), but as a visit to CLAIR's website reveals immediately, ${ }^{36}$ CLAIR has taken on a life of its own. CLAIR has rapidly become the most instrumental body in Japan for developing SNGs as international actors, practically and philosophically. MOHA and SNGs are involved inextricably, and largely cooperatively, in CLAIR's organizational direction and performance, and effectively they drive the organization. MOHA and its successor SHA are closely involved with CLAIR's policy direction as almost all high-ranking officials of CLAIR are either former MOHA officials or currently on secondment from SHA.

CLAIR literature explains CLAIR's work as internationalization at the local level. As its original raison d'etre and still one of its primary tasks, CLAIR implements the JET programme. It recruits from abroad Coordinators for International Relations (CIRs), Assistant Language Teachers (ALTs) and Sports Exchange Advisors (SEAs), dispatches them to SNGs across Japan, and provides overall coordination for the programme. But CLAIR's reach now extends much further. First, it promotes the international exchange activities of SNGs by helping to inform and introduce prospective exchange partners to develop international affiliations such as sister-city ties. Second, CLAIR assists SNGs' international cooperation efforts through programmes that bring foreign SNG officials to Japan for training in Japanese SNGs and sending abroad experienced Japanese SNG officials to work as experts/trainers in various fields. Third, CLAIR responds to SNGs' needs for information about internationalization and undertakes related research projects in conjunction with CLAIR's overseas offices. Fourth, it supports development of human resources by creating opportunities for Japanese SNG employees to 
experience life working abroad and by strengthening networks of associations and others involved in international exchanges throughout Japan.

CLAIR has its headquarters in Tokyo and offices in each of the 47 prefectures and 13 designated cities within Japan. It has also established offices in major cities around the world: New York and London (in 1988), Paris and Singapore (1990), Seoul (1993), Sydney (1994) and Beijing (1997). Some of these offices coordinate activities in neighbouring countries; for example, the Sydney office is responsible for New Zealand and the New York office takes care of Canada. The location of these overseas offices reflects the focus of CLAIR's overseas linkages initially in North America and Europe and later in Australia and Eastern Asia. These nations have the bulk of Japan's sister-city and other local-level cooperative relationships and are the source of the majority of JET participants. ${ }^{37}$ SNGs' interest in developing connections in East Asia has boomed through the 1990s, as I discuss throughout this book. The newest office opened in Beijing in 1997 gives institutional form to the interest that SNGs share with CLAIR, MOHA and other domestic bodies in developing grassroots relations with counterparts in this neighbour that is vitally important to Japan.

CLAIR's sudden institutional pre-eminence in developing grassroots relations between Japanese SNGs and their international counterparts sends various important signals about Japan's international relations and who conducts them. First, it marks the rise of SNGs as more active and valued international actors within Japan. The bulk of CLAIR officials below the rank of director come from SNGs. More and more SNG officials now have 'diplomatic skills', and within SNG ranks there is a growing pool of expertise and knowledge useful for a range of issues that concern international affairs. Second, CLAIR's high profile bespeaks how important SHA has become in Japan's foreign relations as SHA has considerable influence on CLAIR's philosophy and practice. The Ministry plays a highly influential managerial role that includes providing policy guidance to CLAIR's top levels and supplying all of the high-ranking officials in CLAIR's domestic and overseas offices. Particularly through the Ministry's involvement in CLAIR, SHA staff have acquired a great deal of country and policy expertise that in earlier times was the exclusive claim of MOFA officials. CLAIR itself, with SHA and SNG cooperation, has been able to take on a firm role in coordinating local-level international activity since its institutional reach extends broadly to SNGs nationwide.

It is therefore not surprising that an increasing flow of visitors from overseas, including local business leaders and SNG officials, contact CLAIR for introductions and business contacts in Japanese locations. Their Japanese counterparts seeking overseas connections also go to CLAIR rather than to Japanese embassies or consulates abroad that in any case have very little contact at the grassroots levels. Small and medium-sized businesses feel much more comfortable dealing with SNG officials through CLAIR than with the diplomats at Japanese missions overseas. CLAIR offices are a point of contact for local officials and in a limited way for business people. CLAIR itself is not able to assist with all kinds of enquiries and it refers them to relevant organizations such as JETRO or local consulates and so forth. Thus, while CLAIR is a relatively new outfit to promote SNGs' contacts 
overseas, by no means is it designed to step over JICA, JETRO or consulates' jurisdiction. CLAIR's role is rather as a lynchpin. Mostly the different organizations involved here cooperate and coordinate their activities rather than compete or confront each other. CLAIR functions 'relatively independently' as an intermediary body that enables grassroots connections between SNGs inside and outside Japan. It is not a central government body bogged down in bureaucracy and it has both the central and non-central connections that are essential for this task.

\section{Japan Intercultural Academy of Municipalities}

The surge of interest in international affairs among SNGs from the late eighties/ early nineties has created the need for more SNG personnel who have 'international' skills. These skills include expertise in responding to new situations with people from other countries who have cultural experience, protocols and languages unfamiliar to SNG personnel. National training centres such as the Local Autonomy College (Jichi Daigakkō) in Tokyo and the Japan Academy for Municipal Personnel (JAMP, Shichōson Akademi) in Chiba City near Tokyo have provided programmes specifically for SNG employees for quite some time. From fiscal 1993 the Japan Intercultural Academy of Municipalities (JIAM, Zenkoku Shichōson Kokusai Bunka Kenshūsho) came into operation aiming specifically to improve the intercultural understanding and capabilities of SNG personnel through a range of training programmes, and to better equip SNG personnel for their international engagements. ${ }^{38}$

The Academy is a training ground for SNG officials in both domestic internationalization (uchinaru kokusaika) and transborder internationalization (sotonaru kokusaika). Trainees come from throughout Japan to the newly constructed premises in Otsu in Shiga Prefecture near Kyoto for programmes that include training in foreign languages and in issues of globalization, area studies and appropriate administrative practices. The Academy especially serves the needs of smaller cities, towns and villages whose employees may have limited knowledge and few opportunities to learn about how to respond effectively to the impact of globalization on local communities. ${ }^{39}$ As with CLAIR, former MOHA officials head the Local Autonomy College, JAMP and JIAM, and current SHA officials are seconded to these institutions. By the end of fiscal 2003 after its first decade, some 18,000 SNG personnel had completed JIAM training programmes. ${ }^{40}$

\section{Policies, legislation, budgets and personnel}

SNGs and the other institutions discussed above use or are influenced by various mechanisms that shape the international actions of SNGs. Here we turn to the most important of these: policies, legislation, budgets and personnel.

\section{Policies}

In the discussion above, I noted how some SNG administrations have at times preceded the national government in action and policy. This has certainly been the 


\section{Domestic dimensions}

case with SNGs' move into international affairs. Unlike earlier times, here the creative response to local problems was to reach not just beyond the national government but also beyond the national border. Some SNGs took the initiative to pursue local interests in the international arena and develop their own 'local' foreign policies.

The national government began to pay serious attention to SNGs' international initiatives only when it recognized it could no longer afford to overlook or reject them. But this did not translate into incorporating SNG actions within national foreign policy. Through the 1980s, some SNGs expanded their international involvement well beyond overseas cultural activities and set up new international sections (kokusai kōryūka) within SNG offices to oversee their expanding international work. MOFA responded on the back foot with some small initiatives as discussed earlier. But SNGs were not part of MOFA's long-term vision for the nation's foreign policy, and favouring resistance over incorporation of the potential of SNGs' international involvements, MOFA effectively allowed the creation of a policy vacuum in the central government, one that MOHA responded to as a valuable opportunity for ministerial leverage. As the 'SNG' ministry without 'foreign affairs' expertise, MOHA sought to play a proactive role, as a ministry itself and through the SNGs. Yet as McConnell observed:

The effect of these local initiatives was to force the Ministry of Home Affairs into an uncomfortable and unfamiliar role. Accustomed to providing top-down guidance to local governments, officials found themselves mere bystanders. In addition, when local governments did approach them for guidance on international matters, they found it frustrating to have to rely exclusively on the Ministry of Foreign Affairs and their overseas offices to be their eyes and ears abroad. ${ }^{41}$

One means that MOHA used to establish its responsibility was policy. In 1985, MOHA established an international advisory board (kokusai iinkai) to research ways to enhance its own profile as a player in the international scene. In July that year, MOHA released Plans for International Exchange that mapped out a variety of possible projects for SNGs, including sister-city relationships and international exchanges of SNG personnel. In March 1987, it issued Guidelines on the Promotion of Local International Exchange (Chihō kōkyōdantai no kokusai kōryū no arikata ni kansuru shishin), a statement on developing comprehensive policies for SNG action that signalled the Ministry's recognition of the importance of national policy direction - and MOHA's instrumental role in forming this policy direction - to guide SNG action. In 1988, MOHA issued Guidelines for Creating Municipal International Exchange (Kokusai kōryū no machizukuri no tameni shishin) and followed up in 1989 with Outlines for Planning for Local International Exchange Promotion (Chiiki kokusai kōryū suishin taikō no sakutei ni kansuru hōshin). ${ }^{42}$

In 1995, the Ministry released another detailed follow-up aimed directly at SNGs, in the form of Guidelines on Developing Charters for Promoting Local 
Government International Cooperation (Jichitai kokusai kyōryoku suishin taikō no sakutei ni kansuru shishin ni tsuite). This detailed for SNGs how to fine-tune their own institutional structures for international cooperation, so that SNGs could prepare their own comprehensive policies appropriate for the specific conditions of their locality. In 2000, the Ministry released its Policy on the Status of Community Groups in Charters Promoting Local Government International Cooperation and in Charters Promoting Local International Exchange. Here were guidelines for SNGs to strengthen links with NGOs and other community groups in pursuing international cooperation, a further attempt to achieve a comprehensive approach to management and coordination.

MOHA has initiated policy not just to promote SNGs' international action, but also to help maintain its control over this development. Here MOHA has demonstrated not only its capacity to supervise SNGs as its main constituency, through guidance, coordination and developing an official structure for international cooperation at the SNG level. It has also demonstrated its leadership over MOFA in pluralizing Japan's foreign affairs. Institutionalizing SNGs' international cooperation in Japan through the central-government body responsible for SNGs appears to be distinctive internationally, since in other national experiences, the SHA counterpart generally does not take these actions. This has not been exclusively a top-down process by MOHA. Initiative, ideas, actions and plans for institutionalization first came from a few forward-looking SNGs. The national government, mainly MOHA, gave the new initiative a national and international profile and a formal space in national policy after SNGs had demonstrated the pragmatic sense of their actions. Action and policy were the products of two-way engagement between the national and subnational levels, eventually reaching to semi-government and non-government bodies for a comprehensive policy approach to maximizing the national gains from SNGs as international actors.

\section{Legislation}

Consistent with its policy initiatives, MOHA moved to give legal footing to the international work of SNGs, though largely without success. In the late 1990s, MOHA pushed to have SNGs' international role written into Chapter 2 of the LAL and proposed inclusion of a new clause to give SNGs legal authority to act in international affairs. The proposed change to the LAL would have given a legal footing to much of the international role and responsibility of SNGs that so far have been practical and tacit. However, MOFA successfully thwarted MOHA's move with its claim that 'diplomatic' power belongs exclusively to the 'national government' - read 'the Foreign Ministry' - in a bid to block the rise of SNGs. They are, after all, increasingly important international actors that MOFA still regards as a threat to its ministerial domain, which is partly why MOFA derogates their status as international actors to 'non-government'.

Two pieces of legislation that did translate into law are worthy of mention here. One is the epoch-making Local Employees Overseas Dispatch Law (Chihō kōmuin kaigai haken-hō) enacted in April 1988. ${ }^{43}$ The law provided the much-needed 
legal space for SNG employees to pursue opportunities outside Japan in their capacity as SNG personnel. Under this law, SNG employees can be sent abroad to offer specialized technical knowledge, engage with overseas government organizations and other bodies, collect information and data, promote local trade and tourism, assist in natural disasters and participate in international organizations such as the UN and bodies under the UN umbrella. Importantly, the law also enabled SNGs to establish overseas offices in partnership with Japanese nationalgovernment offices. ${ }^{44}$ It also legally sanctioned Japanese SNGs engaging directly with overseas SNGs and other institutions useful for subnational international networking. Ebashi observed in the early 1990s that whereas some SNG personnel dispatched overseas might mistakenly think they are beholden to the national government, the Overseas Dispatch Law gives these personnel the ability to make decisions for their SNG independently of the national government. ${ }^{45}$

The second piece of pertinent legislation is the Omnibus Decentralization Act of July 1999 that has given some administrative independence to SNGs in managing local affairs. Overall the Act has served to create a new political and administrative environment in which SNGs are better placed to push the cause of their international activities. This act also does not specifically mention SNGs as international actors and by maintaining the legal silence, it allows SNGs to continue their international actions without the potential constraint of national law.

\section{Financing}

Parallel with developments in institutionalization and national policy direction, during the late 1980s, the central government began to include SNGs in the nationwide distribution of a huge budget for international affairs. MOHA in particular directed financing to SNGs, through the LAT that SNGs are free to distribute according to their own priorities. More SNGs began to allocate more money to international cooperation from their own financial sources (that include LAT) independent of central government control. Total SNG expenditure on international affairs projects from their own independent sources was 40.2 billion yen in 1989 and peaked at 120 billion yen (approximately US\$1 billion) in 1995, roughly triple the 1989 level. Pressured by stagnation of the Japanese economy, after 1995, SNGs reduced their funding to around 100 billion yen, with 107.8 billion yen in 2001 (see Figure 2.1). Yet even this reduced amount was equivalent to about one-seventh of MOFA's total budget for that year. ${ }^{46}$

Of all expenditures by SNGs on international affairs projects, the share spent on international cooperation (kokusai kyōryoku) has hovered at around 7-8 billion yen since 1994, which is about 7-8 per cent of SNGs' full annual budget on international activities. ${ }^{47}$ The amount in 2001 was 7.1 billion yen which was roughly 1/150th of Japan's official foreign-aid budget, ${ }^{48}$ but $1 / 10$ th of the Austrian government's aid budget and half that of the Luxembourg administration. Comparatively, then, in a global context Japanese SNGs put considerable money and effort into international cooperation as we discuss in Chapter 4. MOHA policies on SNGs' international cooperation give general direction, support and coordination to this work, but SNGs have freedom in some aspects. 


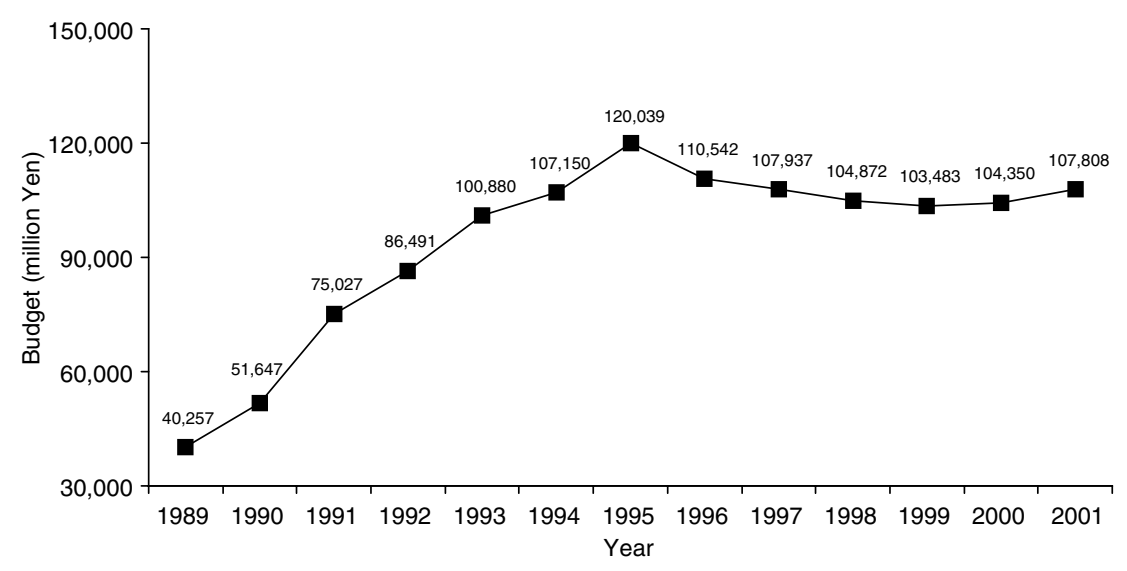

Figure 2.1 Amount of spending on international projects funded independently by SNGs (initial budget).

Source: Compiled from data provided by the SHA.

For a start, SNGs choose the level of spending from their independent budgets and as discussed earlier, SNGs are spending more than before on international cooperation. Second, four types of international cooperation activities came to dominate SNGs' programmes by 2001: assistance to international organizations (39.2 per cent), trainees from overseas (19.4 per cent), organizing and participating in international conferences (17.0 per cent) and exchange of local employees (5.0 per cent) ${ }^{49}$ Third, the geographic preferences of SNGs are clear: China accounted for 34-38 per cent and the US for 23-27 per cent - together 60 per cent of the SNGs' total international cooperation budget for 2001. These figures are indicative of the overall performance of SNGs. Yet we need to note that each SNG has its own distinctive way of spending their international-cooperation budget.

We should also note a largely ignored change in the national taxation system that influences what SNGs do as international actors, especially their ability to facilitate grassroots exchanges with non-government bodies. From fiscal 1992, donations to local associations involved in internationalization at the prefecture and designated city level can be claimed as a financial loss for businesses and as a tax deduction for individuals. Many who are involved in this area recognize the tax change as instrumental in guaranteeing revenue for grassroots international programmes that SNGs work with, and through, to cultivate international activities within their local areas..$^{50}$

\section{Personnel}

Secondment and transfer of personnel between national and subnational-government offices has been practiced for some time. Its purpose is to cross-fertilize ideas and know-how and generate familiarity and goodwill between different government 
bodies to enhance capacity to coordinate overall bureaucratic performance. Mostly it has involved central government employees transferred or seconded to SNGs to work in various capacities, including many in high-ranking positions such as directors, deputy mayors and vice-governors. Most are sent from Home Affairs, although other ministries are also involved. The staff on loan from the national government are paid by the subnational government. ${ }^{51}$

In recent years the very small flow of subnational staff back into the central government and its agencies has increased. Most SNG staff are from prefectural offices and most are sent to SHA and its agencies, although some now go to MOFA. Sumita Kiyoshi, as Project Chief of the International Relations Department in Sapporo City, advised that he was the first SNG employee seconded to a Japanese diplomatic mission abroad in the early 1990s, serving for three years as vice-consul in the Japanese Consulate in Boston. He later worked as an SNG employee in the Economic Cooperation Bureau within MOFA, where he gained valuable experience working with MOFA officials responsible for managing ODA to PNG and Samoa, and East European and Central Asian nations. ${ }^{52}$ This gives us an example of how personnel serve to pass know-how, experience and personal connections between levels of government and other institutions and facilitate the involvement of SNGs in international action.

The flow of personnel does not stop there. In recent years, SNG employees are seconded to work in various extra-ministerial and external organizations (gaikaku dantai) that give SNGs and their staff valuable new opportunities to connect with issues and people outside Japan. One outstanding example is CLAIR and its overseas offices. The directors of all of CLAIR's seven overseas offices are high-ranking SHA officials, but most other staff are from SNGs across Japan. Of the nine staff from Japan in the CLAIR office in Seoul in 2003, two (including the Deputy Director) were on secondment from Tottori Prefecture and one was from each of the Saitama, Toyama, Shizuoka, Nagasaki, Miyazaki, Kagoshima and Okinawa prefectural offices. This composition of staff appears to be typical of CLAIR overseas offices. ${ }^{53}$ As I consider in Chapter 5, many SNGs have now opened their own offices overseas for economic and other connections, staffed by their own employees who act as economic ambassadors for their own locality. Opportunities for staff to gain overseas experience such as in CLAIR overseas offices is therefore invaluable for SNGs seeking to reach externally themselves.

\section{Building SNGs' international capacity}

Some SNGs have a history of international activities across several decades, while many others are new players in this area. Many have sought to build their international capacity through institutionalization and putting in place strategic plans to coordinate and further develop their international activities. International affairs within SNG offices used to be administered by the General Affairs Division or the chief executive's office. Now, most of the larger SNGs and many others manage international activities in independent offices with a number of full-time dedicated staff. CIRs from the JET programme work in these offices.$^{54}$ And it is not just the 
international divisions of SNGs that are involved in SNGs' international affairs. In the climate of globalization, many other departments within SNGs are drawn into international matters. Departments that deal with economics and commerce, port and airport management have long been involved in international affairs through trade, commerce and international tourism. Nowadays, however, even the domestically oriented city-planning, sewerage, water supply and environment departments are routinely part of international training programmes, in partnership with JICA and independently through SNGs' own programmes.

Some SNGs had formalized their approach to international relations through specifically dedicated institutions long before the national government came to acknowledge SNGs' international roles. A high-ranking official in the Kobe City office advised that a number of cities have been active at least since the early 1970s in initiating and managing relations with foreign countries. He explained that international sections and departments (kokusai shitsu and kokusaibu) in some SNG offices have their origins in shögai and gaiji, the protocol and liaison offices set up within pre-war city administrations to deal with international trade and other foreign issues. ${ }^{55}$

Today, many SNG employees in charge of international matters regard themselves as fully trained and capable of dealing effectively with foreign affairs issues without day-to-day guidance from the national government. Larger SNGs with a long history of dealing with foreign issues appear to be more self-assured than 'newcomers' in this area. For example, staff in the prefectural offices of Hokkaido, Hyogo, Fukuoka and Kanagawa and in the city offices of Kobe, Niigata, Sapporo and Yokohama are confident in their own ability to deal with international matters. However staff in the offices of various inland prefectures and of small SNGs that have little experience in international matters are still reluctant to conduct international affairs on their own, and depend on or lean towards larger, experienced SNGs or central agencies before venturing into even a routine matter such as a sister-city agreement. ${ }^{56}$

Whether SNGs are newcomers or old hands in international affairs, most have personnel who have now gained at least some exposure in this area through explicit training or on-the-job experience. As discussed earlier, the institutionalization process has involved establishment of JIAM to train SNG personnel to deal with issues of globalization, intercultural understanding and international affairs. Some receive training and work experience through liaising with central agencies such as JETRO and JICA, or serving on secondment in various ministries and Japanese missions overseas, including, importantly, CLAIR offices inside and outside Japan.

Some SNGs claim a great deal of knowledge and skills concerning a particular country or policy area. Niigata City administration is especially proud of its knowledge of Russian and North Korean affairs and a significant share of its staff in the International Affairs section are fluent in Russian and Korean language and have frequently travelled to those countries. A former Head of the International Affairs Section of Niigata City office is fluent in Russian and during his employment with Niigata City travelled to the Soviet Union more than 60 times on behalf 
of his employer. ${ }^{57}$ Similarly, Hokkaido Prefecture officials claim that they have a better knowledge of the disputed Northern Territories issues than many of their counterparts in the national government. Overall, SNG personnel acknowledge that their capacity is surely limited and they do not have resources to deal with every kind of foreign-affairs issue. But this is not their mandate or their intention. As a number of SNG officials indicated to me during my fieldwork in SNGs across Japan, SNG personnel now appear to be fairly confident of their ability to deal with foreign people on specific issues.

SNG employees' projection of their role in international affairs gives us useful insight. The job titles printed on their business cards portray these personnel as international actors. Business cards that I collected during my interviews for this project between 2000 and 2004 gives one that general feel. They include Director of Niigata City Foreign Affairs Division (kokusai bunkabu); Director International Affairs Division, Niigata Prefecture (kokusai kōryūka); Chief, International Relations Section, Himeji City (kokusai kachō); Director, International Relations Division, Hiroshima City (kokusai kōryū tantō kachō); Manager, International Affairs Division, Okayama Prefecture (kokusai-ka shuji); Director General, International Department, Kobe City (kokusai buchō). All have some combination of 'international'/'foreign' and 'affairs'/'relations' in their official English translation, symbolizing the jurisdictional authority of their offices beyond simply 'international exchange'. Here, we also see signs of diversity among SNGs in their administration of international affairs.

Keeping an account of how SNGs have institutionalized international affairs has not been methodical. The Foreign Press Center's 1996 survey of Japan's 47 prefectures has a section on internationalization revealing that all prefecture offices had in place a basic plan for international activities and/or a set of guidelines setting out strategic directions to promote international cooperation and other aspects of internationalization throughout the prefecture, including in the SNGs within their prefecture. ${ }^{58}$ A much more comprehensive survey of Japanese prefectures published in English and focussing on the United States was conducted at roughly the same time by the Japan Foundation Center for Global Partnership. Findings from this survey confirm that SNGs are taking a more strategic approach to their international programmes; they have moved beyond the general feel-good 'friendly relationship' with international partners to a 'strategy for the future development of the area' ${ }^{59}$ The point is illustrated by the focus of Wakayama Prefecture on developing technology and a resort in association with Florida, Oita Prefecture's 'One Village One Product' (isson ippin) programme for local diplomacy, and the efforts of Niigata, Fukui and Tottori prefectures in developing the Sea of Japan Grouping. The survey also notes SNGs' shift in strategic direction around the mid-1990s from the earlier focus on 'international exchange' to 'international cooperation', which I explore in Chapter $4 .^{60}$

All up, we see many SNGs making serious moves to build their capacity for productive international relationships, particularly through strategic planning and policy, institutional arrangements, capable personnel and the lessons learned from each others' experiences. The national government has responded with institutional 
infrastructure to support, coordinate and guide SNGs in their international activities and in some ways to form partnerships between players across the levels of government. It provides much of the funds that SNGs use to develop their international capacity. This is a nationwide effort at the local level, initiated and embraced by SNGs in the name of internationalization and because SNGs recognize the widespread benefits. It has been co-opted by the national level only with recognition of the scale of these developments and their consequences for the nation as well as for the localities. As SNGs have diversified their international actions well beyond grassroots exchange programmes, they are developing more than institutional and personal expertise. They are developing the political will and the confidence to serve as ever more important international actors whose contributions are recognized appropriately in the nation's foreign policy.

\section{Intellectual and political lobbying}

The move into the international arena has not been plain sailing for many SNGs, individually or collectively. The national government's response is shaped not just by the tussle between the generally supportive MOHA/SHA and sometimes-resistant MOFA, but also by the overriding political will of the national level to retain close control over the SNGs below it. There have been two primary sources of support for SNGs as they reach beyond the national border: intellectual and political.

A strong tradition has prevailed among Japanese intellectuals to support SNGs in their struggle for greater autonomy from the central government. ${ }^{61}$ A significant cohort of the earlier progressive governors and mayors entered subnational politics with a scholarly background and a will to push for greater autonomy for SNGs. ${ }^{62}$ This tradition of strong intellectual support for greater SNG autonomy has extended into the arena of international relations. Supporters of a greater international role for SNGs independent of the central government include university scholars, researchers in think tanks and institutes, journalists, and others engaged in public debate.

Some progressive local chief executives such as Minobe Ryōkichi of Tokyo and Asukata Ichio of Yokohama made news headlines in the 1970s, with policy decisions that affected Japan's foreign relations. A more systematic intellectual and political push for independent action by SNGs in foreign affairs has been at work since the 1980s. The theoretical work of academics Matsushita Keiichi, Sakamoto Yoshikazu and colleagues can be seen as pioneering in its contribution to setting the broad agenda for internationalization at the SNG level. ${ }^{63}$ Other academics contributed conceptually with the notion of 'cooperation', which was later adopted by MOHA, to supersede the earlier label of 'exchange', indicating the broader international agenda of SNGs, the mutual give-and-take in these international programmes and the capacity of SNGs for substantial policy initiatives in international affairs. ${ }^{64}$ Works by Ebashi Takashi (Hōsei University), Watado Ichirō (Meisai University), Yoshida Shinichirō (Community Link International Institute) and Eguchi Yūjirō (Soka University) are especially noteworthy. ${ }^{65}$

Other contributions come from researchers in think-tanks and consultants to SNGs and other organizations, who have produced a range of reports on the 
international role of SNGs. These people include Menju Toshihiro of the Japan Center for International Exchange and Yoshida Hitoshi of the Economic Research Institute of Northeast Asia (ERINA). Some contribute to advancing public knowledge, interest and support for what SNGs are doing through columns in influential national newspapers. ${ }^{66}$ Highly ranked local officials have been at the forefront of promoting the international role of their SNGs and have worked with academics and think-tank staff preparing plans and strategies to implement SNG international cooperation and exchange programmes. Sugioka Akiko (Sapporo City), Ichioka Masao (Niigata City), Utsunomiya Hiroshi (Hyogo Prefecture) ${ }^{67}$ and others from Kobe and Hiroshima cities and Niigata, Hokkaido and Hiroshima Prefectures come straight to mind in this context.

In the mid-1980s, influential public commentator Tanaka Naoki wrote a seminal piece that argued strongly for greater autonomy for SNGs by offering new rationales involving international pursuits. First, Tanaka argued that international relationships are fruitful for enabling SNGs to resolve problems with overseas counterparts that have similar experiences. He argued that this is much more efficacious than taking instruction from a central government in the middle of Tokyo that tries to enforce uniform standards and rules even though it is increasingly out of touch with the distinctive needs of particular localities. Tanaka's example illustrates the ineptitude of the central government offices in Tokyo in planning housing and energy issues for Hokkaido, based on false assumptions about climate. Since Japan is diverse from north to south in climate, topography and demography, uniform approaches nationwide are misguided and outcomes will be maximized if SNGs develop overseas linkages for problem-solving and other mutual benefits, especially as central funding diminishes. ${ }^{68}$ For Tanaka, international exchanges based on citizens' lives should be encouraged to assume their full importance. ${ }^{69}$

Second, he claimed, the international actions of SNGs contribute to national security by creating cooperative relations below the national level. Tanaka cast grassroots SNG diplomacy as the most promising road to peace; not an adjunct to international diplomacy but a completely different way to avoid or resolve tensions between states and a preferable alternative by far. ${ }^{70}$ Writing not long before the end of the Cold War when the Regan administration in the United States had created phenomenal military build-up, Tanaka argued for connections beyond state-to-state level so that international actors and their relationships could be freed from military intimidation. SNG diplomacy would also particularly benefit Japan's relations with China and the then Soviet Union. In Tanaka's view, SNG diplomacy has the potential to transfigure state-level relations and should be encouraged to do so.

Intellectual advocacy for SNG autonomy in general and for SNG autonomy in international actions in particular has offered strong philosophical, ethical and practical support. Final decisions on diplomatic matters are still made by the central government, but SNGs have certainly made considerable headway in their reach into the international arena. It appears that intellectual advocacy for greater power to SNGs in international relations has been a potent force for many local 
leaders and officials as they struggle to make their case for official acceptance of SNGs' more autonomous and active role in international affairs.

SNG chief executives are themselves involved in political lobbying and have been joined by practitioners, citizens' groups and others who are interested practically or ethically in supporting this action. The late Nagasu Kazuji who served as governor of Kanagawa from 1975 to 1995 could be regarded as a pioneer in this field. He worked actively to promote the concept of citizen diplomacy (minsai gaiko ) involving ordinary citizens in international activities, and his proposal was later put into practice through the Community Development Initiative (CDI). ${ }^{71}$ Other SNG leaders have been compelled into action since their international activities have explicit diplomatic ramifications that at times have rankled the Foreign Ministry. Governor Katayama of Tottori has promoted his prefecture's links with North and South Korea and Hokkaido Prefecture officials have made constant efforts to work as a bridge between Moscow and Tokyo to try to resolve the Northern Territories dispute, while promoting Hokkaido's economic and trade interests with the Russian Far East (RFE). Many Japanese SNGs on the Japan Sea have formed linkages with counterparts on the other side of the sea.

SNGs' international actions are still on somewhat contested turf, even though the national government has tried to incorporate them into national policy. The central government is keen to maintain its strong hold over SNGs and the Foreign Ministry in particular is keen to retain hold over what it considers to be the Ministry's 'diplomatic turf'. Such is the nature of this development by Japanese SNGs in the Japanese national context. Like in any complex, multi-party political matter that moves outside the national border, all of the players here - government ministries, SNGs, semi-government bodies, citizens groups and others - pursue sets of interests that coexist, mutate, collide, adjust, are forced into accommodation or are abandoned. Advocates of this move by SNGs have achieved some ground through their support and lobbying, but it appears there is more political turf to be transfigured if SNGs are to achieve the autonomy to pursue international actions that many of their overseas counterparts in the West and beyond, now enjoy.

\section{Conclusion}

Today, nation states are no longer the primary actors in international relationships and national governments do not hold a monopoly on international diplomacy. In Japan, SNGs have joined the circle of international actors alongside the national government, its extra-ministerial bodies, non-government bodies and others. Japanese SNGs have reached into the international arena in their own capacity particularly from the 1980 s, largely to satisfy local needs and interests through their own international policies. Four factors have made international relationships particularly compelling for SNGs. One is opportunities for economic gain outside Japan while SNGs have struggled to manage through domestic economic recession. Another is opportunities for problem-solving and information-sharing with counterparts overseas that have similar experience, while the one-size-fits-all 
policies of Japan's national government fail to meet the needs of diverse SNGs stretched across the national archipelago. Third is the capacity of SNGs to work in international aid delivery for which they are much better equipped than the central government. Fourth, international activities that SNGs conduct in their own name help to increase SNG autonomy from the national government, still a bastion of control over the nation's many freedom-seeking SNGs.

Clearly, we do not have here one national policy and actors speaking in one voice. The SNGs' quest for international action especially from the late 1980s gained momentum that the resisting Foreign Ministry failed to foresee and incorporate strategically into the nation's foreign policy. The Home Affairs Ministry saw the opportunity to expand its responsibility and responded with a comprehensive strategic policy that has provided philosophical guidance and practical direction to SNGs through institutionalization, budgetary assistance and other support. Old and new institutions at both the national and subnational levels have enhanced the capacity of SNGs to undertake international activities. And the Foreign Ministry has become more accommodating. Yet, as we have seen in this chapter, neither the national nor the subnational levels of government are monolithic. The different interests, responsibilities and capacities of their players divide both levels. Here we find national-subnational partnerships alongside rivalries between the two key ministerial players and between the SNGs themselves, particularly for resources. We have also seen how the two levels are intersected by intermediary institutions and other entities that facilitate connections and networking but also complicate the flow of loyalties.

Japan retains its unitary system of government but SNGs are making further headway in their quest for greater autonomy. Limited decentralization of foreign policy enables SNGs to take some responsibility for practical implementation while the centre, particularly MOFA, retains overall responsibility. In the 1970s, SNGs challenged Japan's tightly centralized policy structure through progressive initiatives in domestic policies. Today, they continue the challenge in the international policy arena. Ever more SNGs are initiating and administering international policies for their own localities, moving further onto policy ground that was formerly the sole prerogative of the central government. 'Internationalizing' SNGs and their localities has in this way drawn SNGs into the pluralization of Japanese foreign policy. SNGs' push into the international arena in their own capacities has certainly impacted upon the management of Japan's foreign policy and on the relations between the national and subnational actors, as we explore further in the following chapters. 


\section{International exchanges SNGs lead with a soft approach}

International programmes involving cultural and trading links are some of the earlier vehicles through which Japanese SNGs began to connect themselves directly with the international community, bypassing the official involvement of the central government. These international programmes, both formal and informal, are generally labelled kokusai kōryū or international exchanges. ${ }^{1}$ Postwar, some subnational administrations in Japan began to pursue direct overseas linkages in a quiet but increasingly systematic and institutionalized manner, enabled by the newly established 'autonomy' for SNGs codified in the 1947 constitution and inspired by the precedents of their counterparts in post-war America and Europe. Growing economic prosperity and international awareness inside Japan encouraged some SNGs to extend and diversify their international exchanges, while some also saw in these linkages a valuable opportunity to strengthen their policy autonomy from the central government while yielding benefits for both the Japanese and overseas participants.

Thus, while post-war national leaders and the central government focused their attention specifically on a mercantilist international agenda for Japan - an economic foreign policy - at the grassroots level, popular interest and political will nudged some SNGs towards diverse international linkages through grassroots cultural ties. These actions put SNGs well ahead of central government initiatives in this area of international relations. Subsequent developments in the domestic and international environments have propelled this trend, casting international exchange as an important part of the mandate of increasing numbers of SNGs. In the process, SNGs make significant contributions. Some accrue to the nation: to the foreign relations that the national government seeks to manage formally, to the nation's international profile, and the bank of overseas goodwill towards Japan. Others accrue to SNGs: to their own status as international actors, to their network of international connections, and to their autonomy from the national government.

This chapter focuses on the two most egregious types of international exchange programmes that Japanese SNGs pursue: (1) sister-city relationships and (2) the JET programme. Both types of programmes involve flows of people between Japan and other countries, engaging in local community life on both sides of the national border. Both are conducted through institutional frameworks that formalize specific purposes for the relationships and both involve public and 
private participation. Both also generate contexts for developing other formal and informal relations that are some mix of cultural, economic and politico-strategic. So even while these programmes are implemented largely below the national level, they have diplomatic and strategic consequences for national foreign policy, whether explicit or implicit, and consequences for relations between SNGs and the central government.

Because international linkages through sister cities and JET evolve beyond the formal institutional framework as well as within it, we cannot know precisely how, and how much, these two forms of international exchange contribute to international relationships at the subnational and national levels. Both provide the platform for different parties at grassroots level who share interests to come together across national boundaries in ways that would have been unlikely or impossible without these formalized institutional arrangements. The examples discussed in this chapter reveal how these programmes generally stimulate considerable international goodwill for Japan and sometimes lead to more explicitly instrumental international linkages through the personal connections they cultivate. This is why the national and subnational governments share an interest in promoting these programmes.

Yet there is a distinctive difference between these two programmes in how they are administered. Sister-city programmes originate at the grassroots level and are exclusively for local activities. They are administered independently by SNGs, largely free from central intervention and oversight, and do not form part of a centrally coordinated national programme. Other government and non-government actors can become involved, but SNGs initiate and conduct programmes to suit their local needs without following centrally prescribed national guidelines. The JET programme, on the other hand, is administered through the national government. It is the result of a prime ministerial initiative in the mid-1980s to address the perceived need for a coordinated, nationwide cultural approach to international relations, initially a cultural antidote to Japan's relations with the United States that were then soured by the US response to Japan's mounting trade surplus. SNGs have been the main agents in implementing the JET programme and have used it to foster multifaceted international relationships that also serve SNG interests and are economic and politico-strategic, as well as cultural. Even so, SNGs have limited involvement in JET policy and responsibility is firmly in the hands of the national government.

The similarities and differences between these programmes provide us with a useful picture of SNGs' involvement in what can be seen conceptually as a 'soft' approach to international relations. ${ }^{2}$ For sister programmes, SNGs run the show. SNGs take the initiative to mount and formalize a relationship with the overseas counterpart of their choice and independently finance and administer this relationship through their own resources, to serve what the SNGs perceive are their local interests. For JET, the national government initiated and now runs the show. SNGs engage in a cooperative arrangement with several national bodies and each other, and are guided primarily by central government policy in recruiting and placing JET participants. The central government ministries use the JET 
programme to pursue national interests but these generally coincide with the interests of many SNGs that see JET as a valuable route for the type of internationalization they now pursue keenly. If the JET programme demonstrates the national government's 'arms-length approach' to soft diplomacy, we could describe sister-city partnerships as the national government's 'hands-off approach'. Compatibility of interests between the levels of government in pursuing these programmes is therefore vital to this picture.

As the message of each chapter in this book conveys, we find here that SNGs' pursuits as international actors run counter to the conventional wisdom that SNGs are concerned narrowly with domestic issues and are constrained tightly by the centre within Japan's unitary system of government. From the post-war period, SNGs have played a key role in the soft diplomacy of international exchanges that the national level continued to overlook largely in favour of harder-nosed diplomacy until the late 1980s. The central government was a latecomer to this branch of international diplomacy in which SNGs have been involved since the mid-1950s. ${ }^{3}$ Through sister relationships, SNGs have been leaders in soft diplomacy, and through the JET programme they have become crucial partners of the central government. SNGs are not simply central government agents in international exchange programmes. They are stakeholders that participate astutely to serve the interests of their local communities and in the process usually generate international goodwill and other positive outcomes for Japan.

The role of SNGs in these 'soft' programmes has particular significance for SNG relations with the central government, since in these types of international relationships SNGs can do what the central government cannot do. SNGs have connections, ability, willingness and status that position them better than central government actors to pursue grassroots international linkages. First, because SNGs are closer to grassroots activities within their administration, SNGs have better access to the people and community networks needed to build and sustain international relationships at the local level. Second, SNGs are experienced in addressing local concerns that they share with overseas counterparts at the local level. They are generally better able to appreciate the position of their counterparts, respond effectively to local needs and identify innovative options.

The third factor has particular import for subnational-national relations because it concerns something the centre can never have. Unlike central government actors, SNGs can connect and operate at the local level abroad in part because they do not act in the name of the nation. This status relieves SNGs of much of the diplomatic baggage and official implication that usually attaches to national-government actions abroad, which can become an enabling factor for SNGs internationally and empowering for them domestically. It creates for the central government a limited form of reverse dependence in its relations with the domestically subaltern SNGs. In soft diplomacy, the national government needs the cooperation and in some cases the initiative of SNGs precisely because SNGs are official - they are government - but they are not national, with the diplomatic implications this generates. We begin our examination of this soft approach to international diplomacy with sister-city relationships and then move to the JET programme. 


\section{Sister-city relationships}

I use here the generic term 'sister city' (translated from shimai toshi) since it is used most commonly in Japan. ${ }^{4}$ Different expressions are used in other countries, such as 'twin city' in England and 'partnerstadt' in Germany. The Chinese prefer that their formalized subnational relationships with Japanese SNGs are called $y \bar{u} k \bar{o}$ toshi (friendship cities) or $y \bar{u} k \bar{o} k \bar{o} r y \bar{u}$ toshi (friendship exchange cities), terms that are gender and hierarchy neutral. 'City' is also misleading since these international relationships are not just between cities but at all levels of the subnational structure: in the Japanese case, prefectures, towns and villages as well.

Whatever their terminology, international relationships formalized between SNG counterparts - 'sister cities' - are generally, as Cremer and Dupuis observed, 'for a range of identifiable purposes and largely outside the auspices of any central government involvement' ${ }^{6}$ Usually partners are drawn together through something they share: a geographic feature or geographic proximity; historical, cultural or trade links; a migrant community from the home country; even a problem that shared minds and experience can resolve. Benefits are expected to be mutual though not necessarily in the same quantum for both partners. Usually these involve mutual understanding and propitious disposition. They may also include practical outcomes such as passage of knowledge or skills, commercial development, or practical problem-solving. In the Japanese case, the desired outcome has been primarily goodwill, although over time some SNGs are seeking practical and diplomatically strategic ends as well. Sister relations lubricate the channels for direct trans-border communication between people.

The Japanese concept of sister cities is based on the early post-war US model aiming 'to increase international understanding and foster peace by furthering international communication and exchange at the person-to-person level through cityto-city affiliations'. ${ }^{7}$ Here we see a response to the Second World War, with hope that international relationships between different types of people and organizations at the grassroots level would nurture mutual understanding and goodwill between countries to help prevent international conflict. The premise of this thinking is that allowing the people to communicate directly with each other rather than through their governments opens lines for less conflictual relationships. ${ }^{8}$

\section{The roots of sister-city relations in Japan}

Cities have historically played an important role in international affairs through trade and cultural routes in many parts of the world. Japanese cities are no exception. Many of Japan's SNGs take pride in their historical links with cities and regions abroad and the historical connection sometimes serves as the main reason for forging contemporary bilateral relations.

Fukuoka on the Japan Sea coast became the primary international exchange centre for ancient Japan, with a government-run house that received and entertained visitors from China and Korea during the Middle Ages. By the end of the Warring States period (1467-1568) the city had grown to be a major centre for trade. ${ }^{9}$ Nagasaki's port of Deshima was the only Japanese port open to international 
trade and cultural contacts during the Tokugawa period when Japan's feudal rulers had shut Japan off to the outside world. ${ }^{10}$ Niigata, also on the Japan Sea coast, has a long history of international contact with people from countries like China, Korea and Russia. ${ }^{11}$ For these prefectures and cities, historical connections have certainly served as the basis for forming sister linkages and other contacts.

Many, but by no means all, SNGs have responded enthusiastically to developing international partnerships formalized in sister-city agreements. These partnerships require SNGs to commit their expertise, efforts and limited resources and so approach formalizing the relationship with necessary pragmatism. A few times SNGs have proceeded in the face of opposition from the central government. For example, the Foreign Affairs Ministry at times opposed Hokkaido Prefecture's contacts with nearby Sakhalin in Russia claiming these contacts worked against the national interest, but this did not prevent Hokkaido from establishing a friendship agreement with Sakhalin, where the national government recognized Hokkaido's formal link could serve as a vehicle for ongoing connections in the absence of formal bilateral relations at the national level and with tensions at various levels, including diplomatic. ${ }^{12}$

Nevertheless, the national government recognizes that overall, sister cities serve national diplomatic interests as well as local interests, as informal city-to-city connections have done for centuries. The sister-city framework has been used to facilitate multiple relationships at multiple levels through personal connections, for goodwill, economic linkages and chances to cultivate political and other diplomatic connections. The national government thus continues its hands-off approach to sister cities since this is one of the most effective ways for the nation to reap the benefits of local-level arrangements that the centre itself is less able or unable to achieve.

\section{Stages of development post-war}

Yoshida's study of Japan's local-level international exchanges observes in sister relationships a slow development during the first two decades from the mid1950 s, noticeable growth in the 1980s, a great leap forward towards the end of the 1980s and early 1990s, and a peak around 1992. ${ }^{13}$ Japan's first sister-city relationship was between Nagasaki and St Paul in 1955, in response to a US initiative. Under the Eisenhower sister-city programme, American organizations based in Japan initiated and facilitated sister ties, producing linkages between Nagoya and Los Angeles, Kobe and Seattle, and Okayama and San Jose. ${ }^{14}$ In time, Japanese SNGs began to take their own initiatives, finding their own partners, broadening geographic reach to other continents and diversifying the shared interests that serve as the adhesive in these partnerships.

The earliest relationships were largely official and symbolic. Most of the action in the first two decades was reciprocal visits by high-ranking officials and politicians, producing the handshakes, public pronouncements and photo opportunities of kanpai gaiko ('three cheers' diplomacy). At this time, national attention was firmly on economic growth and most foreign-policy tools and actions were to serve this aim. International engagement beyond economic linkages was peripheral. 
People-to-people links through more practical programmes were developed from the mid-1970s after the emergence of progressive local leaders who were keen to promote minsai gaikō (people's diplomacy). ${ }^{15}$ The premise of minsai gaiko is that participation of ordinary citizens in grassroots international programmes helps to create local conditions for effective international diplomacy between national governments. ${ }^{16}$ From the late 1970 s, more and more ordinary citizens began to participate in diverse international programmes involving education, sport and other cultural events. Some of these programmes were the key means for establishing direct links with places such as the Soviet Union where formal diplomacy was highly restricted under Cold War conditions.

The period of solid growth in sister relationships during the 1980s inspired gradual establishment of formal bodies locally and nationally, as discussed in Chapter 2. These bodies were to strengthen the institutional framework supporting SNGs' international efforts including the sister-city scheme. CLAIR (Jichitai Kokusaika Kyōkai), established in 1988, serves as the main national-level organization supporting the sister-city and other international programmes of SNGs through information, contacts, domestic coordination and other advice and services. CLAIR is the main institutional vehicle for coordinating the JET programme. Yet, SNGs retain full control over their sister relationships and are under no obligation to report to CLAIR about these relationships. SNGs generally choose to consult with CLAIR because SNGs were major supporters behind the creation of CLAIR which has the resources and information that SNGs find useful, and SNG officials have a significant presence in CLAIR offices in Japan and overseas which allows productive contacts to flourish vertically (between MOHA and SNG officials) and horizontally (between SNG officials who work in CLAIR offices). CLAIR thus serves to lubricate rather than collar SNGs' actions in sister relationships.

Domestic developments at this time contributed to the eagerness of some SNGs to pursue sister-city relationships vigorously. The slogan 'chiho no jidai' (the era of localities) initiated by progressive local chief executives in major urban centres caught on in many local administrations. 'Kokusaika' (internationalization) was harnessed to the chihō no jidai movement and signs of stronger international connections were clearly evident in local communities. More and more Japanese were travelling abroad and more and more 'foreigners' came to Japan, partly in response to the shortage of labour in a booming economy. The citizenry inside Japan generally became more receptive to international connections and SNGs became more capable of developing and dealing with these connections. Many SNGs were now engaging directly with people from other countries inside their administration. ${ }^{17}$

Developments in the international arena paralleled and intensified developments in the domestic context. From the 1980s, overseas interest in Japan grew hugely. Japan's trading reach was worldwide, its economy had become the world's second largest, and its official aid programme had become the world's largest. This served to increase overseas receptivity to Japanese initiatives for forming sister partnerships and through some of these partnerships 'learning from Japan'. ${ }^{18}$

We see here a confluence of factors that promoted sister-city partnerships from inside and outside Japan and encouraged SNGs to expand the form of 
these partnerships well beyond the initial aims of seeking peace through cultural relations. Today programmes include technical, scientific and environmental cooperation and commercial development, with participation by a broad range of people in local communities across the country. An ideological shift has further legitimized the institutional framework of sister cities. The currently popular political philosophy that public policy will succeed only when ordinary people see themselves as stakeholders applies to international policy through sister-city programmes. Hence, many local leaders with diverse political backgrounds now speak a language almost identical to that of their progressive predecessors who pushed for minsai gaiko from the late 1970s. Sister-city relations are important tools of soft diplomacy and some SNGs use these judiciously to serve local ends.

\section{How far have sister cities come?}

CLAIR maintains the most comprehensive record of SNG international linkages, which includes formalized sister-type relationships as well as sister cities. According to CLAIR records, ${ }^{19}$ as of April 2003, 954 of Japan's 3200 SNGs had established affiliations with counterparts overseas, in 57 countries across North and South America, Europe, Asia and Australasia, including just two in Africa. The total number of formalized affiliations stood at 1475, as some SNGs have multiple affiliations. In North America, there were 435 affiliations with American SNGs and 70 with Canada; in Central and South America, Brazil dominated overwhelmingly with 59 of 74 affiliations. In Europe, France, Germany and Russia respectively accounted for 47, 46 and 40 of 298 affiliations. Australia had 105 and New Zealand had 43 of the 151 affiliations in Oceania. In Asia, of 445 affiliations, China accounted for 290 and Korea for 94.

Several noteworthy features are apparent from the CLAIR data. First, in three continents, the vast bulk of these relationships is with one country; in North America it is the United States, in Central and South America it is Brazil and in Oceania it is Australia. In Asia, China and Korea together account for 384 of the 445 affiliations. Europe is exceptional since France, Germany and Russia are virtually at par and Italy with 31 affiliations is not far behind, but the United Kingdom with 13 is not particularly strong. Africa remains almost totally neglected. Second, fewer than one third of all Japanese SNGs have institutionalized affiliations with a counterpart abroad, and 8 of the 47 prefectures have no formal sister linkages as defined by CLAIR. ${ }^{20}$ Third, while large and medium-sized cities in urban areas are generally more active than other types of SNGs in the exchange process, some 475 towns and villages are also keenly pursuing exchange programmes, including some very successful projects. ${ }^{21}$ With the current round of municipal amalgamations these numbers are likely to reduce, although not significantly. ${ }^{22}$ Fourth, exchanges and ties at SNG level are more pervasive than these data indicate. Since CLAIR records include only officially established affiliations, the extensive engagements between SNGs and overseas counterparts that are not formalized in official agreements are not reflected in these data. ${ }^{23}$ 


\section{Geographic focus}

Nations important in Japanese international diplomacy and to national/local economic well-being are perhaps inevitably more popular among Japanese SNGs for sister partners. The CLAIR data discussed earlier reflect not only local interests but also the general orientation of Japan's international interests, both economic and strategic. Longitudinal data reflect shifts in this orientation. This of itself indicates how sistering at the subnational level reflects and helps to reinforce developments at the national level, with the rapid take-up rate with China in the 1990s and virtual absence in Africa - both clear examples. Until the late 1960s, almost 70 per cent of all sister linkages formed by Japanese cities were with American cities and states. No Japanese prefecture established a relationship with a counterpart outside America until 1969, when Hyogo Prefecture formalized its tie with Khabarovsk in what was then the Soviet Union.

Menju explains the early focus on American partners as the result of Japanese people's admiration for Western nations and America in particular, so it was seen as an honour for a Japanese SNG to have a formal link with a counterpart in a Western nation, especially the United States. ${ }^{24}$ However, the United States was more than simply an emblem of prestige. It was Japan's foremost security ally and holder of Japan's nuclear umbrella under Cold War conditions and it was also Japan's largest import market at a time when the nation's economic growth depended on a vigorous international trade programme. The opportunity to cultivate mutual knowledge, interest and goodwill through valuable grassroots connections was surely an attractive feature for the sistering partners on either side of the Pacific and an avenue for soft diplomacy in which both national and subnational governments shared interests.

Growth in the size and scope of the Japanese economy involving more international contacts at all levels gave Japan's SNGs opportunity and reason to expand their programmes into other continents and regions. Statistical data in CLAIR's annual directories of Japanese government international affiliations and in Japan Foundation surveys confirm broadening in the 1980s and 1990s from the original focus on counterparts in the United States, to relationships with Asia and Australia. A few links were forged with SNGs in Indonesia, Malaysia, Nepal and Mongolia, but most were made with counterparts in China and Korea, the two closest Asian neighbours with strong historical links and rapidly growing economies. ${ }^{25}$ Indeed, from the 1990 s, we see a flourish of sister-style relationships with counterparts in China as the economy of Japan's neighbour began to surge and SNGs responded to the need to accept greater responsibility for their locality's economic well-being as recession tightened public purse strings at all levels of government in Japan. Japan's special relationship with Brazil because of its history of strong migration from Japan is also reflected in the significant number of sister-city relations between Japanese and Brazilian counterparts.

At the start of this section, I noted that nations important in Japanese international diplomacy attract Japanese SNGs as sister partners. This observation applies not just to nations with which Japan has friendly alliance. Indeed, it has 
had special significance for nations that are important to Japan, but with which the national government has had other than friendly relations, or no official diplomatic relationship at all. SNG ties through sister partnerships have provided the valuable lines of communication bilaterally that the central government did not have. The strongest examples are the SNGs that in the 1960s and 1970s began to partner with counterparts in what were then socialist neighbours across the Sea of Japan: the Soviet Union and China. Some progressive SNGs, particularly on the Japan Sea coast, were keen to develop these ties that the national level would not or could not pursue for diplomatic reasons. Niigata, Hyogo and Hokkaido in particular established formal sister ties in the 1960s with SNGs of the then Soviet Union when Cold War tensions kept the national governments in Tokyo and Moscow formally apart. ${ }^{26}$ Similarly, the progressive administrations of Kobe and Yokohama were the first to link with Chinese cities (Tianjin and Shanghai respectively, both in 1973) when relations at the national level were still strained by failure to reach a peace treaty (signed in 1978) despite Japan's diplomatic recognition of the PRC in 1972.

Geography is an important factor in the sistering process, both inside and outside Japan. There is now a concentration of active sister relationships in countries geographically closest to Japan, especially where there are economic and diplomatic opportunities to share, as the westward reach of Japan Sea coastal cities and Hokkaido's reach into the RFE indicate. We also see the significance of the official but 'non-national' status of SNGs for opening and maintaining vital international relations that the central government with its diplomatic considerations is unwilling or unable to conduct. The Russian and Chinese examples of sister-type relationships are very revealing of Japanese SNGs' interests, capacities, motivations and ultimately their relations with the central government. We therefore consider both examples in some detail later in this chapter.

\section{Motivations}

Over time SNGs' interest in pursuing sister relationships has diversified, as the broader purpose and geographic reach of these relationships suggest. The state of Japan's international relationships and the national prestige factor - of other nations and of Japan - inevitably influence the motivation for partnering on both sides of the relationship. For example, the 1950s trophy connections with cities in the United States were unlikely to have the same cachet in 2003 when newspapers reported that the majority of Japanese citizens were aggrieved at the US administration for the unilateral invasion of Iraq. And what is claimed to be the primary motivation for forming sister relationships - developing mutual knowledge, understanding and friendship to promote international peace - is not destinationspecific. ${ }^{27}$ This may be a primary interest of the national government that is keen to have international goodwill towards Japan, but SNGs have reasons that concern their own local interests. So what does motivate Japanese SNGs to link formally with SNGs overseas, and what determines their choice of partner, especially when the central government does not control these choices? 
Discussion earlier indicates the variety of shared interests or features that form the basis of these connections, ranging from geographic features and geographic proximity, to shared history and culture. A 1994 survey carried out in Australia by the Sydney office of CLAIR found that industry compatibility (fishing, wine or pearling, e.g.) and interest in private visits for leisure, business and education also motivated the formalising of local-level linkages as sister relationships. ${ }^{28}$ Two particular aspects of SNGs' motivation to partner deserve discussion here: economic and geo-strategic. Both reveal how the changing place of SNGs in domestic politics has motivated SNGs to pursue mutually beneficial relations outside Japan independently of the central government, and how in reaching outside Japan through sister relationships, SNGs are influencing national-subnational relations inside Japan.

First is economic motivation. The boom in sister partnerships from the 1980s was motivated partly by SNGs' search for economic opportunities independently of the national government. Financially stretched while their limited budgets from the national public purse needed to finance ever more 'local' responsibilities, SNGs began to explore how they could develop economic opportunities for their locality, including through sources abroad. Some SNG officials have come to regard the sister linkage as a launching pad for commercial as well other grassroots activities. They appear to be savvy on the soft diplomacy of cultural exchange, the pragmatism of SNG-promoted mutually productive economic relations, and the capacity of sister partnerships to effectively deliver both of these.

While he was governor of Kumamoto from 1983 to 1991, former Prime Minister Hosokawa Morihiro actively promoted trade and other economic ties through Kumamoto Prefecture's sister linkage with Montana in the United States. In his view, about 200 companies from Montana were successfully exporting their products to Japan partly as a result of long-term cultural exchanges between Kumamoto and Montana, and Kumamoto opened its trade office in Montana to facilitate this bilateral trade. ${ }^{29}$ The examples discussed later and in Chapter 5 illustrate the types of commercial and other economic arrangements that are now part of some Japanese sister-city relationships, particularly in some destinations such as in China. Japanese SNGs are by no means alone in this strategy, which is now virtually de rigueur for SNGs in many countries. ${ }^{30}$

Even so, authorities at the national level in Japan tend to deny that SNGs have a direct role in forging commercial ties through sister partnerships and some national-government representatives involved in developing sister-city links (e.g. through CLAIR) do not endorse the economic dimension of sister-city relationships. ${ }^{31}$ The national government has long seen international trade as a national, not local, policy concern and since international trade has produced such contentious issues over the past two decades, as well as huge rewards throughout post-war, the national government is keen to maintain its centralized coordinating capacity and control. Here we see how the national government responds in an area where it shares with SNGs a great interest in the outcome-economic benefit not just for the SNG locality but also for the nation. The national government uses careful posturing to balance its desire to maintain control over SNGs, while 
not resisting their efforts at economic stimulation through international sources. It therefore neither endorses the economic dimension of sister-city relationships nor does it actively hold back SNG involvement.

The second aspect of SNGs' motivation concerns geo-strategic dimensions, which in some cases have prompted SNGs to flex diplomatic muscle. When progressive SNGs developed sister-type ties with counterparts in communist or socialist countries from the 1960 s, they were motivated partly by ideological reasons. Their actions were therefore of great consequence for the national government, which was of a different ideological persuasion and saw the national level as fully responsible for international relations, especially with those on the Soviet side of the US-Soviet Cold War divide.

This meant that the SNGs acted against the national government's resistance in forming external ties that the national level would not develop, but with the centre's approbation in forming ties that the national level could see as potentially helpful but could not develop for strategic reasons. It demonstrated to both SNGs and the central government that SNGs could take important policy initiatives in the international arena with or without the centre's support, and in cultivating relations with some of Japan's most important neighbours, SNGs were more capable than, and ahead of, the central government.

Some 16 SNGs established sister relations with Soviet cities and regions during the Cold War period, from as far back as in 1961 when Maizuru City in Kyoto established a formal link with Nakhodka. Japanese SNGs are not exceptional in this regard since there are many examples worldwide of formal subnational ties below national-level tensions. ${ }^{32}$ Nevertheless, given Japan's centralized government structure, the actions by SNGs to establish friendly ties with counterparts in countries not on 'friendly' terms at the national level is significant, particularly since it demonstrates SNGs' capacity to independently conduct their own international relationships.

From here let us turn to comparative analysis of the sister and sister-type relationships between Japanese SNGs and their counterparts in different national contexts. A variety of stories reveal different parts of the larger 'SNG sistering' picture. We will consider relationships with SNGs in China, Australia, Russia and North Korea. These examples show how relations at the national level influence but do not determine the diverse relationships that SNGs develop at the subnational level. National strategic considerations have a variety of policy implications when they meet with local interests and concerns at the subnational level and SNG interests are usually, but not always, in alignment with those of the national government.

\section{China as number two ${ }^{33}$}

China is a latecomer as a destination for ties with Japanese SNGs through 'friendship' (sister-type) relationships. ${ }^{34}$ But with a flourish of partnerships formed in the 1990s, alongside stagnation in some of the earlier fast-growth destinations, by the turn of the century China had the second most SNG sister 
relationships with Japan, after the United States. ${ }^{35}$ This surge of interest reflects Japanese acknowledgement that as a neighbour at Japan's backdoor, China has rapidly become strategically and economically very powerful. Cultural and educational links head the agenda of these sister relationships, although one reason for the growth of the SNGs' interest in China is their desire to expand commerce within their localities while economic opportunities are abundant, a pursuit that coincides very much with what the central government perceives to be in Japan's national interest. Hence it is not surprising that about half of Japanese SNG sister relationships in China are with SNGs in coastal provinces such as Jiangsu, Zhejiang, Hebei, Shandong and Liaoning, which have all experienced phenomenal economic growth and are geographically close to Japan.

After bilateral relations were 'normalized' officially in 1972, Kobe City was the first to establish a formal sister-city link in China with Tianjin in May 1973, followed six months later by Yokohama City with Shanghai. Both Japanese cities were then headed by progressive mayors who were committed, like many others in Japan, to quickly setting bilateral relations on a firmer footing through a peace treaty. They believed that formal links at the local level would facilitate the signing of a peace treaty at the national level, which eventually came through in 1978. The Japanese SNGs had broken new diplomatic ground since these relationships were the first to officially link Chinese cities with any foreign counterpart since China became a communist state in 1949. SNGs had wide-ranging agendas that included political connections, revival of historical links and genuine cultural exchange. ${ }^{36}$ However, then as now, commercial opportunities were a major motivation so it is not surprising that Japan's two most internationalized, commercial cities were the first to forge these relationships.

Official ties were developed remarkably quickly during the $1990 \mathrm{~s}$, from just over 100 in 1989 to 290 by April 2003. The 256 municipal relationships accounted for almost 20 per cent of Japan's total number. And in prefecture-province relationships, China was clearly the front-runner (34, or about one-third of Japan's 117 official SNG ties at prefectural level), well ahead of relations with US states (23 prefecture-state ties). These 290 official sister relationships with Chinese counterparts accounted for 65 per cent of Japan's 445 sister relationships in Asia. ${ }^{37}$ Japanese SNGs' budgetary allocations also confirm the recent strong focus on China. Over 25 per cent of Japanese SNGs' total budget allocation on sister programmes in 1998-2000 was for programmes in China, well ahead of expenditure on programmes with the United States even though Japan has more sister relations with US counterparts. The proportion of expenditure becomes even greater when narrowed to just the prefectures. Of about 2.5 billion yen that prefectures spent on sister ties in 1998, more than half (1.3 billion yen) was spent on ties with Chinese SNGs. ${ }^{38}$ The Japanese SNGs are likely to see expenditure on their Chinese programmes as an investment for the future, which may yield economic as well as other potential benefits as China ascends further as a great power.

Larger cities on both sides have been most proactive, with prefectural and provincial governments sometimes following their lead. For example, Niigata City linked with Harbin (Heilongjiang) in 1979 and Niigata Prefecture linked 
with Heilongjiang Province in 1983; Naha City in Okinawa linked with Fuzhou (Fujian) in 1981 and Okinawa Prefecture linked with Fujian Province in 1997. But follow-up with higher level administrative linkage is not always the case. Hokkaido's capital city Sapporo linked with Liaoning's capital Shenyang in 1980, but in 1986 Hokkaido Prefecture linked with Heilongjiang province three years after Niigata Prefecture linked with this province; in Fukuoka Prefecture, Kitakyushu and Fukuoka cities signed agreements with Dalian (Liaoning) and Guangzhou (Guangdong) respectively in 1979 and Fukuoka Prefecture signed an agreement with Jiangsu Province in 1992. Kobe City in Hyogo Prefecture linked with Tianjin Province in 1973, but a decade later Hyogo linked with Guangdong Province. In the Kobe-Tianjin example, we see the Chinese province linking formally with a large, cosmopolitan Japanese port city rather than a prefecture. Generally there is no close coordination between cities and prefectures, which act mostly independently of each other in forming ties overseas. Smaller SNGs sometimes seek advice, but this is from national bodies such as JAMLIF and CLAIR rather than from higher level SNGs.

What are the motivations on both sides for these linkages? For the vast majority, both sides seek cultural, economic and other opportunities for mutual benefit through grassroots cooperation, based on economic complementarity, geographic proximity, historical connections or some other shared feature. Much of the work is by private-sector bodies whose own commercial interests coincide with the interests of their SNG and vice versa. The Chinese side has also been keen for technological spin-offs from these contacts. Japanese survey findings revealed that although education was the most favoured purpose for Japanese sister connections worldwide, with Chinese SNGs 'administrative exchange' topped the list, indicating the priority of Chinese local leaders to learn about local administration and local economic management from their Japanese counterparts. ${ }^{39}$ The desire to foster mutual goodwill, interest and knowledge - soft strategic cachet that is usually sought from this type of official linkage - is pursued through programmes involving shared interests in culture, sport and education.

The example of Nagasaki Prefecture illustrates the significance of these official subnational arrangements with China for Japanese SNGs and their subnational-national relations. Nagasaki is close to the Chinese mainland on Japan's western edge, has a long history as an international trade centre through its ports, and has for years maintained close official and unofficial links with Fujian Province on China's east coast. In 1980, the port cities of Nagasaki (capital of Nagasaki Prefecture) and Fuzhou (capital of Fujian Province) established an official friendship tie. In 1982, Nagasaki Prefecture formed an official tie with Fujian Province and in 1983 the prefecture's second port city, Sasebo, signed an official linkage agreement with Xiamen, a major port city in Fujian. ${ }^{40}$

Nagasaki's post-war interests in China well precede these official link-ups developed in the 1980s. Fishing disputes required the prefecture to interact with China even in early post-war years and in 1955 a Japan-China Citizens' Fisheries Agreement was arranged through Nagasaki in the absence of Japan-China diplomatic relations. The Nagasaki Chamber of Commerce formed a China Trade 
Promotion Society in 1952 and Nagasaki sent a City Assembly member to a trade fair in Shanghai in 1956. The Nagasaki Flag Incident in 1958, in which a rightwing youth dragged down a Chinese flag at a Chinese products fair held in a department store in Nagasaki, caused a major diplomatic row between the two national governments, but had very little impact on the local communities and Nagasaki's plans to develop relations with Chinese counterparts and bilateral relations at the subnational level. ${ }^{41}$ Indeed, the Nagasaki City administration worked for years with prefectural governments across Japan lobbying the central government to resume diplomatic relations. Until diplomatic relations were normalized in 1972, most exports from Nagasaki to China were food since Coordinating Committee for Export Control (COCOM) restrictions on exports to socialist nations debarred exports of the machinery that China particularly wanted.

Relations between SNGs in Nagasaki Prefecture and Fujian Province continued to strengthen in the 1980s. The early 1980s formalizing of three key local relationships - Nagasaki City with Fuzhou City, Nagasaki Prefecture with Fujian Province, and Sasebo City with Xiamen City - has provided the partners with both institutional framework and motivation to focus mutually on their shared interests and complementary opportunities. Mutual exhibitions, trade promotion offices and economic survey teams have helped to build economic relations between the prefecture and province. Trade in marine products is especially strong and includes used fishing vessels. Department stores in the sister cities have formed special ties, with Japanese stores receiving Chinese trainees and selling Chinese goods. A Chinese Consulate was opened in Nagasaki in 1985 as a result of lobbying by Nagasaki, and a direct cargo-shipping route from Nagasaki to Fuzhou was opened in 1990. Air services between Tokyo and Shanghai and Tokyo and Beijing fly via Nagasaki and link it to the political and commercial capitals of China.

The formal relationships that Nagasaki SNGs have with Fujian and other SNGs in China including Omura City's ties with Minhang in Shanghai appear to provide Nagasaki with a useful stepping stone into the economic powerhouse of China's southern coastal strip up to Shanghai, which is almost parallel with Nagasaki. Some in Nagasaki worked hard to reopen the route to Shanghai, with local banks and industry forming a 'Shanghai Club'. Nagasaki Prefecture opened its office in Shanghai in 1991 and does not have a formal sister-type relationship with Shanghai since the prefecture already has an official tie with nearby Fujian and there is the connection between Omura and Minhang into Shanghai. This example illustrates the utility of the sister-styled 'friendship' programme in providing the opportunity to make connections in one part of a country to open the door for developing connections in another part.

Nagasaki SNGs may be exceptional in the range and depth of their linkages with counterparts in China. The prefecture's historical connections since the Edo period when Chinese traders came to Nagasaki port and its geographical perch on Japan's western seaboard make China's coastal strip an obvious target for bilateral relations, especially when the opportunities for mutual reward are strong. But beyond the strong economic ties, a diverse range of 'cultural exchanges' - academic, sports, artistic and medical programmes - have been developed to cultivate and extend 
these relations. And there is another reason for these firm connections since Fujian province, according to the Nagasaki website, is the main source of Chinese nationals living in Nagasaki. ${ }^{42}$ However, like Nagasaki, all of Japan is close to China. It is not surprising, then, that with the Chinese economy booming and with shared cultural and historical interests, there is a groundswell of interest among Japanese for cultural exchange with Asian neighbours, particularly China. ${ }^{43}$ This makes fertile soil for development of sister-styled friendship linkages between Japanese and Chinese SNGs as attested by the boom through the 1990s.

\section{Australia: an asymmetrical relationship}

Australia is very distinct culturally and historically from China. Yet from the 1980 s, it became a major destination for Japan's sister-city programmes in the Asia-Pacific region. Japan's twinning arrangements with Australia began in 1963 between Yamatotakada City in Nara Prefecture and Lismore in New South Wales. Following the general trend in Japan's sister-city relationships, there were few in Australia in the 1960s and 1970s, with only 11 municipal-level agreements and none at the prefecture-state level. But the 1980s saw a huge rise in these numbers. Of the six state-prefecture agreements in place by 1993, five were signed in the 1980s, and the other (Okayama-South Australia) in 1993. At levels below prefecture-state, the pace was even faster; some 50 agreements were signed in the $1990 \mathrm{~s}$, about double the number signed in the 1980s, and 12 agreements were signed between February 2000 and October 2002. These data indicate Australia's popularity as a destination for sister-city relationships with Japanese counterparts. Japan is Australia's number one trading partner and the source of a vast flow of inbound tourists and study of Japan and Japanese language is strong at all levels of education in Australia. When we compare Australia with Canada, both middlepower nations and important exporters to Japan, we see Australia has many more sister relationships with Japan than has Canada. Canada had 69 while Australia had 105 in April 2003. All Australian states have an official link with a Japanese prefecture, but in 2003 only one of Canada's 10 provinces, Alberta, had such a link. ${ }^{44}$

Recognizing Australia's population and the size of its economy, Australia has proportionally many more sister relationships with Japanese SNGs than any other country does. The relatively high level of SNG sistering with Australian counterparts indicates that more than in any other bilateral context, both the Japanese and Australian sides seek diverse partnerships with an institutional basis. We see how diverse the purposes of the partnerships can be when we compare the Australian and Chinese examples since both nations are very popular among Japanese SNGs but are very different from each other in many respects, including their relations with China. Yet one similarity here appears to be quite significant: both Australia and China were booming in their economic relations with Japan when the boom in SNG partnerings was at its strongest.

The results of a survey in the late 1990s found the Japanese and Australian sides have rather different motivations for these relationships. O'Toole's study of this survey divides sister-city relationships into three interlinking categories: associative 
activities that include international understanding and culture, reciprocal activities such as educational and other exchanges and commercial activities that focus on tourism, trade and investment. He found that for the Japanese side, sister-city relationships are directed primarily at the first two categories, whereas the Australian side was more inclined towards the third category. ${ }^{45}$

Many policy-makers at state and city levels in Australia believe that sister-city ties should try to introduce local business communities to each other to forge business links and joint commercial activities. ${ }^{46} \mathrm{~A}$ visiting official from the international division of Okayama Prefecture was surprised to find that the South Australian side of its sister agreement was more interested in exploring business and commercial opportunities than cultural and educational exchange activities. ${ }^{47}$ When this author questioned a range of local officials in Japan, including some in CLAIR, about sister partnerships for commercial purposes, the consistent response was that these officials felt SNGs might serve as facilitators but not as initiators of business links and that business people exclusively should deal with business issues. Yet despite this apparent difference in the expectations of each side, the number of relationships rose in the 1990s and new ties continue to be established. This is especially surprising when the overall trend of SNGs is towards consolidation and in some cases even stagnation as the most recent CLAIR data suggest.

It appears that in the case of sister relationships with Australian counterparts, the institutional framework satisfies both sides since their interests, even if slightly different, are easily reconciled. Both sides recognize the long-term invisible gains from this soft form of diplomacy with spillover effects on political and economic relations and on both public and private participants. ${ }^{48}$

\section{'Cold War' neighbours}

Two of Japan's closest neighbours, Russia and North Korea, offer examples that contrast with the Chinese and Australian examples, to some extent because the Japanese national government still views both neighbours largely through a Cold War lens even in a post-Cold War global environment. Here, sensitivity abounds. With Russia, Japan has diplomatic relations but the two have still not signed a peace agreement after the Second World War since they cannot resolve a territorial dispute. ${ }^{49}$ The Japanese government sticks to the principle of seikei fukabun, insisting that politics and economics are inseparable, so at the national level Japan will not fully cooperate with Russia economically while political issues remain unresolved. The bilateral relationship in 2004 is far less tense than it was during the Cold War period, but very little progress has been achieved since dismantling of the Soviet Union, despite a number of summit meetings between the two sides. With North Korea, Japan does not have diplomatic relations and the former remains a closed communist state. The bilateral relationship has soured badly while unresolved issues have festered, including North Korea's abductions of Japanese nationals and its clandestine nuclear programme. The launching of missiles towards Japan in 1998 particularly disturbed the Japanese people. 
The approaches of Japanese national and subnational governments towards these two nations appear to be vastly different particularly on the part of the larger SNGs that are geographically closest to these nations. The national government has maintained an inflexible attitude driven by hard-nosed strategic thinking towards these nations, while some SNGs have for decades taken a more pragmatic 'soft' approach, initiating a range of cultural and economic programmes to engage their neighbours. Sister-city programmes are a formalized part of this approach, which SNGs believe will help to open doors to other activities and eventually lead to improved relations at the national level. We can observe three fundamental differences between the two levels of government in their relations with northern neighbours, which is why the national government has at times resisted SNGs' actions. The first concerns interests; SNGs are aiming to satisfy local interests, which during the Cold War diverged from what the central government perceived to be national interests, although the inconsistency is now less so. The second is approach - soft diplomacy for the SNGs and hard diplomacy for the national government. The third is capacity. I have noted earlier in this chapter how SNGs can act as they do because of their status - they do not represent or act in the name of the nation - and because they have better access to grassroots connections than the central government does.

\section{Russia}

Six prefectures and the Tokyo Metropolitan Government (with Moscow) have affiliations with Russian counterparts. Japan's largest northern island Hokkaido has half of all Japanese sister-city links at municipal level with Russia - 17 of 33 in April 2003 - and Hokkaido Prefecture is linked with Sakhalin, so Hokkaido is our focus here. ${ }^{50}$ The central government's rather rigid views on the bilateral territorial dispute during the Cold War period could not prevent SNGs in Hokkaido attempting to develop what SNGs saw as 'good neighbour' relations with their neighbours in the Soviet Far East, establishing sister ties even when diplomatic relations at the national level remained tense. Governor Yokomichi Takahiro of Hokkaido provided a classic example in 1990 when he signed an agreement on partnership between Hokkaido Prefecture and the Soviet Union, an 'extraordinary' move by the head of a provincial government in Japan to enter into an agreement with the Chairman of the Soviet Union's Council of Ministers. ${ }^{51}$ Hokkaido has reasons for seeking these friendships. It is geographically very close to Sakhalin and the four disputed territories, and has a long post-war history of progressive local leaders keen to develop relations with socialist neighbours. ${ }^{52}$ As Steiner noted, 'Japan's "frontier" may also have been receptive to progressive appeals, or less receptive to conservative mobilization methods, because of its distinct social and political history'. ${ }^{53}$

Williams has discussed various types of exchanges of people between Hokkaido and the RFE within the ambit of 'soft' diplomacy that includes sister or sister-type linkages. Some of these linkages were surely not just a soft cultural approach and carried clear political overtones. For example, both of the "joint declarations' signed in 1972 for the affiliations between Kitami and Polonaisk 
cities and between Wakkanai and Nevesk cities included a clause aimed at 'promoting the conclusion of a Japan-Soviet Peace Treaty', and came just before the first round of peace-treaty negotiations between the foreign ministers of Japan and the Soviet Union in October 1972. Williams observed, 'One can surmise that these "joint declarations" were timed to pressure both the Japanese and Soviet governments to conclude a peace treaty successfully'. ${ }^{54}$ We may question whether the SNGs' declarations could actually pressure their national governments to shift position, but surely these sent unambiguous signals about SNGs' aspirations to all who observed. Exchanges and cultural visits with political significance have also taken place outside the sister-type framework. For instance, in October 1967, a delegation from Sapporo, Otaru, Asahikawa and Nemuro, comprising municipal officials and representatives of the Chamber of Commerce and labour groups, visited Sakhalin to celebrate the fiftieth anniversary of the Bolshevik Revolution. Their counterparts in Sakhalin made similar visits to Hokkaido for the Sapporo Winter Olympics in $1972 .{ }^{55}$ Hokkaido maintained sports exchanges with Khabarovsk, Primorye and Sakhalin in the early 1970s while Cold War tensions soured relations at the national level. In the 1980s, initiatives included the 'Journey to Sakhalin' programme (1981) and the 'Peace Boat' (1985).

However, in early 1989, the Japanese government vetoed an invitation from Takinoue Town to the Russian inhabitants of the Northern Territory to participate in a popular springtime Japanese cultural event. The national government feared that this type of activity might be seen as legitimizing the Soviet occupation of the islands. Here, we see an example of conflict between what the central government perceived as national interest and what an SNG perceived as subnational interest and tried to pursue through soft cultural programmes. Although the central government does not control the SNGs in their sistering and cultural programmes, it can do as it did with the four disputed islands, construing any SNG exchanges with the islands as potentially signalling Japan's recognition that the Northern Territories are part of Russia. Indeed, any action within sister-type relations that works against what the national government perceives to be the national interest could draw regulatory control or at least admonition by the national government. But with the break-up of the Soviet Union in 1991, the Japanese government mitigated its resistance to the soft approach of the progressive leader and agreed to support grassroots exchanges as a way to help create an environment that might lead to resolving the Northern Territories dispute. ${ }^{56}$

\section{North Korea}

Whereas Hokkaido SNGs have been active in the RFE, other SNGs have taken initiatives to develop cordial grassroots relations with North Korea. Progressive local chief executives tried to engage the socialist countries in Japan's neighbourhood during the 1970s and 1980s and more recently newer local chief executives have followed this approach. Governor Minobe Ryōkichi of Tokyo, for example, was instrumental in engaging North Korea through a number of initiatives that included visiting the country in 1971. 
Niigata City also maintains relatively close relations with North Korea. Since 1959, it has served as the main port for the ferry service for returning North Korean emigrants. Mayor Watanabe Kōtarō of Niigata City officially visited North Korea in 1972, while serving as President of the National Mayors Association of Japan (Zenkoku Shichōkai). He held extensive discussion with North Korean President Kim Il-Sung for more than three hours, making a rare event in international affairs with a local government leader conducting diplomacy with an extremely inaccessible national leader. Niigata has also sent a number of delegations to North Korea and relations are close to the extent that residents in Niigata report proudly that children in North Korea who do not know the location of Tokyo can point to Niigata on a map. ${ }^{57}$

But neither Hokkaido nor Niigata featured in the landmark development on 14 May 1992 when two port cities, Sakaiminato in Tottori Prefecture and Wonsan in Kangwon Province signed a 'friendly city' agreement. A number of SNGs in Niigata and elsewhere have relations with North Korea, but for Sakaiminato the compulsion for a formal linkage was especially strong. Other cities on the Japan Sea coastline have deep-sea ports that enable them to trade with a number of countries, but Sakaiminato's shallow waters enable only smaller ships such as those from Wonsan to enter port without difficulty. Sakaiminato's economy depends very much on this trade so it not surprising that the city's mayor and assembly members have actively promoted trade with Wonsan, under way even before the Second World War. ${ }^{58}$ The central authorities in North Korea also endorsed Sakaiminato as their preferred choice of affiliated city. ${ }^{59}$

The entire local assembly of Tottori was behind this diplomatic initiative and generations of Sakaiminato people have been active in promoting relations with Wonsan. ${ }^{60}$ As far back as in December 1971, the local assembly passed a resolution to promote friendly cooperation between Japan and North Korea, and in 1979 established the League of Councillors to Promote Friendship Relations between Sakaiminato City and North Korea, the first of its kind in Japan. In September 1990, the assembly issued a proposal for Japan to normalize relations with North Korea and in March 1992 passed a resolution to establish the friendly relationship with Wonsan, the only one between a Japanese SNG and a North Korean counterpart. ${ }^{61}$

Although the local level was keen, the Foreign Affairs Ministry apparently opposed the formal agreement. ${ }^{62}$ According to a retired Foreign Affairs official who was a senior diplomat at the time, the Home Affairs Ministry intervened and persuaded the Foreign Ministry to allow the agreement to go ahead. As discussed in Chapter 2, Home Affairs resents interference by Foreign Affairs in SNG matters, as this example illustrates. In the event, while the official position of Foreign Affairs opposed the agreement, some Foreign Affairs officials privately regarded establishment of the friendship link as a pragmatic idea. They also recognize that whatever the Ministry's official position, Foreign Affairs has little institutional capacity to regulate SNGs. ${ }^{63}$

Perhaps ironically, it is Tottori's dependence on the central government that has helped to inspire its leaders to seek opportunities outside Japan. Tottori Prefecture 
has Japan's smallest prefectural population, and with geophysical features that afford it very limited means for economic activity, Tottori depends heavily on subsidies from the national government. Especially since Katayama Yoshihiro became governor in 1999, Tottori has paid special attention to pursuing opportunities in neighbouring countries including North Korea. During Katayama's trip to North Korea in 2000, officials of Sakaiminato supported the governor, sharing their local knowledge and connections derived largely through the 'friendly city' affiliation with Wonsan to help build further contacts in North Korea. Governor Katayama avows that he is not acting on behalf of Japan or the national government and that he tries to serve the interests of Tottori in pursuing links at the regional level in North Korea. ${ }^{64}$ Yet, he recognizes that what happens at the subnational level can significantly influence the national level and he believes that the friendly tie between Sakaiminato and Wonsan helps to build trust between the two nations from the grassroots level upward. ${ }^{65} \mathrm{He}$ and other SNG officials have worked strenuously to overcome sporadic difficulties, trying to make the 'friendly cities' relationship an anchor for higher-level diplomatic relations. This friendship tie clearly has both symbolic and practical diplomatic value. ${ }^{66}$

Here we see how Tottori has carved out for itself - by design, default or some mix of both - what can be recognized as a strategic kitty of potentially great value to the central government. It has used grassroots actions to develop relations with North Korea (at both grassroots and national levels) partly formalized through the friendly city agreement. It also seeks to develop knowledge, personal connections and experience, especially relating to the Japan Sea Rim. The SNGs of Tottori hope to make a valuable contribution to the Japan Sea region, to national diplomacy and to the nation. They would like the national government to respond with interest and willingness to support their endeavours.

This would be a reversal in the flow of influence between the national and subnational levels since in Japan's unitary structure of government, policy has generally been developed by the centre and passed down to the SNGs, encouraging the national level to have little will and to believe it had little reason to learn from SNGs. However, as we see in the case of Tottori, some SNGs are gaining influence and diplomatic leverage in international relations through their autonomous decision-making and action. This challenges the top-down decision-making structure of Japan's political system. And as revealed in the examples of sister and sister-type relationships with China, Australia and the 'Cold War' neighbours examined here, some SNGs have been able to strengthen their position in relation to the national government through the potential for greater economic independence and diplomatic leverage that these international linkages can provide.

\section{The JET programme}

The JET programme is by any measure an extremely successful network of international exchange, promoting internationalization in Japan's local communities by helping to improve foreign-language education and developing international connections at the community level. JET was launched by the national 
government in 1987 mainly as a counter-response to US criticism of Japan's growing international economic prowess but low international profile in political and cultural realms. JET has mushroomed into one of the world's largest educational and cultural programmes that connects Japan with one quarter of the world's nations, initially through young people at grassroots level. ${ }^{67} \mathrm{SNGs}$ implement the programme in cooperation with three ministries - Home Affairs, Foreign Affairs and Education - and CLAIR, as discussed in Chapter 2. Under the JET programme, young participants come to Japan mostly to work in either of two capacities for at least a year: (1) CIRs who work with the international divisions of SNGs, experience the inside workings of Japan's political and administrative systems and may facilitate formal or informal connections to the CIR's home country; or (2) ALTs who work in high schools helping Japanese teachers to teach the ALT's native language.

The programme has expanded enormously in almost all respects. Its 847 participants from four English-speaking countries in 1987 multiplied into 6226 participants (speaking French, German, Russian, Chinese, Spanish, Italian, Korean and many other languages) from 47 countries in $2003 .{ }^{68}$ Despite financial stringencies in most areas of public spending in Japan, the budget for the JET programme has ballooned from about $\$ 100$ million in initial years to about $\$ 400$ million in the late 1990s. ${ }^{69}$ A new category of Sports Exchange Advisors (SEAs) was added in 1994 to promote international contact through sports, but this has not been institutionalized or expanded greatly as with the other two categories, and SEAs are request-based. In 2004, around 2000 SNGs, close to two-thirds of Japan's 3200 SNGs, accepted JET participants.

CLAIR materials and even some academic publications about the JET programme suggest that it operates through a top-down decision-making process run by the three main ministries and CLAIR. ${ }^{70}$ Yet, there are indications that SNGs have relatively independent involvement. First, SNGs are not bound to participate; they do not have to accept JET participants in their localities and do so only of their own choice. As noted earlier, about two thirds of all SNGs accept JET participants. Second, as CLAIR brochures advise, 'Each participant's assignment (including placement and duties) within each Contracting Organization [the SNG] is determined in accordance with the assignment plan that is prepared autonomously [emphasis added] by each governor or mayor'. ${ }^{71}$ SNGs have considerable room in designing the involvement of JET participants to meet the distinctive needs of SNGs. The national government does not impose rigid rules or a one-size-fits-all formula on SNGs since successful implementation of the programme requires flexibility so that local needs can be taken into account most effectively. Third, SNGs are financially responsible for their involvement. They receive special grants from the national government through the LAT mechanism, but they pay for participants' remuneration and travel expenses through their own budgetary process. Fourth, SNGs indicate their preferences for the countries from which they want to draw their participants and the programme's central administration tries to accommodate these requests as far as possible. SNGs are not directly involved in recruiting their own participants but 
SNG staff work in CLAIR offices in the seven countries where the bulk of JET participants originate and their representatives sit on the selection panel representing SNGs' interests. Arase's study found that SNGs on the Japan Sea side that pursue cooperation with counterparts across the Japan Sea draw a sizeable number of their JET participants from China, Russia, or South Korea and many of these participants work in the international divisions of prefectural and city offices to facilitate the Japan Sea cooperation process. ${ }^{72}$

Literature about the JET programme generally acclaims the role of CLAIR, the ministries and the JET participants. The instrumental role of SNGs in implementing, financing and contributing enormously to the programme's success is often not acknowledged. Neither is another element that is crucial to the JET programme's rapid expansion - recognition by many SNGs of the programme's real utility while SNGs seek to manage their own internationalization under conditions of globalization inside and outside Japan. Increasing numbers of SNGs see that the JET programme can serve their local interests well by providing direct support for both foreign-language teaching and development of international connections at various levels, which SNGs use to help manage and further develop their international engagement. This is a core reason why SNGs have come on board with JET and have contributed hugely to the triumph of this programme in grassroots cultural diplomacy.

Effectively, the participating SNGs see their involvement in JET as getting value for money. After 16 years and over 40,000 people from across the world sojourning (in a few cases remaining long-term) in local communities in Japan, there are loads of examples of the broad range of cultural, economic, diplomatic, strategic and other benefits that SNGs derive from the JET programme. One of many examples from McConnell's book illustrates how the JET programme can lead to valuable international linkages for SNGs and others involved. McConnell explains how the JET programme was at the forefront of reviving historical and cultural links and establishing friendship ties between two cities in Japan and China. The arrival in Kagawa Prefecture of a JET Coordinator for International Relations from Shaanxi Province in China in 1992 symbolized a 1200-year history of exchanges between Kagawa and Shaanxi. The Kagawa governor and highranking officials in the prefecture maintained interest in the CIR during his stay, and after returning to China, the former CIR became closely involved in preparing a friendship agreement between the two SNGs, signed in 1994. Since then, Shaanxi and Kagawa have sponsored at least ten exchange events annually. ${ }^{73}$

Not every experience in such a vast international flow of people will deliver great, or even any, benefit at all to both sides of the exchange. But overall, the impact of the JET programme on developing goodwill, international understanding and human cooperation is huge and immeasurable, especially when we take into account the ripple effect of JET alumni. Many return to their home country well-placed to cultivate grassroots interest and bilateral connections, especially through working in Japan-related jobs, teaching Japanese language or about Japan, or studying Japan-related subjects in graduate school. Some have stayed in Japan working in various capacities and there have been many cross-cultural 
marriages. ${ }^{74}$ The JET Alumni Association (JETAA) with already more than 15,000 members serves to sustain the interest and linkages formed through participation in the programme, thus extending the benefits that all parties may achieve in the longer term. ${ }^{75}$

Just as SNGs have been instrumental in the success of the JET programme, the JET programme has to some extent been instrumental in developing SNGs' capacity and motivation to pursue productive international relationships. JET contributes to Japan's local and national diplomacy far beyond all initial expectations. For SNGs, it opens valuable channels to develop formal and informal relationships outside Japan. It provides human connections that can reach well beyond the socio-cultural and into the economic and geo-strategic arenas. These channels are two-way, bringing in practical expertise to help equip SNGs and their local communities with the language skills and cultural knowledge needed for beneficial international engagements, and sending back similar expertise on Japan into local communities overseas when the JET participants return home. Crucially, the JET programme is also designed to try to maximize mutual goodwill, an essential 'soft' ancillary to the practical capacity. And there is institutional follow-up to maximize long-term connections. The JET programme therefore prepares the way not only for SNGs and their local communities to internationalize, but also for SNGs to develop further as capable, concerned and confident international actors.

\section{Conclusion}

For the last half-century, Japanese SNGs have taken a pioneering role in developing various types of international exchanges with counterparts in other countries. They have worked on these programmes quietly, without national fanfare and largely outside national foreign policy. Here, SNGs have led the way with a soft approach to international affairs. They have used international exchanges to undertake ever more diverse grassroots activities in pursuit of local interests, while the national government has focused on the formal diplomacy of foreign policy to achieve the economic, political and strategic objectives that it recognizes as national interests. SNG leaders have shown audacity as well as foresight and innovation in heading out on an international route. They have judiciously used legal and constitutional silence on SNGs' international engagements to bypass restrictive controls that the national government exercises over SNGs through Japan's centralized government structure.

Progressive leaders at the local level in the 1960s and 1970s began to link their communities to others outside Japan through people-to-people diplomacy, largely via sister-city relationships. More SNGs responded to propitious international and domestic circumstances from the 1980s, with a strong flourish of sister relationships to make grassroots international connections for various types of mutual benefit. The national level responded with a soft approach by default - but in what has become a class act of cultural diplomacy - in 1987, with establishment of the JET programme. The JET programme has continued to balloon only 
with the close cooperation and major contributions from a large bulk of SNGs, which recognize opportunities for local as well as national benefit from this programme.

Discussion here of sister/sister-type linkages and the JET programme has revealed how the two main types of SNGs' international exchanges are rooted in a similar philosophy concerning the value of international linkages at the grassroots level, but these two programmes are administered differently. Sister cities are independent operations, initiated and managed by individual SNGs through their own resources. These relationships are generally with tacit oversight but without intervention by the national government, although as we have seen in SNGs' sister-type relationships with 'Cold War' neighbours, the national government attempts to lay a firmer hand on these operations when it perceives that they are out of alignment with national interests or articulated national policy. Even then, the national government does not speak with one voice; the Home Affairs Ministry has supported SNGs at times when the Foreign Ministry has preferred SNG withdrawal from what the Foreign Ministry sees as contentious 'international diplomacy' that is its exclusive bureaucratic sphere. The 'friendly city' linkage between Sakaiminato in Tottori Prefecture and Wonsan in North Korea offers a clear illustration. The JET programme, on the other hand, is centrally managed and coordinated by three national-government ministries with cooperation from, and administration by, CLAIR. The now two-thirds of Japanese SNGs that participate in the JET programme also contribute administratively and financially. They act with some independence, particularly in determining how the JET participants will be involved on the ground in their locality to best support local needs.

In both the sister-city and JET programmes, SNGs have been able to do what the national-government bodies sometimes cannot do. Inside Japan they work at the local level closer to the people and so have experience and access to resources that the national level does not have. They also act without the official diplomatic baggage that is attached to national-level actors in an international context, which has enabled SNGs to achieve in some instances - such as connections with the RFE and in 1970s Communist China - what the national government could not. More and more SNGs have not just the capacity but also the political will to make international connections for a variety of benefits to both sides. They have taken international exchange well beyond symbolism into pragmatic engagements that involve cultural, economic and geo-strategic connections and influence national and local policies. Many SNGs have responded with vigour to the call for 'internationalization' and have harnessed it creatively to the concept of international exchange. In this spirit SNGs have pursued sister ties, JET and other informal programmes, to meet local needs, create opportunities for their localities and establish their own role as international actors that contribute positively both to the Japanese nation as well as to their local constituency. 


\title{
4 International cooperation
}

\author{
A strategic edge
}

Chapter 3 explored the pioneering role of Japanese SNGs as international actors in their own right through a soft approach to international affairs, known as international exchange. This chapter turns to a type of SNG international engagement that has a harder strategic edge. It has drawn SNGs more actively into the international arena, parallel with and occasionally lubricated by, the sister-city arrangements. This type of international engagement is generally labelled kokusai kyōryoku or international cooperation. Generally programmes and projects emerging from these engagements have a more strategic edge than most of the sister-city arrangements since they involve practical, hands-on, and much-needed contributions by SNGs to the national foreign-policy effort.

International cooperation by SNGs evolved with the emergence of a new set of ideas, policies and institutions particularly through the late 1980s and 1990s. Developments were formalized and propelled from the early 1990s by MOHA that introduced a new slogan in the local government lexicography, 'Kōry $\bar{u}$ kara kyōryoku e' (from exchange to cooperation). At this time, uncertainty about Japan's new international role as a regional and global power in a multilateral post-Cold War world challenged the Foreign Ministry in managing the nation's foreign policy. The Foreign Ministry had put forward the term kokusai kōken (international contributions) to encompass succinctly and in a politically palatable way, Japan's more diverse international participation, carried out by a more diverse array of Japanese actors outside the Foreign Ministry.

The growing involvement of SNGs in international-cooperation programmes therefore has a double edge of symbolism. First, as an assertion by SNGs and their central-government body MOHA, it symbolized the push by some SNGs to gain greater autonomy from the central government in their role as international actors. The slogan 'Kōryzu kara kyōryoku e' signalled to unyielding policy-makers of the central government outside the Home Affairs Ministry, particularly in the Foreign Ministry, that some SNGs had the wherewithal - both political will and practical capacity - to operate as legitimate international actors. Timing was important here since the central government needed 'contributions' from SNGs to make Japan's 'international contributions' to an evolving, post-Cold War international order. Second, the development signals a strategic shift in the nature of SNGs' international engagements beyond the soft approach of international exchange. What was 
initially the diplomatic symbolism of sister-city programmes for some SNGs has evolved to include the instrumental contribution of many SNGs to the national foreign-policy effort through their own cooperative arrangements and through their part in the nation's ODA communities. The latter role makes SNGs ever more important partners to the central government in Japan's international diplomacy, since ODA is a vital part of Japan's international engagements.

The national government has established an institutional framework so that it can to some extent manage SNG involvement in international cooperation and the Foreign Ministry can maintain a firm hand on the nation's foreign-policy rudder. Nevertheless, for many SNGs, international-cooperation programmes have been a vital part of building their international experience, identity and political autonomy, while they take a more active and independent role in international relations. Funding for SNGs to participate in or undertake international-cooperation programmes comes generally from three sources: the national-government budget through the LAT mechanism, allocations from the budgets of the Foreign Ministry, JICA and JBIC, and allocations from SNGs' own budgets for wide-ranging cooperative activities. Significantly, many SNGs take creative initiatives that draw on their distinctive capacity and experience at the local level and on the valuable coalitions they have built with a range of actors locally, nationally and internationally.

This type of international involvement has developed the domestic profile of SNGs as irreplaceable contributors to Japan's national programme of international cooperation. SNGs use their involvement in these programmes to portray themselves as international actors in their own right, not just as subaltern lower levels of a national government whose interests may not necessarily coincide with SNGs' local interests. By early 2002, a leading newspaper, the Daily Yomiuri reported that 'An increasing number of local governments - from tiny villages to major cities are becoming involved in international activities and projects comparable to those assisted by the central government's official development program'. Media, business, government and the Japanese people have come to acknowledge and accept the expanding roles of SNGs in international cooperation and by extension the significant roles of SNGs as international actors in their own right. ${ }^{2}$

In many ways the role of Japanese SNGs in international-cooperation programmes resembles the roles that some of their European and North American counterparts have been performing from the post-war period, in conjunction with, and independent from, their central governments. European SNGs have pursued with increasing vigour a programme of international cooperation that the international cooperation of Japanese SNGs now resembles. ${ }^{3}$ We should not be surprised by this development since in virtually all countries where SNGs are involved in international activities, the SNGs have begun to move into these types of international-cooperation programmes. The examples of SNGs outside Japan provide both useful precedents and valuable SNG networks that facilitate the work of Japanese SNGs in international cooperation.

I present two arguments. First, involvement in international-cooperation programmes has stretched the international role of Japanese SNGs well beyond soft cultural activities into a strategic realm that was previously the exclusive 
domain of national government. This has brought SNGs more firmly and visibly into the formal fold of Japan's international diplomacy and has helped to legitimize SNGs' domestic status as international actors. Push and pull factors are both at work here while the forces of globalization and its consequences reshape the local, national and international political landscapes. SNGs seek to pursue local interests, policy autonomy and their conviction that they can take on significant, innovative roles in international affairs and help their counterparts in other countries. The Foreign Ministry, in response to the dramatic changes driven by globalization and the financial squeeze from prolonged national recession, has been forced to move beyond its exclusive approach to foreign-policy management towards a pluralistic approach to policy and actors, and thus a reallocation of foreign-policy roles. The Ministry accepts increased SNG involvement in international-cooperation programmes since unlike most other possible actors, SNGs not only have resources, expertise and valuable connections, but are also likely to comply with the directions given by the national government. As discussed in Chapter 1, SNGs are themselves 'government' actors (even though MOFA claims it does not regard them as 'government') below the national level and to some extent are financially beholden to their central paymaster.

My second argument takes us to a core concern of this book, that is, the consequences of this work reallocation for SNGs' relations with the central government. The involvement of SNGs in international-cooperation programmes, especially in selected ODA projects, has served to connect the central government with SNGs as partners in an important area of Japan's foreign policy. The central government needs SNG contributions at a time of increasing interdependence between most actors in the international arena. Thus, formal allocation to SNGs of some responsibility for conducting these official aid programmes enhances the position of SNGs in their relations with the central government, as indicated by some of the examples I discuss in this chapter.

First, I examine briefly the slippery concept of international cooperation and SNGs' interests and motivations for participating. I then consider the growth of SNG involvement in international cooperation and how this has been institutionalized in various stages from the 1970s. Next, I look at the types of internationalcooperation programmes that SNGs pursue, with examples engaging Japan's immediate neighbours in Northeast Asia and Russia. These are Japanese SNGs' most common partners because of their geographic proximity and because they present as natural destinations for the types of cooperation programmes that Japan's SNGs are keen to pursue. ${ }^{4}$ I then turn to recent developments in national ODA policy that formally recognize SNGs' role in Japan's ODA programme, ${ }^{5}$ exploring how complex changes have forced both better coordination between local and national actors and a greater role for SNGs and other grassroots actors working cooperatively in this area of foreign policy. I conclude by relating the two arguments mentioned above that I develop throughout this chapter to the two central questions pursued in this book: what does this development mean for the conduct of Japan's foreign affairs and what are its implications for the national-subnational relationship? 


\section{Conceptualizing kokusai kyōryoku}

Inside Japan there is considerable ambiguity, among those who work in this area and in the writings on this subject, about the language referring to these international programmes. ${ }^{6}$ Two terms in particular are used, sometimes interchangeably: kokusai kōryū (international exchange) and kokusai kyōryoku (international cooperation). The meanings of these terms share much. Kōry $\bar{u}$ and kyōryoku both suggest symmetry between partners, here the SNGs in Japan and partners overseas, and mutual agreement; there is no hint of imposition in these actions. Both terms can refer to movements of hardware and software - material goods, information, people and ideas - in this case across national borders and the benefits are seen to be mutual: mutual understanding and knowledge and enhanced economic and social development. Both terms are therefore relatively politically benign.

However, there is an important distinction between these terms, as conveyed by the apposite Japanese literature and during my interviews with SNG officials and MOHA advisers who generated the slogan 'Kōryū kara kyōryoku e'. Kōryu tends to imply something symbolic, whereas kyōryoku has a more pragmatic edge. It appears that $k \bar{o} r y \bar{u}$ was put forward in the early days of sister-city programmes to highlight their symbolic goodwill. We can therefore understand MOHA's support for use of 'Kōryū kara kyōryoku e' from the mid-1980s, since SNGs had extended their sister-city and other international programmes far beyond diplomatic symbolism and internationalist 'feel good'. The slogan was to help propel this shift by SNGs from symbolic, mutually rewarding activities with international partners to actions that signify a 'cooperative', supportive, and by implication more strategic, engagement on the Japanese side. The slogan thus signalled a new stage in SNGs' international activities as they began to think strategically of their own aims as international actors and their contributions to the nation's international diplomacy.

Another aspect of 'kyōryoku' (cooperation) also needs explanation. Whereas the term can convey mutuality of sharing and benefit, it can also have the connotation of 'enjo' (assistance) that responds to others' needs, as in foreign-aid programmes where the primary purpose is a unilateral flow of aid from donor to recipient. Particularly from the late 1980s, SNGs' involvement in kokusai kyōryoku has been expressly to provide assistance to others outside Japan, through their own resources and increasingly through their involvement in national ODA projects that SNGs now help the central government to deliver. Considerations of symbolism/pragmatism, mutuality/unilateral flow and sharing/ giving inevitably create confusion for identifying and talking about the international programmes of SNGs. There are no hard-and-fast rules of language in this domain and some SNG officials explained to me that often officials in charge of a specific project decide on the most appropriate label after considering the project's overall picture, including monetary value, aims, partner and format. ${ }^{7}$

These nuances in the language highlight how SNGs carry out international cooperation in two distinct realms. One is the cooperative framework between SNGs for mutual learning and problem-solving with foreign counterparts. Some SNGs have found collaborative arrangements with their foreign counterparts very 
productive while they struggle to stretch tighter budgets to fulfil their administrative responsibilities to citizens, perform more administrative tasks that the central government hands down to them and manage their local economies efficiently all the while trying to maintain their hold on government. Many Japanese SNGs increasingly rely less on the national government to address specific problems and instead seek resolution through transnational coalitions of SNGs that share their concerns. These collaborative arrangements for problem-solving and information-sharing involve SNGs in a range of nations regardless of their level of economic development.

The second realm of SNGs' international-cooperation programmes usually involves more explicitly unilateral assistance by Japanese SNGs and has two forms. One is the various types of 'assistance' such as technical cooperation, that are initiated and funded by SNGs independently of the national government, and are often referred to as local ODA (jichitai $O D A) .{ }^{8}$ The second is SNG involvement in delivery of the national ODA programmes where SNGs work in partnership with the national government. Responsibility for international cooperation through technical assistance and foreign aid still rests with the national government, but SNGs are assuming more comprehensive roles as the national system for delivering ODA is reformed. ${ }^{9}$

With 'local ODA' international cooperation, SNGs provide largely independent assistance, outside the national ODA programme and sometimes outside formal partnerships such as sister-city arrangements. Some SNGs use local ODA to provide support for counterparts in nations that are not officially eligible to receive Japan's national ODA, demonstrating these SNGs' practical and strategic capacity to act independently of the Foreign Ministry and the national foreign policy. ${ }^{10}$ Carrying out independent programmes places SNGs in a better position to be part of national ODA when opportunities arise. In recent years, many SNGs have made some of these independent cooperation programmes mutually beneficial rather than narrowly outward assistance, as we consider later in this chapter. Increasingly, however, SNGs provide assistance through the national ODA programme. They work in cooperation with the central aid agencies such as JICA and JBIC, or simultaneously with central and other levels of government, ${ }^{11}$ or in association with local community groups such as NGOs, educational institutions and other citizen groups. ${ }^{12}$

The first realm of international cooperation - collaborative problem solving - is particularly useful for SNGs to carry out effective administration at the subnational level. It also helps to strengthen SNGs' autonomy from the national government, since here SNGs are acting in a largely independent and self-designed capacity. But it is in the second realm of international cooperation - aid-giving - that much of our discussion will focus since it is here that SNGs are trying to carve a new role for themselves in an area that was earlier the exclusive domain of nationalgovernment actors. SNGs' involvement in foreign-aid giving has profound consequences for the SNGs and for their relations with the national government, since it can generate not only international goodwill and international connections, 
but also economic cooperation and commercial spin-offs. These programmes raise the profile of SNGs within the community by dispatching people from local communities in Japan to assist with training in communities abroad, and bringing trainees from different parts of the world into local communities in Japan. These human flows give the programmes a visible and palpable form. Recent pluralism in ODA policy now offers opportunities for local organizations such as NGOs, educational institutions and individuals also to be involved.

As with sister-city relations, some prefectures and cities are more active than others in international-cooperation programmes. Influences upon the extent and the nature of SNG involvement in these programmes are complex. They include the preferences and capacities of local leaders, the localities' historical links and geographical location, local interests, capacities and needs and the willingness of the local administration and ultimately the local constituency to help people in other countries by providing local know-how, experience and resources. Influences on the choice of partners for these programmes are also complex, but especially in the realm of enjo through local ODA, partners are predominantly in neighbouring countries. This is quite significant for what it suggests about distribution of geographic responsibility in aiding Asian countries, between the national and subnational levels of government that to some extent work cooperatively here. Japan's national ODA programme has a bulk of projects in South Asia and in 2003, India became the number one recipient of Japanese ODA. But South Asia is beyond the strategic framework of SNGs' involvement in local ODA as SNGs focus on supporting their counterparts in the immediate neighbourhood in the Asia-Pacific region.

\section{SNG motivations for international cooperation}

A mix of factors ranging through altruism, idealism and enlightened self-interest motivates SNGs to participate in international cooperation. Some of these programmes are undertaken in a spirit of giving and sharing to help people in other parts of the world using local strengths and expertise. Some programmes are explicitly to gain economic, political or strategic advantage for the SNG and those it represents, and deliberately or otherwise, for the Japanese nation at large as well. Usually both motivations are involved. We cannot be surprised that SNGs pursue international cooperation to gain for their own locality since they finance these programmes from the public purse, whether through the SNG's own budget or the national budget.

Some cooperative arrangements result from sister-city or other official ties where both parties feel they have lessons to learn from each other's experiences, in fields ranging from agricultural production, manufacturing, and city management, to human resource development and environmental protection. For example, Kumamoto City and Heidelberg in Germany both rely on groundwater as their sole source of water and the two cities have worked together on water conservation programmes since 1995. Their sister-city tie was established in 1992 on the basis of this shared concern. ${ }^{13}$

A few SNGs with specialized knowledge and skills have established institutions to share their strengths with others, although large-scale institutional arrangements 
are fairly exceptional. In 1980, Kitakyushu City formed the Kitakyushu International Techno-cooperative Association (KITA) to promote the city's capacity to provide international assistance in environmental management ${ }^{14}$ and Yokkaichi City in Mie Prefecture established the International Centre for Environmental Technology Transfer (ICETT) to promote environmentally sound international passage of technology. ${ }^{15}$ Both cities have strong banks of expertise in managing industrial pollution after suffering severe environmental degradation from heavy industry during Japan's early post-war industrialization. These institutions conduct their own research projects funded by a range of government and private bodies, and provide international training and technical cooperation on behalf of both their SNGs and national aid agencies such as JICA. Commercial spinoffs for the locality are not a stated purpose of these institutions, but in interviews with me, SNG officials observed that technical training and cooperation programmes can have commercial value for their locality since recipient SNGs are likely to order products from local suppliers within the institutions' locality.

Hyogo Prefecture and Kobe City have valuable experience in city reconstruction following one of the largest earthquakes ever experienced in the prefecture in 1995. Both SNGs have extended help to overseas destinations that experienced similar destruction, including Sakhalin (Russia), Turkey, India and Taiwan. Hyogo and Kobe provide training programmes in disaster prevention and other activities in disaster management throughout Asia-Pacific nations, both as part of the JICA training programme and in their independent capacity. ${ }^{16}$ Similarly, Minamata City in Kumamoto Prefecture in southern Japan has been willing to share with similarly afflicted overseas SNGs the lessons learned from its experience of residents who suffered mercury poisoning from factory wastes flowing into Minamata Bay in the 1970s. In 2000, the city received nine trainees from China, Indonesia, the Philippines, Thailand and Malaysia who spent three months in Minamata City learning about environmental management and protection. ${ }^{17}$ A JICA official opined that the altruism behind Minamata's programmes of sharing its lessons with other Asian SNGs to prevent a repeat of Minamata's misfortune is similar to that of Nagasaki and Hiroshima cities as they aim to spread the message of peace internationally through the anti-nuclear movement. ${ }^{18}$

Undoubtedly, there is genuine altruism and idealism as SNGs mount these programmes. Yet clearly self-interest is at work here too, as we must expect while SNGs draw from the public purse for these programmes. SNGs are political players. They recognize that some citizens in their locality do not favour giving selflessly to others outside Japan, especially when financially, times are relatively tougher under economic recession at home. SNGs also recognize that some citizens do not fully appreciate the unvalorized benevolence that these programmes generate as an investment in goodwill in the future when it might be of great value to the donor SNG. Therefore pragmatism inclines SNGs to pursue these programmes for some economic gain for their locality and for some political gain for SNGs themselves. This is particularly so as these programmes have become much more instrumental than symbolic. 
Various types of international-cooperation programmes yield economic gain over time for the SNG's locality, and SNGs pursue such programmes precisely for this reason. The examples I mentioned above of Kitakyushu's KITA that promotes environmentally-sound international passage of technology, and Yokkaichi's ICETT for international cooperation in environmental management, both open opportunities for commercial gain within these localities through commercial spin-offs. Indeed, there are many examples of programmes that have led to valuable commercial opportunities for SNGs to develop. The abacus project between Yokota in rural Shimane Prefecture and Roiet Province in Thailand, helped by the Minsai Center in Tokyo, began as a simple educational programme to enhance reading, writing and arithmetic (yomi, kaki, soroban) using Japanese abacus in some local Thai schools. It resulted in a national ODA project supported by JICA, which brought economic and other benefits to Yokota whose abacus industry was on the verge of extinction. ${ }^{19}$ Misumi Town, which is also in rural Shimane and specializes in traditional paper-making technology, cooperated with the Kingdom of Bhutan by passing on this technology, a move that resulted in reviving the traditional industry in Misumi. ${ }^{20}$ These two examples of economic spin-offs for SNGs in rural Japan point to the potential value of these programmes in the national context of attempts at rural revival as the consequences of globalization diminish the economic and social livelihood of many rural areas. ${ }^{21}$

Political gains are less noticeable but they are surely important for the SNGs. These gains are largely concerned with empowering SNGs vis-à-vis the central government, and are thus particularly valuable for SNGs seeking to strengthen their autonomy. Participation in international-cooperation programmes gives SNGs new roles and channels for influence within the domestic power structure via the connections they make in the international arena. First, international-cooperation programmes create or lubricate practical international linkages that can also have diplomatic value for SNGs, especially when the centre needs to draw on SNGs to access these connections. Second, through these programmes SNGs have built domestic coalitions that include not only other Japanese SNGs but also some of the central agencies such as JICA and JBIC that now work closely with SNGs. We see here how SNGs' participation in international cooperation gives them new opportunities for alliance building within and outside Japan, which SNGs can use for leverage in their relations with the national government.

A third political consequence of these programmes concerns their symbolic impact on SNGs' domestic political profile. SNGs recognize that participating in international cooperation helps to build the image of SNGs as capable and independent actors in Japan's foreign relations. This is an area of national political life that some SNG leaders claim should not and cannot be the exclusive domain of the central government, especially while the Foreign Ministry is pressured to manage diplomatic affairs while the nation takes on more, and more complex, roles in the international arena and SNGs are well placed for greater involvement. ${ }^{22}$ Thus a mix of motivations ranging across the pragmatic and the practical, the symbolic and the instrumental, the pursuit of mutual benefit and of altruistic 
unilateral giving, work alongside self-serving political and economic interests in shaping SNG involvement in international cooperation activities.

\section{The post-war evolution of subnational international cooperation in Japan}

Like sister-city arrangements, the post-war history of international cooperation at the subnational level in Japan can be divided roughly into three decade-long stages. Generally we find that in the first two decades, the 1970s and the 1980s, much of this cooperation was for SNG problem solving. The concern here was for sharing and resolving local problems collaboratively, with benefit for all participant SNGs. This was not cooperation for providing unilateral assistance or enjo, nor really for expanding the role of SNGs in Japan's foreign policy. These motivations gained real momentum only from the late 1980s, when SNGs began to realize that they could offer valuable support to other SNGs outside Japan through their independent programmes of assistance. SNGs were also drawn further into delivery of the national ODA package and into coalitions with other domestic and international actors that strengthen the SNGs' position in relation to the national government.

The first stage is the 1970 s, marked by the aftermath of intense industrialization with Japan's transition from high to stable economic growth. SNGs were then trying to cope with the socio-environmental consequences of particularly vigorous economic growth. Their initial moves towards international cooperation were therefore motivated by their need to address local problems that they saw their counterparts in other countries also trying to address. Progressive leaders headed a number of local government administrations and could see that the central government was unwilling and unable to work seriously to resolve these problems at the local level. Their lead was followed by other local chief executives in subsequent years.

Some Japanese cities hosted international conferences to facilitate exchange of ideas and policy approaches in specific fields. The Tokyo Metropolitan Government set the ball rolling in 1972 with the 'World Big City Convention' in Tokyo focusing discussion on participants' shared concerns about environmental pollution, housing problems and transportation. In 1984, Shiga Prefecture hosted an international conference on water quality and lake management to further develop bilateral and multilateral networks with overseas counterparts, ${ }^{23}$ in 1985 Tokyo held the World Major City summit, and in 1987 Kyoto held the World Historical City summit. ${ }^{24}$

Some international meetings for cooperation had significant diplomatic import, providing channels for communication and trade that for diplomatic reasons could not be carried out at the national level. For example, the Japan-Soviet Coastal Mayors' Association (since 1992, the Japan-Russia Association of Mayors of Japan Sea Coastal Cities) was established in 1970 at the initiative of Niigata City, with 20 member cities. Its aim was international exchange and cooperation between these Japan Sea SNGs and local administrations in socialist bloc countries. Cooperation through this association demonstrated how governments 
below the national level could establish productive international ties even while Cold War animosities had ruptured 'official' contacts at the national level. In 2004, 26 Japanese cities were members of this association. Its counterpart on the Russian side is the RFE Siberia-Japan Association comprising 18 cities. Similarly, the Conference of Japan Sea Coastal Cities for Japan-North Korea Friendship and Trade Promotion was held in 1972 at the initiative of Niigata, and now some 20 Japanese cities participate in this process as cities around the Sea of Japan aim to engage North Korea. ${ }^{25}$

The 1980s saw expansion of this international collaboration concept. Efforts were still practical, instrumental and in pursuit of shared problem-solving, underscored by the notion of mutuality. The distinctive trend at this time was towards institutionalizing collaborative linkages inside Japan. One clear manifestation was the 'Local Exchange Group Concept' (kyokuchi kōryūken kōzō), initiated by a group of opinion leaders (chishikijin) from a number of SNGs and later incorporated in both SNG policy and national policy concerning SNGs. This concept melded national and local interests in a policy approach aimed at establishing geographic blocs such as the Japan Sea Rim, to revitalize and promote Japanese localities through international exchange and cooperation at the SNG level. ${ }^{26}$ Here was the understanding that these international linkages would generate economic opportunities that groupings within Japan could help to maximize.

From the 1990s, SNGs' involvement in international cooperation activities has expanded in a direction different from the earlier periods. Some of the catalysts have been the national government's reports on reform of ODA policy, which recognize and formally incorporate the capacity of SNGs and other actors. These policy moves have legitimized the involvement of SNGs and other actors in international aid delivery at a time when the national government has needed their contributions in delivering the ODA programme. The policy changes have not made SNGs major players in ODA delivery and do not preclude SNGs from pursuing their own international-cooperation programme for collaborative problemsolving or enjo outside the national ODA programme. However, drawing SNGs more closely under the regulatory framework of national ODA policy has allowed the national government to adopt a more comprehensive approach to institutionalizing and coordinating the work of SNGs within the national ODA programme.

Most SNGs have been at least willing, and some very eager, to diversify their international roles in this direction. Above, we considered how the early 1990s slogan 'Kōryū kara kyōryoku e', 'from exchange to cooperation', encapsulated this philosophical and practical shift in SNGs' international activities and their readiness to move into strategically oriented action. Indeed MOHA affirmed the new role of SNGs and its ministerial support for their international-cooperation programmes by proclaiming 1995 as the foundation year of international cooperation (kokusai kyōryoku gannen). These conceptual and institutional shifts in the third phase have therefore generally been consistent with the will of both national and subnational levels of government.

The shifts have significant implications for relations between the two levels of government and for relations within each level of government, especially since 
the third party, the aid recipient, is outside Japan, which increases the diplomatic import of these arrangements. Although the involvement of SNGs in the ODA programme is limited, it nevertheless increases the central government's dependence on, and capacity to oversee, SNGs in this area of work.

In the first two phases, SNGs initiated and conducted most of their own international-cooperation programmes involving international assistance with some support from central agencies such as JICA. In the third phase, where technical and other types of assistance and participation in aid delivery have become a key element of SNGs' activities in the international arena, the central government supports much of the SNG actions. It provides stronger budgetary and institutional support, including through international cooperation centres established in municipalities across Japan. SNGs' inclusion within the formal institutional framework for aid delivery, labelled as 'international cooperation', has helped to make these programmes much more common in most Japanese localities. ${ }^{27}$

Institutional framework to support alliances or networks has been established for SNGs' involvement in all three types of international cooperation: problemsolving, 'local ODA', and the national ODA programme. Some institutional arrangements effectively serve the objectives of all three since they provide the space in which actors with shared interests can meet, discuss and garner useful ideas for implementation.

\section{Problem-solving as international cooperation}

Some SNGs have formed their own bilateral or multilateral alliances to share ideas and information and exchange technological know-how best suited to their own local needs. The Sapporo City Office in Hokkaido serves as the secretariat for the International Association of Mayors of Northern Cities, whose main task is forging cooperation among member-cities on shared problems arising from their cold locations. Issues include city planning, housing, winter transportation, winter tourism, snow clearing, pollution and countermeasures for natural disasters. As of November 2001, 19 cities in 10 countries belonged to this association. ${ }^{28}$ The Association's genesis is a network formed in 1981 by then Mayor of Sapporo, Itagaki Takeshi. As Sapporo City officials explained, finding solutions to local problems through overseas contacts has helped to increase the local autonomy of Sapporo City by decreasing its dependence on the national government for solving problems that are anyway relevant only to the colder northern part of the nation. These officials opined that their colleagues' comments suggest that elsewhere in Japan, too, transnational coalitions of SNGs that share similar concerns have enabled SNGs to rely less on the national government and more effectively address local issues. ${ }^{29}$

Tanaka Naoki, a high-profile public commentator, reveals a similar view in his claim that the central government housed in Kasumigaseki in Tokyo is inevitably divorced from environmental and social systems best suited to particular localities that are distant and different from the national capital. He illustrates his argument with the example of how the central government has been inept in 
dealing with housing and energy issues in Hokkaido since its plans are based on wrong assumptions about climate. Tanaka discusses the Northern Region concept (Hoppōken kōsō) initiated by the Hokkaido Prefecture through its third Comprehensive Development Plan in 1971 as one arrangement enabling SNGs and local groups to develop new knowledge through exchange of information overseas. ${ }^{30}$

Another example of a transnational coalition of SNGs successfully addressing shared concerns through information sharing and joint research is Takasaki City in regional Gunma Prefecture. In 1995, Takasaki City established a multinational study group on global environmental problems, in association with partner cities in the United States, Brazil, China and the Czech Republic. Project results were posted on the Internet for wide accessibility. This initiative led to several cooperative multilateral research programmes, and has been used as a precedent by other Japanese cities. In Okinawa, for example, several island SNGs from South Korea, China and Indonesia came together to consider tourism in their island settings and embarked on cooperative arrangements such as joint marketing and exchange between tourism operators of each of these islands. ${ }^{31}$ These examples illustrate Japanese SNGs' initiative and productive involvement in international-cooperation programmes with counterparts in both economically developed and economically developing nations for problem solving and mutual benefit through sharing information and experience. They also indicate how the transnational coalitions serve to enhance Japanese SNGs' independence from the central government and give the SNGs a valuable diplomatic reward - an extensive network of international connections and international goodwill - that can also serve the SNGs in their relations with the national government.

\section{SNGs' local ODA and national ODA as international cooperation}

We noted above that SNGs are now involved in two types of international aid delivery: (1) local ODA, funded from the SNGs' own budgets and resources and initiated and implemented independently by SNGs; and (2) the national ODA programme funded through the national budget, where SNGs work in partnership with the national government's agencies and other actors. A few SNGs have been involved in small-scale technical cooperation or assistance programmes for many years. ${ }^{32}$ However, involvement of all types of SNGs in national ODA delivery has grown enormously from the 1990s. This was inspired by the central government's efforts to reallocate practical implementation of the nation's huge ODA programme as efficiently and effectively as it can, drawing on a diverse range of domestic actors that the central government administers, regulates and coordinates while maintaining overall responsibility through its agencies. ODA has been one of the principal grounds for the Foreign Ministry and its agencies' decentralization efforts.

According to one informed estimate, in the early 2000s, each prefecture carries out about 10 projects annually, either through their own resources or in cooperation with central government ODA projects. This means that each year prefectures alone implement about 500 international cooperation projects that deliver international 
aid. Municipalities also carry out at least this number of projects, making the number of aid projects implemented by SNGs each year more than 1000, at a moderate estimate. ${ }^{33}$ Such extensive SNG involvement has seen SNGs coming to be regarded as a valuable part of Japan's foreign-aid delivery community.

The central government has included SNGs in national ODA delivery largely because they have the expertise and experience most needed for these projects and which the national government does not possess. The types of ODA projects involving SNGs are those that draw on this local expertise and experience, including environmental conservation and protection, health care, education, agriculture, disaster relief and protection of cultural assets. These are all part of the SNGs' routine functions. The national government allocates most projects according to the SNGs' ability to mobilize specialized expertise and personnel and make use of distinctive regional characteristics that suit the needs of the partner region as recipient. ${ }^{34}$

From here let us turn to see how this discussion of the SNGs' expanding role in ODA plays out in practice. I have chosen as illustration examples of international cooperation with China, Russia, South Korea and North Korea. Many Japanese SNGs favour China and South Korea for conducting local ODA because of their geographical proximity and the rich opportunities they present for benefit on both sides of the cooperation. North Korea provides instructive example of SNGs taking international action where the Foreign Ministry and national foreign policy are limited in the absence of diplomatic relations between the two national governments. Russia is Japan's closest neighbour geographically and very close to the localities of the Japanese SNGs surrounding the Sea of Japan - SNGs that have actively sought to improve relations with Russia, despite the national government's rigid attitude towards Russia. We mainly consider the work of SNGs in prefectures adjacent to the Japan Sea since these SNGs particularly favour an eastward reach to Northeast Asia in their international activities.

\section{The People's Republic of China}

As a very powerful nation on Japan's geographic doorstep, China occupies a special place with Japanese SNGs. China has a burgeoning national economy and shares cultural and historical links with Japan, as well as strategic interests. About half of the international-cooperation programmes that involve Japanese SNGs are with the PRC.

One of the most popular programmes conducted with cities and provinces in China is caring for the physical environment. ${ }^{35} \mathrm{~A}$ particular concern of Japanese SNGs has been to assist Chinese counterparts in pollution control and other environmental management. Self-interest is clearly part of the motivation here since pollution in China can have serious damaging effects on the physical environment of Japan. A 1995 report by Energy Information Administration Japan claimed that pollution from China was adversely affecting certain areas of Japan and noted that for Kyushu, 'In 1992, a reported 30 per cent of the total amount of acid compounds released into the air by Chinese industries fell on the region.' 36 
Kitakyushu City is linked to Dalian City through a friendship programme established in 1979. Kitakyushu is renowned internationally for improving local water and air quality after severe pollution problems in the $1960 \mathrm{~s}$. When rapidly industrializing Dalian faced similar environmental degradation in the early 1990s, the Kitakyushu SNG helped the Dalian SNG to develop an environmental protection plan that included passing on technological know-how for water-quality improvement, waste-disposal management and other areas of concern. In 2000, the Japanese national government chose Dalian as one of three Chinese cities (with Chongqing and Guiyang) for the Japan-China Model City Plan. ${ }^{37}$ Here a cooperative local aid relationship in environmental protection led to a larger grant through Japan's national ODA programme, establishing a precedent in Japanese ODA history for bottom-up rather than top-down policy-making. ${ }^{38}$ The SNG project was so successful that Dalian received a UN Environment Programme award in 2001.

Mutual interest in environmental cooperation is also evident in the flow of Chinese SNG employees to learn from Japanese SNGs (42 per cent of the total inflow of Chinese trainees in 2000 were for environmental programmes). Japanese SNGs are generally keen to help train their Chinese counterparts, recognizing their own vested interest in environmental clean-up in China. Japanese SNGs are well placed to assist with this type of cooperation as they have considerable expertise in dealing with pollution problems after their own experience following high economic growth in the 1960s.

Industrial technology cooperation programmes with China take increasingly diverse and creative forms, such as preservation of cultural assets in the Xixia Wang Imperial Mausoleum project between Matsue City in Shimane Prefecture and Yinchuan City in Ningxia Province. Medical programmes are also popular, such as the donation of medical equipment by Toyama City in Toyama Prefecture to Qinhuangdao City in Hebei Province. Town planning is also a valued area for cooperation programmes, such as the preliminary survey for the 'Dongjiang River Information System' carried out by Hyogo Prefecture for Guandong Province.

Training programmes are particularly popular, with Japanese SNGs receiving trainees and dispatching technical staff to provide training in a range of educational programmes, mainly through JICA. China dominates as recipient of the SNGs' training programmes. In 1994, Japanese SNGs received some 3250 trainees (41 per cent from China) and dispatched around 440 technical personnel to developing countries (53 per cent to China) ${ }^{39}$ China also dominates the local-government officials training programme: in 1996, 14 of 50 officials from 10 countries; in 1997, 21 of 67 officials from 11 countries and in 1999, 37 of 80 trainees from 17 countries. ${ }^{40}$ Many personnel training programmes are funded via SHA's LAT mechanism and form part of the ODA training programmes funded from the national budget via JICA and directly from the MOFA.

China has strongest representation in the SNGs' self-funded cooperation programmes to support development in their overseas counterparts. A 2001 JBIC survey of all Japanese prefectures identified 19 that were using their own resources for development projects in developing countries including Nepal, Indonesia, Thailand, Ghana and Brazil. Seventeen prefectures had one or multiple 
projects in China, concerning health, environment, agriculture, revitalization of local economies, tourism, or 'one village, one product' movements. ${ }^{41}$ Many of these cooperation programmes can be regarded as enjo, involving one-way flow of technology and other assistance from Japan. Yet other self-funded programmes by SNGs involve cooperation for explicitly mutual benefit, such as learning by a range of local actors on both sides. This is in response to a new concern to secure public approval from local constituents for the SNGs' considerable expenditure on these cooperation programmes outside rather than within their localities. These expenditures are, after all, from the public purse and could be spent where local constituents see more visible benefits.

The cooperation programmes by Niigata City and Niigata Prefecture in China offer useful examples. With its finances shrinking due to Japan's severe economic recession, Niigata Prefecture explicitly supports projects that enable SNG prefectural administrators to explain clearly to local citizens why the SNG is spending their taxes to benefit people abroad and not on directly improving citizens' livelihoods in Niigata at a time of greater financial stringency for many Japanese. The focus of some international cooperation projects is shifting from purely assistance (unilateral benefits for the recipient) to cooperation (mutual benefits for donor and recipient) and partnership (e.g. with JICA). In collaboration with the government of Heilongjiang Province, Niigata Prefecture has begun to impose specific considerations on projects funded from either from the national budget or from the prefecture's own budget. These projects must now (1) have the approval of local citizens; (2) be mutually beneficial; (3) generate new value; (4) be in the field of social development; and (5) involve local citizens and groups as participants.

Two salient examples of these cooperation projects are the Heilongjiang Province and Harbin City Medical Technology Cooperation Project (Kokuryukoshō Harubin-shi iryō gijutsu kyōryoku jigyō) and the Road Paving Technology Cooperation Project for Cold Areas of Heilongjiang Province (Kokuryuko-shō kanreichi dōrō hosō gijutsu kyōryoku jigyō). Both were carried out in 2001-04 under JICA's grassroots technical cooperation projects, with funding from the ODA budget, Niigata Prefecture SNG and Niigata City SNG.

The aim of the Heilongjiang Province and Harbin City Medical Technology Cooperation Project is the two-way passage of medical technology through equal partnership between Niigata Prefecture and Heilongjiang Province via its capital Harbin City. Hospitals in Niigata, which are advanced in Western medicine, provide the Heilongjiang medical centres with the technology to treat malignant blood diseases such as leukaemia. Niigata receives information about new medical technology using traditional Chinese medicine, in which the Chinese side excels. The project therefore has potential to improve medical technology in both Heilongjiang and Niigata - and by extension in China and Japan - thereby improving the welfare of local citizens initially and at a national level in the longer term as the modern and traditional technologies are passed on in their new national settings. ${ }^{42}$

A group from the Niigata Prefectural Cancer Centre visited Heilongjiang Provincial Hospital in October 2001 to conduct studies and academic exchange. 
During the visit, an expert from Niigata gave a lecture on the use of chemotherapy for treating malignant blood diseases, which was well received by the many Chinese who attended. This became an important catalyst for the cooperation to take off. The Niigata Prefectural administration became the coordinator for the project and the cooperation group was reconfigured to include non-government actors in the locality with capacity to contribute effectively: representatives from Niigata Prefecture's major medical institutions such as Niigata Prefectural Cancer Centre, Niigata University Faculty of Medicine and Niigata Citizens' Hospital. The prefectural government applied to the national government, which accepted this proposal as a national ODA project.

The medical benefits of these projects between Niigata Prefecture and Heilongjiang Province are primarily, or at least initially, for Chinese and Japanese citizens. However there are other mutual benefits from international cooperation like this that are not immediately obvious but may reasonably be expected to result from the 'local' cooperation. These benefits include the positive connection and personal linkages fostered between governments at both the local and the national levels. And what may be priceless for both governments is the mutual goodwill among citizens and opportunities for developing other connections that these programmes tend to create. These potential outcomes are further reasons why the central government is interested in involving SNGs in ODA-funded international cooperation.

\section{Russia}

A territorial dispute between Japan and Russia over four islands north of Hokkaido has stopped both sides from signing a peace treaty after the end of the Second World War. The four disputed islands are under the jurisdiction of Sakhalin under the Russian government, which opposes the Japanese government's claim to their sovereignty. Because of this dispute, Japan does not promote economic cooperation with the Russian Federation (Russia), which in some ways serves as an incentive for international cooperation at the SNG level. PostelVinay notes that here 'interlocal diplomacy has been building up at a notably faster pace than state-to-state diplomacy: from 1989, officials of local governments in western Japan were visiting their counterparts several times per year, whereas Mikhail Gorbachev's historic visit to Tokyo - the first by a Soviet head of state to Japan - only took place in April 1991, ${ }^{43}$

Here we see significant diplomatic implications from cooperation at the SNG level because of rupture between the national governments. With Russia, as with China, these programmes are diverse. A distinctive feature is the enormous scale of several of these projects and their explicitly commercial nature, particularly where the SNGs are of Japanese prefectures and Russian regions. This feature suggests that SNGs are taking up the lucrative development projects that the national governments or private sector interests would likely take up if the bilateral relationship were fully restored, pointing to how SNGs provide a valuable surrogate role for the national government. 
The best known example of Japanese-Russian international cooperation at subnational level is the huge cooperation programme drawn up by the Joint Standing Committee on Economic Cooperation between Hokkaido Prefecture and the Russian Federation Far East Region, involving a number of large, integrated projects. Another is the 'Cooperation to Develop the Sakhalin Continental Shelf Oil and Natural Gas Project', which includes training business managers, providing transport for access, joint development of forestry, fisheries, natural resource industries and economic information systems. The programme comprises projects across far-eastern Russia, including 23 in Siberia, 22 in Khabarovsk and 25 in Sakhalin. Hokkaido Prefecture has also created the 'Plan to Promote Economic Exchange between Hokkaido and Sakhalin' and is promoting cooperation in economics, transport, marine and forestry. ${ }^{44}$ Akaha notes the willingness of the prefecture and provinces to cooperate 'despite the bleak prospects for a breakthrough' in the territorial dispute between Japan and Russia. $^{45}$ The interests of local actors in economic and commercial benefits dominate the cooperation agenda, rather than the national diplomatic-political concerns that restrain Tokyo and Moscow. Postel-Vinay has observed that the strong role played by SNGs is especially significant since here grassroots diplomatic relations help to compensate for very weak bilateral relations. The national governments see the disputed territories as an insurmountable obstacle, whereas the SNGs recognize their central governments' intransigence as compulsion to overcome the obstacles and work to promote their local cooperation. ${ }^{46}$

Niigata Prefecture, like Hokkaido, is close to Russia's far-east coast. Niigata drew up cooperation project plans with the Russian coastal areas and with the Khabarovsk region in 1993 and with Irkutsk in 1994. This prefecture has for years engaged in joint research into marine processing technology and exchanges of public servants. ${ }^{47}$ Niigata is also playing a key role in developing port facilities in the coastal region of the RFE. Hook speaks of this cooperation by Niigata as " "Official Development Assistance" in all but name'. ${ }^{48}$ Toyama Prefecture entered into an official friendship tie with the Primorsky region in Russia in 1992 and has since been expanding into economic, environmental conservation, cultural and other cooperation projects such as holding 'Seminars to Support the Transition to a Market Economy'. The aim here is to prepare northern Russian regions for future economic ties with Toyama Prefecture.

At a municipal level, the Mayor of Niigata served as secretary in the 1970 establishment of the Japan-Soviet Coastal Mayors' Association. The Association (now the Japan-Russia Coastal Mayors' Association) has a membership of 26 Japanese cities and 18 Russian cities. The Association was formed to expand goodwill and economic cooperation between the cities of the Japan Sea coast and those of the RFE and Siberia. ${ }^{49}$ It has promoted exchange and cooperation between the SNGs on environmental, urban and some commercial issues. Themes of the Association's international conferences have included mutual cooperation in tourism and other economic projects and environmental concerns such as migratory birds.

Akaha and Vassilieva have observed a clear geographic division of labour between Niigata and Hokkaido as the two prefectures most active in developing 
cooperation with the RFE. Whereas Niigata focuses on the continental Far East, Hokkaido focuses on Sakhalin, as evident in their sister-city linkages and the transportation links they have developed. ${ }^{50}$

\section{Republic of Korea}

With its remarkable economic development from the 1970s, the Republic of Korea (South Korea), graduated some years ago from eligibility to receive ODA. There is, however, a strong programme of international cooperation that is not enjo at the SNG level. Some Japanese observers from CLAIR notice as a distinctive feature of cooperation programmes with South Korea, a strong motivation on the South Korean side to develop multilateral cooperation to satisfy shared interests. ${ }^{51}$ The SNGs in South Korea have followed trends set by the Japanese side. For example, the Korean Local Authorities Foundation for International Relations (KLAFIR) was established in 1994, modelled after CLAIR. KLAFIR has an office in Tokyo and liases closely with CLAIR in increasing numbers of joint cooperative projects between SNGs of the two sides. There is also strong institutional framework to support cooperative programmes through bilateral and multilateral memberships that join different types of SNGs (e.g. provinces/ prefectures with cities) and join Japanese and South Korean SNGs with counterparts in the Northeast Asian region.

The Japan-Korea Strait Exchange Association of Governors of Coastal Prefectures, Cities and Provinces is a well-known institutional arrangement for promoting these programmes. It joins the prefectures of Fukuoka, Saga, Nagasaki and Yamaguchi with the South Korean provinces of Chollanam, Kyongsangnam and Cheju and the city of Pusan. Exchange and cooperation programmes are being developed in a variety of sectors including environmental technology, marine science, tourism and other commercial areas of mutual interest. ${ }^{52}$ Exchanges of trainees include the Toyama Prefecture-Kangwon Province 'Cutting Edge Biological Agricultural Chemicals Technology Traineeship' (2002) and the Kitakyushu City-Inchon City 'Small and Medium Enterprise Technical Traineeship' (2002). ${ }^{53}$

Another bilateral institutional arrangement promoting diverse practical exchanges and cooperation in economic, environmental and other fields is the Japan Sea Group Subnational Governments International Exchange and Cooperation Summit, which was established at the initiative of Tottori Prefecture and Kangwon Province. Both of these SNGs are also involved in creating the East Asia Subnational Government Tourism Forum with eight other SNGs that include Jilin Province in China, and counterparts in the RFE, Siberia and Central Mongolia. $^{54}$

\section{Democratic People's Republic of Korea}

The Japanese government and the Democratic People's Republic of Korea (North Korea) do not have formal diplomatic relations. The absence of official diplomatic channels with North Korea adds an imperative to linkages at the SNG level 
and gives them a strong diplomatic edge, in some ways a substitute for national relations. In 1972, Niigata City led the process to establish the Japan Sea Coastal Cities Council for Japan-North Korea Friendship and Trade Promotion (Nitchō Yūkō Bōeki Sokushin Nihon Kai Engan Toshikaigi), a group of 20 port cities on the Japan Sea coast. The Niigata mayor serves as the Secretary General and the Council office is based in Niigata. ${ }^{55}$ North Korea does not have a separate organized presence in relation to this group but works through the Korean Society for Cultural Relations with Foreign Countries (Chōsen Taigai Bunka Renraku Kyōkai $).{ }^{56}$ The Council has held General Meetings annually with the aim of developing goodwill, trade promotion and information exchange. It has provided a vital venue for communication in the absence of official diplomatic relations. Nevertheless, suspension of the meeting in recent years highlights how the SNGs' initiatives are vulnerable to diplomatic developments at the national level. ${ }^{57}$

Sakaiminato City, which is a member of this Council, has the only formal sister-city relationship with a North Korean counterpart, Wonsan City. Sakaiminato City has developed soft cooperation through citizen-to-citizen exchanges and cultural events such as the trilateral Children's Pictures of Fish Joint Art Exhibition, held in conjunction with Sakaiminato's Chinese sister-city, Hunchun. It is also promoting harder-edged economic cooperation in marine products such as the first imports of Matsuba crabs to Japan. In 2002, Sakaiminato received the Order of Goodwill Second Class Award (Shinzen Kunshō Dainiky u) from the North Korean government as an official gesture of appreciation for the city's efforts. Tottori Prefecture, where Sakaiminato is located, is also increasing its efforts towards formal cooperation with Hamgyongbuk Province and Rason city through a multilateral forum. The Prefectural SNG wanted to invite a North Korean representative to the Summit for International Exchange and Cooperation between Regional Governments in the Northeast Asian region. However, participation by North Korea did not eventuate given the concern of many other Japanese members over North Korea's clandestine nuclear programme and abductions of Japanese nationals. Undeterred, Tottori Governor Katayama frankly claimed that even without normalizing governmentto-government relations at the national level, exchange and cooperation between local governments should be promoted. ${ }^{58}$

\section{Northeast Asian multilateralism}

Before leaving this discussion of instructive examples, let us turn finally to a multilateral institutional arrangement with a membership of 39 SNGs from Japan, China, Mongolia, South Korea, North Korea and Russia. This is the Association of Northeast Asia Regional Governments (NEAR), which originated from several informal conferences held between 1993 and 1996. ${ }^{59}$ The Association aims to promote exchange and cooperation between the member countries in Northeast Asia and mechanisms were set in place to encourage and sustain SNG cooperation programmes. ${ }^{60}$ The Association has held a biennial conference since its launch in 1996, and at the conference in Khabarovsk in September 2002, a 
Charter of NEAR was approved to provide the Association with a firmer institutional basis to strengthen cooperation. ${ }^{61}$ Cooperative projects undertaken by this multilateral sub-regional grouping involve information exchange, joint research and education, the environment and sustainable development and challenges facing small and medium-sized enterprises. ${ }^{62}$

\section{Formalizing SNG involvement in international cooperation through ODA policy}

For approximately a decade, Japan was the world's largest foreign-aid donor. ${ }^{63}$ The central government administered the ODA programme, including economic cooperation, through a highly centralized system relying heavily on its agencies and quasi-government bodies. ${ }^{64}$ Yet, as we have seen in this chapter, during the 1990s an evolutionary change took place in Japan's international cooperation at both national and subnational levels. The central government needed to address external concerns about its aid philosophy and internal criticisms about inefficient practice, especially while fiscal problems forced leaner budgets. At a time when national-government policy-makers recognized the need to involve other domestic actors as partners in aid delivery, SNGs were developing a keener interest in becoming involved in these programmes.

Incorporating SNGs into the national ODA process therefore dovetailed SNGs' pressure from below for a greater role in international cooperation, with the national government's pragmatic response from above to streamlining ODA policy. Both levels of government have interests in developing partnerships for delivering ODA through international-cooperation programmes. The central government still largely funds and seeks to direct aid programmes, but the SNGs are gaining ever more capacity to shape the course of these policies and programmes as they pursue the interests of their locality and their own more influential international role. Many have expertise, experience and local connections within and outside Japan and recognize that they can now flex a collective SNG muscle to influence the ODA programme.

\section{Developments in ODA policy}

Changes in ODA policy through the 1990s reflect the results of this pull from below and push from above, creating an environment increasingly conducive to the SNGs' involvement in delivery of ODA as international cooperation. More SNGs than ever before now seek a greater role in the nation's ODA projects through international cooperation. The nature of ODA programmes has also shifted from mainly a heavy emphasis on large-scale traditional infrastructure projects such as dams, power and transportation facilities, to provision of social infrastructure such as poverty-reduction programmes, human security, human-resource development and environmental improvement. These are precisely the areas where SNGs are well placed to contribute with expertise and experience. 
Policy statements and reports through the 1990s, gave the official nod to SNG involvement in ODA delivery as part of the new pluralization of this policy. The 1992 ODA Charter and the 1994 ODA White Paper noted the valuable role of SNGs in ODA delivery alongside government and non-government bodies. Yet, since the Foreign Ministry sees that the SNGs are, as the Japanese term sets out literally 'local authorities' and not part of 'government', the Ministry casts their status in aid administration as that of private bodies and treats them as 'non-government'. It also articulates that their role in the ODA programme is ancillary. The Ministry sees SNGs as bodies helping to implement (ninaite) ODA programmes, but not as principal actors (shutai). ${ }^{65}$ Statements from the Cabinet Office (formerly the Economic Planning Agency) Committee on Economic Cooperation Policy, Towards Sustainable Economic Cooperation in 1997 and Towards Further Reforms of Economic Cooperation in 1998, recommended greater involvement for SNGs. ${ }^{66}$ The Final Report of the MOFA Council on ODA Reforms for the twenty-first century, released in January 1998, is largely consistent with the Cabinet Office reports, proposing 'contracting out' international cooperation where the central government allocates responsibility for certain aspects of this work. SNGs are thus one of various types of contractors in delivering Japan's ODA. A Cabinet resolution accepted the policy on ODA that incorporated these reports, and subsequent trends in ODA delivery reveal this policy is now in practice.

\section{SNG partnerships with organizations involved in international cooperation}

\section{Japan International Cooperation Agency}

JICA is one of the principal government agencies for managing and delivering the technical cooperation or 'soft component' of Japanese ODA. In 1999, JICA established a Domestic Projects Department to help strengthen the involvement of SNGs and non-government actors through the 'contracting out' method. ${ }^{67}$ Particular types of international-cooperation projects have been targeted for collaboration with SNGs, including those noted earlier where the SNGs have particular capacity: environmental protection, medical care, agriculture, disaster management and training of education and administrative personnel.

JICA surveys conducted through its regional offices across Japan identify SNGs' strengths and where they have a 'competitive edge' to run programmes for trainees from developing countries. ${ }^{68}$ For example, the JICA office in Sapporo in association with the Hokkaido International Center produced a comprehensive report based on their surveys of localities in Hokkaido to identify which SNGs' expertise could be used for programmes described as 'capacity-building' in developing countries. ${ }^{69} \mathrm{JICA}$ has been increasingly willing to involve SNGs, with many of its training programmes and projects for small-scale development partnerships responding to local proposals. 
As discussed in Chapter 2, in October 2003, JICA was given a new status as an 'independent administrative institution' (dokuritsu gyōsei hōjin). Its new structure and new leadership for the first time by a non-Foreign Ministry bureaucrat are likely to give JICA more flexibility and willingness to work with a range of actors including SNGs. The focus of JICA projects has been broadened to include conflict prevention and peace building through development assistance and postconflict reconstruction to provide infrastructure, governance, economic recovery and support for the socially vulnerable and those disabled by conflict. ${ }^{70}$ Many of these are areas where the SNGs have shown great interest and capacity in their international cooperation programmes. Assistance is offered not just to SNGs overseas; Japanese SNGs have also carried out aid programmes at the national level in recipient countries. JICA programmes under way in 2004 with support from SNGs include mother-and-child health projects between Saitama Prefecture and Indonesia and Chiba Prefecture and Mongolia, primary health-care projects between Kochi Prefecture and China, and projects to prepare school textbooks between Hyogo, Oita and Hiroshima prefectures and Ghana. ${ }^{71}$

\section{Japan Bank for International Cooperation}

Where JICA is responsible for the technical training provided through 'soft ODA', JBIC is responsible for yen loans, the 'harder' side of ODA. JBIC too has shown considerable interest in involving SNGs in its cooperation programmes and since 2001 has conducted survey research to inform its plans for collaboration. ${ }^{72}$ JBIC loans are for constructing infrastructure in recipient countries. Proper management of facilities after construction requires administrative skills and procedures for which SNGs are well equipped to provide training. SNGs are providing valuable support under the 'contracting out' system by encouraging businesses in their localities to bid for projects funded by JBIC yen loans in their overseas partner localities. Under the new JBIC-SNG partnership framework, Kitakyushu is providing technical assistance to Chongqing (China) and Surabaya (Indonesia) for waste management and is examining ways to pass on know-how and technology to these countries. ${ }^{73}$ Similarly Gifu Prefecture is passing on local knowledge for economic revitalization through 'drive-ins to promote local products' (michi no eki-chiiki tokusanbutsu o hanbai suru doraibuin) with loans through JBIC. ${ }^{74}$ Because of its expertise, Nara Prefecture is involved in a JBIC 'road stations' project at Buddhist sites in the Indian state of Uttar Pradesh, and Akita Prefecture has been engaged to set up road stations in China's Gansu Province with which it has a sister relationship. ${ }^{75}$

\section{National-subnational interface}

The SNGs' increasing involvement in international-aid delivery is not unique to Japan. International organizations and national governments of most developed nations now draw on the capacity of SNGs to assist in international-cooperation programmes. This proceeds from an understanding that balanced development at 
the local level is crucial for successful aid programmes and the SNGs have the expertise, personnel and experience to make major contributions to projects for effective development of local-level communities.

Japan's national government therefore has strong reasons for expanding the role of the SNGs in international-cooperation programmes. First, SNGs have considerable capacity to contribute to effective implementation of these programmes. This has particular significance at a time of budget cutbacks and criticisms about inefficiency. Second, the SNGs have relevant expertise and are well placed to help with coordinating these programmes and mobilizing support from a range of actors on the ground including local NGOs, businesses, educational institutions and individuals. Third, SNGs are generally willing - or eager to take on these roles when the central government has allocated the necessary funds and central government bodies are generally willing to have the valuable contribution that SNGs can make towards collaborative international cooperation. Here the national and subnational levels share interest in SNGs' international activity. Fourth, after several decades of collaboration with counterparts abroad, Japanese SNGs are now well connected internationally and domestically in SNG networks, which can also enhance their capacity to contribute to internationalcooperation programmes with developing countries. Nevertheless, although the SNGs have certainly assumed a greater international role through involvement in ODA as cooperation, the national government and particularly the Foreign Ministry maintains the final and overall responsibility.

\section{Challenges for SNGs in international cooperation}

Even while SNGs' involvement in international cooperation is further institutionalized within the framework of central-government policy, there is greater space for them to initiate and administer their own policies - for some, to specialize or even lead in an area of cooperation - in response to changes in policy environments inside and outside Japan. Hyogo Prefecture, for example, is keen to become a leading SNG in Human Security. ${ }^{76}$ Cultural, economic and political challenges continue to confront SNGs as they extend their involvement in international cooperation. Here we take up two that are particularly consequential: the place of SNGs within the central government's move to expand and coordinate contributions, and the public accountability required of SNGs when using public funds for this endeavour.

\section{Coordination and expansion of community contributions to international cooperation}

Policy statements from both levels of government underscore calls particularly for two new approaches to international cooperation. One is to extend participation in these programmes right across local communities. The other is to better coordinate actors and their actions by coordinating programmes not just within the administrative domains of SNGs but nationwide. Both approaches require 
a clearer division of labour and responsibility among those who are immediately involved in policy coordination. They give SNGs a considerably more important role in coordination and initiation of programmes, while still under the national government's direction and control.

Recent policy papers propose the 'community-participation model' of international cooperation, ${ }^{77}$ with a clear role for SNGs in both generating and coordinating participation at the local level and in, effectively, popularizing these cooperation programmes inside Japan. The model sets out strategies that some SNGs are already implementing to conduct their new role effectively. One is for SNGs to carry out community-wide public relations to keep citizens informed about the international cooperation projects under way in their local communities, to develop broad-based community understanding, support and public participation. Second, SNGs themselves identify projects that can be delegated to purpose-specific institutions - research bodies, universities, NGOs and business groups - and to members of the public within the locality. Third, SNGs clarify the selection criteria and review methods for projects in line with local conditions. Fourth, SNGs explore new ways to strengthen both compensated and voluntary involvement of a broad array of participants in cooperation projects. ${ }^{78}$ Better coordination by SNGs requires local assemblies to hold regular public hearings so that community members have a sense of participation, inclusiveness and ownership. The attempts by Niigata SNG administrators, particularly in programmes with the Chinese SNGs discussed earlier in this chapter, provide a useful example of how some SNGs are responding to the challenge.

\section{Public accountability}

Public accountability has a new urgency in this picture for two primary reasons. First, as noted earlier, poor performance of the national economy has forced continued domestic economic stringency, compelling actors at both levels of government to satisfy public concern that their spending of public funds is well managed and efficacious. Second, public concern must be satisfied in order to achieve the broader community participation in the cooperation programmes that both the government levels now have responsibility for creating. Members of the public who accept altruism may want to see benefit at least to communities in the receiving country; those with concerns closer to home, especially when their own financial times are tough, will want programmes to deliver some benefit to their own community and/or to their nation. With funding set to become a major problem for international cooperation, both levels of government are keen to incorporate financial and other input from a range of non-government bodies and individuals. ${ }^{79}$

SNGs are aware that to increase public accountability for their involvement in international-cooperation projects they need to establish systems to review projects thoroughly and enable free public access to information about the projects. Some SNGs have considered forming public committees that include representatives of local groups and the local community, and have input into SNG policy 
decision-making to reflect public opinion. Here we see the relevance of the 'community participation model' for reforming Japan's international-cooperation programmes and the role of SNGs in establishing new directions. The SNGs are testing the potential fluidity of their position in this environment as they try to best position themselves for strong roles in an international policy area where they now have the proven capacity.

\section{Conclusion}

In this chapter we have explored the emergence of Japan's SNGs in a new policy arena that builds and diversifies international relationships at the local level. The international cooperation that Japanese SNGs initiated in the 1970s for shared problem-solving with international counterparts seeking mutual benefit took a different direction in the 1990s, yielding a more structured and institutionalized role for SNGs in national policy on international cooperation, particularly the ODA, with support from MOHA and other national agencies such as JICA and JBIC. Alongside the cooperative framework for mutual problem solving, in the twenty-first century international cooperation also presents SNGs with a way to help resolve international development problems, through programmes supporting environmental protection, human-resource management, education, agriculture, technology, medicine and maintenance of what can be broadly defined as global public goods. It is the major means by which SNGs make valuable contributions to national foreign policy and forge their identity as capable international actors in their own right. Clearly these developments have implications for the national-subnational relationship and for the conduct of Japan's foreign affairs, even if these are largely unrecognized.

The central government has become ever more reliant on a range of domestic actors that include SNGs for delivering international cooperation effectively and efficiently, as part of its move to improve the national ODA programme. SNGs have capacity and experience of working on the ground at the local level, which the central government does not have. Again we see that SNGs are able to extend their international roles because their work locates them closer to the people than the more removed position of the central government, its agencies and bureaucracies. SNGs are also without much of the diplomatic baggage that constrains central government, a status that has enabled them to undertake some extremely significant programmes in places where the central government is unwilling to operate, such as we have noted between Niigata and a number of SNGs across the Japan Sea, between Hokkaido and the RFE and between Tottori and North Korea. Some SNGs also have an international network of local-level connections that can be essential for initiating and implementing internationalcooperation programmes effectively.

SNGs' involvement in a range of cooperative arrangements with their partners, pursuing mutuality and reciprocity as well as enjo or assistance, has therefore helped to position some SNGs with greater leverage in their relations with the central government. SNG officials know that in this policy area they have what 


\section{International cooperation: a strategic edge}

the central actors need and they can use this to try to gain advantages for their locality. They can work to attract training projects in their locality through JICA and to secure yen-loan projects for local businesses through JBIC by involving in cooperative programmes a range of institutions and people from their locality, to generate some financial benefit and usually substantial mutual goodwill.

The valuable role of Japanese SNGs in international cooperation for the national ODA programme has both symbolic and practical consequences for the conduct of Japan's foreign affairs. It has brought many SNGs more visibly into Japan's official international diplomacy and has helped to legitimize the domestic status of SNGs as international actors. Small SNGs like Yokota and Misumi have come under the national limelight through their international-cooperation programmes in abacus and papermaking. The national government, especially the Foreign Affairs Ministry, has been forced to recognize and incorporate the role of SNGs in this area of foreign policy after years of reluctance to share policy territory with actors outside its own supervisory jurisdiction.

As the role of the SNGs in this area is recognized more widely in the international community, particularly among potential ODA recipients, it is likely that SNGs will also become a more important point of contact for ODA-related projects rather than just the Foreign Ministry. The number of bottom-up ODA projects such as in the Kitakyushu-Dalian example is likely to increase in the future. Thus, unlike the top-down mode of the past, designing and implementing ODA projects will not simply flow from the central government bodies down to SNGs. Already there are signs of an emerging reverse-flow where some projects are generated at the SNG level and worked up to the national level for inclusion in the national ODA programme. The reverse flow of operations here has major implications for national-subnational relations in this field of Japan's foreign affairs, and indeed, perhaps also for the conduct of the national ODA programme.

The early 1990s slogan, 'Kōryū kara kyōryoku e' symbolized a new era for SNGs as international actors. Through international-cooperation programmes, 'kyōryoku' has pulled SNGs well beyond 'soft' cultural-exchange activities into the realm of more substantive and wide-ranging cooperative programmes. These also involve SNGs in the nation's official aid delivery, and in 'local ODA', with diplomatic and strategic implications. This interfacing between the levels of government has come over time, and with little fanfare for SNGs. But it is a highly significant step in the evolutionary change under way in the management of Japan's international relations overall, not simply in international cooperation. It is also highly significant in expanding the capacity and the international role of Japanese SNGs, since it has helped them to become instrumental as well as symbolic players in one of Japan's most significant foreign-policy domains. 


\section{Economic diplomacy}

Trade and commerce are the international activities that many Japanese SNGs facilitate most vigorously, both independently of central authorities and in conjunction with them. These are economic activities generally without major diplomatic or strategic consequences for national policy, which de-sensitizes and legitimizes this type of international involvement by SNGs in the eyes of the national government. Indeed, national-government actors share an interest in SNGs pursuing economic ventures abroad since these ventures provide opportunities for local and regional economic benefit that all levels of government are keen to develop. In a climate where globalization of capital and markets has forced the market imperative into most layers of government, many SNGs see that they have little choice. Here is an opportunity for SNGs to address their need to create vibrant local/regional economies while the central government has limited resources and cannot micro-manage local economies.

Here we explore Japanese SNGs as international economic actors in their own right, operating independently or in conjunction with actors from the central government and the corporate sector. We begin with examining why SNGs have taken on this role, recognizing developments that have induced less restrictive economic regimes inside and outside Japan and have oriented SNGs to pursue overseas economic opportunities in this freer market environment to maximize the interests of their locality. Case studies of individual SNGs and of geographic regions comprising groups of SNGs illustrate distinctive international economic strategies, both independently of the national government and in cooperation with it. Our focus is mainly on SNGs on the periphery of national economic growth that even now are less developed than the prosperous economic centres around the Tokyo-Nagoya-Osaka Pacific belt on the archipelago's main island.

These case studies illustrate the use of bilateral and multilateral arrangements that, where the SNGs see the need, may bypass the central government. Bilateral arrangements are naturally diverse given the diversity of the SNGs, their locations and conditions. Hokkaido's focus on the RFE is driven by considerations quite different from those of Okinawa seeking economic opportunities through the Pacific. Multilaterally, some SNGs form regional groupings to collectively pursue their shared interests that are specific to regional needs, such as those of the SNGs around the Sea of Japan. 


\section{Economic diplomacy}

SNGs pursue various types of strategies to create conditions for more extensive international economic engagements, through high-level trade missions, overseas offices to develop and maintain economic connections, incentives for foreign corporations to establish business in their locality and exploring possibilities for economic links through official sister or partner agreements. The national government's moves to deregulate the national economy help to lubricate the international economic path for some SNGs, as does the work of the quasigovernment body JETRO which has this mandate for the nation. In particular, we turn to JETRO's recently developed 'Local-to-Local Initiative' programme that supports SNGs and regional businesses in developing economic opportunities with international partners to secure local economic advantage.

Overall, the interests of SNGs pursuing local economic objectives abroad are usually in alignment with the interests of the national government pursuing national economic strength. However, some of the case studies reveal resistance by central government actors where they perceive that SNG economic relationships with partners in certain overseas destinations have the potential to harm the national interest strategically, or intrude on what national bureaucrats perceive to be their exclusive ministerial turf. Here the national-level actors try to bring SNGs in line with national goals and objectives, but where the SNGs' independent policy orientations have conflicted with national policy directions, the SNGs have determinedly pursued their local agendas to satisfy local economic interests.

\section{SNGs as economic actors}

The economic condition of their locality is a crucial matter to SNGs in Japan. As SNGs elsewhere, Japanese SNGs seek to maximize their financial capacity to run their administration effectively and to sustain a strong economic base that provides economic growth, employment and prosperity for the well-being of residents. These imperatives motivate SNGs to encourage profit-maximizing commercial activities to prosper in their area, even while the SNGs are not themselves commercial organizations driven by the profit motive. To this end SNGs now take up economic strategies that facilitate trade, investment and other commercial activities. This move has new life - and a much broader, more competitive reach into international markets - in response to the recession slowing Japan's national economy and the opportunities and pressures opened up by the end of the Cold War and the globalization of markets and capital. Global competition has 'hollowed out' many Japanese industries, which has eaten into SNGs' local tax bases and created unemployment, while the national government has passed on further administrative responsibilities to SNGs without parallel funding for this work.

Yet we must bear in mind here what each chapter of this book reminds us: from post-war, the centralized nature of Japan's unitary political system has continued to limit the freedom of SNGs to take independent action. It long compelled the SNGs to act largely as subservient units following directives from the national government to serve what the central leadership in Tokyo determined 
as national interests. The SNGs were financially largely beholden to the central government while it remained the major source of their annual budgets from the public purse and regulator of their capacity to generate their own income through local taxes and other local sources. Until approximately the late 1980 s, only a few SNGs acted stridently to pursue their own economic interests domestically or through international markets.

SNGs have therefore long been competitors for their share of the national economic pie that the centre is responsible for handing out. This 'national economic pie' comprises not just budgetary allocations from the national public purse but also the policies that endow a locality with opportunities to build economic benefit. From post-war, SNGs across Japan have competed vigorously to attract economic infrastructure and industries to their locality and draw the necessary support from the national government through subsidies and policy decisions that favour their localities.

Over time, other factors have fed into this competition among SNGs and among the regions where they are located. One factor is preferential treatment by the central government; some regions have thrived economically whereas others have achieved comparatively much slower economic growth. Historical, political, geographic and other considerations have worked in conjunction with SNGs' capacity to compete for the national economic pie, producing regionally uneven economic development across Japan. This has served to intensify inter-regional competition: Kanto (Tokyo-centred) versus Kansai (Osaka-centred); the Pacific growth corridor (Tokyo, Nagoya and Osaka) versus the Japan Sea side (including Kyushu, Niigata, Hokkaido); mainland Japan (principally Honshu) versus 'outlying' areas (including Hokkaido in the north and Okinawa in the south); and metropolitan/ urban versus rural/semi-rural areas.

Yabuno depicts the influence of central policy on regional development in the 'umbrella' and 'rocket' models, which explain the difference in regional experience. In the umbrella model, economic development through Tokyo has a positive impact on some, generally nearby regional economies, pulling them into economic strength of central prosperity under the umbrella. The rocket model accounts for a very different experience of regional development where central prosperity enables Tokyo to rocket ahead without flow-on to regional centres, leaving these regions behind to 'eat the dust' of the progress experienced in Tokyo. ${ }^{1}$ This was evident when, despite various programmes through the 1960s to the 1980s purportedly to decentralize economic well-being, the centralization of government functions drove many private enterprises to abandon headquarters in Osaka, Nagoya or Sapporo and move to the capital region, creating 'the Tokyo phenomenon'.2

The unequal distribution of wealth that the rocket model highlights is important to the present discussion. Unequal distribution of wealth became the cause of deep tensions between the have-most SNGs and the have-less SNGs, and ultimately has influenced how and where the SNGs in both camps have pursued economic opportunity outside Japan as actors in their own right. Some SNGs, especially in peripheral areas, began to actively challenge the 'over concentration' of economic strength in Tokyo and demanded allocation of more resources for 


\section{Economic diplomacy}

their areas. ${ }^{3}$ Hokkaido in the far north and Okinawa in the far south are within this economic periphery; distinctive historical, political and geo-strategic circumstances have served to hold these islands outside the main orbit of the nation's Tokyo-centric post-war economic growth. Yet, the most glaring economic disparity is between the economically prosperous Pacific side of Japan and the areas surrounding the Sea of Japan, pejoratively labelled ura Nihon (hidden or backdoor Japan) that by comparison are relatively undeveloped. Under Cold War conditions, national post-war policies favouring trade outward across the Pacific brought great opportunity and prosperity to the major centres on the Pacific side, while on the side of the Sea of Japan, the closest trade partners were the then economically poor and diplomatically disfavoured China, Russia and the Koreas.

However, post-Cold War conditions have dramatically shifted the strategic, political and economic ground on which SNGs act, within and increasingly outside Japan. Domestic circumstances have pushed SNGs beyond their dependence on the national government for financial support and policy directions. Pressures have come from multiple sources including the domestic consequences of globalization with demands for deregulation and liberalization and the 'post-bubble' national recession that has left localities in economic difficulties and prompted the central government to reduce its subsidies, leaving SNGs financially strapped. As Hook observed, 'No longer able to rely upon the national government to revitalize the local economy on a long-term basis, prefectural and other subnational political authorities throughout Japan are being forced to develop their own economic strategies. ${ }^{4}$

International circumstances have facilitated moves by SNGs to stimulate local economic growth by pursuing markets overseas, without the firm hand and national policy directives of the central government. Post-Cold War geo-strategic conditions have opened the way for Japanese economic actors to pursue economic engagements in nations that were previously 'off bounds' within the Soviet/ communist blocs or their alliances in Asia and Eastern Europe. International consequences of globalization have forced easier access into overseas markets for all economic actors and opened the field to new types of economic actors that include the SNGs. Another compulsion was virtually 'knocking at the door'. The Chinese economy has continued to boom from the 1990s in particular, presenting what commercial operators including Japanese SNGs recognize as tremendous opportunities for mutual economic gain with their Chinese counterparts. This is particularly so while China's economic takeoff is still in fairly early stages, with potential for Japanese SNGs to cultivate longer-term benefit through helping to shape the markets and other economic architecture that deliver rewards at a later stage of development.

Another part of the international picture is also important. This is the precedents of SNGs in Western nations, especially in Europe and the United States, that showed Japanese SNGs how some of their economically strongest overseas counterparts have successfully taken an international route to building the economic strength of their locality, some since the 1970s, as noted in Chapter 1. Japanese SNGs could see from these examples how operating directly in international 
markets as economic actors in their own right, with international counterparts or other economic actors as their partners, could serve the economic interests of their localities very well. These actions could also serve the SNGs' own political interests.

The strategy would enable SNGs themselves to maximize opportunities for local economic development in their locality through trade, investment and other commercial arrangements with partners outside Japan, rather than deferring to central government direction. SNGs have better working knowledge of the capacity and needs of their localities and the central government's policy directives are sometimes clearly not in the localities' best interests whether the centre's policies serve 'the nation' at large or indeed at all. The do-it-yourself strategy demonstrated by overseas counterparts would therefore enable Japanese SNGs to develop some financial and policy independence from the central government and their own international connections that could offer the SNGs some useful leverage in their relations with central government actors.

\section{SNGs as international economic actors}

The discussion above reveals why the Japanese SNGs have taken up strategies to revitalize local economies through economic relationships outside Japan. But what do these strategies involve? Cases discussed in this chapter reveal the broad range of approaches, initiatives and institutional arrangements that SNGs use for maximizing the capacity of their international efforts to build the economic strength of their locality. Choices are shaped largely by the abilities and preferences of the people living in that location, who the SNGs represent and work to support, as well as by economic capacities and geo-strategic concerns.

SNGs pursue these opportunities independently or through various types of strategic alliances. They may form formal or informal ties with overseas counterparts through multilateral regional groups, bilateral regional arrangements, sister-city and other linkages. They may also form ties with domestic counterparts through industry-specific or geo-strategically prudent linkages and other arrangements that may or may not be formally institutionalized. To illustrate, I present case studies of a major region (Kansai), a multilateral arrangement, the Japan Sea Economic Group (JSEG), a bilateral arrangement (Hokkaido and the Soviet Far East) and an individual prefecture (Okinawa).

\section{Kansai: a region in search of its past glory}

Most regions outside Tokyo deeply resent uneven economic development across the Japanese archipelago and Tokyo's stronghold on the nation's high-profile facilities. ${ }^{5}$ Since post-war, the strongest regional rivalry has concentrated in the Kansai region. Kansai was at the centre of Japan's commercial activities through much of the Edo period (1600-1868) and in the early twentieth century. Although post-war it became one of the main beneficiaries of the umbrella model of economic growth on the Pacific belt of Japan, Kansai never recovered its prime commercial status. 


\section{Economic diplomacy}

One major strategy explicitly to restore the region's lost commercial glory as the national centre of international trade was to push mega public-works projects. These were intended to make the region more commercially attractive to national and international firms than the Tokyo metropolitan area. ${ }^{6}$ Projects included the Kansai Science City and Osaka Bay Area Development Programmes and the Kansai International Airport (opened in 1994 as Japan's first round-the-clock airport) in a package of 882 projects under way in the early 1990s with a budget of more than 42 trillion yen (US $\$ 400$ billion). ${ }^{7}$ The region's primary goal was to restore Kansai as Japan's main gate to global economic and commercial activities. Kansai's global approach contrasts with the regional strategies of the SNGs left behind under the rocket model, such as those along the Japan Sea Rim that have focused their economic attention on nearest neighbours like China and Korea.

Within Kansai, Osaka Prefecture and Osaka City have been at the forefront of economic and commercial activities. ${ }^{8}$ Economically huge with a GDP of US $\$ 355.8$ million in 1999, the size of Osaka's economy ranked parallel with the thirteenth among the countries in the Organization for Economic Cooperation and Development (OECD). Once Japan acquired the world's largest trade surplus and the national trade-policy emphasis was shifted from exports to imports, here too, Osaka City took the lead. Osaka City in association with locally raised capital built Japan's World Trade Centre (WTC), the Osaka Building and the Asia Pacific Trade Centre in the Osaka Bay area in the 1990s. In the recessed national economy of the 1990s and beyond, when domestic capital was drying up, Osaka attracted foreign investment by large foreign-affiliated companies like Bayer AG, Universal Studios Japan and Carrefour that now operate in Osaka. The Osaka Business and Investment Centre (O-BIC) established in 2001 by Osaka Prefecture, Osaka City and the Osaka Chamber of Commerce and Industry, is the main organization promoting Osaka worldwide. Those in Osaka promote the region as an alternative to Tokyo with comparative advantages in office rental and other corporate expenses, tax cuts offered by the prefectural government (business tax reduction for up to five years) subsidies offered by the Osaka municipal government for market research, feasibility studies and so forth. ${ }^{9}$

Kobe City in Hyogo Prefecture, which is also in Kansai, has been another major player in the region's economic revitalization. Famous for its entrepreneurial initiatives that earned the city its sobriquet 'Kobe Inc.' (Kōbe kabushiki kaisha), Kobe has been at the forefront of plans to internationalize through international trade and investment and has drawn high-profile international organizations such as the regional offices of the World Health Organization (WHO) and the UN Office for the Coordination of Humanitarian Affairs (OCHA) to locate their offices in Kobe. ${ }^{10}$ Kobe has limited its focus so narrowly that it has competed vigorously not just against Tokyo overconcentration but also against 'Osaka overconcentration' within Kansai. ${ }^{11}$ Kobe's economic self-preoccupation has drawn criticism and the ire of a number of anti-development movements. It amplifies the response of cities that are aggrieved by the national government's centralization of resources and functions in Tokyo. ${ }^{12}$ 
SNGs of large cities such as Osaka and Kobe that are within the geopolitical orbit of Tokyo have been able to secure multi-billion dollar facilities and connect themselves successfully to the global economy by using their political clout, economic wherewithal and ability to mobilize local corporate support. They are also well supported by the national government and fit neatly within the umbrella model of development. However, SNGs of smaller or less powerful administrations, especially small and rural prefectures and those far from Tokyo or beyond the nation's main stage on the Pacific side have been less fortunate, as we see later. They have resented Tokyo's neglect that they see as having produced economic and other disparities. Some powerful national-level politicians helped with additional subsidies to some of the neglected localities, such as then Prime Minister Tanaka Kakuei's political pork to his native prefecture of Niigata in the early $1970 \mathrm{~s},{ }^{13}$ but overall these SNGs remain relatively disadvantaged economically. New domestic and international conditions under the post-Cold War regional order, marked by globalization, deregulation and decentralization, have presented opportunities that some SNGs have responded to prudently, to serve explicitly local interests. These SNGs have moved to connect themselves to the global and particularly regional communities to revitalize their economies largely under their own steam, through bilateral and multilateral routes.

\section{Multilateral structures}

One trend is for SNGs in a particular geographical region to work together, across political lines and in conjunction with the private sector, to form a multilateral structure that fosters ties with foreign counterparts to enhance commercial and other economic opportunities. Scalapino calls these natural economic territories (NET). ${ }^{14}$ Here I explore one of the most consequential of these territories: JSEG (kan Nihonkai keizaiken) in which Japanese SNGs have been the key players. Breslin, Hook and others refer to these groupings as micro-regionalism to distinguish groups of subnational actors from the higher level 'regionalism' that comprises national actors across several continents such as APEC and from 'sub-regionalism' comprising neighbouring nations such as the Association of Southeast Asian Nations (ASEAN). ${ }^{15}$ Hook clarifies micro-regionalism as a project 'seeking to build links across national boundaries, but without necessarily involving the total sovereign territory of the states involved' ${ }^{16}$ Micro-regional groupings in Japan are formed through the initiatives of the SNGs, local business and other groups as part of their increasing role in international affairs without necessarily involving national-level actors. Input from central players is minimal and the entire initiative is conducted at the subnational level.

\section{Left behind in the race to economic pre-eminence: ura Nihon}

\section{The Japan Sea Economic Group}

The Sea of Japan area has remained relatively neglected since post-war, even though historically it was a central route for Japan's trade, commerce and rich 
cultural and human flows with mainland Asia. During the Edo period (1600-1868) when Japan's feudal rulers closed the nation to almost all contact with the West, the Sea of Japan coastline was economically vibrant. Yet, during the Cold War, the region's geo-strategic location adjacent to Soviet territory served to truncate most of the region's pre-Cold War contacts across the Japan Sea and thus much of this region's potential for post-war economic growth. The postwar history of the Japan Sea area is marked by struggle at the national level between notions of capitalist democracy and socialist totalitarianism while Japan's strategic and economic orientation was towards its principal ally the United States and other Pacific nations. Tokyo's public works programmes and other pledges to redress the regional imbalance did not significantly improve the local economies of this area. As Arase notes, 'without exception the Japan Sea prefectures have seen their position relative to Tokyo significantly decline in per capita terms in the period $1980-92^{\prime} \cdot{ }^{17}$

Decades before the end of the Cold War, SNGs along the Sea of Japan began to take independent initiatives to link themselves directly with counterparts in the Soviet Far East and Northeast China. With the Cold War ending and under the slogan 'Sea of Japan: Sea of Peace' (Nihonkai o heiwaikai ni), these SNGs stressed multilateral cooperation between regions around the Sea of Japan, initiated by subnational rather than national governments. This was to be primarily for mutual economic development, although educational and other cultural ties developed as well. ${ }^{18}$ Much of SNGs' motivation for promoting their own economic development is their lack of faith in the proposals coming from Tokyo, with its established neglect of ura Nihon and apparent failure to recognize potentially valuable opportunities. Even post-Cold War, Tokyo's role in transborder economic-community building around the Sea of Japan has remained peripheral.

JSEG is a vital part of the Japan Sea revival. This institutional arrangement draws together as a loose regional community with shared interests, the diverse regional and city SNGs along or near its periphery - in Japan, RFE, South Korea and China's northeast region. North Korea and Mongolia are involved marginally via their national governments, as here SNGs have almost no autonomy. The Japanese presence is significant since 16 of the 47 Japanese prefectures are JSEG members.

The idea of JSEG stretches back to the 1960s, but it was not until the mid1980s that prefectures such as Niigata embraced the concept with alacrity and began to promote it widely within Japan and in the region. Soviet President Mikhail Gorbachev's ascendancy and his 1986 speech that introduced a discernible thaw in the Soviet-Japan relationship presented a real chance for progress. ${ }^{19}$ Hook has noted the potential strategic consequences of responses inside Japan, recognizing how the end of the Cold War gave rise to 'a reconceptualization of Japan's spatial location in the region, with the Japan Sea coastal side of the nation now exerting a powerful pull away from the subjective representation of Japan as a "Pacific power" ${ }^{20}$ This reconceptualizing has great strategic significance for Japanese and other nations' SNGs in the Japan Sea area and for their 
respective national governments, since greater cooperation and economic activity has the potential to redirect at least some of Japan's national economic and strategic focus from the Pacific to the Eurasian side of the archipelago.

Various factors underscore the importance and potential of the Japan Sea region. It is the central meeting place for the diverse cultures of Japan, Russia, China, Mongolia and the Korean Peninsula. The land area of subnational regions along the Japan Sea Rim is more than 25 times the land area of Japan and their total population in the late 1990 s was some 290 million or 2.4 times that of Japan. ${ }^{21}$ The combination of Japan's highly developed technology, South Korea's production and manufacturing strengths, China and North Korea's abundance of labour and the unexplored natural resources of the RFE and Mongolia offer this region potential for economic growth, rarely available in micro-regional groupings.

Yet despite this apparent importance, the East Asian national governments have maintained that the payoff is still too small to prompt them to push economic cooperation here. Existing multilateral initiatives at the national level in Northeast Asia may be proving their point; projects such as the Tumen River Area Development Programme (TRADP) have achieved little, despite their high-profile publicity. ${ }^{22}$ The 'high politics' of territorial dispute between Russia and Japan, Japan's intransigence towards North Korea and distrust of Japan by China and both Koreas appear to eclipse the prospects of region-wide reward from a multilateral economic framework in Northeast Asia, which could deliver not only great economic gain but potentially an invaluable flow on of regional inter-dependence and stability. Another contentious issue for all players at the national level concerns the very naming of the Sea. Regional actors outside Japan want the present name changed, recognizing its capacity to imply that Japan owns the Sea.

Here is the space, then, for trade and investment initiatives at the subnational level, producing JSEG through a bottom-up process with minimal top-down guidance. ${ }^{23}$ Indeed, the distinctive feature of this multilateral economic group is that subnational rather than national governments are its driving force. Most of the initiatives have come from SNGs of Japan, China and Russia; Mongolia and North Korea are involved as followers rather than leaders. ${ }^{24}$ SNGs and other local actors proceed from the understanding that promoting economic integration in the region, however small-scale initially, is precisely what can work to develop the region's political stability and economic strength. Here, SNG moves to stimulate regional integration through the micro-regional level have unmistakable implications for the national government and its international affairs. Arase observes of JSEG that even though central government ministries, business groups, international organizations and citizens' groups are involved, 'the subnational authorities are the ones signing the exchange agreements, funding the bulk of activity and building the required physical infrastructure that is the backbone of regional development'. ${ }^{25}$

Governors of all 16 prefectures along the Japan Sea coast have met in multilateral and bilateral forums to endorse the multilateral framework and arrange how to pressure Tokyo for more support to develop their trade potential. Niigata City has been the key player in pushing the JSEG framework and its large-scale projects 


\section{Economic diplomacy}

have enhanced trade and other commercial activities across the Sea. ${ }^{26}$ Niigata has long seen itself as a strategic operator for ura Nihon, especially through shipping with the RFE and trade links with Harbin, a local economic hub in northern China. ${ }^{27}$ Here we see how geographical proximity, historical connections, contemporary ties and future prospects orient SNGs towards a particular area within the JSEG process. Hokkaido, for example, is interested in the RFE, especially Sakhalin. Southern prefectures like Yamaguchi and Fukuoka are keenly involved in promoting mutual economic interests between China and the two Koreas for another multilateral group called the Yellow Sea Economic Zone (kan kōkai keizaiken). ${ }^{28}$

Efforts at grassroots level are lubricating the JSEG process, with new trade routes through sea and air connections. But political and economic factors are also at work to restrain economic developments in the micro-regional sphere. Political factors are not simply between nations but also within them. For Japan, one is the continuous struggle for autonomy between the national and subnational governments. Arase has noted how the national bureaucracies in Tokyo view SNGs' initiatives with some ambivalence, and even though they do not oppose the notion of greater initiative in principle, 'in practice decentralization is resisted because bureaucratic authority in Tokyo opposes any loss of power and status'. ${ }^{29}$

For example, although Japanese subnational officials have sporadically visited RFE and Siberia to negotiate air services and other facilities, the Ministry of Transport objected to negotiations concerning air routes, claiming that the SNGs had wrongly bypassed the central government by entering into direct negotiations. Ötsu's analysis refutes the Ministry's claim, explaining that the Japan Sea SNGs had already divided responsibility (bunkatsu toji) among themselves and were working together to avoid excessive competition for one air route, so demand for flights was not part of this tension. Ötsu also rebuts the Defence Agency's objection that the air routes would interfere with its flight zones. ${ }^{30}$ The unfounded objections of both parties shed light on how the national-government bureaucracies claimed that negotiating air routes is the exclusive prerogative of the Japanese government, not the SNGs and how their opposition was narrowly self-serving rather than to serve the interests of the nation or the locality.

Other problems concern economics as well as politics. Foremost, the different nations and SNG localities in the micro-region are in different stages of economic development. Most Japanese SNGs are frustrated by Russia's regulatory regimes and failure to institutionalize fair trading principles. And even within Japan, there is competition between prefectures to maximize economic opportunities for themselves, even as the Japanese players are trying to work collaboratively for the higher-level success of the JSEG grouping. Nevertheless, progress with JSEG indicates that SNGs in Northeast Asia are committed to their own local and subregional interests and despite national-level resistance are willing to pursue these through a loose but purposeful multilateral structure operating mainly through subnational networks to promote cooperation around the Japan Sea.

Assessments of JSEG by various observers differ widely. Rozman is extremely sceptical on the grounds that far too many challenges face SNGs for them to 
achieve real progress with regionalism. ${ }^{31}$ Arase is more optimistic, recognizing that even though difficulties at the state-to-state level have hindered steady development of the group, SNGs have prepared the ground for rapid progress if national-level problems can be resolved. Arase perceives that the JSEG process may not by itself resolve issues of high politics, 'but it is a tension-reducing, trade-centred strategy of engagement designed and implemented by subnational authorities that builds both habits of cooperation and mutual interests within Northeast Asia'. ${ }^{32}$ Mochizuki is more confident, viewing the various projects under way in this region as a valid sign that JSEG is now moving down the path of development. ${ }^{33}$ The national government is certainly focused on national priorities such that bilateral and regional tensions subvert the steady formation of a Northeast Asian economic grouping at SNG level. Nevertheless, the commitment of SNGs like Niigata, Toyama, Tottori and Hokkaido in particular is building momentum for increasingly closer economic links with counterparts across the Japan Sea, quietly building the networks, interdependence and trust that are essential for a micro-regional institution such as JSEG to operate.

JSEG is typical of several multilateral structures that were established to promote economic cooperation between SNGs internationally but are yet to achieve great success. These arrangements show that SNGs in Northeast Asia recognize that they share economic interests with each other and are willing to at least explore ways of working together to achieve their own local and subregional interests. A flourish of bilateral and submicro-regional activities has been recorded across the Japan Sea under the broad JSEG concept, ${ }^{34}$ as we see below in Hokkaido's effort to pursue its interests in the RFE.

\section{Hokkaido: Japan's northern gateway to the world}

Tension in the relationship between the Russian and Japanese governments has shaped, although not determined, the economic relationships that Hokkaido has developed in Russia, particularly in the resource-rich RFE. Meetings at the national level produced some encouraging signs but have not resolved the dispute between the two national governments over the 'Northern Territories', the four islands between Hokkaido and Sakhalin that Russia has held since the end of the Second World War, over which Japan claims sovereignty. The Japanese government has refused to negotiate any major economic cooperation unless the Russian government signs a peace treaty and returns the islands to Japan. It has also tried to curtail the efforts of both the SNGs and the private sector in fostering commercial links with their Russian counterparts, under a national policy that insists on the inseparability of politics and economics vis-à-vis Russia. The national government has maintained its concern that the activities of these actors could have symbolic and legal implications for the territorial dispute.

Japanese SNGs closer to the RFE do not share this view. Their position gives them a lens that is quite different from the lens on Russia held by national bureaucrats in Tokyo - geographically, strategically and economically. Hokkaido has a distinctive geographic position, closest not just to Russia but also to the disputed territory. 
Hokkaido in particular has tried to pursue economic and other opportunities, even during the Cold War and certainly since its end in the early 1990s. ${ }^{35}$ Hokkaido is the main centre within the JSEG for all matters concerning the RFE.

During the Cold War, the national government's opposition made it very difficult for Hokkaido to have close contact with the resource-rich RFE. Even so, the quiet and persistent efforts of Hokkaido SNGs have prepared the ground for closer cooperation when the political climate is less restrictive. The Northern Regions Centre (Hoppō-ken Sentaa) was opened in 1978 to undertake a range of research projects related to the Soviet Union and to serve as a centre for cultivating contacts and future cooperation with Hokkaido's SNG counterparts in the countries of the northern regions, but mainly the RFE. ${ }^{36}$

Local attitudes in Hokkaido reflect geographical proximity. Surveys have shown that policy-makers and residents attach special importance to the RFE and take pride in their understanding of Russian affairs. Importantly, most see the dispute over the Northern Territories as an obstacle to national-level relations that should not seriously impede contacts at the local and regional levels. ${ }^{37}$

Geographical proximity also produces an economic dynamic of its own and gives companies in some lines of business in Hokkaido an advantage over their counterparts in other parts of Japan. But it is not just geographical proximity that facilitates trade. A similar climate means that some products developed in Hokkaido can be very attractive to people in other countries with severe winters, including Russia. Firms that manufacture furniture and heating systems in Hokkaido have special expertise well suited for living in extremely cold conditions. Housing companies in Hokkaido are well equipped to supply to the housing demand in Sakhalin and opportunities are likely to expand when the Russian economy improves. Agriculture, forestry and fisheries also present economic opportunities to businesses in Hokkaido with local experience, knowledge and capacity. Sakhalin's low self-sufficiency in food and Hokkaido's strong food industry also make them natural partners. ${ }^{38}$ Hokkaido also has a clear interest vested in other projects, especially large-scale energy development that could well serve the prefecture and the Japanese nation. SNGs in Hokkaido are keen to become the major support and logistics base for the Sakhalin oil and gas development projects.

The more positive attitude of the Russian government to both marketization and political decentralization since the break-up of the Soviet Union has also enabled closer relationships to form between the Hokkaido SNGs and their Russian counterparts. Moscow now generally supports Sakhalin's attempts to foster closer economic relations with Hokkaido since these help to integrate Russia economically as well as in other ways with the Asia-Pacific, which is an important objective of the Russian leadership. ${ }^{39}$ These circumstances suggest that conditions are ripe for SNGs in Hokkaido, independent of Tokyo, to push for more extensive economic links with the RFE.

Yet the Japanese government still maintains a restrictive stance, claiming that the actions of Hokkaido and other SNGs have legal and symbolic implications for the territorial dispute. One clear example is Hokkaido's attempt after the Soviet 
break-up to open a trade office in Yuzhno-Sakhalinsk in July 1994 to promote economic relations with the RFE. The Foreign Ministry thwarted the move claiming that establishing the office could be seen as acknowledging Russian control of the disputed territories. Yet Hokkaido persisted and eventually formed an extragovernmental organization - the Hokkaido International Trade and Industry Promotion Association (Hokkaidō Bōeki Bussan Shinkōkai) - with an office in Sakhalin that was a prefectural office in all but name. With diplomatic relations between Tokyo and Moscow improving, the Japanese government established a branch consulate in Yuzhno-Sakhalinsk in 1998 and subsequently upgraded it to a full-fledged consulate in March 2001. This finally paved the way for the Hokkaido prefectural government to upgrade the status of its Trade and Industry Association office in Sakhalin and officially assume full control. ${ }^{40}$ In May 2001, the city of Wakkanai in Hokkaido opened its own representative office in Yuzhno-Sakhalinsk primarily to promote trade and investment ties, the first Japanese municipal government to establish an office in the RFE. ${ }^{41}$

Local political leadership has been essential to improving these economic ties. Hokkaido's Socialist governor Yokomichi Takahiro, elected in April 1983, was a great supporter of forging links with Sakhalin, despite Tokyo's active resistance. His initiatives include a February 1984 agreement facilitating periodic economic exchanges between SNG officials in Hokkaido and five regions in the Soviet Far East, and he was instrumental in establishing the Japan-Soviet Far East-Hokkaido Friendship Exchange Conference held in Khabrovsk in April 1984. In August 1987, the governor led a delegation of Hokkaido officials to Khabarovsk, Nakhodka and Yuzhno-Sakhalinsk to discuss ways to expand barter trade in Japanese agriculture and Soviet marine products. The initiative produced some tangible results particularly in timber processing, hotel and fisheries joint ventures. ${ }^{42}$ In June 1990, the Governor led a local delegation to several places including Moscow, Khabarovsk, Vladivostok and Yuzhno-Sakhalinsk. In Moscow, he signed an agreement with his Russian hosts to develop mutually cooperative relations in wide-ranging areas such as commerce, technology and culture. The agreement was the first of its kind between a Japanese SNG and a Soviet republic.

When Hori Tatsuya replaced Yokomichi as Hokkaido's governor in April 1995, he continued with the policy initiatives of his predecessor, despite his different political allegiance. In September 1997, Governor Hori and his Sakhalin counterpart Igor Farkhutdinov agreed to explore the possibility of joint economic development of the four disputed islands, but the Japanese Foreign Ministry was deeply aggrieved by Hori's action and immediately dispatched an official to Hokkaido to chasten the governor. As Williams observes, 'This particular incident highlighted the problem for both regional governments of balancing the desire for closer economic exchange with the Northern Territories problem, within the restrictive framework of state-level diplomacy. ${ }^{43}$

It appears that both the Hokkaido Prefectural government and its Sakhalin counterpart recognize their mutual economic linkages have potential value far beyond economic benefit: these linkages can help to resolve the bilateral political tensions at the national level. In November 1998, the parties signed an Agreement 
on Friendship and Economic Cooperation (Yūkō keizai kyōryoku ni kansuru teikei), known as the 'mini peace treaty'. This was seen as the most symbolic move so far by the two regional SNGs to promote mutually beneficial economic ties. But both sides also recognized that it would provide a valuable forum for helping to resolve the territorial conflict and could move the parties towards some economic interdependence that can help pull the two nations closer together. Demonstrating skilful diplomatic expertise, the two SNGs held off on a formal agreement until concurring on their respective economic and political roles within their sensitive national contexts. The 1998 agreement for friendship and economic cooperation is qualitatively different from the sister-type agreements that city and municipal governments in Hokkaido have established with Russian counterparts since $1967 .{ }^{44}$

Data on commercial ties between the two regions indicate noticeable progress in trade. In the 1990s, imports from Russia to Hokkaido grew but exports remained rather static. ${ }^{45}$ Japan's share of trade in the RFE is significant at number two after China but Russia is not a major trade partner for Japan and Russia's significance in Hokkaido's trade is in imports rather than in exports. ${ }^{46}$ In 2000 and 2001, Russia was the second largest source of imports for Hokkaido after the United States, accounting for 14.2 and 12.7 per cent respectively. However, Hokkaido's exports to Russia are rather modest, accounting for 2.3 per cent in 2000 and 2.5 per cent in $2001 .{ }^{47}$ Hokkaido's exports to Russia consist of sheet steel, steel tanks, tin cans and fishnets. Only 130 types of items were exported in 1987, but this figure grew to 600 in 1991, with most items exported in small quantities. Hokkaido imports much more from Russia, including timber, crude oil, bituminous coal and marine products (cod, prawns, crab and cod roe). ${ }^{48}$ Hokkaido pursues trade actively in many parts of the world but in 2000, although 47 per cent of Hokkaido firms that were engaged in international trade and investment were operating in East Asia and 22 per cent operated in North America, only 5 per cent operated in Russia. ${ }^{49}$

Comparative data from 1997 to 2001 suggest some strengthening in Hokkaido's economic ties with Russia relative to Hokkaido's other economic partners. Russia entered Hokkaido's table of top ten export destinations to take ninth place in 2000-01 and moved from number three to number two as the source of Hokkaido's imports in the same period..$^{50}$ One area where trade has flourished in recent years is marine products, with greater involvement of joint-venture companies. Sakhalin's increasing emphasis on exporting marine products has drawn it closer to Hokkaido whose consumer market is attracted to these products. ${ }^{51}$ We need to note, however, that much of this trade is not recorded in official statistics since mafia groups on both sides conduct trade illegally. This is recognized as a 'guerilla' economy where an indeterminable number of transactions are not recorded in trade statistics because of this unorthodox business environment. ${ }^{52}$

Complicated regulatory frameworks for foreign investment and taxation, law and order problems and market uncertainties in the RFE inhibit the potential for commercial relations between the two sides and make many Japanese businesses, not just those in Hokkaido, reluctant to invest in the region. ${ }^{53}$ American companies 
accounted for about 98 per cent of Sakhalin's investment inflow in 1999 while Japanese companies accounted for 0.3 per cent. ${ }^{54}$ The state of the bilateral relationship between Tokyo and Moscow is another deterrent to trade and investment from Hokkaido. But even with these hurdles, the Hokkaido prefectural government maintains it is committed to developing economic ties with the RFE, particularly Sakhalin and initiatives between Hokkaido and the RFE continue. ${ }^{55}$

Postel-Vinay offers a positive assessment of how these inter-local relations have intensified despite persisting conflicts at the national level. ${ }^{56}$ Akaha opines similarly that developments through the 1990s indicate the willingness of the two subnational partners to cooperate with each other despite the bleak prospects for a national-level breakthrough. ${ }^{57} \mathrm{He}$ points to productive fishery negotiations, agreements between the Hokkaido government and the Soviet Council of Ministers and initiatives taken by the Hokkaido government in the Sakhalin-1 and Sakhalin-2 oil and gas development projects that have included study groups, lectures, seminars and information-gathering activities. Smaller SNGs in Hokkaido such as Wakkanai, Hakodate and Otaru have also become involved in economic activities, particularly through provision of economic infrastructure. Some projects are providing transportation networks. Regular air services now operate between Chitose in Sapporo and Yuzhno-Sakhalinsk and regular shipping operates between Tomakomai and Nakhodka, between Otaru and Kholmsk and between Wakkanai and Korsakov. ${ }^{58}$ Gradual establishment of the infrastructure needed for more intensive commercial engagement between Hokkaido and its northern neighbour is likely to lubricate further growth of the economic relationship between these subnational actors, even as territorial and other tensions continue to rupture diplomatic relations at the national level and restrain the Japanese government in its own economic engagements with Russia.

\section{Okinawa - an economically neglected outpost}

Like Hokkaido, Okinawa has a distinctive history and is relatively distant from Tokyo. But Okinawa has relatively dire economic circumstances as the least economically developed of Japan's 47 prefectures and with the lowest per capita income, about half that of Tokyo. ${ }^{59}$ Although Okinawa is in the Pacific, from postwar it has remained on the periphery of Japan's economic resurgence. This is largely because Okinawa was under US control from 1945 until 1972 and since then has been retained as a key post for US defence outreach into Asia-Pacific, housing the largest number of US troops stationed in Japan. For Tokyo, Okinawa's worth is in its strategic rather than its economic contribution to the nation and the national government's moves in Okinawa have been at least as much for political compensation to the Okinawan people for housing US bases as for the people's economic well-being. For Okinawa, the national government's disposition is a festering sore. If, for Hokkaido, economics is 'separate' from politics, for Okinawa the two are surely inextricably linked.

Economic geography has Okinawa well placed as a point for commercial contacts between mainland Japan and fast growing economies in the Asia-Pacific 
region. Yet Japan's reach to Asia-Pacific has been from and through the TokyoNagoya-Osaka corridor. The national government has been largely obstructive to the various initiatives that the Okinawa prefectural and city governments have put forward to revitalize the Okinawan economy. ${ }^{60}$ It has provided assistance for transport infrastructure including new docking facilities and improvements in airline services connecting Okinawa with Taiwan, Seoul, Shanghai and Hong Kong. And JETRO has tried to help Okinawa in its attempt to attract foreign and domestic businesses to the prefecture. ${ }^{61}$ But the national government has conceded little in other areas until very recently and only in the face of Okinawa's persistence.

Okinawa has for years sought a special status for the prefecture as a free trade zone in a bid to overcome the prefecture's economic underdevelopment. Yet, the national government has resisted the move claiming its opposition to the creation of 'two systems in one state'. ${ }^{62}$ In 1999, Okinawa's constant pressure on Tokyo resulted in the establishment of a special free trade zone in Nakagusuku on the east coast of the main island. The zone's purpose is to revitalize Okinawa's economy and strengthen its economic self-reliance by attracting investment and promoting trade with mainland Japan and East Asia. ${ }^{63}$

A similar breakthrough came in 2002 with the establishment of a special financial and information technology zone to serve as a tax haven for the banking and IT industries in the rural city of Nago. ${ }^{64}$ Nago Mayor Kishimoto Tateo initiated the proposal after observing how a special financial zoning system offering tax breaks brought businesses and jobs to the Irish capital Dublin, earning it the moniker 'the Celtic Tiger'. ${ }^{65}$ Mayor Kishimoto's hardest task was to persuade national policy-makers, especially Finance Ministry officials, to pass special laws that would create what national officials were resisting as 'two systems in one country'. The battle was won with support from veteran LDP supporter of Okinawa and former Trade Minister Yamanaka Sadanori, who held strong connections with the tax bureau of the Ministry of Finance. ${ }^{66}$ It was recognized widely that the national government agreed to this special tax zone in the Henoko district of Nago City to compensate Okinawa for accepting relocation of the US airbase in Futenma in the face of vitriolic local resistance. ${ }^{67}$ Here the SNGs of Okinawa used their forced acceptance of US bases as a compromise to secure an economic deal from the national government, one that they hope will increase the attractiveness of the local economy to international business and so the financial autonomy of the prefecture's SNGs.

The Nakagusuku and Nago zones have so far produced only limited results. Cheap labour costs in Okinawa had already begun to attract multinational companies to locate their call centers in Okinawa. At the time of the new legislation, Citibank, Nomura Securities and IBM had brought 3800 new jobs to Nago and the special tax incentives are expected to intensify this relocation. ${ }^{68}$ But while some businesses have moved back-office operations to Okinawa to benefit from cost advantages, the prefecture faces tough competition from its Asian neighbours where production costs are much lower than even in Okinawa.

The free trade zone in Nakagusuku New Port industrial complex provides at least one valuable benefit for Okinawa. It enables the lowest manufacturing costs 
in Japan by allowing low-priced parts to be imported duty-free from Asian countries and these manufactures produced relatively cheaply still bear the 'Made in Japan' label which commands a 20-30 per cent higher price in the international market. ${ }^{69}$ But the expected results have been slow to materialize; by 2002, no Taiwanese or other foreign companies had invested in the zone. ${ }^{70}$

Overall, the economy of Okinawa still languishes. The national government has resisted most subnational efforts to open up Okinawa's economic potential which would strengthen the prefecture's position vis-à-vis the national government. Both the national and subnational governments recognize that while the prefecture remains economically weak, Okinawa is more vulnerable to nationalgovernment directives - a reason for the national level to resist Okinawa's independent economic growth via the international market and for the subnational government to solicit this growth actively. The prefecture's economic interests thus conflict with the national government's perception of national strategic interests. Local leaders are willing to forge links overseas for local economic development but the dominance of the national government's position concerning the strategic environment has impeded their independent actions. The strategic context on the one hand limits the prefecture's SNGs in their bids for economic independence but on the other it gives them a small amount of political leverage to achieve small economic gain, as we see explicitly in the example of the Nago tax-haven. Here, we observe an interesting case of SNGs' involvement in international matters with the national government using economic means for political ends and the SNGs using political means for economic ends.

\section{Overseas offices to promote economic opportunities}

Some SNGs in Japan have followed the precedent of many overseas counterparts by establishing offices overseas to promote trade, investment and other commercial activities. Overseas offices facilitate mutual flows of information and personal interaction at the local level, which help SNGs to establish economic links either independently of the national government or in association with organizations such as JETRO. They are venues for promoting their locality overseas to attract investment, tourists and multinational corporations to their areas, for supporting commercial operators from their locality who want to pursue opportunities in the overseas location and for learning about experiences of localities in other countries directly rather than through national organizations. They are very much the signifiers of, and vehicles for, SNG autonomy.

Growth in the number of the SNGs' overseas offices signifies the push by SNGs for independent economic capacity abroad. It also indicates the central government's acceptance of SNGs' greater role in this area. As noted in Chapter 3, the national government and especially the Foreign Ministry earlier disproved of SNGs having independent offices overseas, which forced the major SNGs that wanted to pursue economic opportunities internationally to base operations inside JETRO overseas offices. The national government's recognition that it shares 
a very strong interest in local economic revitalization has seen it move to allow SNGs to open independent offices abroad.

In 2000, Japanese SNGs had a total of 115 offices overseas, in 42 major cities within 21 countries. These offices are for 31 prefectures and 17 cities. All of these numbers are quite small relative to the full extent of Japanese SNGs and when we recognize that some are representative rather than independent offices and some operate within JETRO overseas offices, the scale of this exercise looks even less impressive. ${ }^{71}$ Still, overseas offices are a relatively new strategy for Japanese SNGs and a decade ago there were only a few. Maintaining an overseas office is expensive, with costs of personnel, office rental and other expenses. SNGs therefore choose locations very strategically, where economic opportunities are seen to be strongest. It is therefore not surprising that the focus of the original major destinations in the United States and some other Western countries in the 1980s have shifted to some neighbouring Asian countries, particularly China, Korea and Singapore, from the mid-1990s. In 2000, China topped the list of nations with 36 Japanese SNG offices and the United States came a distant second with 22. More than half of all Japanese prefectures and designated cities have at least one office in China, with Shanghai and Hong Kong being the most popular destinations.

Overseas offices are not necessarily in the SNGs' official partner cities or provinces, since some of these partnerships were formed on the basis of historical ties or for cultural exchange rather than specifically to pursue economic opportunities. Overseas offices are to deal primarily with hard-core economic matters. The goodwill generated through them is an incidental, though still welcome, outcome. ${ }^{72}$ It is difficult to measure the success of these overseas offices, but those that are not successful are closed. ${ }^{73}$

The offices in China, as elsewhere, collect information about local economic conditions, arrange reciprocal visits by local officials, business groups and trade missions, promote investment from their locality, offer advice to business groups from their locality that seek to do business in the Chinese destination and facilitate relocation of Japanese production units. Kanagawa Prefecture's Economic Trade office in Dalian (Liaoning) provides office space at rock-bottom prices to enterprises from the prefecture investing directly in China, with economic information, interpreting, secretarial support, transport and office equipment included. ${ }^{74}$ Miyazaki Prefecture's office in Hong Kong also sells Miyazaki produce and promotes Miyazaki as a tourist destination.

Chiba Prefecture opened an office in Singapore in 1996 to seek investment and tourists from Singapore and learn about Singapore's port and airport management which is highly regarded globally. Chiba was then undertaking a largescale development project in Makuhari that would have to compete with similar large development projects such as Yokohama Minato Mirai, Tokyo Rinkai Fukutoshin and Tokyo Wangan in the Greater Tokyo area, which is in close proximity to Chiba. Chiba administration was convinced that the office spaces and convention facilities available in Makuhari could not be filled by Japanese corporations and turned to prospective parties abroad. In June 1999, Chiba's Governor Numata opened a seminar in Singapore emphasizing the price competitiveness of 
the capital region (including Chiba on its periphery) due to falling real estate and rental prices. ${ }^{75}$ Chiba Prefecture pursues international conferences and promotes Chiba port for business, and here too, Singapore is especially attractive since it serves as the hub of business in Asia. Since many SNGs in Japan have recognized the growing importance of Asia for their current and future economic well-being, it is not surprising that growing numbers of SNGs are opening offices in Asia, especially in China's coastal cities and Hong Kong.

\section{Inward foreign investment - a weak link in SNGs' economic diplomacy}

Japan has been a major investor overseas but has a very poor track record in attracting investment inward. Japan's stock of FDI remains extremely low relative to other economically advanced nations, both in value and as a percentage of nominal GDP. At the end of 2000, Japan's FDI stock was 1.2 per cent of GDP, which compares with the 1999-2000 figures for the United Kingdom at 34.1 per cent, the United States at 30.1 per cent, Canada at 25.3 per cent and France at 16.7 per cent. The ratio is even lower as a percentage of gross domestic capital formation; in 2001, a mere 0.3 per cent compared to the developed-country average of 10.9 per cent and the world average of 11.1 per cent. Japan's ratio of outward to inward FDI stock thus remained very high at 5.5 at the end of 2000, as against 1.9 for the United Kingdom, 0.9 for the United States and 1.1 for Canada in $1999 .^{76}$

Conditions at the national level disinclined SNG leaders from attracting foreign investment to their localities. First, the national government's strict regulatory regime served as an obstructive institutional hurdle. Second, ample domestic capital meant that local leaders had no need to seek investment from abroad in the way local leaders in other countries such as the United States have done for several decades. Instead, Japanese SNGs lobbied the national government for special favours and grants for public-works projects. Third, the national-government policy seeking to bring about 'equality' through tax allocations entrenched a non-competitive philosophy that discouraged SNGs from seeking out economic opportunities themselves to strengthen the economy of their localities. They saw no reason to draw into their locality, from overseas, the vehicles for economic growth such as foreign corporations. Foreign enterprises were limited to large centres such as Tokyo and were very rare in regional areas.

All of these conditions no longer hold. And while SNGs are forced to take more responsibility for the economic well-being of their locality, attracting foreign enterprises to stimulate the economy and create jobs in their locality is an attractive option for increasing numbers of SNGs. A 1999 survey found that 70 per cent of municipal governments were 'highly interested' in drawing foreign capital. In 2001 Negishi noted that 'Touting tax incentives, lower land prices and proximity to factories in related industries, [SNGs] are encouraging foreign firms to ditch Tokyo and set up in other areas.' 77

As governor of Mie Prefecture (1995-2003), Kitagawa Masayasu championed the push for inward FDI. He worked tirelessly in Japanese inward-investment 


\section{Economic diplomacy}

circles, spearheading 'an integrated, industrial cluster-based, delivery-focused approach to FDI promotion' ${ }^{78}$ The US semi-conductor parts maker, Cabot KK was wooed by various Japanese cities and prefectures but settled for Kitakoyama Industrial Estate in Geino in Mie Prefecture because of a 'good deal' offered by the local SNGs and proximity to clients such as Fujitsu, Toshiba and Sharp corporations that have factories in Mie. ${ }^{79}$ Since opening its facilities in 1998, by 2000 , Cabot doubled its production space in Mie, at a time when domestic companies were scaling back their production and workforce.

Recent examples show how this trend is taking off among SNGs across Japan. The German firm Fresenius, the worlds' number one in the field of dialysis, set up in Fukuoka Prefecture in 2000 after Governor Aso Wataru's direct negotiation with the company president. German automotive firm Inergy Automotive Systems set up in Kitakyushu City in Fukuoka Prefecture on the basis of the city SNG's direct lobbying and strengths in advanced engineering, environmental regulations, capable public service and a history of strong local leadership. Sendai City in Miyagi Prefecture in northern Japan has a unique arrangement with Finnish firm FINPRO that deals in services and manufactured equipment for welfare-related businesses. Sendai and Miyagi Prefecture have focused on Japan's elderly population as a niche market and were recommended by the Development Bank of Japan when FINPRO approached looking for the most suitable place for establishing its business in Japan. ${ }^{80}$

Some instances such as Cabot KK locating in Mie, noted earlier, involve foreign corporations that are interested in the presence nearby of other foreign companies. These circumstances have special appeal to some SNGs that are keen to draw bulk investment to their localities. Foreign companies interested in a cluster arrangement create space for collaborative arrangements among SNGs at different levels and foreign corporations, as we see in the collaboration between Hyogo Prefecture, Kobe City and Procter and Gamble. In June 2004, Hyogo Governor Ido Toshizo held a briefing session with the president of Kobe-based Procter and Gamble Far East Inc., as part of their informal partnership to attract businesses to Kobe and other parts of Hyogo. Kobe City SNG promotes its vicinities as 'the Best Portal Zone' for businesses in Japan and offers a website (www.hyogo-kobe.jp) where prospective investors can access wide-ranging information that includes cost/benefit analyses through simulation facilities. ${ }^{81}$

Bringing foreign investment directly into their localities has consequences for SNGs' relationships with the national government. It enables them to improve their own tax base and generate local employment which can enhance their economic and political autonomy from the central government. The view put forward by Fujimoto Kazuhiro, director of Mie Prefecture's Industrial Site Development Division appears to be typical of his SNG cohort, as I learned through my fieldwork in SNG offices in 2002-04. Fujimoto believes SNGs need to secure independent revenue sources to achieve policy independence; for him 'there is no such thing as money from the central government without strings'. He regards local-tax revenue as 'our own money and we can use it to have the most effect in the economy' ${ }^{82}$ Foreign investment directly into localities also gives SNGs direct 
connections with foreign corporations through collaboration, networking and other grassroots personal connections and these can be a valuable resource for SNGs when the national government needs to draw on their international corporate contacts.

But political will is one thing for SNGs, and capacity to fulfil their ambitions is yet another. Many regional centres find it difficult to attract foreign firms since the regions lack the infrastructure to sustain foreign workers, including international schools, hospitals with English or other foreign-language skilled staff and other facilities for expatriates. Osaka, Kobe, Fukuoka and some of Tokyo's neighbouring SNGs in Chiba, Kanagawa and Saitama are best able to compete successfully with Tokyo to attract foreign investment. ${ }^{83}$ For example, Yokohama hosts the German, British, Canadian and US trade centres and six of Kobe's top 11 corporate tax-payers are foreign-owned corporations. Both are port cities with comprehensive programmes to support international investors.

Attracting direct foreign investment is still a relatively new option for SNGs, as a source of independent revenue and of some autonomy from the central government. It seems likely that as momentum grows with a greater flow of inward direct investment to the regions beyond Tokyo, their prospects for attracting foreign corporations will improve. Smaller and non-core SNGs have much to do to vie successfully for foreign investment. They generally lack social infrastructure and are poor at advertising their strengths to potential investors. Most have not equipped their websites with detailed information in English and other foreign languages about their investment environment. ${ }^{84}$ One area for attracting FDI is international tourism in Japan, which appears to have barely registered in the minds of subnational policy-makers. Overall, it appears that there are still various areas that SNGs could develop creatively to generate independent income and jobs through foreign investment, using old and new strategies to pursue opportunities.

\section{Sister-city links as vehicles for economic ties}

As noted in Chapter 3, sister-city ties were initially vehicles to develop cultural and educational links, founded on the notion of building international peace through grassroots mutual understanding in the early post-war period. But in the present period of globalization, these ties reach well beyond the original lofty ideals, as sister and other formalized 'friendship' links sometimes become an important vehicle for SNGs' international commercial activities. Sister agreements provide a catalyst for developing business and other economic networks. Some who are attached to the national level in Japan still regard sister and friendship ties simply as an exercise in cultural activities as noted in Chapter 3. But certainly for some SNGs that do have these links, using the formal sister/friendship tie to foster commercial deals is no longer taboo and is, in fact, a strategically useful approach to achieving mutual economic benefit. It can also be the basis for formalizing economic connections. In 2001, the mayors of Hiroshima and Chongqing signed a memorandum on economic exchange to promote mutually profitable 


\section{Economic diplomacy}

economic activities in the automotive and other industries while maintaining and furthering exchange projects under their existing friendship agreement. ${ }^{85}$

Importantly, as discussed in Chapter 3, SNGs' formal sister/friendship links can be the entree for economic links curtailed bilaterally by tensions at the national level. This was made clear in the case of Hokkaido and Niigata Prefecture establishing economic linkages through their formal friendship ties with counterparts in the RFE even during the Soviet period. We also noted how Tottori Prefecture, especially Sakaiminato City, developed commercial links with North Korea through a formal 'friendship' tie formed with Wonsan City in 1992. In May 2002, the Tottori prefectural government joined Tottori-based companies participating in the international trade fair in Pyongyang and became the first Japanese SNG to participate in a North Korean trade fair. Tottori governor Katayama saw this as a chance to help North Korea take its place in the community of nations, and for Tottori 'to put one foot in the door' and boost the Sakaiminato-Wonsan friendship tie, which is the only one between Japanese and North Korean SNGs. ${ }^{86}$ Tottori has also done solid groundwork towards establishing regular shipping routes with North Korea to enhance trading capacity.

Niigata City has been particularly active in forging economic relations with formal friendship partners across the Japan Sea. Niigata City serves as the major port for trade between Japan and Russia, which was one of the aims of Niigata City forming ties with Khabarovsk city in April 1965. Mayor Watanabe Kōtarō made great efforts to establish the foundations for subnational diplomacy towards Russia in the early 1960s. Extensive negotiations with assistance from the president of a Japanese company specializing in trade with Russia and the invitation of a high-ranking Aeroflot official to Niigata saw the two SNGs agree to establish a new air route between Niigata and Khabarovsk in 1971, which began operating in June $1973 .{ }^{87}$

Niigata was also pursuing low-key exchanges with Vladivostok in the Primorsky Region from the early 1960s, when Vladivostok was a 'closed city' during the Cold War and a formal relationship was impossible. Soon after the Gorbachev initiative in the mid-1980s, Niigata Mayor Wakasugi Motoki attended the Coastal Trade Fair in Vladivostok in 1987 and the first post-war tourist vessel departed from Niigata for Vladivostok in 1989. Missions were exchanged and a sister-city agreement was signed in February 1991, even before Vladivostok was formally opened to the world in January 1992. A principle purpose of the agreement is to establish commercial and other economic links including support for Vladivostok to complete its international airport. After his return from

Vladivostok, the Mayor of Niigata City lobbied business and other groups to invest in the airport project. ${ }^{88}$

\section{Central support and deregulation}

SNGs have moved ahead with their own local economic agendas through strategies designed to avail their localities of opportunities in the international marketplace, now through both inward as well as outward engagement. But even while national 
and subnational interests in the economic outcome of these economic pursuits coincide, national actors do not all share interests solely in these outcomes and the national actors are clearly not monolithic. The reasons are largely conflict between goals of national policies and conflict over bureaucratic turf. National-government dealings with diplomatically sensitive destinations such as Russia and North Korea demonstrate both conflicts. Defence Agency staff have disciplined SNGs in line with national-security policy and the Transport Ministry has resisted SNGs' international transport arrangements that the Ministry believed encroached on its bureaucratic turf. The Foreign Ministry discountenances SNGs on both scores inconsistency with and incursions on foreign policy. Nevertheless, the central government accepts that Japan's economic difficulties cannot be addressed through central initiatives alone; in the interests of the national economy, SNGs must be given some policy autonomy through decentralization and deregulation. One example of deregulation with consequences for SNGs as international economic actors is the central government's move to create special designated zones (tokku), where SNGs can undertake unregulated economic activities.

\section{Special zones}

Tokku (special zones) are a trial scheme for deregulation, put in place in 2002 as part of Prime Minister Koizumi's structural reform initiatives. The scheme aims to encourage SNGs to propose and implement new ideas for operations in specially designated deregulated zones within their localities. Tokku are not required to follow national guidelines and they receive no national government subsidy. They are based on the principle of free-market local economic development, through local initiative carried out by SNGs autonomously. ${ }^{89}$ Schemes under way in 2003 included an industry-revitalization programme in the highly industrial city of Yokkaichi whose economy suffered under regulations introduced in the 1970s, promotion of wine-making in Katsunuma Town in Yamanashi by removing restrictions imposed by the Agricultural Land Law and enabling service providers such as non-profit organizations to provide fee-based transportation services to mobility-impaired individuals in Yamato City in Kanagawa through deregulation of the Road Transportation Law. ${ }^{90}$

Some observers think bureaucratic resistance to tokku is inevitable since deregulation removes some of the power of the national bureaucrats. Nevertheless, the initiative in itself indicates that some elements of the national leadership recognize the importance of deregulation at the local level for enabling the SNGs to play a central role in revitalizing the subnational and the national economies. ${ }^{91}$ The move is relevant to our discussion here since some SNGs seek to revitalize their local economies through international trade and investment links and the tokku zone system will allow SNGs to prepare for and connect more extensively with the international community, with far fewer regulations than in the past. Sendai's international information industrial zone enables SNGs in Sendai to invite foreign participants to local events and obtain visas for these participants on a priority basis. In the international academy of Ota City in Gunma Prefecture, 
foreign instructors teach all subjects in English and hiring teaching staff is the responsibility of the city itself rather than a centrally established process. ${ }^{92}$

\section{JETRO as supporter}

JETRO's actions from the late 1990s also indicate how central agencies are allowing the SNGs more latitude in their international dealings, here at one remove through a quasi-government organization. JETRO serves as an intermediary vehicle to support and coordinate but not control SNG international economic activities. As discussed in Chapter 2, JETRO is a Japanese government-funded body supervised by METI to promote trade, investment and other commercial opportunities worldwide. With national economic difficulties from the early 1990s, JETRO has been keen to establish new programmes directly with SNGs to help stimulate local economies.

In 1996, JETRO launched the 'Local-to-Local' or 'Region-to-Region' programme to encourage and support commercial links between Japanese SNGs and their counterparts abroad through inward and outward foreign investment, trade, technology links and other tie-ups such as among academic and research institutions. By fiscal 1999, this initiative supported some 25 long-term and 71 short-term projects in 37 prefectures and 19 countries, in fields such as information technology, tourism, biotechnology and agriculture. For example, Nagasaki Prefecture and the Nordhein-Westfalen region in Germany facilitated establishment of a joint-venture company producing equipment to care for the environment in Nagasaki and Kumamoto Prefecture worked with Oregon State in the United States to establish a joint-venture software company in Oregon. ${ }^{93}$ However, as in any commercial programme involving a mix of actors from government, the private sector and a quasi-government body, some projects do not deliver the desired outcomes. A case study of attempted links between Ehime Prefecture and Queensland in Australia demonstrates that Japanese SNGs are keen to obtain JETRO funds and develop new international projects through sister ties but that very careful planning is also needed for these projects. ${ }^{94}$

In the early 2000s, the Ehime Prefectural Government received JETRO funding to develop welfare and rehabilitation products and services in Queensland, with which Ehime has a Memorandum for Economic Cooperation. The Queensland government had identified aged-care as an industry with support available for research and development of commercial products. Queensland helped Ehime prepare its application for a 'mini' programme that was later converted to a fullscale programme. The Queensland side participated in Welfare exhibitions in Ehime with the visiting delegation's expenses paid by JETRO and this served as an important vehicle for networking on both sides. Queensland business people have gained some exposure to the workings of the prefectural government and Ehime officials have visited several Queensland facilities. However no direct business has flowed from these meetings. My Queensland informant points to several reasons for the absence of concrete results: this was an Ehime initiative and the Queensland business people were not very interested in developing relationships with Ehime; the Ehime side was happy to leave further development 
to the business community, but the Queensland government was interested in more immediate business outcomes; and Ehime sent different, poorly briefed officials to Queensland for each visit, leaving the task of briefing to the Queensland side. A central reason is that Ehime was interested in hardware that Queensland does not produce and was not really interested in software research and intellectual property that Queensland does produce. Here we have a picture of mismatches, misunderstandings and apparently very poor planning.

This case highlights the need for shared understandings, shared expectations and perhaps most importantly strong knowledge of the other side, its business circumstances and practices. JETRO support cannot facilitate successful projects if this underlay is not mutually in place before the project begins. The EhimeQueensland case is an exception and does not represent the typical JETRO-SNG partnership programmes, but it does illustrate the potential weakness of programmes driven by central agencies such as JETRO that can encourage SNGs to chase central funding without putting sufficient effort into strategic and other considerations. Still, as the examples of Kumamoto and Nagasaki prefectures indicate, the JETRO programmes can work very well for local economic revitalization and strengthening SNGs' international economic role in the process.

\section{Conclusions}

Today, external and internal pressures compel SNGs more than ever to pursue their own economic diplomacy proactively, in a post-Cold War, globalizing environment characterized by less restrictive regimes nationally and internationally. SNGs in Japan, like their counterparts abroad, recognize that they can no longer rely only on central government guidance and budget allocations and the economic flow-on of domestic corporations and local capital for the economic well-being of their location. They have a practical need to link their locality to economic opportunities with international partners, building the economic strength of their localities in partnership with local and sometimes international enterprises. Many of Japan's SNGs now pursue an international economic role not as an optional add-on but as a necessary part of their operations.

The international economic activities of SNGs indicate the broad range of approaches, initiatives and collective as well as independent arrangements that SNGs use to build the economic strength of their locality through international engagements - both inward and outward. Some of the main arrangements examined in this chapter include overseas offices, incentives to draw FDI, sister/ partner relations as vehicles for economic relations, the tokku zones under the national deregulation programme and JETRO's local-to-local/region-to-region programmes. We see in this picture, the political will and creativity of some SNGs to pursue economic opportunities where possible, practicable and most likely to deliver the maximum economic gain for their locality. This is very much in the interests of their locality but it is also much in the interests of the SNGs as they try to increase their financial independence and by extension their policy and practical autonomy from the national government. 
The national government is generally supportive of the SNGs' activities, having acknowledged that Japan's protracted economic problems are partly structural and cannot be addressed through central initiatives alone. The Japanese government is now moving to facilitate international economic ties by giving the SNGs some policy autonomy through decentralization and deregulation. In taking these moves, the central government's motivations are to resuscitate the national economy rather than to politically liberate the SNGs from the centre's still rather firm hand. And even while national and subnational governments share interest in economic gain for locality and nation, tensions arise between the national and subnational levels when the national level sees that the SNGs' international moves may intrude on national interest or on ministries' much coveted ministerial turf. SNGs connecting with Russia and North Korea demonstrate these conflicts well and how SNGs will push ahead determinedly to secure international economic linkages despite national government resistance.

The case studies also demonstrate two important features of relations between national and subnational players on this landscape. First, the nationalgovernment actors do not speak with one united voice since national economic strength, national security and other 'national interests' can sometimes conflict, leaving the responsible ministries in discord rather than in collaboration. Second, while in some ways SNGs are competing against each other for economic opportunities internationally, they are also capable of recognizing their shared interests in regional economic strength and can work as partners in regional groupings to achieve shared interests as well as the economic interests of their locality. It is clear that the potential for alliance and division runs across and between these players and the private sector and quasi-government actors with which they work to achieve local and national economic strength as well as political objectives.

Finally, what does the ascent of SNGs as international economic actors mean for Japan's international relations? I argue that it is something potentially major. Maintaining the national economy is a top government priority, so SNGs' contributions through their roles as international economic actors should give them a more significant place in foreign affairs. Yet this contribution is likely to pass under-acknowledged in Japan's international diplomacy since the SNGs' international economic relations tend to become a 'diplomatic matter' usually only in dealings with diplomatically sensitive partners such as Russia and North Korea. SNGs in Okinawa have used the islands' contributions to national security through hosting US forces as a lever to try to gain local economic benefit and autonomy through international links. Yet, there is something much more important evolving here. It is the way in which the SNGs' international economic relationships can, and are already beginning to, sow the seeds of economic interdependence between countries of Northeast Asia. This type of economic interdependence and its geo-strategic consequences can be extremely significant in time if the economic interdependence becomes not just a fertile underlay, but a compulsion to maintain close bilateral and multilateral relationships among national governments across East and Northeast Asia. 


\section{Hard diplomacy SNGs and national security}

National sovereignty can be a hotly contested site. Usually contestation is between a national government and external parties such as other national governments or international bodies, or between a national government and internal bodies seeking a new state through a separatist movement. In this chapter, we turn to another contested aspect of national sovereignty that receives little attention, where the contest is within the nation, between national and subnational government. Here the national and subnational priorities differ. We see how national-government actions to protect national sovereignty intrude on the well-being of local patches within this sovereign space, forcing some citizens to live with consequences impacting upon their daily lives and so to bear the burden for the rest of the nation.

SNGs represent these aggrieved citizens in the closest, most accessible political capacity and by taking into the national-policy arena their constituents' concerns, SNGs give political life to the tension between national security and the quality of life for a minority of local citizens. Some SNGs have tried to resist the powerful intrusion of national-security policy on life at grassroots level to secure their constituents' well-being. Some express constituents' displeasure with the stance of the national government on peace and war, strategic alliances and nuclear cargo. Although some SNG actions are symbolic with no tangible effect on national-security policy, others force the national government to accommodate local interests within the national-security design.

In the previous three chapters we have considered areas of generally shared interest. Through the 'soft diplomacy' of international exchange and cooperation programmes, and economic ties, SNGs have worked largely in cooperation with, or at least with tacit acceptance of, the national government. The few cases of SNGs' resistance to central government directives, or of central government resistance to SNG actions, were exceptions rather than typical examples. A rather different picture emerges for the few SNGs involved in the 'hard' diplomacy that surrounds national security. Here the national government tries to protect its bureaucratic turf with an iron-fist. This is the primary area of international affairs where the national government wants sole involvement, with the complete exclusion of SNGs. Pluralism and decentralization have little part in this policy. We might expect that the central government's iron-fist would deter SNGs from coming onto its protected diplomatic patch, especially since the highly centralized nature 
of Japan's unitary system of government structurally inhibits SNG involvement in sensitive national-security issues. Yet, some SNGs have brought their interests and their actions to the centre stage of national-security policy, at times with serious ramifications for Japanese international diplomacy.

This is not simply the result of different interests between the subnational and national levels of government. SNGs and their local constituents surely have an interest in the nation's security, just as the national government has an interest in the well-being of citizenry wherever they are located in Japan. Rather than different interests, it is different priorities that motivate the different levels of government - priorities shaped distinctively by the history, geographic location and political leadership of the SNG, as well as the size of the constituent body. ${ }^{1}$

Japanese SNGs have been slower than some of their counterparts in the United States and parts of Europe in challenging their central government on issues of national security and international politics and are still by no means as active as these counterparts in the West. Two factors in particular weaken the SNGs' political will and capacity for international action. First, Japanese SNGs are not legally or constitutionally empowered to challenge national-policy priorities, unlike their counterparts in less centralized systems of government (especially state governments in the United States). Second, the nature of Japan's centralized unitary system of government still firmly limits the autonomy of SNGs under the national government as commander and paymaster. We have seen in each chapter of this book how this structural arrangement has limited the political and administrative capacity of SNGs to act autonomously and has compelled them to find ways to take autonomous action through silences in the constitution and the law that fail to proscribe such action.

The cases examined in this chapter reveal how some SNGs have developed their own legitimate space for action on matters of hard diplomacy. One is through the ambiguity surrounding legal and constitutional interpretation of what the SNGs can and cannot do. The other is through taking efficacious action in their own space where they have regulatory capacity, such as administration of ports (to prohibit docking of US ships with nuclear cargo) and responsibility for streets (to prohibit US tanks from using them). And after two decades of precedents established by SNGs from the archipelago's far north to far south, by the early twentyfirst century more SNGs are confident of their capacity and political responsibility to represent their constituents' local interests against the national-government's security policy and its local consequences. Today, some SNGs openly express opinion that diverges from or even directly criticizes this policy. Some have mounted low-key but disruptive policy challenges that have embarrassed the national government on key national-security concerns such as Japan's nuclear policy and its principal security relationship with the United States.

A few SNGs in some European countries and the United States have acted stridently to support international political movements such as for democracy, human rights and refugees. Japanese SNGs have been unable and disinclined to follow this lead. ${ }^{2}$ Their foremost concerns in this domain have been resistance to national remilitarization and pursuit of international peace, especially through 
nuclear disarmament and opposition to war. Some have taken a leading role in the peace and anti-nuclear movements globally and have formed alliances with likeminded SNGs overseas. National remilitarization, nuclear weapons and international peace are issues literally 'closest to home' for the Japanese people. Their nation has historically recent experience under a military government that took the nation into a disastrous war and was defeated by allied powers in 1945, after the world's first and only cases of nuclear bombing on two Japanese cities that left massive devastation. Today, some Japanese SNGs speak out at domestic and international forums on war, peace, security and other diplomatic issues that fundamentally affect the lives of local residents, to whom SNGs are much closer than the centre and whose interests SNGs strive to protect.

We turn first to early post-war examples where the actions of progressive leaders had some impact on Japanese diplomacy and security. We then consider specific cases where SNGs' protest actions had significant strategic consequences for the central government and reveal much about SNGs' political and administrative capacities on issues that greatly concern SNGs and their constituents at the local level. One is the SNGs' agenda for international peace through the anti-nuclear movement and Mayors for Peace Movement and the other concerns national security and the diplomatic hinge of national-government policy, the US-Japan Security Treaty. We examine how this is a site of continued tensions between the national and subnational levels through three highly contentious issues: nuclearequipped warships, the US-Japan Defence Cooperation Guidelines, and US bases and facilities. In the third section we consider national territory, with the spotlight on Hokkaido's position in Japan's most contentious territorial dispute with the Russian Federation (and the former Soviet Union). Fourth we consider distinctive SNG leaders whose personal style has had profound consequences for some of Japan's most important bilateral relationships.

Whereas some SNGs have vigorously opposed aspects of the national government's security and international-diplomacy agendas, others have been involved constructively in 'peace diplomacy', working independently of the centre and developing political goodwill through international movements. They use a range of strategies from direct appeal to higher-level authorities and overseas visits to garner support and understanding, to legal action, negotiation and reconciliation. As highlighted in previous chapters, here too the striking feature of this landscape is the diversity of SNGs in the nature, extent and reason for their engagement in hard diplomacy and their different levels of political will to become involved at all. In fact, a large majority of SNGs is disinterested or simply unwilling to take action, believing that they have neither the ability nor the political authority to be involved in these politically contentious issues, which are best left to the national government. $^{3}$

\section{Early diplomatic activism}

The conservatism that dominated Japan's local politics in early post-war changed significantly from the late 1960s with the election of progressive chief executives 
to head SNGs in many urban and metropolitan areas. Not only did these leaders oppose national-government policy priorities that did not suit local needs, some also challenged the national government's foreign-policy priorities and took steps that created difficulty for the national government. Some of these new SNG leaders enjoyed more clout in the national capitals of other countries than did the Japanese national leadership.

Policy differences between progressive SNGs and the conservative national government in the late 1960s and 1970s were accentuated by the Cold War political divide that polarized nations into opposing ideological camps. The Japanese government had tied itself firmly to the United States through its bilateral security treaty and other diplomatic and commercial agreements. When progressive leaders supported by the Japan Socialist and Japan Communist parties made their debut at the local level, they voiced their displeasure at the national government's strategic policies and its unequivocal support for the security framework of the United States as Japan's principal military ally. ${ }^{4}$ Kanagawa Prefecture and particularly its progressive governor, Nagasu Kazuji (1975-95), remained critical of the US-Japan security relationship, especially since it allowed nuclear weapons to be stored within the prefecture's administrative jurisdiction in Yokosuka and made Kanagawa the second largest US military base after Okinawa. ${ }^{5}$

Approximately 12 years before Nagasu was elected as Kanagawa governor, Asukata Ichio was voted in as mayor of Yokohama City in Kanagawa Prefecture. Asukata took an active interest in diplomatic issues through what some described as 'diplomacy from opposition' (yato gaikō). ${ }^{6}$ A prominent JSP leader of national status, Asukata tried to carry out some of his Socialist Party's policy agenda through his actions at the local level, while an overwhelming majority of conservative forces dominated the national parliament. Asukata spearheaded an antiVietnam War campaign from his locality to raise public criticism of Japan's support for the United States in the Vietnam War. Vietnam-bound US tanks were stopped in Yokohama for more than 90 days in August 1972 on the ground that permission had not been obtained from Yokohama city authorities for heavy, oversized vehicles to pass along the city's roads. ${ }^{7}$ A panicked national government was forced to negotiate with city officials before the tanks could be released. ${ }^{8}$ Asukata's 'diplomacy from opposition' tested the public mood and drew overwhelming support. This action by his administration generated more than symbolic 'opposition' to the war, since it sent a clear message to the national government that the SNGs could make life very difficult for the national government if it attempted to pursue 'security' measures without full cooperation of the SNGs. The Yokohama resistance demonstrated that SNGs could use their own regulatory capacity creatively to achieve outcomes obstructive to a national policy overriding political sentiment at the local level.

Mayor Asukata not only played the politics of 'opposition', but contributed positively to promoting Japan's national interests, as the Socialists perceived these interests at that time. In November 1971, even before the national government moved to negotiate with the PRC on normalizing bilateral relations, Mayor Asukata led a mission to Shanghai seeking to restore Japan's diplomatic relations with China. 
Asukata's mission proposed a draft agreement to establish a friendship relationship between Yokohama and Shanghai and this was signed formally in $1973 .{ }^{9}$

Another high point of this 'diplomacy from opposition' came in April 1974 when Yokohama hosted the Second Asian Table Tennis Tournament. Some were apprehensive about possible conflict between Yokohama and the national government since Japan did not have diplomatic relations with certain countries such as Vietnam, ${ }^{10}$ which Yokohama City office had invited. Mayor Asukata used his opening speech to express views dominant at the grassroots level in Yokohama and raised the motto of 'contributing to peace in Asia', claiming:

I believe that the only way to make fundamental changes in the problems of the Japanese government's diplomatic stance and the aggressive international economic expansion of major Japanese companies may be for the Japanese people themselves to join hands with the peoples of Asian nations to deepen understanding. On this understanding it would be unacceptable to fail to criticize these major Japanese companies and censure Japan's advancing trade economy, this 'ignoble Japanese conduct'. I was delighted, in this context, to take on the hosting of the Second Asian Table Tennis Championships in Yokohoma. ${ }^{11}$

The 75 participants included representatives from eight Arab nations. Significantly for its organizers inside and outside the Yokohama City office, the event drew huge press coverage that raised community interest in broader diplomatic issues such as those emanating from the 1973 oil shock and the Vietnam War. Holding the championships was part of Asukata's agenda to encourage participation by the local people (shimin sanka) in public life, in international as well as domestic matters. The event provided opportunities for ordinary Japanese people in Yokohama and beyond to mingle with international participants in a classic example of the 'public diplomacy' (shimin gaikō) that Asukata advocated and worked to generate.

Other progressive SNG leaders were instrumental in building bridges between Japan and the PRC beyond Mayor Asukata. One was the egregious governor of Tokyo, Minobe Ryōkichi (1967-79). In 1971, when the Japanese government led by Prime Minister Satō Eisaku was keen to 'normalize' Japan's diplomatic relations with China, it could not find a diplomat acceptable to the Chinese leadership who could initiate the process of negotiations with Beijing. Ultimately, progressive Governor Minobe was asked to deliver to the Chinese leadership a letter written by the LDP Secretary-General, during the governor's trip to the PRC and North Korea in November $1971 .{ }^{12}$ Minobe was a subnational rather than a national leader and was supported by the Socialists and the Communists rather than the conservative LDP that dominated national politics. Minobe fulfilled the task to serve what he recognized as the interests of the nation, believing that reconciliation with the PRC was worth achieving even under the rule of his political adversaries in the conservative party. ${ }^{13}$ The move indicates how the national government used the elevated political standing of a subnational leader to have him represent the Japanese nation rather than simply his electorate of Tokyo Metropolis. 
It also demonstrates how an SNG leader could command more clout overseas than Japan's national leaders could at that time and place.

There are various instances where SNG leaders have worked to prepare the ground for achieving an amicable settlement of troubled relations with immensely important neighbours. One is the former Soviet Union (now Russia) with which Japan has yet to sign a peace treaty, and another is North Korea with which Japan does not have diplomatic relations and which is perceived as a major security concern for Japan. We consider some of these instances in later sections of this chapter. Here, we need to note that a few SNGs under progressive leaders have been serious in pursuing 'hard' diplomacy even since the 1970s. The initially slow accretion of SNG efforts provides examples to other SNGs of approaches and methods. They are also proof of SNG capacity to work for and actually register local concerns, in the face of national-government resistance to SNGs entering its sacred ground of international diplomacy.

\section{SNG agendas for peace and against nuclear weapons}

Peace is a palpable concern for many Japanese citizens who remember and/or hope to prevent repeat of Japan's experience as vanquished nation in 1945. Japan is the only nation with first-hand experience of the devastation of nuclear bombing that destroyed most of Hiroshima and Nagasaki. Pursuit of peace, often conflated with rejection of war and of nuclear weaponry, remains high on the agenda for many Japanese. The spirit of peace is embedded firmly in the Japanese constitution prepared in early post-war. Article IX renounces the threat or use of force to settle international disputes and prohibits Japan from maintaining military forces ${ }^{14}$ and the preamble sets out the goals of 'peaceful cooperation with all nations' and 'peace for all time'. The national government claims to follow the 'letter' of the constitution, but through legislation and a security framework with the United States as Japan's chief military ally, the national government has made numerous moves in national security that raise serious public concern about their constitutional validity.

Some citizens have responded through their SNGs, aiming to reach a seemingly impenetrable national government through the levels of government below it. With public support on the ground before them, many SNGs have opposed national-government policies that their citizens generally regard as unconstitutional and have initiated local policies to defend the constitution and to pursue the overall objective of world peace. Since Japanese SNGs do not have constitutional or legal rights to establish legislation, they have pursued their objectives through two means, always backed by popular support. One is passing resolutions, declarations and pronouncements in their assemblies. The other is through protest action such as speaking out against war at public rallies or formal organized events in support of peace movements and forming networks at national and international levels to pursue shared goals.

Post-war, most Japanese initially saw issues of peace and war as matters for the national government with active involvement almost exclusively by those in localities affected directly by the war through nuclear bombing (Hiroshima and 
Nagasaki) and protracted US occupation (Okinawa). In time, across Japan, these localities came to be at the forefront of peace movements. SNGs that actively support peace and denounce Japanese involvement in any activity associated with nuclear weapons act autonomously from the national government, recognizing it is their duty to try to secure peace through legitimate and democratic means to truly represent the voice of their constituents. Their approaches are consistent with the tendency nationwide, on the basis of the Hiroshima and Nagasaki nuclear bombings, to conflate pro-peace with 'anti-nuclear', as the popularity of anti-nuclear movements indicates.

\section{Anti-nuclear and peace movements}

An ever-increasing number of Japanese SNGs has made official peace declarations since the 1950s. Japan's anti-nuclear movement by SNGs has its roots in Gensuikyo (the national movement to prohibit atomic and hydrogen bombs). The disaster of the 1954 Bikini Atoll underwater nuclear detonation precipitated the August 1955 World Conference Against Atomic and Hydrogen Bombs held in Hiroshima, which culminated in Gensuikyō as a national movement. ${ }^{15}$ Gensuikyō was highly politicized from its birth and in the 1960s split into Socialist and Communist groups. They sparked some public interest in the anti-nuclear movement, but as Kamimura notes, despite their strong international moral appeals, the anti-nuclear groups had little impact on the policies of successive conservative national governments throughout the Cold War. ${ }^{16}$ Very few Japanese SNGs were willing to endorse or participate actively in this highly politicized movement. Conservative-supported SNGs completely shunned involvement recognizing that their primary interest was to obtain benefits for their locality from the national government, which was one of the movement's arch enemies.

Fresh impetus to the anti-nuclear movement in Japan came in the late 1970s and early 1980s through strong anti-nuclear movements worldwide, after positioning of United States and Soviet medium-range nuclear missiles in Europe and UN official resistance. Japanese citizens responded with vigour to the 1978 and 1982 United Nations Independent Commissions on Disarmament and Security Issues that urged citizens across the world to lobby their UN representatives for abolition of nuclear arms. The SNGs' role in the anti-nuclear movement began in earnest in 1982 after the UN Special Arms Reductions Conference. Following a European trend, the number of Japanese SNGs making anti-nuclear declarations adopted and approved by their local assemblies began to grow phenomenally in the $1980 \mathrm{~s}$ - from less than 10 at the start of 1980 to more than 2000 by $1995 .^{17}$

Many SNGs had made anti-nuclear and peace declarations and erected signs or statues in 1960 to protest the national government's renewal of the Japan-US Security Treaty. Akashi City in Hyōgo Prefecture had issued a 'Nuclear Disarmament City Declaration' even before revision of the Treaty, prohibiting manufacture, storage and bases housing nuclear weapons in the city. ${ }^{18}$ The value of these declarations is their symbolic significance, which when aggregated even 
at a rhetorical level, indicates to the central government the level of public disproval at its actions on national security.

The advent of the hawkish Nakasone government (1982-87) was another trigger to action. This administration pushed to strengthen the military with a greater role for the Self Defence Forces (SDF, or military by another name) in revised national defence plans. Yoshida argues that much was expected of SNGs in the intensified struggle against military revival since the SNGs were closer than the central government to the people who elected them and could voice their constituents' protests in their capacity as officially elected representatives. ${ }^{19}$ Demands from SNGs that the national government observe the constitution's three anti-nuclear principles intensified as Nakasone drew the nation more firmly under the US nuclear umbrella and the number of SNGs making Anti-Nuclear City Declarations shot up dramatically. In 1982, 57 SNGs declared their localities nuclear-free; 410 SNGs made this declaration in 1984. By 1995, approximately two thirds of all Japanese SNGs including 2019 cities had declared their localities nuclear-free. ${ }^{20}$ A 2001 report put this figure at 2497 or about 75 per cent of Japanese SNGs, with many also demanding that the national government adhere strictly to the three non-nuclear principles. ${ }^{21}$

The concept of non-nuclear localities appeals widely, not just to residents but also to the majority of the SNGs that have embraced these declarations in public policy. The nature and content of these declarations vary widely, although Yoshida has made three general observations. First, their content is usually vague and they are addressed to 'peoples' or 'citizens' of the world, although some specifically address the Japanese government and countries that have nuclear-weapons capability. Second, the declarations of cities that host military bases are quite different from those that do not. The former criticize the national government's nuclearweapons policy and demand dismantling of US military bases in Japan on the grounds that they store nuclear weapons. Even some SNGs that do not host US bases have made similar declarations (e.g. Toshima Ward in Tokyo and Tokushima Prefecture). Third, some SNGs such as Nakano Ward in Tokyo bolster their declaration with defence of the constitution. ${ }^{22}$ These declarations are not legally enforceable but they do send signals to the national government as a barometer of community response. They may also serve as vent for community anger at the national government's apparent abuse of Article IX of the constitution and the spirit of peace in which it was composed and ratified.

In 1984, 200 (10 per cent) of the declared nuclear-free localities in Japan established the Consortium of Nuclear-Free Subnational Governments (Nihon Hikaku Sengen Jichitai Kyōgikai), which mobilizes support for peace movements and helps localities and other groups to organize rallies, raise funds to promote peace studies and conduct similar activities inside Japan. It also establishes links with counterpart bodies overseas. ${ }^{23}$ The Consortium's philosophy is that crossborder promotion of peace by SNGs helps to act as a check on military expansion and promotes peace across the globe. Some see the Consortium as a ceremonial, consultative body with little influence on the nuclear disarmament movement domestically or internationally. ${ }^{24}$ Others believe that it acts as a useful pressure 
group, with capacity for greater clout if it partners with NGOs to mobilize support and lobby the national government as a united front. ${ }^{25}$

The 'anti-nuclear' issue has the potential to unify large numbers of SNGs against the national government through their shared grievances, as we see with the SNG Consortium. It is also a potentially potent a site for confrontation between the two levels of government, as SNGs try to bring the voice of the people to the seemingly deaf ears of the national government. So far the SNGs have rejected confrontation and have taken careful measures not to get too far offside with their central policy masters. SNGs recognize their need to represent their constituents' voice against nuclear weaponry but also their far greater need to secure funds from the central government so that they can attend to virtually all other needs within their locality. The national government's response here has been to reassert its control over SNGs' capacity to take diplomatically significant action, especially actions protesting the national government's stance on issues so contentious within and outside Japan.

\section{The Mayors for Peace Movement}

The two cities at the forefront of the peace movement in Japan are Hiroshima and Nagasaki, the only two cities in the world that have suffered the consequences of nuclear bombing, just before the end of the Second World War. The SNGs of these two cities have taken a keen role in contributing institutionally through the Mayors for Peace Movement. Hiroshima City Mayor Araki Takeshi proposed the body as a pioneering initiative at the Second UN Special Session on Disarmament at UN Headquarters in June 1982. This was at the height of Cold War tensions when the Japanese government was on the verge of revamping the nation's military role. The proposal to promote the solidarity of cities working for total abolition of nuclear weapons offered a vehicle to consolidate a trans-national movement at grassroots level. This evolved into the Mayors for Peace Movement (Heiwa Shichō Kaigi), registered officially as a Category II NGO with the UN Economic and Social Council in May 1991. In September 2003, 554 SNGs in 107 countries officially supported this organization. ${ }^{26}$

Successive mayors of Hiroshima in particular have taken a range of initiatives to build an international community to promote peace through disarmament and opposition to nuclear arms. They have travelled widely to meet with senior officials, politicians and NGO leaders, they have addressed legislators and city councillors, presented seminars, and invited pre-eminent leaders to Hiroshima to understand more deeply how a city suffers from nuclear bombing. Mayor Akiba Tadatoshi travelled to England, France, Russia and the United States in 2001, to the UN Headquarters in 2002 and to India in 2003 to meet with officials and legislators, spread the message of peace to nuclear-weapon states and solicit support for the Mayors for Peace Movement. ${ }^{27}$

Other Japanese members of the Mayors for Peace Movement have also voiced criticism of their national government's stance on nuclear weapons through 
international forums. The WHO and the UN General Assembly sought an advisory opinion in 1995 from the International Court of Justice in The Hague as to whether the use of nuclear weapons in a military conflict violates international law. Representatives of various countries and organizations expressed their view before the Court. Whereas the Japanese government called the use of nuclear weapons 'inhumane', mayors Hiraoka Takashi of Hiroshima and Itō Itcho of Nagasaki declared these weapons 'illegal'. Commentators claimed that 'The [Japanese] government has avoided calling use of nuclear weapons illegal, apparently because of Tokyo's security dependence on the nuclear umbrella of the Unites States'. ${ }^{28}$ Here the national government pursued a moral dimension, while the SNGs favoured a legal line. It was almost the reverse of the approach taken by the two levels of government inside Japan where in most diplomatically sensitive matters, the national government insists on determination by legal judgement while almost all that the legally unsupported SNGs can mobilize is the weight of moral judgement.

Some Japanese mayors have even sharply criticized the US government for its nuclear policy. City officials and peace activists in Hiroshima and Nagasaki criticized a subcritical nuclear test in Nevada in early December 2001. ${ }^{29}$ Hiroshima mayor Akiba Tadatoshi sent messages of protest to both US President George W. Bush and US Ambassador to Japan, Howard Baker. Akiba condemned the nuclear test as a betrayal of the people's desire for abolition of nuclear weapons. ${ }^{30}$ Speaking on the fifty-nineth anniversary of the bombings of Hiroshima and Nagasaki in 2004, the two city mayors reserved their most scathing remarks for the enhanced nuclear capabilities of the United States. ${ }^{31}$

The mayors of Hiroshima and Nagasaki take their message internationally in hosting the four-yearly World Conference of Mayors for Peace through Inter-City Solidarity (Sekai Heiwa Rentai Toshi Shichō Kaigi), with executive meetings held periodically to take stock of the movement. An October 2003 executive meeting held in Manchester discussed new strategies for launching a campaign to ban nuclear weapons and devised plans to lobby national delegates and work in cooperation with NGOs to heighten public awareness of nuclear issues. Another concern was to focus the attention of the UN conference on reviewing the nuclear non-proliferation treaty in 2005, marking the sixtieth anniversary of the atomic bombings. ${ }^{32}$

Some Japanese observers have made general observations that the SNGs and others who are involved in Japan's pro-peace and anti-nuclear movements achieve almost nothing, that their initiatives and actions are simply symbolic and that they shrink from any initiative that might jeopardize US nuclear deterrence and capabilities. ${ }^{33}$ Others perceive SNGs as actually playing a diplomatic role through supporting the peace movement and opposing nuclear armaments, since the symbolism is itself a type of force that helps to promote world peace. ${ }^{34}$ Certainly, the actions of some SNGs and their leaders demonstrate the will and capacity of SNGs to put forward dissenting voices in national and international venues and to initiate and develop networks of like-minded SNGs internationally to bolster their cause, for domestic and international peace. 


\section{Japan-US security relations}

Japan's principle bilateral security relationship with the United States is a source of deep contention between the national government and some SNGs across Japan. The US-Japan Security Treaty was signed alongside a peace treaty in 1951 and was renewed in 1960 and automatically extended from 1970. The treaty sets out how the United States provides security to Japan including protection under the US nuclear umbrella. The Japanese government sees this as a desirable arrangement since it spares Japan the need to develop a fully fledged military force and its own independent nuclear-weapons programme - an enormously contentious issue, even to approach. However the treaty requires that Japan host US bases in Japan, which many in the Japanese population and some SNGs that represent them locally have struggled vigorously to resist. Thus, although there is widespread support for the Security Treaty, 'there is strong opposition to concrete manifestation of the treaty: US bases and deployment of military personnel' ${ }^{35}$ Here, we consider the three most significant sites of tension: (1) visits to Japan by US warships; (2) the Japan-US Defence Cooperation guidelines; and (3) US bases in Japan, through case studies of Okinawa Prefecture and Zushi City.

\section{Protests against nuclear-equipped warships}

Japan's national-security policy explicitly disavows nuclear weapons through the 'three non-nuclear principles' enunciated formally by Prime Minister Satō Eisaku in 1967. These principles are that Japan will not possess or manufacture nuclear weapons or allow such weapons to be brought into Japan. The national government has found upholding the third principle particularly troublesome. To allow entry of US navy ships carrying nuclear arsenal into Japanese ports, the Japanese government's stance is to simply accept the US position of 'neither confirming nor denying' the presence of nuclear facilities. But the actions of Kobe City in 1975 considerably upped the ante on the port issue for the national government.

After the end of the Second World War, Kobe port was placed under US military occupation and was used as home for the US Seventh Fleet until the port was returned fully to Japan in 1974 with the end of the Vietnam War. During the Vietnam War, US aircraft carriers often used the port and US military ships made 423 visits from 1960 to 1974 . The Kobe City administration brought visits by US navy ships to an abrupt end in March 1975 when the City assembly passed a resolution requiring all foreign warships to produce a certificate certifying the complete absence of nuclear facilities on board. ${ }^{36}$ Newly elected progressive mayor Miyazaki Tatsuo had strong backing from Kobe citizens and other groups that provided electoral support, enabling him to have this resolution passed by the City assembly. Usually the non-nuclear declarations of cities are not supported by mechanisms for concrete action, but here Kobe City used its authority over the city's ports to give substance to its anti-nuclear stance, through a space where the law and the constitution did not rule out an SNG's resistance action. ${ }^{37}$ 
The Kobe non-nuclear formula has been the subject of national debate and national and international attention, especially since Kobe port's capacity for docking US navy ships is greater than that of any other Japanese port. Of most gravity to the Japanese government, the Kobe strategy serves as a model for SNGs in port cities across Japan to pass similarly obstructive assembly resolutions. The legal basis for Kobe City's resolution is the Port Law (kōwan-hō) that gives authority to manage port administration to the city-level SNG. US diplomats in Japan claim that the US-Japan Security Treaty gives the US military the right to access any facility in Japan and that SNGs should not have the authority to obstruct US ships if the Foreign Ministry allows their entry. But Japan's politicians and the Foreign Ministry have taken a middle path through this divisive patch, reaffirming the rights of the United States and the basic tenets of the security treaty and making it clear that they will not force a showdown with Kobe on this issue. ${ }^{38}$ Kobe City claim of its right to manage the city's port and enforce the certificate requirement appears to be enshrined in the constitution and fully defensible under law. Even former, pro-military Prime Minister Nakasone Yasuhiro could not deny the legality of the Kobe Declaration when questioned on it in parliament. ${ }^{39}$

Kobe's successfully obstructive approach and the possibility that other SNGs may adopt a similar resolution naturally drew a backlash from US authorities. The US government and its representatives in Japan have continued to press Kobe to abandon its formula and allow US warships to enter Kobe port without the 'nonnuclear' certificate ${ }^{40}$ The US authorities have used both carrots and sticks to win unfettered access to Kobe port for the US navy. They have promised city administrators, politicians and labour unions more investment in Kobe if the Declaration is abandoned. But sometimes the pressure is less co-optive and more admonitory; once the US Consul General commented that 'if Kobe retains the Kobe Formula rejecting the entry of US military ships, it would be misinterpreted that Kobe is an anti-US city'. ${ }^{41}$ The US strategy has also involved peer pressuring; US ambassador Thomas Foley informed a group of Japanese SNG officials in 1999 that he wanted US warships to be able to visit Kobe port before he left office. ${ }^{42}$

SNGs depend on the national government for financial and other support and risk losing some of the favour with which this support is endowed if they move against the central government's position on a strategically sensitive issue. But some SNGs recognize a degree of reverse need on the national government's part. Kobe as a large and prosperous city is less dependent on the national government than localities that are smaller or have less opportunity for partially sustaining themselves economically as we see with Okinawa in the next section. Kobe's antinuclear port stance has not affected the city's economy in any significant way, nor weakened its clout vis-à-vis the central authorities. The relationship between Kobe City and the Foreign Ministry and the Defence Agency is strained, but Kobe appears to have significant sway with other ministries as evident in its ability to score a new airport in Kobe despite the presence of two major airports in Kobe's neighbouring city, Osaka. US authorities also appear to recognize Kobe's economic and political strengths with their use of a co-optive, conciliatory approach rather than confrontation to try to prevail over Kobe on port use. 


\section{The revised US-Japan Defence Cooperation Guidelines}

In April 1996, US President Clinton and Japanese Prime Minister Hashimoto issued a Joint Declaration to revise the 1978 US-Japan Defence Cooperation Guidelines and a revised version of the Guidelines was released in September 1997. The revised Guidelines sparked controversy nationally and internationally as they specifically expanded the earlier defence cooperation beyond repelling an attack directly against Japan as specified in the 1978 guidelines, to include cooperation during crisis situations in 'areas surrounding Japan' (shühen jitai). Some observers saw this as a major and portentous leap from the position specified in the original guidelines ${ }^{43}$ The revised defence guidelines had taken 'national security' and the responsibility of Japanese defence forces demonstrably offshore, beyond the narrow limits of the Japanese nation that had contained the defence zone in the original guidelines. One of the many pieces of legislation to enable implementation of the revised guidelines was therefore the proposed Law Concerning Measures to Ensure the Peace and Security of Japan in Situations in Areas Surrounding Japan (Shühen jitai anzen kakuho-hō) (hereafter the SASJ law). This would give Japan's SDF new legal capacity to operate in 'areas surrounding Japan', by extending rear-area support and engaging in search-andrescue operations with US forces.

Controversy at the SNG level was instant. The concern for SNGs was less about Japanese forces operating offshore than about US forces operating more extensively within the SNGs' localities. The proposed SASJ law required SNGs to provide their port and airport facilities to US warships during a crisis situation in Japan's vicinity and to cooperate with US requests for logistical support in such conflicts. ${ }^{44}$ Attention flooded back onto the contentious Kobe anti-nuclear port model that the Japanese, US and Kobe City governments had been happy to keep well away from front-page news. Support for SNGs to follow the Kobe port "no nuclear' declaration grew gradually, but gained real momentum by mid-1999, just before parliament finally passed the SASJ law. Calls for SNGs to adopt 'nonuclear' certificates based on the Kobe model came from SNGs nationwide and continued to needle the central government on its most important bilateral security relationship. An Asahi Shinbun survey in February 1999 found that 177 SNGs in 32 prefectures had adopted statements either protesting the revision of the guidelines or expressing concern about them.$^{45}$ Another report claimed that by May 1999, 215 SNGs in 35 prefectures were demanding action against the revised guidelines. ${ }^{46}$

There was diversity among SNGs, even in their resistance. ${ }^{47}$ For example, the Kazo City assembly in Saitama Prefecture opposed the SASJ bill on the basis of the City's status supporting peace and 'no nuclear', and reaffirmed the principles of global peace and security. The Nikko City assembly in Tochigi Prefecture went further, declaring that for these reasons Nikko City 'could' not cooperate in military resolution of disputes. The small SNG of Higashi Iwai Gun with a population of approximately 20,000 in Iwate Prefecture resolved not to accept the SASJ law on two grounds: (1) the cooperation required with the US military 
would expose local citizens to the US military's oppressive behaviour, threatening citizens' lives and security; and (2) the SASJ law violates the constitution. A few SNGs indicated that the peace and security of their locality were already threatened by low-flying US aircraft and they would not be able to endure further intrusion under the new guidelines requiring them to make their ports and airports available to the United States. ${ }^{48}$ The Nakagawa Gun assembly in Hokkaido went so far as to demand that the Japanese government offer an apology to surrounding countries since peace must be the first consideration in foreign policy. ${ }^{49}$

One of the most controversial proposals came from Governor Hashimoto Daijirō of Kochi, a small prefecture on Shikoku Island. In February 1999, Governor Hashimoto proposed that the prefecture adopt a no-nuclear ordinance to help the prefecture prevent foreign warships carrying nuclear weapons from calling at the prefecture's ports. ${ }^{50}$ It would also protest against the national government's failure to cooperate in trying to resolve the problem of low-flying US military aircraft passing over the prefecture. The governor's proposal to regulate foreign military ships through a 'no-nuclear certificate' ordinance - a legal instrument - had more political muscle than the assembly resolution - an administrative instrument - used in Kobe's prohibition formula. ${ }^{51}$ The Governor's proposal seriously alarmed policy-makers in Tokyo and Washington since it was the first time that a prefecture proposed passing such an ordinance and the national government had twin concerns and matching counterclaims against the SNGs. First, it wanted to protect its foreign policy turf. Chief Cabinet Secretary Nonaka Hiromu put forward stridently the claim that matters relating to defence and diplomacy are within the jurisdiction of the national government and LDP assembly members of Kochi Prefecture parroted Nonaka to declare foreign policy issues outside the jurisdiction of SNGs.

Second, the national government claimed that Kochi's proposed ordinance would violate the constitution since Article 73 stipulates that management of foreign affairs is the responsibility of the cabinet. However, supporters of the Kochi proposal challenged the national government's position on the ground that Article 73 sets out the cabinet's responsibility only in relation to the other two branches of the national government, the judicial and legislative arms; since it does not define the relationship between the national and subnational level of government, SNGs are not bound by this article. ${ }^{52}$ Moreover, Article 94 of the constitution gives SNGs 'the right to manage their property, affairs and administration and to enact their own regulations within law'. And while Article 65 vests executive power in the cabinet, the exception is in areas where power is already vested in SNGs. ${ }^{53}$

Newspapers flowed with opinions and editorials on this issue. Mainichi Daily editorialized in favour of Kochi's proposal on the basis that it was consistent with the government's three non-nuclear principles as the basis of national-security policy. Kochi Prefecture was therefore taking steps to reinforce, not contravene, national policy. ${ }^{54}$ Similarly, Asahi Shinbun questioned why a proposal giving substance to the government's three non-nuclear principles would arouse such strong resentment on the government's part. Asahi observed that the port law leaves control of port facilities to SNGs partly in repentance for allowing the military to have top priority in using port facilities during the Second World War. 
The editorial went so far as to claim that the controversy had brought to light that 'the three non-nuclear principles are fictional' and reminded citizens of their leaders' fears that if a non-nuclear certificate is required of US vessels at a time of crisis, Japan could not cooperate effectively with US forces. ${ }^{55}$

In the face of the media brouhaha and pressure from both the prefectural assembly and the central government, Governor Hashimoto backed down on his proposal. There was strong opposition from an LDP-dominated assembly and only tepid support from the public and his peer group of governors. But although the proposed 'no nuclear' ordinance did not eventuate in Kochi, other SNGs have raised the prospect of establishing such an ordinance to follow the Kobe model. ${ }^{56}$ Johnston reported in 2001 that an estimated 20 local governments around Japan had considered, or were considering, some version of the Kobe declaration, 'not just to keep nuclear weapons out, but to send a message to the US and to the central government that they do not want to become pawns in a regional conflict'. ${ }^{57}$

The national government upholds that an assembly resolution does not have a legal basis and that local assemblies' resolutions and citizens' requests do not influence the administrative exercise of authority. Many still counter the former claim, arguing through the legal logic of default that SNGs are not bound by law to not declare themselves nuclear-free or to require foreign ships to certify the absence of nuclear weapons in their cargo, since by law SNGs are ultimately responsible for port management. But the second claim appears to be manifestly proven in the Kochi example: citizens' requests did not influence the administrative exercise of authority - at least not at the national level that used political channels through the top-down unitary system to subvert popular dissent at grassroots.

Nevertheless Kobe's 'no nuclear' resolution on docking in its ports should make it clear that a resolution can be a powerful tool for SNGs. Even though without the legal force of an ordinance, it carried a load of potential to stimulate copies by SNGs across the country. The potential threat that it raised to the national government certainly made the Kobe precedent more than symbolic. In this light, we see how revisions to the Japan-US Defence Cooperation Guidelines and the SASJ law helped to intensify the impact of the Kobe port model on Japan's foreign relations and particularly on Japan's most important bilateral relationship, in the sensitive, hard-diplomacy area of security and defence.

\section{Bases and facilities for US troops}

We find very similar currents in the most overt and politically contentious manifestation of the US-Japan Security Treaty inside Japan: the US bases. Here too, the 'international' dimension of the security treaty has become the site on which local politics is battled, again mostly because of the clash in the priorities of subnational and national interests. The heavy presence of US troops in Japan has been a festering sore for the SNGs that have US bases in their localities. Very few SNGs have opposed the US-Japan Security Treaty outright, but they have certainly struggled against the national government to obtain reduction of both troops and intrusive military activities such as low-altitude flying and night-flying exercises. Some have called for the bases to be totally withdrawn from their locality, 
a classic example of NIMBY (not in my backyard), although Okinawa's protest has been more about sharing responsibility for hosting bases throughout Japan. SNG leaders have been elected and defeated on these issues. ${ }^{58}$

Here, we observe the Japanese national government taking shelter under the US-Japan Security Treaty that it assumes will provide a national cloak of acceptability for its actions, while it shunts aside the serious concerns of citizens in localities whose lives are very much imposed upon by US bases. Some SNG leaders have not hesitated to bypass the national government and appeal directly to Washington through petitions and personal visits to concerned authorities and other interest groups, including the media. Let us consider two very important examples of these localities. Okinawa, Japan's southernmost prefecture, has the heaviest concentration of US bases in Japan and is relatively distant from Tokyo, while Zushi is a city that houses a US base quite close to Tokyo - politically as well as geographically.

\section{Okinawa}

Okinawa is historically very distinctive within the Japanese national context. It was assimilated into Japan as Okinawa Prefecture in 1879 after the Japanese government deposed the last king of what was until then the Ryukyu Kingdom. ${ }^{59}$ Okinawa was a site of fierce battle during the Second World War when some 230,000 lives were lost. Okinawa is also geostrategically distinctive, as a pivot to and from East Asia. The island chain is physically quite removed from the rest of the Japanese archipelago, with the Pacific Ocean on one side, and the East China Sea and beyond it mainland China and Taiwan, on the other.

After Japan's defeat by the Allied Forces in 1945, Okinawa was kept under US occupation until 1972. Particularly during the Occupation and throughout the Cold War period, US authorities saw Okinawa as strategically crucial to their security design for Asia-Pacific. Thus, even after the return of sovereignty to Japan, Okinawa remained home to a heavy concentration of US troops in Asia-Pacific, by far the largest within Japan. The end of the Cold War and changes in regional geopolitics did not change Okinawa's status as the most concentrated base for US troops. Okinawa has less than 1 per cent of Japan's land area but hosts some 75 per cent of all US troops based in Japan. Accidents and misdemeanours arising from the bases abound. SNGs in Okinawa have continued to oppose the intrusion of the bases on their localities, which the local people see as 'discrimination' against them. Tokyo has continued its cool response to their demands for fairer treatment, upholding the nation's critical security treaty with the United States. ${ }^{60}$

Reported cases of rape of local citizens by US servicemen since the 1972 reversion exceed 100. After a US serviceman raped a 12-year-old schoolgirl in 1995, locals could no longer suppress their anger and mounted opposition to the US-bases policy on an unprecedented scale. The rape incident inspired a 'people's rally' of 85,000 participants protesting at how policies made in Tokyo about US bases in Okinawa overrode Okinawan interests. ${ }^{61}$ Okinawa Governor Ōta Masahide (1990-98) fought firmly for his prefecture's interests, using legal and popular mechanisms. 
Governor Ōta demanded that the number of US troops be reduced immediately. Then he went much further; he refused to sign land-lease agreements associated with the US bases by challenging the tenuous legal basis on which the national government takes prerogative over Okinawan land for these bases. ${ }^{62}$ The Supreme Court rejected Ôta's law suit in August 1996. Yet, there is no doubt that if the governor had not taken such a recalcitrant stance and spoken out with conviction for the ordinary residents of Okinawa, the national government would not have taken up the issue of crime and other grievances arising from the bases in Okinawa to the level that it actually did. Ironically, here the issue was certainly 'security', but for whom and of what? At the local level in Okinawa, security must include protecting ordinary people from crime and personal harm, which may well arise from intrusive US bases right within their localities. At the national level, as construed by politicians in Tokyo, security is a matter of protecting national borders from external intruders. For the national government, the US military help to repel external intruders; for the people of Okinawa and their local leaders, members of the US military are the external intruders.

To protect local interests, Governor Öta negotiated with the national government, challenged it in the courts and travelled with delegations several times to the United States to seek the support and understanding of US officials and the American public. Both the Japanese national government and the US leadership appeared to take the challenge rather seriously. US President Bill Clinton publicly expressed regret over the incident and his administration established jointly with the Japanese government a Special Action Committee on Okinawa (SACO) ${ }^{63}$ In the previous year, the Japanese government agreed to establish the Consultative Committee on Okinawa Base Problems (Okinawa Beigun Kichi Mondai Kyōgikai) for prefectural representatives to negotiate directly with top-ranking national officials on matters concerning the US bases in Okinawa, the first of its kind in Japan. Thus, by 1996 the prefectural government had forced two sets of direct negotiation processes between the three key players to address the US bases problem - one set between Okinawa and Tokyo, the other between the Japanese and US governments.

Öta's tough stance on the bases issue brought the relationship between Okinawa and Tokyo from a center-periphery type onto a more equal footing. Ōta sought to change not only national policy on US military bases in Okinawa, but also the process by which this policy is made. It meant seeking a greater role for prefectural governments in contributing to national policy on security and defence matters, the very policy area that the national government is most reluctant to relinquish. Öta's response to the 1995 rape incident and the public outpouring of anger that it inspired, forced the Japanese government to renegotiate with him over continued use of US bases under his SNG prefectural administration. ${ }^{64}$ Some have observed in Ōta a new breed of determined local politician who was willing to oppose the national government when national policies undermined local welfare. ${ }^{65}$

In 1996, Ōta and his supporters stridently opposed the relocation of Futenma Air Base to a floating/anchored airfield. Futenma symbolized the base-related concerns of Okinawans such as aircraft-noise pollution and the danger of crashes. 


\section{Hard diplomacy: SNGs and national security}

The base occupied a quarter of the total area of Ginowan City, right in the city's centre. Roads, waterworks and sewerage systems had to be detoured around the air station and the height of buildings near the base was restricted to avoid inconvenience to approaching US aircraft. These presented major obstacles to improving the city's infrastructure. ${ }^{66}$ Öta's opposition was not to the SACO recommendation that Futenma Base be moved, but to the chosen site for the replacement heliport offshore from Nago and still in Okinawa. Ōta and his supporters saw the relocation as a burden to all Okinawans, particularly those near Nago and the local assemblies in Kadena and Nago affected by the recommendations passed unanimous resolutions against the construction of the proposed heliport. ${ }^{67}$ A 1997 referendum in Nago City that rejected the relocation created further difficulty for the Japanese and the US governments.

In the following year, Ōta lost the gubernatorial election. As a progressive governor supported by leftist parties, Öta could not prevent the erosion of his public support by the national government effectively threatening to hold back economic aid to the prefecture if an anti-base candidate were re-elected. Pro-base, LDP-supported Inamine Keiichi won the election. Inamine has taken a deliberately conciliatory approach but has requested that the US bases in Okinawa be used only up to $2015 .{ }^{68}$ Despite his political colour, Governor Inamine shares Ōta's feelings that the US military presence must be reduced and makes similar demands on the Japanese government to renegotiate the 1972 Status of Forces Agreement that governs operation and management of US troops in Japan. ${ }^{69}$

Local resistance to the US bases in Okinawa gives us useful insights into SNGs as international actors. First, we see how SNGs can be drawn into the international arena whether they seek this role or not. They can become potent diplomatic actors by harnessing popular support to challenge the central government on such crucial national matters as defence and security, with serious implications for Japan's foreign policy. ${ }^{70}$ Second, we observe the capacity of SNGs to act independently, especially when their SNG policy priorities conflict with those of the national government and few other SNGs share so deeply a particular concern (such as intrusive US bases). Okinawa is not a sovereign entity and cannot stand on an equal footing with national government in Tokyo or Washington. Yet, Governor Ōta built a direct bridge between Naha and Washington and his six visits to the city resulted in closer ties between authorities in Okinawa and the US administration.

This highlights the third lesson: the value for SNGs of making direct contact with parties abroad, including potential allies as well as adversaries. Direct personal links with Washington gave Okinawa some bargaining power with the Japanese government that it could not have developed without the direct contact. Some SNGs have learned strategically that they can bolster not only their access to the centre's favours but also their own capacity to influence Japan's foreign affairs through building bridges and forming alliances directly with the media, public opinion makers, pressure groups and politicians beyond the national boundaries. The fourth lesson comes in on the previous point: the capacity of the national government as SNG paymaster and policy-maker to firm up its diplomatic ground by using an ultimate political retaliation: money and political favour. It can threaten to wield financial stick and to withhold financial carrot 
to help create local political conditions that are more conducive to the preferences of the national government as we see with Öta's gubernatorial loss and Inamine's win.

Finally we see the unmistakable influence of an SNG leader's personal style. Under the Progressive Governor Ōta, Okinawa was very much at the forefront of opposing the heavy concentration of US troops and further pressuring the central government to reconsider its national security arrangements with the United States. Governor Ōta took initiative, direct action and determinedly resisted pressure from the central government to toe the line on national security or at least not to redraw the line further back inside SNG policy territory. In this sense, Ōta is a good example of how the work of SNG leaders to challenge the US-Japan Security Treaty can help to uphold the norm of anti-militarism. ${ }^{71}$ The case of Zushi City, to which we turn here, illustrates this further.

\section{Zushi City}

Zushi City is in Kanagawa Prefecture neighbouring Tokyo, and so is much closer to the main stage of national politics than the far flung islands of Okinawa. ${ }^{72}$ In the mid-1980s, residents of Zushi City mounted a movement against a proposal to construct a housing complex for the families of US military personnel. Since the housing complex was to be situated in a 290-hectare forest area of the Ikego Hills, residents opposed the site of the housing to protect local flora and fauna. This is more a combination of concern for the environment and NIMBY opposition than Okinawa's resistance. Voters forced out of office the incumbent prohousing complex mayor who served as 'agent' of the national government, and voted in a local leader to serve the interests of most Zushi residents who stridently opposed both the complex and the national government's position on it. Proconservation mayor Tomino Kiichirō, elected in November 1984 to oppose the proposed housing, took the movement from the local to the national and international arenas. His appeal to the national government had yielded the response that the Japanese government could really do very little. The housing complex was in response to the US government demand for this facility under the 'overriding' mandate of the US-Japan Security Treaty, so the national government's hands were tied - or perhaps were holding on tightly to those of their top security partner.

In February 1988 after some three and a half years in office, Mayor Tomino went to the United States to solicit American understanding. He intended that his visit to explain the position of Zushi residents to the US public and policy-makers would also provide proof that US-style liberal democracy had taken root in post-war Japan. He advised the US authorities that some 70 per cent of Zushi residents supported the Security Treaty, but that a large bulk of his constituents firmly rejected the housing plan seeking to preserve the ecology of the Ikego forest. The mayor drew no assurances from the authorities in the United States, but his visit generated a great deal of support from other quarters, especially from NGOs and academics specializing on US-Japan relations.

The housing complex went ahead in the name of the US-Japan Security Treaty and what the national government claimed as the national interest, despite 
grassroots opposition and a slim band of overseas support. Yet, not only did opposition considerably slow the project and its completion, it also served as a lesson for the national government and the US authorities that the acquiescence of local residents in Japan should not be taken for granted. Here, the citizens of Zushi indicated that they would no longer silently accept 'orders from above' and would struggle to protect their local ecological interests, even if these conflicted with the housing complex that the national government tied to the US-Japan Security Treaty as an inviolable national interest. Like the Okinawa opposition movement, the Zushi movement shows that SNGs can make it difficult for the national government to presumptuously impose its policy priorities on seemingly vulnerable localities, in the name of the Security Treaty, national defence and the national interest, when these trample upon the priorities and the well-being of local residents.

To conclude this section, the case studies considered here make it clear that the US-Japan security relationship is indeed a site of continued tensions between the national and subnational governments. The cases examined demonstrate how SNGs are becoming linked inextricably in the politics of such vital national concerns as peace and war, nuclear-weapons policy, and Japan's relations with its most valued security partner, the United States. These matters have enormous implications for Japan's foreign policy, particularly national-security policy, and for how and by whom these national policies are implemented and decided. Here SNGs are articulating the dissenting voices of the people, triggering public debate and questioning the national government on highly sensitive national-security matters. As throughout this chapter, we see that the SNGs are pursuing local interests that have a quite different, lower priority for both the national government and other SNGs in different geo-strategic, economic and political circumstances elsewhere in Japan.

\section{Territorial issues}

Another area involving hard diplomacy is territorial disputes, which like the previous sections in this chapter concern not just national sovereignty but also national security. Japan has disputes with a few of its neighbouring nations in relation to territorial claims. The issue of sovereignty over the Senkaku Islands or Diaoyutai (Chinese term) flares from time to time between China and Japan, leading to claims and counterclaims by both parties. ${ }^{73}$ Similarly, Japan and South Korea have a long-standing dispute over a group of strategically insignificant islands, the Takeshima (in Japanese) or Tokdo (in Korean). These disputes have sporadically become sites of nationalistic fervour and have led to occasional grandstanding at the political level, but neither has reached anywhere near the point of a breakdown in the national-government relationships between Tokyo and Beijing or Tokyo and Seoul.

The ongoing dispute between Japan and Russia over the island territories north of Hokkaido is, however, a quite different concern - with much greater political and diplomatic import and deep-seated tension. Both national governments have remained instransigent in their claims to sovereignty. Because of this, Japan and Russia have yet to sign a peace treaty for a war that ended in 1945 and official 
relations are still rather frosty even with the end of the Cold War in the early 1990s. Sixty years after Russia (then as lynchpin in the Soviet Union) took control of the disputed territory at the end of the Second World War, little progress has been made in resolving this dispute as both national governments hold on to national pride and the desire to control this strategic patch between northern Hokkaido and southern Sakhalin. The Japanese refer to it as Hoppō ryōdo (the Northern Territories).

The territory under dispute comprises four islands: Etorofu, Kunashiri, Shikotan and the Habomai islets. These are currently held by Russia but Japan lays claim to them on historical and legal grounds. ${ }^{74}$ Despite the rigid attitude of the Japanese and Russian national leaderships to the territorial issue, SNGs in both countries have shown a much more flexible stance. Some have forged multifaceted relationships in the face of powerful resistance at the national level, as we have seen in earlier chapters concerning SNGs' cooperation and economic programmes. In this discussion of Japanese SNGs' views and responses on the territorial dispute, we therefore bring to light an important but usually unrecognized aspect: some SNGs very much desire resolution and are trying actively to achieve it. Their localities have a strong interest in resolving national-level tensions.

These SNGs are working to develop an underlay of economic interdependence, personal linkages and strong goodwill believing that this will prepare the way for a better bilateral relationship at the national levels of government and eventually for signing a peace treaty between the two nations. Some prefectures and cities have actively sought cultural and economic ties with Russia for some time and even during the Cold War. Our discussion here will focus on Hokkaido Prefecture and SNGs within it. This prefecture is geographically closest to the four disputed islands and naturally has a vested interest in good neighbourly relations with the RFE that is its neighbour just above the disputed islands.

Hokkaido, like Okinawa, has worked actively on hard-core diplomatic issues. Hokkaido's diplomatic activities are more systematic, persistent and structured than those of other prefectures. ${ }^{75}$ Its SNGs from prefectural to village level firmly believe that through subnational activism they can help to create an environment that will eventually lead the two nations to sign a peace treaty. The Hokkaido Prefectural Government and other municipalities have played a crucial role in ensuring that the long-standing territorial dispute between Japan and the former Soviet Union/now Russia did not get out of hand even during the heightened tensions of the Cold War years. They forged cultural and economic ties even during the Soviet period, as discussed in earlier chapters.

The Foreign Ministry has opposed Hokkaido's activism when the Ministry has perceived it to be out of sync with the national government's approach. In Chapter 5 we considered a classic example of hard diplomacy by all players when the Foreign Ministry barred Hokkaido Prefecture from establishing a prefectural office in Sakhalin in the early 1990s. Nevertheless, skilful diplomatic manoeuvring by the Prefecture SNG enabled it to establish as good an office, not contravene the Ministry's directives and pave the way for the central government to open a consular office in Sakhalin's capital city Yuzhno-Sakhalinsk, and subsequently open the Prefecture's own official office in that city. 
Hokkaido's strategic importance was heightened considerably during the Cold War, as part of a northern frontier for the Western alliance. Sakhalin and the Kuril Islands served as crucial strategic points for the Soviet Union in defence against US-led forces in East Asia. Hokkaido was therefore a key location for protecting Japanese territory from possible Soviet invasion, for both Japan and the United States. Sakhalin and Hokkaido were both heavily militarized. Japan deployed some 40 per cent of its SDF facilities to Hokkaido to defend Japan against possible attack from the north. Even in such an environment of military hostility, some Hokkaido SNGs made diplomatic initiatives towards neighbours to the north and conducted low-key cultural and economic programmes at the SNG level despite Cold War tensions.

The end of the Cold War and dismantling of the Soviet Union has brought little progress towards settlement of the territorial dispute while both sides play 'the waiting game'. ${ }^{76}$ The Japanese government maintains its uncompromising policy of 'no territorial settlement, no economic cooperation', although in the late 1990s, 'new thinking' appeared to have emerged within the Foreign Ministry to not always link politics with economics. ${ }^{77}$ SNGs on both sides unequivocally support their national governments' claims to the territories, but this has not stopped SNGs on either side from pursuing their local interests in the more relaxed post-Cold War environment. Some SNGs have demonstrated great pragmatism in their capacity to facilitate resolution of the dispute through various mutually beneficial cooperative arrangements. They see tension at the national level as compulsion for them to work as bridge builders till such tensions are resolved. ${ }^{78}$ In this capacity, they are certainly functioning at least as surrogate diplomats in a sensitive area of hard diplomacy.

In 2000, the governors of Sakhalin and Hokkaido signed agreements on economic cooperation, environmental protection and disaster prevention measures as well as ways to improve regional relations. ${ }^{79}$ Sakhalin's Governor Farkhutdinov has proposed a plan under which Russians and Japanese could both live in the disputed islands under joint management and Russian sovereignty. Governors on both sides see that the territories need foreign investment for development, which has been a spur to the SNGs' cooperative programmes. Hokkaido Governor Yokomichi Takahiro (1987-95) and his successor Hori Tatsuya (1995-2003) $)^{80}$ took practical steps to develop regional cooperation and contacts for settlement of the territorial issue. Although the Foreign Ministry discouraged economic interaction with the islands, Governors Yokomichi and Hori upheld the view that regional interaction would serve as a foundation for successful settlement of the territorial dispute. ${ }^{81}$

Dialogue '92 was an important diplomatic initiative of Governor Yokomichi. He pursued the dialogue eagerly not just to meet the principal aim of holding serious discussion on the territorial issue, but also to make the point to the Japanese government that a prefectural leader was capable of organizing such a serious dialogue. ${ }^{82}$ Sakhalin responded positively to the initiative since with the Cold War over, the RFE and other regions in the Russian Republic had just entered a new era of regionalism where they could act independently of Moscow in pursuit of regional interests. ${ }^{83}$ Yet the Japanese Foreign Ministry was less willing to hand over responsibility to an SNG. The Ministry frowned upon Hokkaido's independent action and deputed a high-ranking official to the meeting 
to keep the Ministry informed of developments. It was the first time that residents of the two regions met to discuss the Northern Territories problem at an open forum, and drew praise as an unprecedented, epoch-making event, where local governments discussed a territorial problem involving state sovereignty. ${ }^{84}$

The implementation of visa-free visits in the early 1990s was another landmark development in which SNG leaders played a crucial role. Successive Hokkaido governors conducted a major campaign to make it possible for the former residents of the disputed territories who now live in Hokkaido to visit their ancestral land. The visa-free visits arrangement was announced at a meeting between Prime Minister Kaifu Toshiki and President Mikhail Gorbachev in April 1991 and in October the foreign ministers of the two nations signed an agreement on the scheme. ${ }^{85}$ Under this programme, Hokkaido and Sakhalin accepted exchanges involving current residents of the disputed islands and former residents of the islands who now reside in Japan. This arrangement was based on Yokomichi's conviction about the benefits of regional cooperation and person-to-person connections to build mutual understanding and trust and eventually to achieve a territorial settlement. ${ }^{86}$

Okuyama argues that successive governors in Hokkaido have pursued regional linkages in the hope that these will produce political leverage for them to help settle the territorial dispute. ${ }^{87}$ Certainly, pressures from both the local community and the Hokkaido regional administration to develop regional cooperation helped to nudge the central government to modify its principles, replacing its policy of tying together politics and economics with a strategy of 'expanded equilibrium' and a multi-dimensional approach in the 1990s. ${ }^{88}$ Since the mid-1990s, the Japanese government has given financial support to some large development projects such as Sakhalin II and has backed Russia's entry into the Asia-Pacific regional forum, APEC.

But SNG leaders have been able to pursue an alternative approach to this knotty diplomatic issue only because they had strong local support for their position. Local perception of the issue in Hokkaido generally differs from the national government stance. Polling of Hokkaido residents taken in the mid-1990s found very few residents supported the national government's position that politics and economics must be linked and more than 70 per cent favoured economic cooperation even without a political solution of the dispute. They see that promoting regional economic assistance, creating effective communication networks and interchange of personnel between the two regions will help towards resolving the territorial dispute. ${ }^{89}$ Yet, viewpoints vary depending on local and personal interests. For example, fishers in Nemuro, which is adjacent to the disputed islands and the frontline in the Northern Territories Return Movement, generally favour return of only two of the four islands (presumably Habomai and Shikotan) as once agreed in the 1950s, since this could be achieved more quickly than holding out for all four and would give them access to the islands' rich fishing grounds. Some Hokkaido residents claimed they are not concerned if sovereignty over the islands is not ever returned to Japan. ${ }^{90}$

Both the central government and Hokkaido Prefecture SNG have an interest in halting the spread of such ideas and maintaining national unity on the claim to 
all four islands. ${ }^{91}$ Hokkaido Prefecture SNG has always upheld the national government's position affirming Japan's full claim on the territories, if not the best way to secure their return even while some in Hokkaido accept a more relaxed position on sovereignty. The prefectural SNG has tried to promote regional cooperation and to create an environment conducive to a peace treaty, since the SNG sees these to be in the prefecture's economic and diplomatic interests. But it has never deviated from the national government's position on return of sovereignty. Importantly for Hokkaido, if the islands are returned to Japanese sovereignty, Hokkaido will be the administering SNG, replacing Sakhalin which currently holds administrative jurisdiction. This factor may also inspire the Hokkaido Prefecture SNG's careful diplomacy on the disputed territory issue.

\section{Other political and diplomatic issues}

Let us turn to consider the contributions of individual SNG leaders to the hard diplomacy of their SNGs. This provides another set of insights into how SNGs become involved in hard diplomacy, in this context through the distinctive personal styles of their individual leaders.

Governor Ishihara Shintarō of Tokyo is notorious for his inflammatory remarks about other countries and their citizens. Before his election as governor of the largest, most powerful SNG in the country, he gained an international reputation for his fiery publication, The Japan that Can Say No. Here, he added fuel to an already heated debate on US-Japan relations through his techno-nationalist position that Japan can simply ignore the United States, or say 'no'. ${ }^{92}$ As governor of Tokyo, he has continued the outbursts criticizing some of Japan's most important regional neighbours, particularly China. He claimed publicly that in times of major disasters, very serious riots could occur involving sangokujin (literally 'third-nation residents' but usually understood as a derogatory reference to Chinese and Koreans). While in Taiwan in May 2000 to mark the inauguration of President Chen Shui-bian, he remarked that 'Jiang Zemin should not annex Taiwan by force, because such an action could make him be perceived as the Hitler of China. ${ }^{93} \mathrm{~A}$ year later, in an attention-grabbing interview with Business Week, he claimed China is the world's only remaining empire. ${ }^{94} \mathrm{He}$ again criticized China's attitude towards Taiwan and its positioning of nuclear weapons at India. And to raise the hackles at home he spoke of China's irredentist position on Okinawa, claiming that one day China might claim ownership on historical grounds. He welcomed US President George W. Bush's election in 2000 since Bush would be tougher on China than his predecessor. He perceives a new kind of cold war played out between the United States and China, with danger that Japan might be caught in the crossfire.

The media and the public now expect Ishihara's polemical words to pack a heavy political punch. He was formerly an influential LDP politician who served as minister in the national government, and now as governor of the nation's most powerful SNG he has huge influence nationwide and beyond. Today, Ishihara is renowned for his diatribes, which some observers see as a political strategy to 
gain popular support. In terms of what this says about his capacity for hard diplomacy, since he speaks as Tokyo governor his words are seen internationally as carrying some political and electoral weight. He does, after all, have fairly strong support in SNG elections. Some may also perceive that because of his experience in national politics and his present place, virtually at the apogee of the local-level administrations, Ishihara sometimes voices what other politicians, particularly in the national government, feel that they cannot voice. To whatever extent he truly represents the interests of constituents who elect him to office, Ishihara certainly delivers some of the hardest diplomacy of any politician in the country and sometimes, because of external perception that his views reflect those of his country, he creates hard diplomacy for the national government.

While representing Japan's most populous SNG, Ishihara has projected a negative image of Japan's powerful and crucial neighbour China. Other leaders, however, have worked tirelessly through SNGs to improve relations with Japan's neighbouring nations. One is Governor Katayama of Japan's least populous prefecture, Tottori. This governor talks of substance over form and focuses on real links between people - software rather than empty hardware. Katayama has taken initiatives to opening 'pipelines' to North Korea through visiting in an unofficial capacity. In August 2002, he sought to open a regular sea route to Tottori, moving beyond intermittent vessels carrying to Tottori their cargos of crab. Katayama has even criticized what he sees is the Foreign Ministry's rushed approach to 'normalization' of relations with North Korea, which he claims is out of sync with public opinion. He believes educating the Japanese public about North Korea is the first step towards building a better relationship; the bilateral relationship should not be normalized until the Japanese community has some understanding of North Korea and no longer fears its unidentified vessels and Taepodong missiles. ${ }^{95}$ Although favouring improvement of relations with North Korea, he is also emphatic that the North Korean government must inform the citizenry of its actions (including abduction of Japanese citizens and so forth). ${ }^{96}$

SNGs have showed resilience and are not necessarily swayed by swings of national mood due to international developments. When relations between Japan and the Soviet Union cooled after the Soviet invasion of Afghanistan in December 1979 and the Russian downing of a civilian aircraft in the Republic of Korea in 1983, the Russia-Japan Governors meetings were suspended. But Niigata City authorities were resilient in the face of national-government resistance and did not suspend the Coastal Mayors meetings, which continued as before. As Ichioka observed, 'Niigata's view was that national diplomacy and local diplomacy have different interests in international affairs' ${ }^{97}$ More recently, at the time of the Iraq War, many SNGs passed a resolution against Japan's endorsement of the US-led coalition's invasion of Iraq, which was not backed by a UN resolution. By late February 2003, at least 112 local assemblies had passed resolutions against the US-led invasion of Iraq and favoured a peaceful resolution via the United Nations. These included the nine prefectures of Hokkaido, Fukushima, Kyoto, Osaka, Hyogo, Kagawa, Tokushima, Fukuoka and Oita and the five designated cities (seirei shitei toshi) of Sapporo, Yokohama, Kawasaki, Osaka and Kobe. ${ }^{98}$ 


\section{Conclusion}

The preceding discussion challenges conventional wisdom that the hard-core diplomatic issues of war, peace, territorial conflict, security and defence are exclusive jurisdictions of Japan's national government. Many Japanese SNGs have pursued some of these issues and are becoming more active than ever in these pursuits. Some actions by SNGs such as non-nuclear declarations may mostly have symbolic value, but even on this matter Kobe demonstrated a much more instrumental outcome in banning US nuclear-bearing warships. Other pursuits such as promoting peace internationally through advocacy and networking may also not influence the course of Japanese policy. But some actions such as those taken by Okinawa and Hokkaido at Japan's far south and far north have impacted upon national policy, just as national policy has impacted deleteriously - upon these prefectures. They pursue their interests passionately while national-security policy impinges deeply on the lives of their local citizens. With the end of the Cold War and easing of conventional security issues, both Hokkaido and Okinawa are inclined to take an independent position on issues of security and national territory. Nevertheless, they are by no means the only SNGs to resist the national government's position on matters of hard diplomacy. A number of other SNGs, as discussed throughout this chapter, have pursued some locally contentious issues with full political force, and in some cases were successful in forcing national policy to accommodate subnational concerns.

What do we learn from this discussion of hard diplomacy in relation to this book's two central strands: the impact on the national-subnational relationship and implications for the management of Japan's foreign relations?

First, despite sharing views on certain policy matters, the national government and the SNGs pursue different lines of action as the policy priorities determined by national and subnational governments diverge. Both levels of government, for example, hold similar views on controversial diplomatic issues of the Northern Territories and North Korea. But some SNGs because of their proximity to the disputed areas and in pursuit of local economic and politico-strategic benefits, pursue different strategies with the aim of securing friendly and interdependent relations at the subnational level despite tensions at the national level. The examples of Tottori, Niigata and Hokkaido in relation to North Korea and the RFE clearly illustrate this point. The national government does not easily allow SNGs to take action where it perceives this action to work against national policy. And where SNGs do not conform with the central government's perception of the national interest, the central bodies generally achieve compliance through advice and negotiation. Where this fails, legal, constitutional, juridical and political tools are put to work. We have seen this in Hokkaido's proposal to open an office in Sakhalin, Kobe's declaration requiring no-nuclear certificates, Kochi's attempts to follow the 'Kobe model' and Okinawa's refusal to renew land leases for US bases.

As discussed, SNGs do not acquiesce easily to the central government. They cannot contravene national laws or the constitution, but some have demonstrated their creative capacity to find other routes to satisfy their local interests through areas where they have regulatory capacity, such as ports and streets. Hokkaido was able to 
open an office in Sakhalin via an alternative arrangement to the one the national government prohibited. Some SNGs have even challenged the national government on legal grounds such as Okinawa contending against the national government in the Supreme Court. Some SNGs have appealed directly to the people and policymakers overseas to garner support for their cause, as did both Okinawa and Zushi appealing to US authorities and opinion-makers. Neither was completely successful in achieving their desired results, but both were able to influence the course of Japanese national policy to accommodate local priorities: the crucial issues of housing facilities for US military personnel in Zushi and stationing of US troops throughout Okinawa. Most noteworthy is that in both cases the policy-making process concerned US bases, which are a central plank in Japan's national security arrangement with the United States. This is a fiercely protected domain of the national government and yet SNGs were able to break both new policy ground and old boundaries on exclusive bureaucratic turf. Here the need for nationwide sharing of the burden of national defence - and US bases are popularly recognized across Japan as a burden on any local community - was brought into the policy arena and the need for compensation was used for political leverage over the central government.

Some SNGs do more in their international reach than self-interestedly pursue local concerns. Some have also tried to pursue humanitarian concerns by promoting peace and disarmament through advocacy and international networking. The Mayors for Peace movement and Hiroshima's role in it are noteworthy. These movements have help to act as a counter force to some national-government policy preferences, particularly through criticizing the actions of Japan's most important ally, the United States. Their actions usually have not brought immediate results and must always accommodate political pressures from multiple sources, but they nevertheless act as a partial restraint on unbridled national-government policy action.

Nation states are still the main actors in issues that involve national sovereignty. Here, particularly when the national government sees that national security is brought into contention, this level of government stands firm; pluralism is not on this agenda. Nevertheless, international and domestic circumstances push or pull other actors such as SNGs into the complex web of strategic issues concerned with security, war and peace. The cases we have examined through this chapter reveal that national governments can no longer simply ignore the views of SNGs on these matters. Now SNGs put their viewpoints into action that compels the national government to respond. Security for the Japanese people no longer fits the national government's conventional definition of 'national security' and responsibility to spread the burdens of achieving this national security has been forced further to register in the channels where national-policy decisions are made. SNGs as the level of government working in closest contact with the people they represent have brought the voice of the people from villages, towns, cities and regions across Japan to register in national policy. SNGs have come some way in meeting with the national government's hard diplomacy to accommodate the preferences of the people nationwide who all levels of government are elected to represent. 


\section{Conclusion}

Early in the twenty-first century, Japanese SNGs are clearly becoming significant actors in the international arena. In the last two decades, they have developed wide-ranging policies and spent millions of dollars annually within and outside Japan, pursuing international activities very similar to those taken up earlier by counterparts in the West. In Asia, Japan's SNGs have rapidly become the pioneers of such international activism. This is despite their relatively late start and has occurred without fanfare or acknowledgement of their evolving role as vital players in Japan's international affairs. As Arase notes astutely:

In their development visions Japanese subnational authorities in the postwar period viewed their relationship with Tokyo as central and the international dimension as peripheral. Today, however, almost without exception these actors locate themselves in a global setting with their proximity to foreign neighbours a point of emphasis. ${ }^{1}$

SNGs' reach into international affairs is not surprising as much of 'the local' is now internationally conditioned. Forces driven by technological revolution, the globalization of capital and markets and the ending of the Cold War have triggered a reconfiguration of the international arena and the nature of Japan's political economy within it. These factors have enmeshed national and local policies and therefore also all levels of government, across international as well as national concerns. Yet, the new conditions have also created new areas of competition and further unhinged the alignment of interests and priorities between and within the players each side of the national-subnational divide. We therefore see a new arrangement of alliances, cleavages, flexibilities and possibilities between and within players in the subnational and national levels. We also observe more complex interdependence between levels of government as SNGs are drawn further into more strategically entangled international roles. Many Japanese SNGs have become diplomatic entities because of their international pursuits and in spite of the will of some of the central bureaucracies.

The rise of SNGs as significant international actors has profound implications for Japanese politics. Two of the most important have been addressed throughout this book: (1) national-subnational relations; and (2) the management of Japan's 
international affairs. In this brief conclusion, we draw together the findings from each chapter to make overall observations on both domains. We then consider the implications of both for the capacity of SNGs to operate as local administrators. We close by considering what conclusions can be drawn about the overall role of Japan's SNGs as international actors and future prospects arising from recent developments in this arena.

\section{Subnational-national government relations}

Some studies of domestic policies have concluded that the Japanese state is more complex than the term 'centralized' connotes. SNGs have more autonomy from the central government than is generally understood, but both the degree and the exercise of autonomy are diverse, depending on such factors as the SNGs' location, political leadership and resources available. ${ }^{2}$ This observation is also true of the SNGs' actions in international affairs. The structure of Japan's unitary system of government has shaped but not determined the international roles that SNGs develop and indeed by now we can also speak of a reverse flow of influence: the international roles of Japanese SNGs surely do not determine the structure of Japan's system of government but they have reached a stage where they surely do influence the power relationships exercised within this unitary system, as demonstrated throughout the book.

We have seen here the various ways in which SNGs have pursued international action to increase their financial and policy autonomy from the national government, which in a limited way makes them more independent political entities. Conversely, the national government has needed to call on the SNGs and incorporate their international activities within foreign policy to meet the multiplepolicy demands that the national level is unable to address but that which the SNGs can perform efficiently. The Foreign Ministry has decentralized some foreign-policy areas, such as ODA delivery and cultural relations, so that SNGs have some responsibility for their international actions. But institutional arrangements have also been established to enable the central government authorities in Tokyo to guide, coordinate and supervise much of this action. This is consistent with the ethos of the central government that national sovereignty and national security are the last bastions of 'foreign affairs' and thus central to its bureaucratic prerogative.

Clearly, the evolution of SNGs as international actors has induced a more complex, interdependent relationship between the national and subnational levels. It coincides with and in some ways precipitates new competitive forces that realign the domestic and international interests of players on both sides and compel new and more flexible alliances across a range of parties inside Japan and beyond. Neither national nor subnational levels are monolithic - in their disposition, their interests, or their ways of pursuing their interests. Some incompatibility arises from the different priorities that each government body pursues to best meet the perceived needs of their constituency. It produces conflict even on matters of hard-core diplomacy such as management of the US-Japan security treaty. Although this treaty is the lynchpin of Japan's security policy, some SNGs have 
tenaciously resisted the national government in its management of some aspects of the treaty such as in Okinawa.

Yet the expansion of SNGs' international roles and the parallel pluralization of foreign policy mean that there are also more areas for cooperation between both levels of government and with other actors that have both international and domestic interests. Sometimes SNGs work in partnership with the central government or with guidance and advice from it. Some SNGs work collectively in regional and micro-regional groups, particularly for pursuing economic aims. Some have also demonstrated a surprising degree of independence in their international pursuits and some pursue careful strategic planning that functions as local foreign policy without government guidance or support. National and subnational governments appear to share interests most strongly in the SNGs' international economic pursuits, but the motivations of both sides differ somewhat. The national government keenly supports these economic pursuits with an eye on resuscitating the national economy. SNGs are eager not just for local economic benefit but also for the partial liberation from the national government that their economic self-sustenance brings.

It is difficult to identify the type, extent and value of the political leverage that SNGs gain from their international engagements and the manner in which they use this leverage in domestic and international political life. SNGs derive from their international involvements some combination of financial and policy independence, valuable international connections experience and confidence in their capacity to act independently of the national level and collectively with other SNGs within and outside Japan. All of these enhance the political cachet that SNGs use in their overall politicking with the central government. Valuable diplomatic cachet is likely to derive from SNGs' successful pursuit of the international relationships that the central government cannot and will not pursue at all. These relationships provide the national government with a viable and legitimate alternative to its own incapacity and provide the SNG with expectation of a later reward.

\section{Management of Japan's international affairs}

SNG involvement in international affairs is one of many indications that international diplomacy is no longer the sole preserve of the national government in Japan as elsewhere. The transformation of the nation-state system has forced the Japanese government to incorporate the contributions of subnational and non-state actors within the nation's international diplomacy. Particularly from the mid-1990s, the Foreign Ministry has followed a path of cautiously pluralizing Japan's foreignpolicy actors because the Ministry and other central government bodies could not effectively meet what the foreign-policy slogan cast as 'Japan's international contributions'. These 'contributions', ranging from foreign aid and other forms of international cooperation, to assistance with international disasters, crime and peacekeeping, reached well beyond the Foreign Ministry's capacity to deal with them. Perhaps to reinforce its own dominance as the pre-eminent government player in international affairs, the Ministry recognizes SNGs not as actors from 
another level of government but as private-sector bodies. This helps reinforce the authority that the Ministry struggles to preserve around its position of final responsibility for the nation's international affairs.

The pluralized lineup of international actors now includes NGOs, corporations and other private bodies and citizens, alongside national and subnationalgovernment bodies. To a limited extent, and in some policy areas such as foreignaid delivery and international-cooperation programmes, the Foreign Ministry has ceded some responsibility to the SNGs. Yet, it has maintained its hand firmly on the helm of foreign-policy overall, with advice, coordination and support. As we have also seen with Okinawa, Hokkaido and other SNGs along the Japan Sea, the Ministry can also deploy constitutional, legal and political tools to coerce compliance with its vision of the nation's foreign policy if it deems this necessary.

SNGs have gained experience and confidence in their capacity for international engagement. They are becoming increasingly strategic in their approach and more carefully assessing challenges and possible rewards on the basis of both their own experiences and the precedents of their counterparts. They have demonstrated in a relatively short time that the SNGs can make valuable and needed contributions to Japan's foreign policy. Throughout this book we have seen that SNGs are sometimes able to do what the Foreign Ministry is demonstrably incapable or unwilling to do precisely because it is the Foreign Ministry. Clearly SNGs have the capacity to supplement the business of formal foreign affairs.

\section{SNGs as local administrators}

Overall, it is clear that SNGs' pursuit of international opportunities has been beneficial for their local and regional constituents. Economic relations have yielded economic benefits and in a few cases revitalization for some localities, particularly in rural areas suffering economic downturn in response to forced market liberalization. Similarly, SNG involvement in sister city and other cultural programmes has generated cultural and other benefits, and international-cooperation programmes have yielded an array of economic, socio-cultural and strategic rewards for local communities.

We can also suggest that for a number of reasons international experience strengthens the capacity of SNGs to deliver effective and efficient local administration. Here, I offer five of the most significant reasons. First is the stronger financial capacity and consequent political autonomy that international engagement brings to localities. Second is the policy and administrative expertise specific to local conditions, which the SNGs can learn through engagement with counterparts abroad. Third are the socio-cultural linkages that can enrich local communities, such as through the JET programme that brings a regular flow of young people from countries across the world to support language and international programmes in local communities and strengthens opportunities for forging connections with the sending country. Fourth is the experience that the SNGs gain from working with people from other cultures, an important concern when we realise that with internationalization growing numbers of foreigners are living 
within Japanese communities. Fifth and perhaps delivering the most important set of benefits, the SNGs secure various advantages for their locality by proactively shaping the course of their locality's international relations rather than simply living with the consequences of national government action.

Most SNGs work much more closely with the people they are elected to represent than do the national-government actors. This is a distinctive feature for the SNGs as international actors for two reasons in particular. First, it means that the SNGs have the experience and skills of working at grassroots level that enables them to perform similar tasks in overseas destinations as part of internationalcooperation programmes and they have precisely the expertise that the Foreign Ministry and other central actors need to effectively implement parts of the national ODA programme. Second, proximity to constituents means that SNGs serve as a vent or channel for people at grassroots level to register their views, especially dissent, with the seemingly impenetrable Foreign Ministry and Defence Agency. The discussion through Chapter 6 highlights some SNGs' resistance to national-government strategic policies and directives on international matters such as upholding nuclear prohibitions, stationing US troops in parts of the nation (particularly Okinawa) that are vulnerable to central government fiat and developing relations with neighbours such as in the RFE that the national government frowns upon. Here we observe the will of some SNGs to stand up for aggrieved citizens locally and in some instances to use their political clout astutely as bargaining tools for political or economic compensation. We may expect this style of popular politicking through the SNGs against the central government's international actions to become more salient, as SNGs strengthen their skills in international diplomacy and the citizens they represent become more vocal. Strong expressions of public dissent at Japan's contributions to the recent Iraq war indicate both the political efficacy of SNGs conveying constituents' voices to the national government and the capacity of SNGs to act as a restraint on politically wilful but publicly opposed national policy. ${ }^{3}$

Overall, then, international engagements help SNGs to become more effective administrations and to directly or indirectly deliver a range of benefits for individual localities or regions. Some SNGs remain focused more narrowly on domestic affairs with little interest in international pursuits. It is thus likely that there may be a widening gap in performance between the SNGs that pursue rewarding international relationships and the SNGs that close their localities to the possible rich rewards of international engagement through their inexperience, inertia or simply their preferred political style.

\section{The role of SNGs as international actors}

Overall, we have strong reasons to assess the international role of SNGs as very favourable for Japan's international diplomacy. For five decades, some SNGs have taken pioneering roles, generally unnoticed, in international policy. But what began as fairly benign international cultural exchanges for a handful of SNGs, is today a significant international role for many SNGs, one that places 
them as indispensable actors in the conduct of Japanese international affairs. SNGs have made important contributions to gaps in Japan's international diplomacy - particularly through contributions to cultural diplomacy whereas foreign policy focussed on the national economy through the 1970s and 1980s and through aid diplomacy and other areas from the 1990s as the national government needed to incorporate the contributions of SNGs to meet Japan's 'international contributions'. The mutual flows of people and goodwill that have stemmed from many of the international engagements of SNGs can never be evaluated, but we may reasonably conclude that they are diplomatically invaluable.

Some of the value of SNGs' roles as international actors lies in the capacities and expertise that SNGs possess and the national government does not. The national level lacks the expertise, experience, local contacts and grassroots administrative capacity that many SNGs have. And SNGs are not weighted with the national diplomatic status and consequent need for diplomatic formality that the national level on some rare occasions needs to disengage from, in attempting to manage sensitive international relations most effectively.

Their ambiguous status as neither national government nor non-government has at times enabled SNGs to pursue relationships with foreign counterparts where the national government bodies are inhibited by bilateral sensitivities. Here the SNGs' roles have been enabling for the Foreign Ministry. As we see in the examples of SNGs in Hokkaido, Tottori and elsewhere dealing with the RFE and North Korea, the national government can use the SNGs to further its own purposes in forging stronger economic linkages at subnational level while the national level appears to remain true to its articulated policy that precisely prohibits such moves. This is a valuable if unrecognized role that some SNGs play as surrogates for the Foreign Ministry, while the latter appears 'policy pure'.

Yet, we must also mention some noteworthy limitations on SNGs as international actors. First, their geographic reach is limited, with focus generally on those parts of the world with which Japan has closest connections. Not surprisingly, today we see a concentration of activity in Northeast Asia, particularly in China, the rising power virtually on Japan's doorstep. Second, the capacity of SNGs to adopt international roles is also limited. A locality's size, resources, location, political leadership and constituent support naturally help to determine what an SNG can undertake and achieve through international engagement. So too can the capacity of the SNG to creatively use its regulatory space, as we saw with Kobe closing its ports to US navy ships carrying prohibited nuclear cargos and Yokohama's decision to close its streets to US army vehicles. A third factor concerns the current trend of amalgamating SNGs in line with the nationalgovernment ethos that 'bigger is better'. ${ }^{4}$ The folding down of some SNGs may end their relationships that were formalized through sister and other types of bilateral or multilateral linkages. A fourth limitation is financial, arising from stagnation in SNGs' income from taxes. Budgetary decline is likely to force SNGs to reduce expenditure on cultural and symbolic programmes. Both the amalgamations and the budgetary decline create new imperatives that will force SNGs to adopt a more strategic approach to the types of international 


\section{Conclusion}

engagements they pursue and with which international actors they pursue these programmes.

Future roles of SNGs as international actors are naturally contingent on national circumstances and developments in the global political economy. Of particular importance here is the state of the Northeast Asian region. Japan is located in very close proximity to the world's rising power China, the volatile Korean Peninsula and the RFE to the north. Here the SNGs can make significant contributions to regional stability. International economic relationships pursued by SNGs are already beginning to sow the seeds of economic interdependence between the countries of Northeast Asia. This interdependence is likely to become not just a fertile underlay, but also the compulsion to maintain close bilateral and multilateral relationships between national governments across East and Northeast Asia.

Present trends suggest it is very unlikely that SNGs will wind down their international programmes since they gain significant economic benefits, autonomy, connections and to some extent opportunity for domestic political leverage through successful international linkages. Indeed, the rewards accruing from specific types of international engagements suggest that in time we are likely to see a more focussed strategic approach by the SNGs in their newly amalgamated forms. In all likelihood they will continue to make valuable contributions to Japan's international affairs and become even more influential in foreign policy. 


\section{Notes}

\section{Introduction}

1 SNGs are the governing bodies elected as the administrative units at all levels of administration below the national level, for villages, towns, cities, prefectures and so forth. Instead of the term 'local government' that is used commonly in academic writings on Japan, I use the generic term 'subnational government'. The former term is potentially confusing since in federal systems it refers to administrative units below, but not including, states or provinces. Japanese prefectures, which are the equivalent of those units in Japan's unitary political system, are part of 'local government'. 'Subnational' is therefore more precise in discussion of the Japanese case. This term 'subnational government' is also used widely in the comparative literature. Japanese SNGs include all government bodies below the national government: 47 prefectures (to, $d \bar{o}, f u, k e n), 13$ designated cities (shirei shitei toshi) and all other municipal bodies from large to small cities, towns and villages. Basic structures of Japan's SNGs are presented in Chapter 2. See, for example, Reilly, 2000; Gray, 1994.

2 See, for example, Steiner et al. (eds), 1980.

3 MacDougall, 1975, pp. 416-89; Watanabe, 1988; Abe and Shindō, 1997, pp. 201-13. By 1998 more than 40 per cent of SNGs had endorsed the voting rights of permanent foreign residents in Japan, see Morris-Suzuki, 2002, p. 173.

4 Shuman, 1994.

5 These observers have paralleled Japan's experience of opening to international forces in the late twentieth century with the nation's experience of being 'forced to open' first by Western powers in the 1850s after two centuries of internally enforced international isolation and a second time after defeat in the Second World War in 1945. See Helweg, 2000.

6 Jain and Mizukami, 1996.

7 Kitayama has examined several cases of industrial and economic policies of SNGs that were established in response to the centre's shortcomings to serve local interests rather than aligning themselves with what the central government identifies as the national interest. Kitayama, 1995, especially pp. 379-94.

8 On 'horizontal linkages', see Samuels, 1983.

9 A recent book in English edited by one of Japan's pre-eminent scholars of local government Muramatsu, with Iqbal and Kume (2001) does not even mention this development. This is all the more remarkable as eight of the book's 11 contributors are Japansee scholars specializing in local government issues. Similarly books in English on Japan's international relations do not mention Japan's local governments as actors in international affairs. See, for example, Hook et al., 2001.

10 See, for example, Matsushita (ed.), 1988; Yabuno, 1995; Jain and Mizukami, 1996.

11 See, for example, the account by the former chief of Niigata City's international office, Ichioka, 2000; Kanagawa Ken, 1995; Hosokawa and Iwakuni, 1991; Hiramatsu, 1990; also see CLAIR publications such as its monthly Jichitai Kokusaika Fuoramu. 


\section{Notes}

12 Published works in English include David Arase, 2000; Jain, 1991a; Jain, 2000a in Inoguchi and Jain (eds); Rozman, 1999; Hook, 1999 in Yamamoto (ed.); Akaha, 2003.

13 In a recent article on international initiatives, for example, Beauregard and Pierre offer a critique of the various international activities pursued by European and North American SNGs, but no mention is made of Japan, the world's second largest economy whose SNGs have been involved in international activities, especially since the late 1980s. Beauregard and Pierre, 2000.

14 Shuman, 1994, presents comparative research in this area. In Japanese, see Ebashi and Tomino (eds), 2001.

15 See, for example, a special issue of the Foreign Ministry's quarterly journal Gaikō Fuoramu 127: 3, March 1999, titled 'Tayōkasuru Nihon gaikō no akutaatachi' (Diversifying Japan's diplomatic actors: the role of the private sector).

16 This view was expressed to me frequently in my interviews with people in those positions during my fieldwork for this study, 2001-04.

17 Keohane and Nye (eds), 1972.

18 Miyagi Prefecture, for example, boasts of its cities being active in international relations since 1615 when the Keicho Diplomatic Mission had an audience with the King of Spain and the Pope. <www.pref.miyagi.jp/kokusai/E/e-index.html> (accessed 16 November 2003).

19 Steiner, 1965.

20 For an extended discussion of this issue see MacDougall, 1975; Jain, 1989.

21 The ministry responsible for SNGs is now the Ministry of Public Management, Home Affairs, Posts and Telecommunications (Sōmushō). Until reorganization of Japan's ministries and agencies in January 2001, the Ministry of Home Affairs (Jichishō) was an independent ministry in charge of local governments. For the sake of consistency we use the old name MOHA as most policy developments under discussion took place before the new structure was put in place. For developments after 2001, we refer to the new structure as Sōmushō Home Affairs (SHA).

22 Kanagawa Ken, 1995. Also, see Nagasu and Sakamoto, 1986.

23 For example, note the difference in titles of these two publications, one in the late 1980s and the other in the early 1990s Chihō Jichi Seisaku Kenkyūkai (ed.), 1988; Kokusai Kyōryoku Jigyō Shūdan and Kokusai Kyōryoku Sōgō Kenshūjo (eds), 1991. Also, see Taga, 2002.

24 Some of the books and other works in Japanese published in the 1990s use gaiko (diplomacy) in their titles. Abe and Shindō, 1997, the 'Jichitai gaikō' chapter, pp. 189-99; Hagai and Ōtsu (eds), 1994; Ichioka, 2000; Menju, 1998b, pp. 204-18; Menju, 2002, pp. 3-14; Nihon Toshi Sentaa (ed.), 1995.

\section{Contexts: conceptual, comparative and Japanese}

1 Rosenau's 1990 work where he analyses a range of actors including what he calls 'subgroups' is notable, especially pp. 132-35.

2 Here we must acknowledge the differences in ideas even among realists. I highlight some of the key components of their arguments rather than going into specific details.

3 For different types of realist explanations, see contributions in Smith et al. (eds), 1981, pp. $25-115$.

4 Many of these and other global challenges are discussed in Cusimano, 2000.

5 Nicholson, 1998, p. 98.

6 Keohane and Nye, 1981, p. 122.

7 Rosenau, 1980, p. 4. Although Rosenau did not identify as 'sub-units of government' the subnational levels of government that are to greater or lesser extents also responsible to their national level, in his 1990 book he notes subnational governments as one of the sub-groups, albeit only in a passing manner.

8 Mathews, 1997, pp. 50, 65-66. 
9 Camilleri and Falk, 1992, p. 253.

10 Camilleri and Falk, 1992, p. 256.

11 Strange, 1996, p. 82.

12 Willetts, 1997, p. 293.

13 Willetts, 1997, p. 287.

14 Horsmann and Marshall, 1995, pp. x-xi.

15 Horsmann and Marshall, 1995, p. xi.

16 Nicholson, 1998, pp. 105-06.

17 Nicholson, 1998, pp. 30-44.

18 Clough, 1994 and 1998.

19 The Yamamoto and Funabashi (1995) volume, for example, considers the private sector, NGOs, other non-profit organizations and other civilian groups, but not noncentral government actors. See also Higgott et al. (eds), 2000 and Arts et al. (eds), 2001.

20 Breslin and Hook, 2002, p. 8.

21 Price, 2003, p. 580.

22 Most of these studies are in books, though some have appeared in influential US foreign-policy journals such as Foreign Affairs, Orbis and Foreign Policy. See, for example, Clough, 1994; Hatcher, 1996; Shuman, 1986-87; and Newhouse, 1997.

23 Hocking, 1993.

24 Aldecoa, 1999.

25 Duchacek et al., 1988.

26 Aldecoa and Keating (eds), 1999.

27 Duchacek, 1984.

28 Duchacek, 1984; Duchacek et al., 1988.

29 Hocking, 1993.

30 Kincaid, 1993, p. 27.

31 Hocking, 1993, p. 1.

32 Pursiainen, 2003, p. 89.

33 Fry, 1998, p. 4.

34 Mathews, 1997, p. 62.

35 Fry, 1998, pp. 77-78.

36 Newhouse, 1997, pp. 67-84.

37 Fry, 1998, pp. 79-81.

38 Newhouse, 1997, pp. 67-84.

39 Breslin and Hook (eds), 2002; Chen and Kwan (eds), 1997; Perkmann and Sum, 2002; Gilbert Rozman has analysed micro- or sub-regionalism from a critical perspective, in Rozman, 1999.

40 Zheng, 1994, p. 315.

41 Cheung and Tang, 2001, p. 112.

42 Zheng, 1994, pp. 309-21.

43 Cheung and Tang, 2001, p. 117.

44 Sridharan, 2003.

45 The 1993 Constitution recognizes 89 'regions' below the Federation or the 'Centre'. These regions consist of 21 republics, plus 49 regions (oblasts), 6 provinces (krais), the 2 cities of Moscow and St Petersburg, 1 autonomous region and 10 autonomous districts (okrugs). See Nicholson, 1999, p. 14.

46 Pursiainen, 2003, p. 87.

47 Sergounin, 2003, p. 108.

48 Fry, 1998, p. 92.

49 For discussion of SNGs' political resistance on international matters including the comprehensive nuclear test ban, nuclear free zone, divestment, sanctuary for refugees and other political and diplomatic issues, see Hobbs, 1994, pp. 108-21.

50 Shuman, 1994, pp. 1-2. 


\section{Notes}

51 Fry, 1998, pp. 92-93.

52 Guay, 2000, pp. 353, 355.

53 Fry, 1998, pp. 90-93; Shuman, 1994, pp. 4-5.

54 Shuman, 1994, pp. 4, 32.

55 Shuman, 1994, pp. 41-43.

56 Cheung and Tang, 2001, pp. 105-06.

57 Sridharan, 2003, p. 472.

58 Spiro, 1988, pp. 193, 195.

59 Fry, 1998, p. 99.

60 Guay, 2000, p. 376.

61 Fry, 1998, p. 97.

62 Shuman, 1994, pp. 26-27.

63 Shuman, 1994, p. 27.

64 Schep et al., 1995, pp. 12-13.

65 Cremer and Dupuis, 2001, p. 2.

66 O'Toole, 2001.

67 Spiro, 1988, p. 193.

68 Fry, 1998, p. 90.

69 For details, see <www.cities-localgovernments.org > (accessed 23 March 2004).

70 Shuman, 1994, p. 4.

71 Local Government Declaration to the World Summit on Sustainable Development $<$ www.igib.gov.uk/policy/LGdeclarationFinal.pdf $>$

$72<$ www.eurocities.org/news.asp?id=12> (accessed 13 March 2003).

73 Church and Reid 2002, pp. 207-08.

74 Keating and Hooghe, 1996, pp. 222, 226.

75 Interview with Professor Mike Geddes of the Local Government Centre at the University of Warwick, 7 May 2004.

76 Cheung and Tang, 2001, p. 104; Freeman 2002.

77 Segal, 1994, p. 345.

78 Sridharan, 2003, p. 477.

79 Shuman, 1986-87.

80 Alger, 1981, p. 175.

81 Bryant, 1975; Ogata, 1977.

82 Furukawa and Menju (eds), 2003. Also see Yamamoto and Funabashi, 1995.

83 See various essays in Gaikō Fuoramu, No. 127, March 1999, pp. 6-61.

84 Tanaka, 2000, 3-17.

85 Mekata, 2000; Hirata, 2002; Jain, 2000a and 2002; Yamamoto and Funabashi, 1995.

86 Inoguchi, 1993, p. 100.

87 For example, see Koppel and Orr, 1993, p. 348.

88 One of the leading critics of Japan's ODA policy is Sumi, 1989.

89 Rix, 1993; Hirata, 1998.

90 See a recent essay on Japan's soft power by Nye, 2004b.

91 Hirata explains the rise of NGOs in Japan in the context of domestic crises of the 1990s including the recessed economy, political corruption and bureaucratic scandals. See Hirata, 2002.

92 For details, see Jain, 2000b.

93 Abe and Shindō, 1997, p. 198.

94 Abe and Shindō, 1997, p. 198.

95 Hobbs, 1994, p. 5.

\section{Japanese SNGs as international actors: domestic dimensions}

1 For example, Steiner, 1965; Muramatsu et al. (eds), 2001.

2 Ide, 1972, p. 3. 
3 In an interview I conducted (9 April 2002) in the Hokkaido Prefectural office, in discussing Hokkaido's role in the Russian Far East, one official asserted emphatically that Hokkaido Prefecture is a 'chiho seifu'. On the prefecture's website <www.pref. hokkaido.jp $>$ the Japanese version does not use the term seifu, although the English translation of Hokkaido-do is translated as Hokkaido Prefectural Government.

4 For details, see Council of Local Authorities for International Relations, 2002, pp. 41-44.

5 For example, initiation and management of the APEC process in the 1980s and 1990s saw huge rivalry between the MOFA and MITI while both claimed a monopoly on this initiative. MOFA saw APEC as primarily a diplomatic issue; MITI regarded it as an international economic issue. See Funabashi, 1995.

6 Interview in the Ministry of Foreign Affairs, Economic Cooperation Bureau, 26 April 2002.

7 A 2001 survey showed that over one-fourth of governors were former high-ranking Home Affairs officials. The same survey showed that more than half of the governors came from the national bureaucracy. See Kabashima, 2001, p. 17.

8 Muramatsu and Iqbal, 2001, p. 6.

9 Nihon Toshi Sentaa (ed.) 1995, p. 70. See also <www.mofa.go.jp/policy/other/ bluebook/2001/chap2-5-b.html> (accessed 16 December 2003).

10 Ministry of Foreign Affairs, Diplomatic Bluebook 1987, pp. 196-97.

11 Takahashi, 1998, p. 94.

12 The Japan Center for Local Autonomy now focuses on domestic issues. It still has an international section but its role is primarily to publish the magazine Local Government Review that contains English translations of articles published in Japanese. The Centre's website is in Japanese with very little information: <www.hichi-sogo.jp > JAMLIF has been incorporated within CLAIR, discussed later in this chapter.

13 McConnell, 2000.

14 Council of Local Authorities for International Relations, 2002, pp. 53-56.

15 See, for example, Muramatsu, 1988.

16 Steiner et al. (eds), 1980; Jain, 1989; MacDougall, 2001, pp. 40-42.

17 Abe and Shindō, 1997, ch. 12. A number of policy initiatives taken by SNGs are listed in Kitayama, 2001.

18 On the leadership role of the new breed of local chief executives, see Jain, 2004a.

19 The origins of JICA and its early role are well covered in Rix, 1980, pp. 49-80.

20 As an independent administrative institution, JICA must produce its own plans to achieve the medium-term objectives presented by the Foreign Ministry. In principle, JICA is to operate autonomously and be responsible for the management of its own projects and affairs. <www.jica.go.jp/english/activities/schemes/12par.html> (accessed 8 April 2004).

21 Rix, 1980, pp. 49-80.

22 Interview with Mr Asano of the JICA Hyogo Center, 25 February 2002.

23 Interview, JICA Sapporo office, 10 April 2002.

24 Interview with Sumita Kiyoshi, Head of the International Section of Sapporo City Office, Sapporo, 9 April 2002.

$25<w w w . j i c a . g o . j p . e n g l i s h /$ about/newjica.html> (accessed 11 April 2004).

$26<$ www.jica.go.jp.english/about/newjica.html> (accessed 11 April 2004).

27 Interview with Professor Ebashi Takashi of Hosei University, 25 February 2002.

28 Chiba, 2003.

29 Chiba, 2003.

30 For example, see a report on the 2002 US-Japan Local Autonomy Forum organized by the CLAIR and JETRO New York centres. <www.jlgc.org/jlgcnewes/045/ 01 autonomy.html > (accessed 18 April 2004).

31 JBIC was created as a government-run financial institution in October 1999 through the merger of the Export-Import Bank of Japan (JEXIM) and the Overseas Economic Cooperation Fund (OECF). 


\section{Notes}

32 Sawaji, 2000, p. 29.

33 Japan Bank for International Cooperation, 2002a. Also, interviews (various dates) with Yoshida Hitoshi of ERINA who has served in various capacities in developing ideas for a greater role for SNGs in ODA.

$34<$ <ww.jbic.go.jp/autocontents/english/news/2002/000007/> (accessed 15 April 2004).

35 Interview with a group of officials in CLAIR office in Tokyo, April 2002.

$36<$ http://www.clair.or.jp/e/clairinfo/clair.html > (accessed 7 June 2004).

37 There were some 46 countries represented in the 2003 JET programme. Of 6,179 participants in 2003, 4,352 or more than two-thirds came from three English-speaking countries: the United States, United Kingdom and Australia. China and Korea were the two main suppliers in Asia with 80 and 71 participants respectively. Council of Local Authorities for International Relations, 2003b, p. 7.

38 Although it might sound misleading as 'intercultural' is not 'international' (kokusai), the English title as mentioned above is the official name of the Academy.

39 Information on JIAM is from my interview with JIAM director Tabe Yoshihiro at JIAM premises in Otsu on 15 November 2001 and 28 January 2002 and from a booklet prepared by JIAM: Zenkoku Shichōson Shinkō Kyōkai, 2001.

$40<$ www.jiam.jp/outline/e-main.htm> (accessed 20 April 2004).

41 McConnell, 2000, pp. 32-33.

42 Listed in Nihon Toshi Sentaa (ed.), 1995, p. 71.

43 The number of personnel taking overseas assignments more than doubled in the period 1983-91, according to one survey and this was attributed to the establishment of the new law. See Nihon Toshi Sentaa (ed.), 1995, p. 73.

44 Ebashi, 1988, p. 181.

45 Ebashi, 1991, p. 47.

46 MOFA's total budget in 2001 was 746.6 billion yen. Of this, 538.9 billion yen was allocated for ODA. It should be noted that many other ministries in Japan have allocations for ODA in their annual budgets. www.mofa.go.jp/mofaj/gaiko/yosan/15/index.html (accessed 4 April 2003).

47 'International cooperation' is the label given by MOHA to specific international activities that include nationally and locally funded overseas aid and assistance (enjo), a form of non-central foreign aid such as intake and dispatch of trainees and programmes involving one or more SNGs for international problem solving and so forth. I discuss these in Chapter 4.

48 Official foreign aid is usually called 'ODA', an acronym for 'Official Development Assistance'. This is the generic term for the international economic cooperation provided by national governments to developing nations. Japanese ODA is given in the form of grants (donations), technical assistance and loans and is primarily sourced from community taxes and postal savings, the National Pension, and postal savings (national investments and loans). Japan's ODA budget in 2002 was 910.6 billion yen, which was about one quarter of the global ODA budget that year.

49 Figures were made available to me by SHA officials during my interviews with them in Tokyo in May 2004.

50 Nihon Toshi Sentaa (ed.), 1995, p. 71.

51 Inoki, 2001, pp. 132-53.

52 Author's interview with Sumita Kiyoshi in Sapporo, 9 April 2002.

53 Interview with three officials of the CLAIR office in Seoul, 18 September 2003. Yoshida Hitoshi, who has done extensive research on Japanese and Chinese SNGs, confirmed in personal discussion with me that this pattern holds for the CLAIR Beijing office.

54 Most CIRs are from the United States, United Kingdom, Australia, China and Korea. Of the 536 CIRs in 2003, 253 came from the above three English-speaking countries and 66 from China and 57 from Korea. Council of Local Authorities for International Relations, 2003b, p. 7. 
55 Interview with Mr Kusumoto Toshio, Director General of the International Department of Kobe City, 2 December 2002.

56 I make this observation on the basis of my numerous interviews between 2001 and 2004 with personnel in prefectural and city SNGs that I mention here, and three extended interviews in January 2002 with personnel from a number of small and medium-sized SNGs who were participating in a training programme at the Japan Intercultural Academy of Municipalities in Otsu in Shiga Prefecture.

57 Japan Times Weekly, 22-28 April 1991; also see a paper written by Ichioka Masao, then head of the International Affairs Section of Niigata City Office, 1991, pp. 132-36.

58 Foreign Press Center, 1997.

59 Japan Foundation Center for Global Partnership, 1997, p. 11.

60 Japan Foundation Center for Global Partnership, 1997, pp. 11-14.

61 See, for example, Ide, 1972.

62 The long-serving leftist governor of Kyoto, Ninagawa Torazō (1950-78), held a doctorate in economics and before formally entering elected political life was both full professor and Chair of the Economics Faculty at Kyoto University, one of the nation's most highly regarded universities. See Krauss, 1980, in Steiner et al. (eds) especially pp. 393-95. The other progressive star of the 1960s and 1970s was the governor of Tokyo, Minobe Ryōkichi (1967-79) who was a great icon of Marxist intellectual tradition in his time. See Jain, 1989, pp. 190-94.

63 Matsushita (ed.), 1988; Nagasu and Sakamoto (eds), 1986.

64 See essays in Jichirō Jichiken Chūō Suishin Iinkai, 1995.

65 A collection of essays by some of these scholars appeared in Kokusai Kyōryoku Jigyō Shūdan and Kokusai Kyōryoku Sōgō Kenshūjo (eds), 1991.

66 Yoshida Hitoshi, 'Hokutō Ajia de kokumin sanka no gaikō' (People-based diplomacy in Northeast Asia), in the influential Ronsō column of Asahi Shinbun, 2 December 1999; also in English as 'Input from people will benefit diplomacy', Asahi Evening News, 10 December 1999; Menju Toshihiro, 'Kokusai kyōryoku hirogeru chiiki no chikara' (Localities in international cooperation), in the influential Ronten column of Yomiuri Shinbun, 25 May 2001; Akio Terumasa, 'ODA yosan o jichitai kan kyōryoku ni (ODA budget for inter-municipal cooperation), in the influential Ronsō column of Asahi Shinbun, 10 November 2000.

67 Utsunomiya of Hyogo Prefecture is a former MOFA official (1967-84) who resigned from his position in the national government to work for an SNG to promote internationalization from the grassroots level. Personal correspondence with Mr Utsunomiya, December 2001. Also in his unpublished paper, 'Local contributions to international society', available from its author.

68 Tanaka, 1986, p. 228.

69 Tanaka, 1986, p. 235.

70 Tanaka, 1986, pp. 227-39.

71 Kanagawa Ken, 1995; Ebashi and Tomino, 2001.

\section{International exchanges: SNGs lead with a soft approach}

1 As discussed in the Introduction to this book, this terminology is now used alongside other terms such as 'kokusai kyöryoku' or 'international cooperation' to refer to the mixed line-up of SNG involvements in international affairs.

2 Eminent International Relations scholar Joseph Nye describes international cultural programmes as a soft approach to international relations. He uses the concept of 'soft power' exercised partly through international cultural programmes to explain one source of power in relationships between nation states, but I believe this concept is also useful in understanding relationships that SNGs develop through international cultural programmes. His latest work is Nye, 2004a. 
3 In 1987 the Takeshita administration announced cultural diplomacy as one of three pillars of Japan's foreign policy (with foreign aid and international peace keeping). For examination of developments in Japan's cultural diplomacy see Todhunter, 1990.

4 Japanese terminology reflects the origin of the programme; Japan's first sister-city relationship, between Nagasaki and St Paul in Minnesota, was the result of a US initiative.

5 Yoshida notes that for the Chinese side, the term 'shimai toshi' connotes a relationship between senior and junior (shimai means literally older and younger sisters). The Chinese side prefers the term $y \bar{u} k \bar{o}$ (friendship) which is gender neutral and conveys a relationship between equals. In his work, Yoshida uses the term ' $y \bar{u} k \bar{o}$ shimai toshi' (friendly sister cities), 2001, p. 58, note 8.

6 Cremer and Dupuis, 2001, p. 2.

7 O'Toole, 2001, p. 403.

8 Sister Cities International <www.seabrook-tx.com/html/body_sister_city_main. html $>$ (accessed 8 November 2003).

9 Matsuo, 2000, pp. 12-13.

10 Jansen, 2000, pp. 63-95. As Jansen described, 'The famous decrees that closed the country were more of a bamboo blind than they were a Berlin wall', since restrictions imposed on the West did not fully rule out relations with Asia, p. 64.

11 Ichioka, 2000, pp. 129-45.

12 Arase, 2002, p. 186.

13 Yoshida, 2001, p. 31.

14 Menju, 2003, p. 106.

15 Governor Nagasu Kazuji of Kanagawa Prefecture made the term popular when he was elected in 1975. See Nagasu, 1986, pp. 3-16.

16 It is noteworthy here how local chief executives hold similar views even though they might come from opposite sides of politics. For example, the language of progressive Governor Nagasu of Kanagawa in the 1970s and reformist Governor Katayama of Tottori in 2003 about people's participation in diplomacy is very similar. See Nagasu, 1986, p. 8; Katayama and Kenmotsu, 2003, p. 156.

17 See a cross-section of essays in Komai and Watado (eds), 1997.

18 For example, a number of localities in China, the United States, the Philippines, Malaysia and Indonesia adopted the 'one village, one product' movement made popular in Japan in the 1980s by now retired governor of Oita, Hiramatsu Morihiko. We should note that the 'one village, one product' movement reached well beyond sister relationships and was adjusted to local conditions. Oita's sister city Wuhan in China adopted 'one village, one treasure'. Both Shanghai in China and Louisiana in the United States are not linked formally to Oita through sister relationships but adapted the Oita example to form their own 'one factory, one product' and 'one parish, one product' movements respectively. See One Village, One Product 21, The Oita Prefecture One Village, One Product 21 Promotion Council (undated, but likely year of publication is 2000 as it records events up to 1999).

19 Unless otherwise indicated, all data on these sister-city affiliations are from The Council of Local Authorities for International Relations, 2003a. To be included in CLAIR's sister-city directory, the following requirements are essential: (1) there must be a signed agreement between the two parties; (2) the agreement must not be limited to one specific area of exchange; and (3) the local assembly must have endorsed the agreement, which may require budgetary allocations, p. 3.

20 These are Iwate, Fukushima, Ishikawa, Nara, Ehime, Saga, Oita and Miyazaki.

21 Details of many successful projects are available in Sugai, 1989.

22 As of April 2004, there were some 3100 municipalities (shichōson) - but this number is likely to be reduced by more than half by the end of 2005, given the central government proceeds with mergers in response to the twin forces of declining population in regional areas and greater demands on services due to an ageing population. See 'New trends in local government', Asia-Pacific Perspectives: Japan+, June 2004, pp. 18-19. 
23 CLAIR data do not include the many arrangements that Japanese SNGs make with counterparts overseas not formalized in an officially recognized partnership. Some relationships are transformed into formal agreements, others continue informally. These data also do not include agreements and projects between private and nongovernment organizations within the two localities that result because of the existing strong ties between their SNGs. Sometimes rotary clubs, universities and NGOs form informal links with counterparts in localities where their SNGs have established sistercity ties and the two volumes produced by the Japan Foundation Center for Global Partnership are rich with examples. Twinning of ports, gardens, messe (convention centres) etc. is also common. See, for example, Japan Foundation Center for Global Partnership, 1994 and 1997 and Foreign Press Centre, 1997; Chiba Prefecture's links listed in the Foreign Press Center publication on pp. 121-22 give the overall flavour of these relationships.

24 Menju, 1998a, p. 17.

25 The Japan Foundation carried out an extensive survey in the early 1990s on Japan's regional internationalization and US-related exchange activities. See Japan Foundation Center for Global Partnership 1994 and 1997. Statistical data in CLAIR's annual directory reveal geographical shifts over time. See CLAIR, Japanese Local Government International Affiliation Directory, various issues.

26 Of 33 sister ties with Russian counterparts below prefectural level, 17 are with SNGs in Hokkaido. Niigata City linked formally with Khabarovsk in 1965 and Hyogo prefecture and the Khabarovsk region signed a formal agreement in 1969. Otaru City and Asahikawa City in Hokkaido formed ties with Nakhodka and Yuzhno-Sakhalinsk in 1966 and 1967 respectively. For the full list see Council of Local Authorities for International Relations, 2003a, pp. 58-59.

27 For discussion of Japanese using sister partnerships to pursue peaceful international relations see Kitahayashi, 1986, pp. 59-74.

28 Council of Local Authorities for International Relations, 1995, pp. 15-18.

29 Hosokawa and Iwakuni, 1991, pp. 210-14.

30 Shuman, 1994, p. 98. On Canada's sister cities as an example, see Parker and Kershaw, 1995.

31 In many of my interviews between 2000 and 2003 in organizations such as CLAIR in Tokyo and its overseas branches in Australia, South Korea and Singapore, officials reminded me constantly that it is not their brief to facilitate business and commercial links. They did, however, concur with my observation that many state governments and local councils, such as in China, Australia and Canada are interested in pursuing commercial opportunities via their sister-city links with Japanese SNGs and the Japanese partners now appreciate those expectations and the potential opportunities they create.

32 Shuman cites several cases of American and European cities forming ties with their counterparts in the Soviet Union and other communist countries, in Shuman, 1994, pp. 49-52.

33 Parts of the arguments presented here are drawn from my 2004b article published in Global Change, Peace \& Security.

34 Although the preferred term for China is 'friendship' we will use the term 'sister' to maintain consistency.

35 Council of Local Authorities for International Relations, 2003a, p. 109.

36 Both Menju Toshihiro and Yoshida Hitoshi, who have conducted numerous surveys on Japanese SNGs and various facets of their international programmes, have emphasized political, historical and cultural motivations in their conversations and correspondence with me.

37 Council of Local Authorities for International Relations, 2003a, p. 2.

38 The combined budget of SNGs on sister-city programmes in 1998 was 8.7 billion yen, which was decreased to 7.9 billion in 1999 and 7.04 billion yen in 2000. Jichitai Kokusaika Kyōkai, 2002, section 4, pp. 10-11. 
39 Jichitai Kokusaika Kyōkai, 2002, see graphs in section 4, pp. 10-11.

40 Nihon Toshi Sentaa (ed.), 1995, p. 28.

41 For details of Nagasaki's contacts with China from the 1950s, see Nihon Toshi Sentaa (ed.), 1995, pp. 10-31.

$42<$ www.pref.nagasaki.jp/kokusai/2-2e.html> (accessed 30 September 2003).

43 Japan Foundation Center for Global Partnership, 1997, p. 8.

44 Summary of Records of the Canada-Japan Twinning Forum, May 11-12, 1998 'Sister city relationships and beyond: rethinking Canada-Japan people to people relations in the 21 st century', <www.cic.sfu.ca/Japanese/Twinning\%20Lectures/ twinningTOC.html $>$ (accessed 11 August 2003).

45 O'Toole, 2000; also see O'Toole, 2001.

46 Council of Local Authorities for International Relations, 1995, p. 21.

47 Author's interview with the visiting official in Adelaide, 14 March 2002.

48 Interviews, CLAIR Sydney officials on various occasions.

49 Two key recent works in English on the Japan-Soviet Union/Russia relationship at the subnational level are Akaha, 2003, pp. 89-122 and Williams, 2003. Another recent work that analyses the difference in approaches at national and local levels to the question of the Northern Territories is Okuyama, 2003, pp. 37-53.

50 Niigata City has also played a very important role in building bridges with the Russian Far East. See Ichioka, 2000, pp. 169-84.

51 Akaha, 2003, pp. 102-03.

52 This point was made strongly by Professor Kanbara Masaru of Hokkaido University in a meeting with the author in April 2002.

53 Steiner, 1980, p. 323.

54 Williams, 2003, p. 181.

55 Williams, 2003, pp. 168, 169, footnote 22.

56 Williams, 2003, pp. 170, 184.

57 Jain, 1991a, p. 35.

58 The central government recognizes the importance of trade with North Korea for Sakaiminato. In mid-2004 while considering various types of sanctions against North Korea, the Japanese government considered shutting Japanese ports to North Korean ferries including the Man Gyong Bong-92 that ferries passengers and cargo to Niigata from Wonsan. A group of parliamentarians visited Sakaiminato to assess the impact that this might have on the local community. Forty per cent (409 of 1007 ports calls) of North Korean ships docked in Sakaiminato in 2003. Fishing industry representatives urged the visiting parliamentarians to consider the impact of economic sanctions on those in their industry. Daily Yomiuri, 13 June 2004.

59 Central approval is essential in North Korea since Korean SNGs have virtually no independence from the central government. When Tottori Governor Katayama visited North Korea in July 2002, he indicated to senior officials in Pyongyang his preference for a formalized tie between Tottori Prefecture and North Hamgyong Province. The North Korean side indicated its preference for a linkage with Kangwon Province since Wonsan City that is affiliated with Sakaiminato is in Kangwon Province. See <www.pref.tottori.jp/kouhou/kaiken-e/020805.htm> (accessed 15 June 2004).

60 Local assembly member Shitanishi's grandfather had a timber business with North Korea through the port of Wonsan; his father was an assembly member who pushed the idea of closer relations with North Korea, and the third generation Shitanishi often heads delegations to North Korea, even reassuring his interlocutors in Pyongyang that Japan has no intention of starting a war with North Korea. Information from undated materials published in Chügoku Shinbun provided by Professor Tsujiyama Takanobu of the Japan Research Institute for Local Government in Tokyo, 10 May 2004.

61 Ōtsu, 1994, pp. 42-43.

62 Interview with Mr Yoshida Hitoshi of ERINA in Niigata, 14 May 2004. 
63 Interview in Tokyo with a retired senior diplomat (who preferred to remain anonymous) who served as Japanese ambassador to three countries, 10 May 2004.

64 Katayama and Kenmotsu, 2003, p. 157.

65 Katayama and Kenmotsu, 2003, p. 159.

66 Katayama and Kenmotsu, 2003, p. 158. For example, early in the twenty-first century when nuclear, missile and abduction issues have severely strained the relationship between Japan and North Korea, Tottori has continued its relations with North Korea, particularly through Wonsan.

67 For a comprehensive study of the JET programme, see McConnell, 2000.

68 Council of Local Authorities for International Relations, 2003b. Details are also available on the JET programme website $<$ www.jetprogram.org $>$

69 Jain, 1991a, p. 35; McConnell, 2000, p. 3.

70 For example, McConnell's (2000) book analyses the programme from a top-down perspective.

71 Council of Local Authorities for International Relations, $2003 \mathrm{~b}$.

72 Arase, 2002, pp. 184-85.

73 McConnell, 2000, p. 234.

74 McConnell, 2000, p. 258. Also see a special issue of Japanese Studies, 12:1, May 1992, with discussion of successes and challenges of the JET programme as told by early participants in the programme.

75 Details of the Association are available through its website $<$ www.jetalumni.org $>$

\section{International cooperation: a strategic edge}

1 Daily Yomiuri, 11 January 2002.

2 Nishikawa, 1995.

3 Schep et al., 1995.

4 Although there is no comprehensive database, one researcher specializing in this aspect of SNGs has observed that SNGs' international cooperation projects in the 1990s were heavily concentrated in Asia, with 41 per cent of all projects in China. See Yoshida, 2003, pp. 174-75.

5 For example, one instructive report is The 1998 Ministry of Foreign Affairs Final Report on ODA Reform for the 21st Century <www.mofa.go.jp/policy/oda/reform/ report21.html $>$ (accessed 24 March 2003).

6 See, for example, Nihon Kokusai Kōryū Sentaa (eds), 1988.

7 The author's various interviews with SNG officials in Japan during the course of this project.

8 On local ODA see, for example, Jichirō Jichiken Chūō Suishin Iinkai (ed.), 1995; Yoshida, 2001.

9 ODA is a responsibility of national governments. It is based on the guidelines of the Development Assistance Committee (DAC) within the Organization for Economic Cooperation and Development (OECD), and these guidelines make no mention of subnational actors. Nevertheless, SNGs and NGOs in various countries are becoming increasingly active in this policy area.

10 For example, since Russia is not eligible to receive ODA, some SNGs, particularly in Hokkaido and on the Japan Sea Rim, invite Russian trainees under the SNGs' own training programmes.

11 For example, Sendai City in Miyagi Prefecture receives trainees through JICA, through prefectural trainee programmes, and through its sister-city programme established in 1980 with Changchun in Jilin Province. See Satō, 1991, p. 92.

12 Nagasaki Prefecture, for example, has worked closely with Japan Silver Volunteers, Inc. (JSV) since 1996, sending volunteers from Nagasaki to teach at the Shipbuilding Industry Group Corporation in Fujian and at a potassium-chlorate factory in Dalian, among other programmes. See Nishimura, 2000a, pp. 38-39. 


\section{Notes}

13 Nishimura, 2000b, pp. 38-39.

14 More recently its name has been changed to Kitakyushu International Training Association. Details of training programmes are available on <www.kita.or.jp/ index_e.html>

15 Abe, 1998, p. 20. Details of ICETT can be found at <www.icett.or.jp $>$

16 Serita, 2001, pp. 76-100.

17 JICA internal paper prepared for a television programme produced by the University of the Air (Hōsō Daigaku), 4 January 2002.

18 Interview, JICA, Tokyo, 10 May 2004.

19 Akio, 2002, pp. 47-51. Also <www.joho-shimane.or.jp/cc/sic/soroban > (accessed 18 December 2003).

20 Tomino, 1995, pp. 100-07.

21 Rural SNGs in Japan have adopted various 'international' instruments for reviving their economies in the face of globalization. See Knight, 1993, pp. 203-16.

22 This view was put to me in interviews with governors of Oita, Mie and Miyagi prefectures and with high-ranking officials in Hyogo, Niigata, Hokkaido and Gifu prefectures and Kobe, Niigata, Hiroshima and Sapporo cities on various occasions between 2000 and 2003. Overall, my interviews suggest it is highly likely that many other high-ranking SNG officials share this view, even if they did not say so explicitly during our interview dialogue.

23 <www.ses.usp.ac.jp/2001biwa/global/BiwaDecl2001.htm> (accessed 5 January 2002).

24 For details of these meetings see Sasaki, 1988, pp. 3-24.

25 Due to the highly volatile state of relations between Japan and North Korea, particularly in the wake of the North Korean government's admission concerning abduction of Japanese citizens in earlier decades, this process has been temporarily suspended since 2002.

26 On the Japan Sea Rim Zone, see Hook, 1999; also, see Arase, 2000.

27 A 1993 booklet issued by the Kobe International Cooperation Center (KICC) outlining Kobe's involvement in international aid programmes seems to be fairly representative of the work carried out in this area by international cooperation centres. The Foreign Affairs Ministry approved and supported establishment of the KICC. For earlier examples and discussion of the philosophies behind local international cooperation, see Eguchi, 1992, pp. 47-54. Developments in this area are covered in detail in Yoshida, 2001.

28 These countries are Canada, China, Denmark, Estonia, Japan, Korea, Mongolia, Norway, Sweden and the United States.

29 Information from the author's interview with Sapporo City officials in Sapporo on 2 July 1999.

30 Tanaka, 1986, p. 229. The Northern Regions Centre was established in 1978 as a corporate body (shadan hojin) to promote exchange among northern regions, and it is still active.

31 Menju, 1998 b, p. 209-10.

32 SNGs' involvement in technical cooperation and aid activities through their own resources is discussed in Akio, 1990, pp. 39-59.

33 Japan Bank for International Cooperation, 2002b, and personal communication with Mr Yoshida Hitoshi of ERINA.

34 For example, in 1997, MOFA provided 1.3 billion yen to SNGs from its ODA budget for bringing 694 foreign trainees, sending 29 specialists overseas, and recruiting members to serve as Japan Overseas Cooperation Volunteers (JOCV). Japan's ODA Summary 1997, <www2.nttca.com:8010/informofa/policy/oda/summary > (accessed 29 January 2002).

35 See Kaigai Kankyō Kyōryoku Sentaa, 2000; Jichitai Kokusaika Kyōkai, 2001.

36 Energy Information Administration/Japan, Japan: Environmental Report, <lfeld@eia.doe.gov> (June 1995) (accessed 11 July 2002). 
37 This was part of a 1997 agreement between prime ministers Hashimoto Ryūtarō and Li Peng supporting programmes to enhance the environment in Chinese cities. Daily Yomiuri, 6 February 2000. For details of the plans for each city see Yoshida, 2001, pp. 49-53.

38 There are many such cases and 11 key projects undertaken by SNGs from Hokkaido to Okinawa are listed in an article by the head of the policy section of the MOFA Economic Cooperation Bureau. See Horie, 1998, pp. 15-18.

39 See table 3 in Jichi Fuoramu, 461, February 1998, p. 6.

$40<$ www.clair.nippon-net.ne.jp/html_e/sien/shokuin.htm>

41 See Japan Bank for International Cooperation, 2002a, p. 24.

42 Information on these projects was made available by Yoshida Hitoshi, a senior researcher at ERINA in Niigata through correspondence in early 2004.

43 Postel-Vinay, 1996, p. 493.

44 Akaha (2003) presents many examples of cooperation between SNGs in Hokkaido and the Russian Far East, pp. 89-122.

45 Akaha, 2003, p. 102.

46 Postel-Vinay, 1996, p. 500.

47 On Niigata Prefecture's cooperation with the Russian Far East see Ichioka, 2000, especially chapters 6 and 8 .

48 Hook, 1999, p. 136.

49 For background details leading up to this association, see Ichioka, 2000, pp. 189-91.

50 Unpublished paper by Akaha and Vassilieva , made available to the author by Tsuneo Akaha.

51 Interview in CLAIR Seoul office, 18 September 2003.

$52<$ www.net.japan-korea-strait8.org/conference/conference.html> (accessed 16 September 2003).

53 Interview in CLAIR Seoul office, 18 September 2003.

$54<$ www.pref.tottori.jp/soumubu/kokusai/summit.htm> (accessed 16 September 2003).

55 Ichioka, 2002, p. 64.

56 See $<$ www.norpac.or.jp $>$

57 This meeting has been suspended in recent years due to political sensitivities concerning the unresolved issue of the North Korean regime's abduction of Japanese citizens. Interview with CLAIR official in the CLAIR office Seoul, 18 September 2003.

58 Asahi Network <www.asahi.com/english/asianet/report/eng_2001_08.html> (accessed 24 March 2003).

59 One province and one city of North Korea were admitted to the Association in 2003. For the most current membership list, see <www.pref.toyama.jp/sections/1716/ kannihonkai/near/near.html > (accessed 5 April 2003).

$60<$ www.pref.toyama.jp/sections/1716/kannihonka/near/near.html $>$ (accessed 5 April 2003).

61 For text of the Charter, see <www.near.khb.ru/eng/about/charter.html $>$ (accessed 21 June 2004).

62 See Kanamori (ed.), 1999. The host for the September 2004 conference was Heilongjiang Province in China.

63 In 2002, the US eclipsed the Japanese performance and forced Japan back into the number two position.

64 All books on Japan's foreign-aid policy published in the early to mid-1990s discuss only national level actors. See, for example, Rix, 1993; Arase, 1995.

65 See Uchida, 1995, p. 17.

$66<$ www5.cao.go.jp/e-e/doc/e1997bg11.html> (accessed 25 March 2003).

67 Interview with Imazu Takeshi, Managing Director, Domestic Partnership and Training Department, JICA, 17 May 2002.

68 Advice from regional directors of JICA in Sapporo, Kobe and Kitakyushu during my interviews with them at various times in 2001-02. 
69 Kokusai Kyōryoku Jigyō Shūdan and Hokkaido Kokusai Sentaa, Sapporo, 2001.

70 Tadokoro, 2003, pp. 16-17.

$71<$ www.jica.go.jp/partner/jichitai/06.html> (accessed 23 June 2004).

72 Japan Bank for International Cooperation, 2002a.

73 Nakazono, 2003.

$74<$ www.jbic.go.jp/japanese/oec/local_jbic/index.php> (accessed on 5 May 2003).

75 'Road Stations for India and China', Asia-Pacific Perspectives: Japan+, November 2004, p. 33.

76 Here 'Human Security' refers to issues such as the protection of human rights, tackling problems of refugees, environmental disruption, natural disasters and diseases. In October 2002, the Prefecture produced an Action Program Paper on this subject and a copy of the paper was provided to the author by Mr Utsunomiya Hiroshi, DirectorGeneral of Hyogo Prefecture.

77 Discussion of this model and rationale for using it appears in Final Report of the Council on ODA Reforms for the 21st Century, Tokyo: Ministry of Foreign Affairs, January 1998.

78 Ebashi and Tomino, 2001.

79 Funding for international cooperation from private sources comes via exchange associations and CLAIR, which receives money from sources such as the Japan Lottery Association.

\section{Economic diplomacy}

1 Yabuno, 1995, pp. 33-34.

2 See Nakamura, 1996.

3 See, for example, a recent article by the governor of rural Tottori Prefecture, in Katayama, 2002.

4 Hook, 2003, p. 44.

5 See Yamazaki, 1991, pp. 77-106. For comparative economic data on prefectures see Yomiuri Shinbun Kōetsubu (ed.), 2003; for regional voices see Hosokawa and Iwakuni, 1991.

6 On Kansai's political economy, see Jain, 1994.

7 Kansai Economic Federation, 1993. Also see Jain, 1995, pp. 30-31.

8 Osaka City, historically a major commercial centre, was instrumental in initiating and organizing Japan's first international trade fair in 1954. The fair was a great stimulus for developing exports from across Japan, an outcome then imperative for Japan's postwar economic recovery as a trading nation. Kitayama, 1995, p. 226.

9 Information based on promotional fliers obtained from the Osaka Prefectural office in Sydney.

10 Serita, 2001, pp. 114-16.

11 Jain, 1995.

12 For a critical review of Kobe's style of city management, see Shūkan Daiamondo Tokubetsu Shuzaihan (ed.), 2001.

13 Johnson, 1995, pp. 19-93.

14 Scalapino, 1990-91.

15 See Breslin and Hook (eds), 2002.

16 Hook, 1999, p. 128.

17 Arase, 2002, p. 183.

18 Mochizuki, 1993, p. 3. Some consider this concept to be not just economic but more comprehensive, including the idea of a peace zone, a cultural zone and so forth. Ichioka, 2000, p. 185.

19 Ichioka claims that Fukushima Masamitsu first introduced the concept in a June 1968 Koria Hyōron (Korea Review) article, and it was discussed subsequently at various forums. Ichioka, 2000, pp. 188-89.

20 Hook, 1999, 131. 
21 Ichioka, 2000, p. 185-86.

22 Hughes, 2002.

23 Arase, 2002, p. 176.

24 Arase, 2002, p. 179.

25 Arase, 2002, p. 179.

26 For details of these commercial and other activities, see Ichioka, 2000, pp. 185-204.

27 For historical details, see Ichioka, 2002, pp. 57-58.

28 Hook, 2002.

29 Arase, 2002, p. 183.

30 Ötsu, 1994, p. 47.

31 Rozman, 1999.

32 Arase, 2002, pp. 187-88.

33 Mochizuki, 1993, pp. 5-8.

34 See essays in Hagai and Ōtsu (eds), 1994.

35 Arai, 1991, pp. 52-55.

36 Its activities are detailed in its annual report published by the Northern Regions Center.

37 Akaha, 2003, p. 115.

38 Williams, 2003, p. 217.

39 Williams, 2003, p. 227; Nicholson, 1999, pp. 57-59.

40 Information and paperwork provided to me by the Hokkaido Prefectural office during interview in the Sapporo trade office 9 April 2002.

41 Williams, 2003, p. 226.

42 Williams, 2003, pp. 218-19.

43 Williams, 2003, p. 222.

44 See Chapter 3.

45 Okuyama, 2003, p. 45.

46 Akaha, 2003, p. 107.

$47<$ www.pref.hokkaido.jp/keizai/kz-bkkry/results/country/country-e.html> (accessed 5 April 2003).

48 Nihon Toshi Sentaa (ed.), 1995, pp. 167-68.

49 Hokkaido Government, Trade and Economic Exchange Division, Department of Economic Affairs, <www.pref.hokkaido.jp/keizai/kz.bkkry/results/country/ country-e.html > (accessed 5 April 2004).

50 Hokkaido Government, Trade and Economic Exchange Division, Department of Economic Affairs, <www.pref.hokkaido.jp/keizai/kz.bkkry/results/country/country-e. html $>$ (accessed 5 April 2004).

51 Williams, 2003, pp. 240-41.

52 Nihon Toshi Sentaa (ed.), 1995, p. 153; Rozman (2000) also details criminal activities in trade between the two sides on pp. 213-17.

53 Williams, 2003, pp. 228-34.

54 Williams, 2003, p. 238.

55 Akaha, 2003, p. 108.

56 Postel-Vinay, 1996, p. 490.

57 Akaha, 2003, p. 102.

58 Akaha, 2003, p. 103.

59 Yomiuri Shinbun Kōetsubu (ed.) (2003), pp. 33, 99.

60 For example, the national government has continued to refuse Okinawa's request for a visa-free entry system for Taiwanese nationals who form the bulk of international tourists in Okinawa, claiming this could give rise to a new flow of illegal migrant workers into Japan.

61 For example, in October 2002 JETRO led a mission to Okinawa comprising Tokyobased foreign companies, mostly from financial institutions such as insurance firms and banks. See JETRO, 2003, p. 10.

62 Hook, 2003, p. 48. 
63 Hook, 2003, p. 51.

$64<$ www.city.nago.okinawa.jp/kinyu/e02.html > (accessed 24 June 2004).

65 JETRO, 2003, p. 10.

66 See 'Nago', The Economist (reprinted in the Australian, 10 June 2002); Okinawa Weekly Times, 15 December 2001. Yamanaka served in many high-profile ministerial positions including as MITI minister and director general of the Okinawa Development Agency.

67 Hook, 2003, pp. 47-48.

68 The Economist (reprinted in the Australian, 10 June 2002).

69 JETRO, 2003, p. 11.

70 Hook, 2003, p. 47.

71 In March 2000, there were some 38 SNG offices within JETRO premises in various overseas destinations. See JETRO, 2000, p. 614.

72 Yoshida, 2001, p. 49.

73 Yamaguchi Prefecture closed its office in Hong Kong in March 1998 claiming various reasons that included difficulties after Hong Kong's return to China, the prefecture's tight financial situation, and recognition that information can be accessed via EXIM Bank or JETRO. Nihon Keizai Shinbun, 7 June 1999.

74 Yoshida, 1999, p. 9.

75 Nihon Keizai Shinbun, 7 June 1999.

76 Morgan, 2002.

77 Negishi, 2001.

78 Morgan, 2002.

79 Negishi, 2001. Kitagawa's leadership role is discussed in detail in Jain, 2004a, pp. 76-79.

80 These examples are discussed in Sawaji, 2004, pp. 8-11.

81 Daily Yomiuri Online, 19 June 2004.

82 Negishi, 2001.

83 Survey data of METI indicated that 87.7 per cent of FDI in Japan is concentrated in just three prefectures: Tokyo 69.7 per cent, Kanagawa (Yokohama and Kawasaki) 9.1 per cent and Osaka 8.9 per cent. Morgan, 2002.

84 Morgan, 2002.

$85<$ www.city.hiroshima.jp/shimin/kokusai/shimai/chingqing-e.html> (accessed 8 November 2003).

$86<$ www.pref.tottori.jp/kouhou/kaiken-e/020507.html> (accessed 13 November 2003).

87 Ichioka, 2000, pp.172-78.

88 Ōtsu, 1994, p. 46.

89 Okada, 2003, pp. 4-5.

90 See reports in Asia-Pacific Perspectives: Japan +, November 2003, pp. 7-21.

91 Daily Yomiuri Online, 26 June 2004.

92 'Japan Brief', Foreign Press Center, No. 227, 9 August 2002; Asahi Shinbun, 18 May 2004. Changes in some 14 different laws, including those related to the Immigration Control and Refugee Recognition Act, and the Ports and Harbour Law, were accepted to facilitate deregulation in the special zones. <www.kantei.go.jp $>$

93 JETRO Press Release 2000. Supplied by the JETRO Sydney office, 25 October 2001.

94 The case study is based on interviews with officials in the Trade Division of the Queensland Government in Australia on 1 July 2003.

\section{Hard diplomacy: SNGs and national security}

1 Various studies indicate that Japanese SNGs do not follow a uniform direction in policy matters and their policy actions depend upon a range of factors that shape each SNG including population size and economic base. See, for example, Jacobs, 2003.

2 Some high-profile local leaders have spoken out most egregiously, such as Tokyo's inimitable Governor Ishihara Shintarō, who has sporadically voiced concerns over China's 
human-rights abuses and growing defence budgets. He even refused to travel to Beijing to mark the twentieth anniversary of the sister-city relationship between the two capital cities. See Jain, 1999, p. 129.

3 Hard diplomacy is by no means typical for Japanese SNGs. Schuman's study of German SNGs found that although many were involved in matters that concerned strategic aspects of Germany's foreign policy, some municipalities were unhappy about this involvement. Shuman, 1994, p. 105.

4 Many on the Left believed that international tension and military threat could be reduced by Japan pursuing a policy of 'peace with all communist countries' (zenmen $k \bar{o} w a$ ). This thinking also prevailed in the 1950s within the leftist parties at the national level. <www.jimin.jp/jimin/english/history/02.html> (accessed 8 April 2004).

5 Minsai Gaikō 10-Nenshi Kikaku Henshū Iinkai (ed.), 1990, p. 5. According to the Yomiuri Shinbun, right after the Second World War there were 162 military facilities in the prefecture, covering a combined area of about 3600 hectares. Daily Yomiuri, 24 January 2003.

6 Minsai Gaikō 10-Nenshi Kikaku Henshū Iinkai (ed.), 1990, p. 10. This may be termed more accurately as diplomacy in opposition to the central government, rather than from the opposition, as Asukata was an elected representative. However, as a highprofile socialist leader he was also promoting his party's position in his capacity as an elected local leader.

7 Minsai Gaikō 10-Nenshi Kikaku Henshū Iinkai (ed.), 1990, p. 10.

8 See Inokura Kichi Mondai Kenkyūkai (ed.), 2001, pp. 62-63.

9 In Chapter 3, I note the Chinese government's preference for the term ' $y \bar{u} k \bar{o}$ ' to describe bilateral local-level agreements. $Y \bar{u} k \bar{o}$ is a gender-neutral term without implied hierarchy while shimai connotes a relationship between younger and older sisters.

10 The participation of South Vietnam eventuated through an invitation under a private exchange arrangement. Minsai Gaikō 10-Nenshi Kikaku Henshū Iinkai (ed.), 1990, pp. 10-11.

11 Minsai Gaikō 10-Nenshi Kikaku Henshū Iinkai (ed.), 1990, pp. 10-11.

12 Fukui, 1977, pp. 65-68.

13 Fukui, 1977, p. 67.

14 Article IX reads: 'Aspiring sincerely to an international peace based on justice and order, the Japanese people forever renounce war as a sovereign right of the nation and the threat or use of force as means of settling international disputes. In order to accomplish the aim of the preceding paragraph, land, sea, and air forces, as well as other war potential, will never be maintained. The right of belligerency of the state will not be recognized.'

15 Ikeo, 1997, p. 105.

16 Kamimura, 2001, p. 22.

17 Ikeo, 1997, p. 106.

18 Yoshida, 1985, p. 5.

19 Yoshida, 1985, p. 3.

20 Abe and Shindō, 1997, p. 195.

21 Kajimoto, undated; Niigata Nippō of 28 February 2003 reported that in early 2003, more than two thirds of Japanese cities have such a declaration in place.

22 Yoshida, 1985, p. 6.

23 Abe and Shindō, 1997, p. 195.

24 Kamimura, 2001, p. 22.

25 NGOs have played a limited role in Japan's foreign policy, but in some instances they have been able to persuade the national leadership to respond to their demands such as with Japan's ratifying of a global treaty banning antipersonnel landmines in the late 1990s. See Jain, 2000a, pp. 28-29. On NGO's role in Japan's aid policy, see Hirata, 2002.

$26<$ www.pcf.city.hiroshima.jp/mayors/english/outlines/index.html $>$ (accessed 9 July 2004).

27 Times of India, 15 October 2003. 
28 Kyodo News Service, 'Two mayors call nuclear arms inhumane', Japan Times Weekly (International), 20-26 November 1995.

29 Subcritical refers to nuclear reaction in which the chain reaction is not self-sustaining. Cf. a supercritical reaction in which the chain reaction is self-sustaining.

30 Daily Yomiuri, 15 December 2001.

31 Kyodo News on the web, 6 and 9 August 2004.

$32<$ www.pcf.city.hiroshima.jp/mayors/jp/activites/01/1.html> (accessed 9 July 2004).

33 Kamimura, 2001, p. 23.

34 Abe and Shindō, 1997, p. 195.

35 Hook et al., 2001, p. 143.

36 Kajimoto, undated.

37 By the early 2000s such documentation was submitted for 17 of 18 foreign warships that called on Kobe since 1975. A Canadian ship in 1998 did not submit a declaration and Kobe officials allowed the ship to dock only after the Foreign Ministry confirmed that Canadian ships do not carry nuclear weapons. Since the Canadian docking in 1998, no military ships have visited Kobe. See Johnston, 2001 (accessed 29 March 2003).

38 Johnston, 2001.

39 Johnston, 2001.

40 Kajimoto, undated.

41 Kajimoto, undated.

42 Quoted in Schirmer, 2000.

43 The new guidelines also attracted the wrath of some of Japan's neighbours, particularly China. This issue does not relate to my analysis, but has been analysed in a recent paper by Midford, 2004.

44 Toshi Mondai published a special issue (99:10) in October 1999 under the theme 'Chiiki kara mita anzen hoshō mondai kokuei to chihōjichi no hazama de (National security problems at local level: dilemma between national interest and local autonomy), with articles that analysed security from local perspectives and the dilemmas of potential conflict between national interest and local autonomy.

45 Asahi Evening News, 25 February 1999.

46 Tamaki, 1999, pp. 78-79.

47 A number of examples of assembly resolutions are discussed in Inokura Kichi Mondai Kenkyūkai (ed.), 2001, pp. 65-70.

48 Inokura Kichi Mondai Kenkyūkai (ed.), 2001, pp. 65-70.

49 Inokura Kichi Mondai Kenkyūkai (ed.), 2001, pp. 68-70.

50 Mainichi Shinbun, 24 February 1999.

51 Resolutions are an administrative measure that assemblies can pass. They do not have a legal basis but since they are accepted by assembly members they have some political force. Ordinances are an instrument for governing, with legal force and greater political clout. SNGs are authorized to establish ordinances to govern their localities under Article 14 of the Local Autonomy Law.

52 For the debate, see Inokura Kichi Mondai Kenkyūkai (ed.), 2001, pp. 60-61.

53 Professor Kanbara Masaru of Hokkaido University who specializes in local government and legal issues also confirmed his view that it is not unconstitutional for local governments to establish ordinances since the constitution does not prohibit such actions. Interview in Hokkaido, 1 July 1999. Also, see Kanbara, 1999, pp. 43-49.

54 Mainichi Daily, 1 March 1999.

55 Asahi Shinbun, 24 February 1999.

56 See Inokura Kichi Mondai Kenkyūkai (ed.), 2001, pp. 84-119.

57 Johnston, 2001.

58 There are many such examples and some are mentioned in this chapter. In a recent example of the contention, the mayor of Okimi Town which is a small SNG in Hiroshima Prefecture was forced to stand down after retracting a proposal to host an airstrip for night-landing practice by US navy jets. Asahi Shinbun, 6 February 2003. 
59 There is an extensive literature on Okinawa, especially after the 1995 rape incident. For a range of different perspectives see, for example, Johnson (ed.), 1999; Hook and Siddle (eds), 2003.

60 Pollard's study has detailed Okinawan grievances back to the late 1940s. See Pollard, 2002, p. 31.

61 Ota, undated, pp. 85-86.

62 At the end of war in 1945, the US seized the land of farmers for US bases through force as the occupying power. Since the 1972 reversion, the central government leases Okinawan land for US bases. Its instrument of coercion is the 1952 Special Measures Law that enables land owned by Japanese citizens to be expropriated for US bases. The law has not been enforced in mainland Japan since 1962, although it continues to be applied in Okinawa.

63 The stated aim of SACO was principally to 'reduce the burden on the people of Okinawa and thereby strengthen the US-Japan alliance'.

64 Kamimura, 2001, p. 21.

65 Smith, 2000, pp. 75-76.

66 For details of Futenma see <http:/www.globalsecurity.org/military/facility/ futenma.htm $>$ (accessed 31 August 2004).

67 Johnson, 1999, p. 218; Eldridge, 1998, p. 14.

68 Schirmer, 2000.

69 Gabe, 2003, pp. 59-60.

70 Smith, 2000, p. 113.

71 Hook et al., 2001, p. 144.

72 Details of this case are drawn from Jain, 1991b.

73 The islands are currently in Japan's possession, but both China and Taiwan claim sovereignty. A diplomatic feud erupted as recently as in March 2004 when Japanese police arrested seven Chinese nationals who landed on Uotsurijima, part of the Senkaku Islands. See Asahi.com, 25 March 2004.

74 A number of studies provide detailed accounts of this issue. For a comprehensive treatment see, for example, Hasegawa, 1998.

75 On 9 April 2002 during my interviews in the International Division of the Hokkaido Prefectural headquarters $(D \bar{c} c h \bar{o})$ in Sapporo, I was advised that the division has some 50 staff members. The Division has a separate desk for Russian affairs, the Roshia-shitsu, that deals specifically with issues concerning the Northern Territories.

76 Braddick, 2000.

77 Hook et al., 2001, p. 99.

78 Okuyama, 2003, p. 42.

79 Okuyama, 2003, pp. 42-43.

80 In April 2003, an LDP-supported former METI official Ms Harumi Takahashi was voted in to replace Hori as Hokkaido governor.

81 Okuyama, 2003, p. 44.

82 Williams, 2003, p. 170.

83 Stephan, 1998, p. 505.

84 This was the view of Professor Minagawa Shugo of the Slavic Research Centre at Hokkaido University, quoted in Williams, 2003, p. 174.

85 Akaha, 2003, p. 97.

86 Okuyama, 2003, p. 44.

87 Okuyama, 2003, p. 46.

88 Okuyama, 2003, p. 52.

89 Okuyama, 2003, p. 49.

90 Okuyama, 2003, p. 51.

91 For example, the Japanese government has provided special extra-budgetary funding to the Nemuro region through the Hokkaido Development Agency. Hokkaido Prefecture 


\section{Notes}

not only lobbies Tokyo for this subsidy but also has its own programmes to stimulate the Nemuro regional economy. See Williams, 2003, p. 249.

92 Ishihara, 1989, p. 21.

93 Daily Yomiuri, 21 May 2000.

94 'This Cold War is much more dangerous', interview with Shintaro Ishihara, Business Week, May 28, 2001, p. 22.

95 Katayama and Kenmotsu, 2003, p. 137.

96 It is interesting to note Katayama's apparent double standards here since he does not acknowledge Japan's own history of invasion or its responsibility for the suffering of millions of people in dozens of Asian nations during the Second World War.

97 Ichioka, 2000, p. 210.

98 Niigata Nippō, 28 February 2003.

\section{Conclusion}

1 Arase, 2002, p. 186.

2 Jacobs, 2003, pp. 601-02.

3 By late February 2003, at least 112 local assemblies had passed resolutions against the US invasion of Iraq and favoured a peaceful resolution via the United Nations. Niigata Nippō, 28 February 2003.

4 As of April 2004, there were some 3100 municipalities (shichōson) - but that number is likely to halve by the end of 2005, given the current prospect of mergers under the twin forces of declining population in regional areas and greater demands on services due to ageing population. See 'New trends in local government', Asia-Pacific Perspectives: Japan+, June 2004, pp. 18-19. 


\section{References}

Abe Hitoshi and Shindō Muneyuki (1997) Gaisetsu Nihon no chihōjichi (An outline of Japan's local government), Tokyo: Tokyo Daigaku Shuppankai.

Abe Takao (1998) 'Chiiki ni okeru kokusai kyōryoku suishin no taiseizukuri' (Structures for the promotion of international cooperation at local level), Jichi Fuoramu, 461, February, 20-25.

Akaha Tsuneo (2003) 'Despite the northern territories: Hokkaido's courting of the Russian far east', Pacific Focus, 18:1, Spring, 89-122.

Akaha Tsuneo and Anna Vassilieva (undated) 'The Russian presence in Niigata and Hokkaido: preliminary analysis of interviews and surveys', unpublished paper, available from Akaha.

Akio Terumasa (1990) 'Minsai kōryū to chiiki kaihatsu enjo' (Non-government Organization and Rural Development Aid), Toshi Mondai, 81:6, June, 39-59.

(2002) 'Nihon minsai kōryū sentaa no katsudō' (Minsai Centre Activity), Toshi Mondai, 93:1, January, 43-55.

Aldecoa, Francisco (1999) 'Towards plurinational diplomacy in the deeper and wider European Union (1985-2005)', in Francisco Aldecoa and Michael Keating (eds), Paradiplomacy in Action: The Foreign Relations of Subnational Governements, London: Frank Cass, pp. 82-94.

Aldecoa, Francisco and Michael Keating (eds) (1999) Paradiplomacy in Action: The Foreign Relations of Subnational Governements, London: Frank Cass.

Alger, Chadwick F. (1981) 'Foreign policies of US publics', in Michael Smith, Richard Little and Michael Shackleton (eds), Perspectives on World Politics, London: Croom Helm, pp. 173-85.

Arai Nobuo (1991) 'Hokkaidō ga dekiru tai Sō kyōryoku wa takusan aru' (Cooperation with the Soviet Union: the many tasks before Hokkaido), Ekonomisuto, 16, April, 52-55.

Arase, David (1995) Buying Power: The Political Economy of Japan's Foreign Aid, Boulder, CO: Lynne Rienner Publishers.

(2000) 'Shifting patterns of Japan's economic cooperation in East Asia: a growing role for local actors?', in Marie Soderberg and Ian Reader (eds), Japanese Influences and Presences in Asia, Richmond, Surrey: Curzon, pp. 118-32.

- (2002) 'Japan sea regionalism: the role of sub-national authorities', in Markus Perkmann and Ngai-Ling Sum (eds), Globalization, Regionalization and Cross-Border Regions, New York: Palgrave Macmillan, pp. 176-88.

Arts, Bas, Math Noortmann and Bob Reinalda (eds) (2001) Non-State Actors in International Relations, Aldershot: Ashgate. 
Beauregard, Robert A. and Jon Pierre (2000) 'Disputing the global: a sceptical view of locality-based international initiatives', Policy and Politics, 28:4, 465-78.

Braddick, C. W. (2000) 'The waiting game: Japan-Russia relations', in T. Inoguchi and P. Jain (eds), Japanese Foreign Policy Today, New York: Palgrave, pp. 209-25.

Breslin, Shaun and Glenn D. Hook (2002) 'Microregionalism and world order: concepts, approaches and implications', in Shaun Breslin and Glenn D. Hook (eds), Microregionalism and World Order, Houndmills: Palgrave Macmillan, pp. 1-22.

_ (eds) (2002) Microregionalism and World Order, Houndmills: Palgrave Macmillan.

Bryant, William E. (1975) Japanese Private Economic Diplomacy: An Analysis of Business-Government Linkages, New York: Praeger.

Camilleri, Joseph and Jim Falk (1992) The End of Sovereignty? The Politics of a Shrinking and Fragmenting World, Aldershot: Edward Elgar.

Chen, Edward K. Y. and C. H. Kwan (eds) (1997) Asia's Borderless Economy: The Emergence of Subregional Economic Zones, St Leonards: Allen \& Unwin.

Cheung, Peter T. Y. and James T. H. Tang (2001) 'The external relations of China's provinces', in David M. Lampton (ed.), The Making of Chinese Foreign and Security Policy in the Era of Reform, 1978-2000, Stanford, CA: Stanford University Press, pp. 91-120.

Chiba Hitoshi (2003) 'JETRO: investing know-how', Look Japan, March, www. lookjapan.com/Lbecobiz/03MarTB.htm (accessed 18 April 2004).

Chihō Jichi Seisaku Kenkyūkai (ed.) (1988) Kokusai Kōryū Gaidobukku (International Exchange Guidebook), Tokyo: Gyōsei.

Church, Andrew and Peter Reid (2002) 'Local democracy, cross-border collaboration and the internationalization of local government', in Robin Hambleton, Hank Savitch and Murray Stewart (eds), Globalism and Local Democracy: Challenges and Change, Houndmills: Palgrave, pp. 201-18.

Clough, Michael (1994) 'Grass-roots policymaking', Foreign Affairs, January-February, 2-7.

Clough, Mike (1998) 'Consulates belong to yesterday's diplomacy', Los Angeles Times, reprinted in Daily Yomiuri, 17 August.

Council of Local Authorities for International Relations (1995) The Sister City Movement in Australia, Report No. 002, Sydney: Japan Local Government Centre.

- (2002) Local Government in Japan, Tokyo: CLAIR.

- (2003a) 2003 Japanese Local Government International Affiliation Directory, Tokyo: CLAIR.

— (2003b) The JET Program 2003-2004, Tokyo: CLAIR.

- (undated) Japan 2003, Tokyo: CLAIR.

Cremer, Rolf D. and Ann Dupuis (2001) 'International sister-cities: bridging the global-local divide', American Journal of Economics and Sociology, January, www.findarticles.com (accessed 8 November 2003).

Cusimano, Maryann K. (2000) Beyond Sovereignty: Issues for a Global Agenda, Boston, MA: Bedford/St. Martin's.

Duchacek, I. D. (1984) 'The international dimension of subnational self-government', Publius, Fall, 5-31.

Duchacek, Ivo D., Daniel Latouche and Garth Stevenson (1988) Perforated Sovereignties and International Relations: Trans-sovereign Contacts of Subnational Governments, New York: Greenwood Press.

Ebashi Takashi (1988) 'Jichitai kokusai katsudō to hō kōzō' (Legal structures for SNGs' international activity), in Matsushita Keiichi (ed.), Jichitai no kokusai seisaku, pp. 181-206. 
(1991) 'Chihō jichitai to kokusaika: kokusai kyōryoku no hōteki sokumen' (SNGs and internationalisation: The legal side of international cooperation), in Kokusai Kyōryoku Jigyō Shūdan and Kokusai Kyōryoku Sōgō Kenshūjo (eds), Gurōbaru jidai no chihō jichitai: Chihō jichitai to kokusai kyōryoku no arikata ni kansuru kenkyūkai hōkoku (SNGs in an Era of Globalisation: Research Reports on SNGs' International Cooperation), Tokyo: Kokusai Kyōryoku Shuppankai, pp. 44-53.

Ebashi Takashi and Tomino Kiichirō (2001) Jichitai kokusai kyōryoku no jidai (The era of SNG international cooperation), Okayama: Daigaku Kyōiku Shuppan.

Eguchi Yujiro (1992) 'Municipal governments and international cooperation', Technology and Development, 5, January, 47-54.

Eldridge, Robert D. (1998) 'The Nago Heliport problem in the US-Japan relationship', Social Science Japan, 14, 14-16.

Foreign Press Center (1997) Japan: Eyes on the Country, Views of the 47 Prefectures, Tokyo: Foreign Press Center.

Freeman, Carla P. (2002) 'Province, center, and the World Trade Organization: Liaoning and China's WTO accession', Issues and Studies: An International Quarterly on China, Taiwan and East Asian Affairs, 38:3, September, 1-32.

Fry, Earl H. (1998) The Expanding Role of State and Local governments in U.S. Foreign Affairs, New York: Council of Foreign Relations Press.

Fukui Haruhiro (1977) 'Tanaka goes to Peking: a case study in foreign policymaking', in T. J. Pempel (ed.), Policymaking in Contemporary Japan, Ithaca, NY and London: Cornell University Press, pp. 60-102.

Funabashi Yoichi (1995) Asia Pacific Fusion: Japan's Role in APEC, Washington, DC: Institute for International Economics.

Furukawa Shun'ichi and Menju Toshihiro (eds) (2003) Japan's Road to Pluralism: Transforming Local Communities in the Global Era, Tokyo: Japan Center for International Exchange.

Gabe Masaaki (2003) 'It is high time to wake up: Japanese foreign policy in the twentyfirst century', in Glenn D. Hook and Richard Siddle (eds), Japan and Okinawa: Structure and Subjectivity, London: RoutledgeCurzon, pp. 55-73.

Gaikō Fuoramu (1999) 'Min no yakuwari o kangaeru: taiyōka suru Nihon gaikō no akutaatachi' (Diversifying Japan's diplomatic actors: the role of the private sector), Gaikō Fuoramu, 127:3, March, 6-61.

Gray, Clive (1994) Government Beyond the Centre: Subnational Politics in Britain, Basingstoke: Macmillan.

Guay, Terence (2000) 'Local government and global politics: the implications of Massachusetts' "Burma Law"', Political Science Quarterly, 115:3, 353-76.

Hagai Masami and Ōtsu Hiroshi (eds) (1994) Jichitai gaikō no chōsen chiiki no jiritsu kara kokusai kōryū ken no keisei e: kan Nihon kai sōsho 2 (Challenges of SNG diplomacy: from local independence to the formation of international relations networks, The Japan Sea Group Series 2), Tokyo: Yūshindō.

Hasegawa Tsuyoshi (1998) The Northern Territories Dispute and Russo-Japanese Relations, Volume 1; Between War and Peace, 1679-1985; Volume 2, Neither War Nor Peace, 1985-1998, Berkeley, CA: University of California Press.

Hatcher, Patrick L. (1996) 'How local issues drive foreign policy', Orbis, 40:1, Winter, 45-52. Helweg, Diana (2000) 'A rising sun?', Foreign Affairs, 79, July-August, 26-39.

Higgott, Richard A., Geoffrey, R. D. Underhill and Andreas Bieler (eds) (2000) Non-State Actors and Authority in the Global System, London: Routledge. 
Hiramatsu Morihiko (1990) Chihō kara no hassō (Inspiration from the local community), Tokyo: Iwanami Shoten.

Hirata Keiko (1998) 'New challenges to Japan's aid: an analysis of aid policymaking', Pacific Affairs, 71:3, 311-34.

- (2002) Civil Society in Japan: The Growing Role of NGOs in Tokyo's Aid and Development Policy, New York: Palgrave Macmillan.

Hobbs, Heidi H. (1994) City Hall Goes Abroad: The Foreign Policy of Local Politics, Thousand Oaks, CA: Sage Publications.

Hocking, Brian (1993) 'Introduction', in Brian Hocking (ed.), Foreign Relations and Federal States, London: Leicester University press.

Hook, Glenn (1999) 'Japan and micro-regionalism: constructing the Japan Sea rim zone', in Yoshinobu Yamamoto (ed.), Globalism, Regionalism and Nationalism: Asia in Search of its Role in the 21st Century, Oxford: Blackwell Publishers, pp. 126-41.

- (2002), 'The Japanese role in emerging microregionalism: the Pan-Yellow Sea economic zone', in Shaun Breslin and Glenn D. Hook (eds), Microregionalism and World Order, Houndmills: Palgrave Macmillan, pp. 95-114.

— (2003) 'Responding to globalization: Okinawa's free trade zone in microregional context', in Glenn D. Hook and Richard Siddle (eds), Japan and Okinawa: Structure and Subjectivity, London: RoutledgeCurzon, pp. 39-54.

Hook, Glenn D. and Richard Siddle (eds) (2003) Japan and Okinawa: Structure and Subjectivity, London: RoutledgeCurzon.

Hook, Glenn D., Julie Gilson, Christopher W. Hughes and Hugo Dobson (2001) Japan's International Relations: Politics, Economics and Security, London: Routledge.

Horie Masahiko (1998) 'Seifu kaihatsu enjo (ODA) ni okeru chihō no yakuwari' (The role of localities in ODA), Jichi Fuoramu, 461, February, 14-19.

Horsmann, Mathew and Andrew Marshall (1995) After the Nation-State, London: Harper Collins.

Hosokawa Morihiro and Iwakuni Tetsundo (1991) Hina no ronri (Ideas from the countryside), Tokyo: Kobunsha.

Hughes, Christopher W. (2002) 'Tumen River Area Development Programme (TRADP): frustrated microregionalism as a microcosm of political rivalries', in Shaun Breslin and Glenn D. Hook (eds), Microregionalism and World Order, Houndmills: Palgrave Macmillan, pp. 115-43.

Ichioka Masao (1991) 'Nihonkai o kakomu wa o: Niigata no keiken kara' (Peace surrounding the Sea of Japan: Niigata's perspective), Sekai, March, 132-36.

— (2000) Jichitai gaikō: Niigata no jissen: yūkō kara kyōryoku e (Local diplomacy Niigata style: from friendship to cooperation), Tokyo: Nihon Keizai Hyōronsha.

— (2002) 'Niigata shi no kokusai kōryū jigyō' (International Exchange Activities of Niigata City), Toshi Mondai, 93:1, January, 57-67.

Ide Yoshinori (1972) Chihō jichi no seijigaku (The politics of local autonomy), Tokyo: Tokyo Daigaku Shuppankai.

Ikeo Yasushi (1997) 'Jichitai reberu kara mita "anzen hoshō": heiwa kenkyū no shiten kara' ('Security', as seen from the SNG level: perspectives from peace studies), Ritsumeikan Kokusai Chiiki Kenkyū, 10, 95-112.

Inoguchi Takashi (1993) Japan's Foreign Policy in an Era of Global Change, London: Pinter. Inoki Takenori (2001) 'Staff loans and transfers among central and local governments in Japan', in Muramatsu Michio, Farrukh Iqbal and Ikuo Kume (eds), Local Government Development in Postwar Japan, Oxford: Oxford University Press, pp. 132-53. 
Inokura Kichi Mondai Kenkyūkai (ed.) (2001) Watashitachi no hi-kyōryoku sengen: shühenjitai-hō to jichitai no heiwaryoku (Our non-cooperation declaration: the Situations in Areas Surrounding Japan Law and SNGs' power over peace), Tokyo: Akashi Shoten.

Ishihara Shintaro (1989) The Japan That Can Say No (tr. Frank Baldwin), New York: Simon \& Schuster.

Jacobs, A. J. (2003) 'Devolving authority and expanding autonomy in Japanese prefectures and municipalities', Governance: An International Journal of Policy, Administration and Institutions, 16:4, October, 601-23.

Jain, Purnendra (1989) Local Politics and Policymaking in Japan, New Delhi: Commonwealth Publishers.

_ (1991a) 'Japan's urban governments, their international activities and Australia-Japan relations: an exploratory essay', Policy Organisation and Society, 4, Summer, 33-44.

— (1991b) 'Green politics and citizen power in Japan: the Zushi movement', Asian Survey, 31:6, June, 559-75.

_ (1994) 'Japan's regional political economy: a case study from the Kansai region', paper presented to the XVI Congress of the International Political Science Association, Berlin, 21-25 August.

— (1995) 'Decentralisation in Japan's political economy: the Kansai International Airport', Social Science Japan, 5, November, 30-31.

_ (1999) 'Japan's 1999 unified local elections: electing Tokyo's governor', Japanese Studies, 19:2, September, 117-32.

— (2000a) 'Emerging foreign policy actors: subnational governments and nongovernmental organizations', in Inoguchi Takashi and Purendra Jain (eds), Japanese Foreign Policy Today, New York: Palgrave, pp. 18-39.

- (2000b) Japan's Local Governance at the Crossroads: The Third Wave of Reform, Pacific Economic Papers, 306, Canberra: Australia-Japan Research Centre.

- (2002) 'Nihon gaikō no atarashii akutaa to shite no hi-seifu soshiki' (NGOs as new actors in Japan's diplomacy), in Hirata Masao (ed.), Shimin shakai ni okeru NPO/NGO no yakuwari to chii (Civil society and the role and status of NPO/NGO), Yokohama: Yokohama Shiritsu Daigaky Keizai Kenkyusho.

- (2004a) 'Local political leadership in Japan: a harbinger of systemic change in Japanese politics?', Policy and Society, 23:1, 58-87.

- (2004b) 'Japan's subnational governments in China: emerging bilateral relations', Global Change, Peace \& Security, 16:1, February, 19-30.

Jain, Purnendra and Mizukami Tetsuo (1996) Gurasurūtsu no kokusai kōryū (Japan's Internationalisation at the Grassroots Level), Tokyo: Habesutosha.

Jansen, Marius (2000) The Making of Modern Japan, Cambridge, MA: The Belknap Press of Harvard University Press.

Japan Bank for International Cooperation (2002a) Heisei 13 nen do chihō jichitai renkei chōsa: hōkokusho (A 2001 survey report on cooperation with SNGs), prepared by the Mitsubishi Research Institute, March.

- (2002b) 'Jichitai to no renkei manuaru kōshi' (Summary of cooperation manual with SNGs), unpublished document, April.

Japan Foundation Center for Global Partnership (1994) The Survey Reports on Regional Internationalization and U.S.-Related Exchange Activities in Japan, Vol. 1, Tokyo: CGP.

_ (1997) The Survey Reports on Regional Internationalization and U.S.-Related Exchange Activities in Japan, Vol. 2, Tokyo: CGP.

JETRO (2000) JETRO 40-nen no ayumi (40 Years of JETRO), Tokyo: JETRO. 
JETRO (2003) 'Okinawa: unique special zone programs attract businesses to Southern Island', Invest in Japan, special edition, vol. 1.

Jichirō Jichiken Chūō Suishin Iinkai (ed.) (1995) Jichitai no kokusai kyōryoku to jichitai ODA (SNGs' international cooperation and local ODA), Nagano City: Kenmin Bunka Kaikan.

Jichitai Kokusaika Kyōkai (2001) 'Chihōseifukan ni okeru kokusai kyōryoku' (International cooperation by local government), in Chūgoku no kankyō mondai to chihō jichitai no kokusai kyōryoku (Subnational government international cooperation and China's environmental problems), CLAIR Report No. 213, June.

— (2002) Shimai jichitai no katsudō gaikyō - 2001 (Activities and status of sister-city relations - 2001), Tokyo: CLAIR.

Johnson, Chalmers (1995) Japan: Who Governs? The Rise of the Developmental State, New York: W. W. Norton.

(ed.) (1999) Okinawa: Cold War Island, Cardiff, CA: Japan Policy Institute.

Johnston, Eric (2001) 'Kobe declaration a thorn in the side of diplomacy', Japan Times Online, 22 March (accessed 29 March 2003).

Kabashima Hideyoshi (2001) 'Chiji no saitenbo' (Grading the governors), Shükan Kinyōbi, 27, July, 10-18.

Kaigai Kankyō Kyōryoku Sentaa (2000) 'Chihō kōkyō dantai no kankyō kyōryoku' (Environmental cooperation by local government groups), in Nihon kankyō kyōryoku jirei jōhō shiryō shu: Heisei 11 nendo kankyōchō itaku chōsa (Documents with Information on Japan's Environmental Cooperation: Results of the Environment Agency Survey Commissioned in 2000), Kaigai Kankyō Kyōryoku Sentaa, March.

Kajimoto Shushi (undated) 'Role of non-nuclear Kobe formula in establishing nuclear weapons free zones', http://prop1.org/japan/speeches/e-kjmt.htm (accessed 19 March 2003).

Kamimura Naoki (2001) 'Japanese civil society and U.S.-Japan security relations in the 1990s', Medicine and Global Survival, 27:1, April, 20-25.

Kanagawa Ken (1995) Minsai gaikō 20 nen: sekai ni hirakareta Kanagawa o mezashite (Commemorating 20 years of local diplomacy: opening Kanagawa to the world), Kanagawa: Pōtosaido Insatsu.

Kanamori Hisao (ed.) (1999) Bōdaaresu jidai no chiikikan kōryū (Relations between localities in the borderless era), Tokyo: ALC.

Kanbara Masaru (1999) 'Hikaku jōreika wa jichiken no kōshi de aru: seifu no hihanwa naze machigatte irunoka' (Non-nuclear ordinances are the rights of local authorities: why the government is wrong in opposing them), Sekai, May, 43-49.

Kansai Economic Federation (1993) An Introduction to the Kansai Economy, Osaka: Kankeiren.

Katayama Yoshihiro (2002) 'Tokyo wa kore ijō no shūchū ni taerareru ka', Chūō Kōron, October, 216-23. For its abridged English version, 'Stop Tokyo's unbridled expansion', Japan Echo, December 2002, 8-12.

Katayama Yoshihiro and Kenmotsu Kanae (2003) Chiikikan kōryū ga gaikō wo kaeru Tottori Chōsenhantō no 'aru kokoromi' (The Impact of Local Diplomacy: Efforts between Tottori and the Korean Peninsula), Tokyo: Kōbunsha.

Keating, Michael and Liesbet Hooghe (1996) 'By-passing the nation-states: regions and the EU policy process', in Jeremy Richardson (ed.), European Union: Power and Policymaking, London: Routledge, pp. 219-26.

Keohane, Robert O. and Joseph S. Nye (eds) (1972) Transnational Relations and World Politics, Cambridge, MA: Harvard University Press. 
(1981) 'Realism and complex interdependence', in Michael Smith, Richard Little and Michael Shackleton (eds), Perspectives on World Poltiics, London: Croom Helm, pp. 214-25.

Kincaid, J. (1993) 'Consumerism versus citizenship: is there wiggle room for local regulation in the global economy', in Brian Hocking (ed.), Foreign Relations and Federal States, London: Leicester University Press, pp. 27-38.

Kitahayashi Mitsuaki (1986) 'Kakujidai no kokusai kōryū' (International exchange in an age of nuclearisation), in Nagasu Kazuji and Sakamoto Yoshikazu (eds), Jichitai no kokusai kōryū (SNGs' international exchange), Tokyo: Gakuyō Shobō, pp. 59-74.

Kitayama Toshiya (1995) 'Local governments and small and medium-sized enterprises', in Kim Hyung-Ki, Michio Muramatsu, T. J. Pempel and Kozo Yamamura (eds), The Japanese Civil Service and Economic Development: Catalysts of Change, Oxford: Clarendon Press, pp. 376-96.

— (2001) 'Local policy initiatives', in Muramatsu Michio, Farrukh Iqbal and Ikuo Kume (eds), Local Government Development in Post-war Japan, Oxford: Oxford University Press, pp. 222-41.

Knight, John (1993) 'Rural Kokusaika? Foreign motifs and village revival in Japan', Japan Forum, 5:2, 203-16.

Kokusai Kyōryoku Jigyō Shūdan and Hokkaidō Kokusai Sentaa, Sapporo (2001) Hokkaidō ni okeru chiiki shinkō jirei chōsa (Surveys and case studies of localities in Hokkaido), Sapporo: Kokusai Kyōryoku Jigyō Shūdan and Hokkaidō Kokusai Sentaa.

Kokusai Kyōryoku Jigyō Shūdan and Kokusai Kyōryoku Sōgō Kenshūjo (eds) (1991) Gurōbaru jidai no chihō jichitai: Chihō jichitai to kokusai kyōryoku no arikata ni kansuru kenkyūkai hōkoku (SNGs in an era of globalisation: Research reports on SNGs' international cooperation), Tokyo: Kokusai Kyōryoku Shuppankai.

Komai Hiroshi and Watado Ichirō (eds) (1997) Jichitai no gaikokujin seisaku: uchinaru kokusaika e no torikumi (SNG policy on foreigners: towards domestic internationalization), Tokyo: Akashi Shoten.

Koppel, Bruce and Robert Orr Jr (1993) 'Power and policy in Japan's foreign aid', in Bruce Koppel and Robert Orr (eds), Japan's Foreign Aid: Power and Policy in a New Era, Boulder, CO: Westview Press, pp. 341-68.

Krauss, Eliss (1980) 'Opposition in power: the development and maintenance of Leftist government in Kyoto prefecture', in Kurt Steiner, Ellis Krauss and Scott Flanagan (eds), Political Opposition and Local Politics in Japan, Princeton, NJ: Princeton University press, pp. 383-424.

McConnell, David L. (2000) Importing Diversity: Inside Japan's JET Program, Berkeley, CA: University of California Press.

MacDougall, Terry (1975) 'Political opposition and local government in Japan: the significance of emerging progressive local leadership', $\mathrm{PhD}$ thesis, Yale University.

_ (2001) 'Towards political inclusiveness: the changing role of local government', in Muramatsu Michio, Farrukh Iqbal and Ikuo Kume (eds), Local Government Development in Post-war Japan, Oxford: Oxford University press, pp. 29-62.

Mathews, Jessica T. (1997) 'Power shift', Foreign Affairs, 76:1, 50-66.

Matsuo Takafumi (2000) 'Fukuoka looks forward', Look Japan, 46:529, April.

Matsushita Keiichi (ed.) (1988) Jichitai no kokusai seisaku (Local governments' international policies), Tokyo: Gakuyō Shobō.

Mekata Motoko (2000) 'Building partnerships toward a common goal: experiences of the international campaign to ban landmines', in Ann M. Florini (ed.), The Third Force: The 
Rise of Transnational Civil Society, Tokyo: Japan Center for International Exchange, pp. 143-76.

Menju Toshihiro (1998a) 'Shimai toshi to wa' (The meaning of sister city), in Sapporo Bunko (ed.), Shimai toshi (Sister cities), Sapporo: Sapporo Shi Kyōiku Iinkai, pp. 12-27. (1998b) 'Jichitai gaikō no susume' (Local diplomacy), Chūō Kōron, October, 204-14. (2002) 'Jichitai gaikō no kadai to tenbō' (International Policies of Japanese Local Governments), Toshi Mondai, 93:1, January, 3-14.

_ (2003) 'International policies of local governments', in Furukawa Shun'ichi and Menju Toshihiro (eds), Japan's Road to Pluralism: Transforming Local Communities in the Global Era, Tokyo and New York: Japan Center for International Exchange, pp. 89-109.

Midford, Paul (2004) 'China views the revised US-Japan defense guidelines: popping the cork?' International Relations of the Asia-Pacific, 4:1, 113-46.

Ministry of Foreign Affairs, Diplomatic Bluebook 1987 (year of publication and publisher not available), pp. 196-97.

Minsai Gaikō 10-Nenshi Kikaku Henshū Iinkai (ed.) (1990) Minsai gaikō no chōsen (The challenge of people-to-people diplomacy), Tokyo: Nihon Hyōronsha.

Mochizuki Kiichi (1993) 'Quickening development in the sea of Japan economic zone', The Japan Foundation Newsletter, 21:4, December, 1-8.

Morgan, Alastair (2002) 'Promoting Japan for foreign direct investment', Journal of Japanese Trade and Industry, May, www.jef.or.jp/en/jti/200205_014.html (accessed 12 November 2003).

Morris-Suzuki, Tessa (2002) 'Immigration and citizenship in contemporary Japan', in J. Maswood, J. Graham and H. Miyajima (eds), Japan - Change and Continuity, London: RoutledgeCurzon, pp. 163-78.

Muramatsu Michio (1988) Chihō jichi (Local autonomy), Tokyo: Tokyo Daigaku Shuppankai.

Muramatsu Michio and Farrukh Iqbal (2001) 'Understanding Japanese intergovernmental relations: perspectives, models, and salient characteristics', in Muramatsu Michio, Farrukh Iqbal and Ikuo Kume (eds), Local Government Development in Post-war Japan, Oxford: Oxford University Press, pp. 1-28.

Muramatsu Michio, Farrukh Iqbal and Ikuo Kume (eds) (2001) Local Government Development in Post-war Japan, Oxford: Oxford University Press.

Nagasu Kazuji (1986) 'Jichitai no kokusai kōryū' (SNGs' international exchange), in Nagasu Kazuji and Sakamoto Yoshikazu (eds), Jichitai no kokusai kōryū (SNGs', international exchange), Tokyo: Gakuyō Shobō, pp. 3-16.

Nagasu Kazuji and Sakamoto Yoshikazu (eds), (1986) Jichitai no kokusai kōryū (SNGs' international exchange), Tokyo: Gakuyō Shobō.

Nakamura Akira (1996) "The "Tokyo Problem" and the development of urban issues in Japan', in Jong S. Jun and Deil S. Wright (eds), Globalization and Decentralization: Institutional Contexts, Policy Issues, and Intergovernmental Relations in Japan and the United States, Washington, DC: Georgetown University Press, pp. 191-203.

Nakazono Satoshi (2003) 'Local action and cooperation in the Asia-Pacific region', 6 November, unpublished paper.

Negishi Mayumi (2001) 'Localities approach foreign firms to raise tax base', Japan Times Online, 21 June.

Newhouse, John (1997) 'Europe's rising regionalism', Foreign Affairs, 76:1, January/ February, 67-84. 
Nicholson, Martin (1999) Towards a Russia of the Regions, Adelphi Paper 330, Oxford: Oxford University Press.

Nicholson, Michael (1998) International Relations: A Concise Introduction, New York: New York University Press.

Nihon Kokusai Kōryū Sentaa (eds) (1998) Chiiki ga tsunagaru Nihon to Ajia (Local-level cooperation between Japan and Asia), Tokyo: Jichitai Kokusaika Kyōkai.

Nihon Toshi Sentaa (ed.) (1995) Toshi gaikō: jichitai no kokusai kōryū senryaku (Municipal diplomacy: the international relations strategy of subnational government), Tokyo: Gyōsei.

Nishikawa Jun (1995) 'Local governments can play global role', Nikkei Weekly, 9 October.

Nishimura Kunio (2000a) 'Nagasaki's silver pioneers', Look Japan, August.

- (2000b) 'Water sisters', Look Japan, September.

Nye, Joseph S. (2004a) Soft Power: The Means to Success in World Politics, New York: Public Affairs.

(2004b) 'The soft power of Japan', Gaiko Forum: Japanese Perspectives on Foreign Affairs, Summer, 3-7.

Ogata Sadako (1977) 'The business community and Japanese foreign policy: normalization of relations with the People's Republic of China', in Robert E. Scalapino (ed.), The Foreign Policy of Modern Japan, Berkeley, CA: University of California Press, pp. 175-203.

Okada Shin'ichi (2003) 'A regional revolution', Asia-Pacific Perspectives: Japan+, 1:3, July.

Okuyama Yutaka (2003) 'The dispute over the Kurile Islands between Russia and Japan in the 1990s', Pacific Affairs, 76:1, Spring, 37-53.

Ota Masahide (undated) 'Okinawa calls for a just peace: speech to the US Congressional Study Group on Japan', <www.iwanami.co.jp/jpworld/text/okinawa01.htm > (accessed 15 November 2003).

O'Toole, Kevin (2000) 'Perceptions of Australia-Japanese sister city relationships: a comparative report of research conducted in Australia and Japan', CLAIR Correspondence (Sydney), 22, December.

- (2001) 'Kokusaika and internationalisation: Australian and Japanese sister type relationships', Australian Journal of International Affairs, 55:3, 403-19.

Ōtsu Hiroshi (1994) 'Jichitai gaikō no hōri' (The legal principles of SNG diplomacy), in Hagai Masami and Ōtsu Hiroshi (eds), Jichitai gaikō no chōsen chiiki no jiritsu kara kokusai kōryū ken no keisei e: kan Nihon kai sōsho 2 (Challenges of SNG Diplomacy: From Local Independence to the Formation of International Relations Networks, The Japan Sea Group Series 2), Tokyo: Yūshindō, pp. 39-63.

Parker, P. and D. Kershaw (1995) 'Japanese sister cities: Canada's most popular choice', The Economic and Technology Development Journal of Canada, www.ecdevjournal.com/ pubs/1995/art013_95.htm (accessed 18 November 2003).

Perkmann, Markus and Ngai-Ling Sum (2002) 'Globalization, regionalization and crossborder regions: scales, discourses and governance', in Markus Perkmann and Ngai-Ling Sum (eds), Globalization, Regionalization and Cross-Border Regions, New York: Palgrave Macmillan, pp. 3-21.

Pollard, Vincent Kelly (2002) 'Designing a peaceful Okinawa: local opportunities, regional obstacles', Social Science Japan, 23, April, 29-35.

Postel-Vinay, Karoline (1996) 'Local actors and international regionalism: the case of the sea of Japan zone', Pacific Review, 9:4, 489-503.

Price, Richard (2003) 'Transnational civil society and advocacy in world politics', World Politics, 55, July, 579-606. 


\section{References}

Pursiainen, Christer (2003) " "Regionology" and Russian foreign policy: identifying the theoretical alternatives', in Graeme P. Herd and Anne Aldis (eds), Russian Regions and Regionalism: Strength Through Weakness, London: RoutledgeCurzon, pp. 82-100.

Reilly, Adrian (2000) 'The role of subnational government in European Union policy process', PhD Dissertation, Birmingham: University of Birmingham.

Rix, Alan (1980) Japan's Economic Aid, London: Croom Helm.

- (1993) Japan' Foreign Aid Challenge: Policy Reform and Aid Leadership, London: Routledge.

Rosenau, James N. (1980) The Study of Global Interdependence: Essays on the Transnationalization of World Affairs, London: Frances Pinter.

— (1990) Turbulence in World Politics: A Theory of Change and Continuity, Princeton, NJ: Princeton University Press.

Rozman, Gilbert (1999) 'Backdoor Japan: the search for a way out via regionalism and decentralization', Journal of Japanese Studies, 25:1, 3-31.

_ (2000) 'Cross-border relations and Russo-Japanese bilateral ties in the 1990s', in Gilbert Rozman (ed.), Japan and Russia, New York: St. Martin's Press, pp. 207-21.

Samuels, Richard J. (1983) The Politics of Regional Policy in Japan: Localities Incorporated? Princeton, NJ: Princeton University Press.

Sasaki Nobuo (1988) 'Jichitai no kokusai seisaku kōryū' (SNGs' international policy exchanges), in Matsushita Keiichi (ed.), Jichitai no kokusai seisaku, pp. 3-24.

Satō Kōichi (1991) 'Sendai-shi kokusai kyōryoku ni tsuite' (Sendai's international cooperation), in Kokusai Kyōryoku Jigyō Shūdan and Kokusai Kyōryoku Sōgō Kenshūjo (eds), Gurōbaru jidai no chihōjichitai: Chihō jichitai to kokusai kyōryoku no arikata ni kansuru kenkyūkai hōkoku (SNGs in an era of globalisation: Research reports on SNGs' international cooperation), Tokyo: Kokusai Kyōryoku Shuppankai, pp. 91-93.

Sawaji Osamu (2000) 'JBIC boost for Bangladesh', Look Japan, November.

(2004) 'Foreign direct investment: why Japan', Look Japan, March.

Scalapino, Robert (1990-91) 'The United States and Asia: future prospects', Foreign Affairs, 70:5, 19-41.

Schep, Gerrit Jan, Frank Angenent, Jeroen Wismans and Michiel Hillenius (eds) (1995) Local Challenges to Global Change: A Global Perspective on Municipal International Coopertion, The Hague: Sdu Publishers.

Schirmer, Daniel B. (2000), 'President Clinton, a corporate offensive, and Okinawan bases', Boston Okinawa Network, April, www.boondocksnet.com/centennial/sctexts/ schirmer2000.html (accessed 15 November 2003).

Segal, Gerald (1994) 'Deconstructing foreign relations', in David S. G. Goodman and Gerald Segal (eds), China Deconstructs: Politics, Trade and Regionalism, London: Routledge, pp. 322-55.

Sergounin, Alexander (2003) 'Russia's regionalization: the interplay of domestic and international factors', in Graeme P. Herd and Anne Aldis (eds), Russian Regions and Regionalism: Strength Through Weakness, London: RoutledgeCurzon, pp. 101-19.

Serita Kentarō (2001) 21-seiki no kokusaikaron: Hyōgo kara no chōsen (Internationalization theory in the 21st century: The challenge from Hyogo), Kobe: Hyōgo Janarusha.

Shūkan Daiamondo Tokubetsu Shuzaihan (ed.) (2001) Kōbe: toshi keiei no hokai (Kobe: a collapse of city management), Tokyo: Daiamondosha.

Shuman, Michael H. (1986-87) 'Dateline main street: local foreign policies', Foreign Policy, 65, Winter, 154-74.

_ (1994) Towards A Global Village: International Community Development Initiatives, London: Pluto Press. 
Smith, Michael, Richard Little and Michael Shackleton (eds) (1981) Perspectives on World Politics, London: Croom Helm.

Smith, Sheila A. (2000) 'Challenging national authority: Okinawa prefecture and the US military bases', in Sheila A. Smith (ed.), Local Voices, National Issues: The Impact of Local Initiative in Japanese Policymaking, Ann Arbor, MI: The University of Michigan, pp. $75-114$.

Spiro, Peter J. (1988) 'Taking foreign policy away from the feds', Washington Quarterly, 11:1, Winter, 191-203.

Sridharan, Kripa (2003) 'Federalism and foreign relations: the nascent role of the Indian states', Asian Studies Review, 27:4, December, 463-89.

Steiner, Kurt (1965) Local Government in Japan, Stanford: Stanford University Press. (1980) 'Progressive local administrations: local public policy and local-national relations', in Kurt Steiner, Ellis Krauss and Scott Flanagan (eds), Political Opposition and Local Politics in Japan, Princeton, NJ: Princeton University press, pp. 317-52.

Steiner, Kurt, Ellis Krauss and Scott Flanagan (eds) (1980) Political Opposition and Local Politics in Japan, Princeton, NJ: Princeton University Press.

Stephan, John J. (1998) 'Siberian salient: Russia in Pacific Asia', in Mark Borthwick with contributions by selected scholars, Pacific Century: The Emergence of Modern Pacific Asia (2nd edition), Boulder, CO: Westview Press.

Strange, Susan (1996) The Retreat of the State: The Diffusion of Power in the World Economy, Cambridge: Cambridge University Press.

Sugai Norio (1989) Mura kara no kokusai kōryū (International exchange at village level), Tokyo: Gakuyō Shobō.

Sumi Kazuo (1989) ODA enjo no genjitsu (The reality of ODA), Tokyo: Iwanami Shinsho.

Tadokoro Masayuki (2003) 'JICA "Reconstructed"', Look Japan, 49:569, August, $16-17$.

Taga Hidetoshi (2002) 'Jichitai no kokusai kyōryoku' (SNGs' international cooperation), in Iwanami Kōza, Jichitai no kōsō 3 - seisaku (The SNG Concept-3-Policies), Tokyo: Iwanami, pp. 215-40.

Takahashi Masaki (1998) 'Jichitai kokusai kyōryoku e no ayumi to shien taisei' (Chronology of SNGs' international cooperation and the subsidy system), in Nihon Kokusai Kōryū Sentaa (eds), Chiiki ga tsunagu Nihon to Ajia (Local-level Cooperation between Japan and Asia), Tokyo: Jichitai Kokusaika kyōkai, pp. 89-99.

Tamaki Kazuhiko (1999) 'Shiryō: shin gaidorain o meguru jichitai no ugoki' (Material: Movements of Local Authorities after the Recent Revision of the US-Japan Guidelines for Military Operations), Toshi Mondai, 90:10, 77-86.

Tanaka, Akihiko (2000) 'Domestic policy and foreign policy', in Inoguchi Takashi and Purnendra Jain (eds), Japanese Foreign Policy Today, New York: Palgrave, pp. 3-17.

Tanaka Naoki (1986), 'Kokusaika jidai no jichitai gaikō' (SNG diplomacy in the era of internationalization), in Nagasu Kazuji and Sakamoto Yoshikazu (eds), Jichitai no kokusai kōryū (SNGs' International Exchange), Tokyo: Gakuyō shobō, pp. 227-39.

Todhunter, Maureen (1990) 'International cultural exchange - a valuable instrument in Japan's foreign policy in the late 1980s', Honours thesis, University of Queensland, Australia.

Tomino Kiichirō (1995) 'Tesuki seishi gijutsu no iten de chiiki okoshi: Shimane ken Misumichō' (Local revitalisation through transfer of handmade paper technology: The case of Misumi Town in Shimane Prefecture), in Jichirō Jichiken Chūō Suishin Iinkai (ed.), Jichitai no kokusai kyōryoku to jichitai ODA (SNGs' international cooperation and local ODA), Nagano City: Kenmin Banka Kaikan, pp. 100-07. 


\section{References}

Uchida Kazuo (1995) 'Jichitai no kokusai kyōryoku - soreo unagasu yōin to kōsō no shikaku' (SNG international cooperation - viewpoint on the concept and factors behind its development), in Jichirō Jichiken Chūō Suishin Iinkai (ed.), Jichitai no kokusai kyōryoku to jichitai ODA (SNGs' international cooperation and local ODA), Nagano City: Kenmin Banka Kaikan, pp. 11-23.

Watanabe Sumio (1988) 'Zainichi gaikokujin no mondai jōkyō' (Problems of foreign residents in Japan), in Matsushita Keiichi (ed.), Jichitai no kokusai seisaku, pp. 93-116.

Willetts, Peter (1997) 'Transnational actors and international organizations in global politics', in John Baylis and Steve Smith (eds), The Globalization of World Politics: An Introduction to International Relations, Oxford: Oxford University Press, pp. 287-310.

Williams, Bradley (2003) 'Hokkaido-Sakhalin subnational government relations: opportunities and limits of kankyo seibi', $\mathrm{PhD}$ thesis, Monash University, Australia.

Yabuno Yūzō (1995) Rōkaru inishiatibu (Local initiative), Tokyo: Chūōkōronsha.

Yamamoto Tadashi and Yoichi Funabashi (1995) The Role of Non-State Actors in International Affairs: A Japanese Perspective, Tokyo: Japan Center for International Exchange.

Yamazaki Mitsuru (1991) Yutakana chihō jichi o mezashite (Towards prosperous SNGs), Tokyo: Chūkō Shinsho.

Yomiuri Shinbun Kōetsubu (ed.) (2003) Deta de yomu 47 todōfuken jōhō jiten (Information on Japan's 47 Prefectures), Tokyo: Chūkō Shinsho.

Yoshida Hitoshi (1999) Kokusaitekina jichitai no genjō to tenbō: Chugoku Riaoninsho de no jirei kenkyū (Sub-national government and internationalisation: challenges for the future - a case study of Liaoning Province in China), Tokyo: Kokusai Kenkyū Shōgaku Zaidan (The Tokyo Foundation, formerly the Global Foundation for Research Scholarship).

— (2001) Chihō jichitai no kokusai kyōryoku: chiiki jūmin sankagata ODA o mezashite (Local government's international cooperation: ODA and residents' participation), Tokyo: Nihon Hyōronsha.

- (2003) 'Junkangata shakai no tameno jichitai kokusai kyōryoku' (SNG international cooperation for a cyclical society), in Koizumi Itaru (ed.), Nihonkaigaku no shinseiki 3 junkansuru umi to mori (The new century in Japan Sea studies 3 - the cycle of sea and forest), Tokyo: Kadokawa Shoten, pp. 172-84.

Yoshida Yoshiaki (1985) Chiiki kara no heiwa to jichi (Peace and autonomy via localities), Tokyo: Nihon Hyōronsha.

Zenkoku Shichōson Shinkō Kyōkai (2001) Japan Intercultural Academy of Municipalities, Otsu: JIAM.

Zheng Yong-Nian (1994) 'Perforated sovereignty: provincial dynamism and China's foreign trade', Pacific Review, 7:3, 309-21. 


\section{Index}

Abe Hitoshi 36, 173-74, 176-77, 189-90

Abe Takao 184

Africa 69-70

Agreement on Friendship and Economic

Cooperation 'mini peace treaty' 126

Agricultural Land Law 135

AIDS 35

Akaha Tsuneo 103, 174, 182, 185, 187,191

Akashi City, Nuclear Disarmament City Declaration 145

Akio Terumasa 179, 184

Akita Prefecture, road stations in

Gansu Province 108

Aldecoa, F. 175

Alger, C. F. 33, 176

ALTs see Assistant Language Teachers

Andhra Pradesh 23

anti-nuclear movement 141, 145-47;

Gensuikyō 145

Arai Nobuo 187

Arase, D. 120, 122-23, 166, 174, 180, 183-87, 192

Arts, B. 175

Asahikawa City 80, 181

Asahi Network 185

Asahi Shinbun survey 151

Asian Development Bank 23

Asia-Pacific 27, 69, 92; see also

Northeast Asia

Asia-Pacific Economic Cooperation

(APEC) 30; initiation and management of process 177

Asia Pacific Trade Centre 118

Assistant Language Teachers

(ALTs) 49, 83

Association of Northeast Asia Regional

Governments (NEAR) 105

Association of Southeast Asian Nations

(ASEAN) 119
Association of Southeast Asian Nations plus Japan, China and South Korea (ASEAN+3) 29

Asukata Ichio, Mayor of Yokohama 7, 57; politics of 'opposition' 142

Australasia 69

Australia 40, 178; asymmetrical relationship 77-78; CIRs (Coordinators for International Relations) 178; overseas branches 181; SNGs 21, 27; state-prefecture agreements 77 ; see also South Australia

Australian Research Council ix

Austria, government aid budget 54

Baker, H. 148; US Ambassador to Japan 149

Bangladesh 26

Bayer AG 118

Beauregard, R. A. 174

Beijing 50

Belgium 27

Bhutan, Kingdom of 94

Bikini Atoll underwater nuclear detonation 145

Bo-Hai Sea 22

Braddick, C. W. 191

Bradley, T., Los Angeles Mayor 26

Brazil 69, 98, 100; sister-city relationships with Japanese cities 70

Bremen 27

Breslin, S. 17, 22, 119, 175, 186

Bryant, W. E. 176

Bush, George W. 148, 162

Cabinet Office (formerly Economic Planning Agency) Committee on Economic Cooperation Policy Towards Sustainable Economic Cooperation 107 Cabot, K. K. 132 
California 27

Camilleri, J. 16, 175

Canada 26, 40, 50, 69, 77, 184; FDI stock 131; sister cities 181-82; SNGs 21, 27

Carrefour 118

Cheju 104

Chen, E. K. Y. 175

Cheung, P. T. Y. 175

Chiba Hitoshi 177

Chiba Prefecture 108, 131, 133, 171; Governor Numata 130

Children's Pictures of Fish Joint Art Exhibition 105

Chile 25

China, People's Republic of (PRC) 24, 26, 55, 60, 67, 69-71, 86, 93, 98, $121,130,178,184$; authoritarian unitary system 33; CIRs 178; economy boom 77, 116; 'friendship' (sister-type) relationships 73; Japanese SNGs local ODA and national ODA 99-102; marketization in the post-Mao era 23; multilateral institutional agreement 105; northeast region 120; and Okinawa 162; 'one village, one product' movement 180 ; positioning of nuclear weapons at India 162; and South Africa 26; and Taiwan 162; term 'shimai toshi' 180; term yūkō 180, 189; traditional medicine 101; unitary system 20 ; see also Chinese SNGs

China Trade Promotion Society 76

Chinese SNGs 22, 70, 100, 110; in coastal provinces 74 ; and human rights and defence spending 32 ; as international actors 31 ; sister relationships 74

Chitose 127

Chollanam 104

Chongqing 100, 108, 133

Chubu Area xv

Chugoku Area xv

Church, A. 176

CIRs see Coordinators for International Relations

cities/city (shi) 41; core (chūkaku toshi) 41; designated (seirei shitei toshi) 41; friendship y $\bar{u} k \bar{o}$ toshi 66; pre-war administrations, protocol and liaison offices (shōgai and gaiji) 57; reconstruction 93; SNGs in United States 37

Citizens' groups 5
CLAIR see Council of Local Authorities for International Relations

Clinton, Bill 151, 155

Clinton-Hashimoto Joint Declaration 151

Clough, M. 17, 175

Cold War 7, 25, 60, 116, 154, 159; animosities 96; bilateral territorial dispute 78-79; end of 13, 34; neighbours $78-82$; tensions 71 , 147,160

Communist China see China, People's Republic of

Community Development Initiative (CDI) 61

Community Link International Institute 57

Conference of Japan Sea Coastal Cities for Japan-North Korea Friendship and Trade Promotion 1972 7, 96

Consortium of Nuclear-Free Subnational Governments 146

Constitution of Japan: Article IX 146, 189; Article 65 152; Article 73 152; Article 94 152; SNG autonomy 7

Consultative Committee on Okinawa Base Problems 155

cooperation (kyōryoku): aspects of 9, 90; mutual problem-solving mechanisms 28; programmes as enjo 101; projects 101

Cooperation to Develop the Sakhalin Continental Shelf Oil and Natural Gas Project 103

Coordinating Committee for Export Control (COCOM) 76

Coordinators for International Relations (CIRs) 49, 83; in Australia 178; in China 178; from JET programme 56

Council of Local Authorities for International Relations (CLAIR) (Jichitai Kokusaika Kyōkai) ix, 9, 46, 49, 68-69, 75, 78, 83, 104, 177-78, 180-83; annual directories of international affiliations 70 ; data 69-70, 181; grassroots relations 50; JET programme 49; and JETRO 177; overseas branches $50,56,181$; publications 173; Seoul office 56, 178, 185; survey in Australia 72

Cremer, R. D. 66, 176, 180

culture/cultural relations $1,121,167$; approach to international relations 63 ; economic opportunities 75 
Cusimano, M. K. 174

Czech Republic 98

Dalian 75, 112, 130, 183; UN

Environment Programme award for 100

decentralization 37, 39, 139

Decentralization Promotion Act 199536

Defence Agency 34, 122, 135

Democratic People's Republic of Korea see North Korea

Denmark 184

Development Assistance Committee (DAC) 183

Development Bank of Japan 132

development projects in developing countries 100

diplomacy 24-27, 141; citizen (minsai gaiko ) 61; cultural 84-85; grassroots SNG 60; hard 139, 164; informal 26; interlocal 102; municipal (chihō gaikō) 9; from opposition ( yatō gaikō) 142-43; people's (minsai gaikō) 68; pluralization (tayōka) 33; public (shimin gaikō) 143; 'soft' 87, 139; 'three cheers' (kanpai gaikō) 67; urban (toshi gaikō) 9

Domestic Public Relations Section (Kokunai Kōhōka) 43

Dongjiang River Information System 100

Duchacek, I. D. 175

Dupuis, A. 66, 176, 180

East Asia Subnational Government Tourism Forum 104

Ebashi Takashi 54, 57, 174, 177, 179,186

economic conditions/economics: cooperation between Russian regions and Japanese SNGs 24; diplomacy 113; disparity between Pacific side and Sea of Japan side 116; expansion through trade 33 ; foreign policy 63 ; gain, opportunities for 61,94 ; of localities 14, 93; national and subnational players 138 ; recession 39 ; relations with RFE 125 ; in sister-city relationships 72; SNGs in 21-24, 94; Tokyo rocket model 115

Economic Cooperation Bureau in MOFA $43,56,185$

Economic Research Institute of Northeast Asia (ERINA) 60

Edo period 117, 120
Eguchi, Y. 57

Ehime Prefecture 180; and Queensland, links between 136

Energy Information Administration Japan, 1995 report by 99

enjo (assistance) 90, 92, 95-96, 101, 111, 178; see also ODA

environmental management 35,46 , 93-94, 99, 185

ERINA (Economic Research Institute for Northeast Asia) 178, 182, 184

Etorofu island 159

Eurocities 29

Europe 69; cities 22; medium-range nuclear missile 145 ; SNGs 6, 12 , 20-21, 25, 29, 88, 140; quasi-embassies 22; urban policy 29

European Commission (EC) in Brussels 29

exchange to cooperation, from, 'Kōryy kara kyōryoku e' 10, 87, 96

Export-Import Bank of Japan (JEXIM) 177

Falk, J. 16, 175

FDI see foreign direct investment

Federation of Canadian Municipalities (FCM) 27

FINPRO 132

Foley, T., US ambassador 150

Foreign Affairs Ministry see MOFA

foreign direct investment (FDI) 23; and sister/partner relations 137; stock as percentage of nominal GDP 131

Foreign Press Center 181, 188; 1996 survey of Japan's 47; prefectures 58

foreign residents in Japan, voting rights of 173

former Soviet Union see Russia

France 27, 69; FDI stock 131; Rhone-Alpes region 22

Free Trade Zone 128

Fresenius 132

Fry, E. H. 22, 175-76

Fujitsu 132

Fukui Haruhiro 189

Fukui Prefecture in developing Sea of Japan Grouping 58

Fukuoka Prefecture 57, 66, 75, 104, 122, 133, 163; Aso Wataru, Governor 132; link with Guangzhou 75; link with Jiangsu Province 75

Fukushima 163, 180

Funabashi Yoichi 175-77 
Furukawa Shun'ichi 176

Futenma 191; Air Base, relocation of $155-56$

Fuzhou (Fujian) 75

Gabe Masaaki 191

General Agreement on Tariffs and Trade (GATT) 21

Germany 22, 27, 69; Nordhein-Westfalen region in 136; 'partnerstadt' in 66

Ghana 100,108

Gifu Prefecture 48, 108, 184

globalization 114, 133; of distribution process in trade 3; domestic consequences of 39,116 ; forces of 89 ; international consequences of 21,116

Gorbachev, M. 120, 161; historic visit to Tokyo 102

grassroots cooperation 17, 60, 63, 75

Gray, C. 173

Guay, T. 26, 176

Guidelines for Creating Municipal International Exchange 52

Guidelines on Developing Charters for Promoting Local Government International Cooperation 53

Guidelines on the Promotion of Local International Exchange 52-53

Guiyang 100

Gulf War, first 34

Habomai islands 159, 161

Hagai Masami 174, 187

Hamgyongbuk Province 105

Harbin City 101, 122

Hasegawa Tsuyoshi 191

Hashimoto Daijirō, Governor of Kochi 152-53

Hashimoto Ryūtarō, Prime Minister 151; and Li Peng agreement 185

Hatcher, P. L. 175

Hebei 74

Heilongjiang Province and Harbin City Medical Technology Cooperation Project 101

Helwag, D. 173

Heung, P. T. Y. 176

Higashi Iwai Gun, SNG of 151

Higgott, P. L. 175

Himeji City, International Relations Section 58

Hiramatsu Morihiko 173

Hiraoka Takashi, mayor of Hiroshima 148
Hirata Keiko 34, 176, 189

Hiroshima City 144-45; and Chongqing mayors, memorandum on economic exchange 133; International Relations Division 58; mayor Akiba Tadatoshi 147-48; mayor Araki Takeshi 147; see also Nagasaki

Hiroshima Prefecture 108, 148, 190

Hobbs, H. H. 37, 175-76

Hocking, B. 20, 175

Hokkaido and Russian Far East (RFE) 71, 104, 113; initiatives between 123-27; link with Sakhalin 67, 79, 151; role in 177; 'soft' diplomacy 79

Hokkaido International Center 107

Hokkaido International Trade and Industry Promotion Association 125

Hokkaido Prefecture xv, 47, 71, 103, 111, 116-17, 122-24, 134, 163-64, 169, 184-85; bridge between Moscow and Tokyo 61; Comprehensive Development Plan 98; diplomatic activities 159; Government 57, 125, 159, 187; Hori Tatsuya, governor 125 , 160; imports from Russia 126; as Japan's northern gateway to world 123-27; link with Heilongjiang province 75 ; local attitudes in 124 , 161; Northern Territories issues 58; Sapporo linked with Shenyang 75; SNGs 124, 152, 159, 161, 171; strategy, importance of 160 ; ties with Nakhodka and Yuzhno-Sakhalinsk 125, 181; Yokomichi Takahiro, governor 125

Home Affairs Ministry see MOHA

Hooghe, L. 176

Hook, G. D. 17, 22, 103, 116, 119, 173, $175,184-86,188,190-91$

Hori Tatsuya, Hokkaido Governor 125, 160

Horie Masahiko 185

Horsmann, M. 16, 175

Hōsei University 57

Hosokawa Morihiro 72, 173, 181

Hughes, C. W. 187

human rights $15,32,140$; protecting 25 , 35, 186

Hyogo Prefecture 47, 57, 60, 93, 108, $132,145,163,181,184$; governor Ido Toshizo 132; leading SNG in Human Security 109; link with Guangdong province 75, 100; tie with Khabarovsk 70 
IBM 129

ICETT see International Centre for Environmental Technology Transfer

Ichioka Masao 60, 163, 173-74, 179-80, $182,185-87,192$

Idaho, missions to and from Libya 25

Ide Yoshinori 176, 179

Ikeo Yasushi 189

Imazu Takeshi 185

Immigration Control and Refugee Recognition Act 188

India $23,26,93$; federal system 32-33

Indonesia 93, 98, 100, 108; 'one village, one product' movement 180 ; SNGs in 70

industry: by-products 2 ; compatibility 72 ; pollution 2; revitalization programme 135; technology cooperation with China 100

Inergy Automotive Systems in Kitakyushu City 132

Inoguchi Takashi 174, 176

Inoki Takenori 178

international activism: intellectual and political lobbying 59-61; pioneers of 166; at SNG level 39; of SNGs in other countries 12

International Association of Mayors of Northern Cities 97

International Centre for Environmental Technology Transfer (ICETT) 93-94, 184 international cooperation (kokusai kyōryoku) 9, 87, 179; with China, Russia, South Korea and North Korea 99; collaborative problem solving 91; community-participation model of 109-11; concept of 89-90; as exchange 63,87 ; foundation year (kokusai kyōryoku gannen) 96; funding from private sources 186; networking and 27-30; in official foreign-aid budget 54; problem-solving as 61 , 97-98; programmes with PRC 99; slogan 'Kōryū kara kyōryoku e' 112; at subnational level 95; symbolic impact on SNGs' domestic political profile 94; three types of 97 ; see also SNGs

International Council for Local Environmental Initiatives (ICLE) 28

International Court of Justice in The Hague 148

internationalization (kokusaika) 68; domestic (uchinaru kokusaika) 1, 51; of local communities (chihō no

kokusaika) 43, 49; transborder

(sotonaru kokusaika) 1, 9, 51

Internationalization Consultation Centre

(Kokusaika Sōdan Sentaa) 43

International Relations literature 6, 9, 12; outside the Realist school 17; theories, assumption of unitary national government 13

International Union of Local Authorities (IULA) 28

INTERREG (the EU-based Inter-regional Initiative programme) 24

Iqbal, F. 43, 173, 177

Iraq 71; for peaceful resolution via United Nations 163, 192; US invasion of 192

Iraq War 163

Irkutsk 103

Ishihara Shintarō, Governor of Tokyo 162 , 188, 192; negative image of China 163

Ishikawa 180

Italy 22, 69

Iwakuni Tetsundo 173, 181

Iwate 180

Jacobs, A. J. 188, 192

Jain, P. 173-74, 177, 182, 186, 189

JAMLIF see Japan Municipal League for International Friendship

Jansen, M. 180

Japan 120, 184; civilian role 35; concept of sister cities 66 ; corporations as transnational actors 33; defeat by Allied Forces in 1945 154; diplomatic recognition of PRC 71; experience of opening to international forces 173; FDI, stock of 131 ; foreign affairs community 35 ; intellectuals support to SNGs for autonomy 59; internationalization (kokusaika) at grassroots level 3; multilateral institutional agreement 105 ; Northern Territories see Northern Territories; nuclear umbrella under Cold War conditions 70; ODA see ODA; pro-peace and anti-nuclear movements 148; reach to Asia-Pacific 128; and Russia 103, 158; SNGs see SNGs; and South Korea dispute over group of islands 158; special relationship with Brazil 70; twinning arrangements with Australia 77; US military bases in Okinawa 155; World Trade Centre (WTC) 118; see also Japanese government 
Japan Academy for Municipal Personnel (JAMP, Shichōson Akademi) in Chiba City 51

Japan Bank for International Cooperation (JBIC) 9, 46, 48, 88, 94, 108, 111, 174, 178, 184-86; 'road stations' project at Buddhist sites in Uttar Pradesh 108; and SNG partnership framework 108; survey of all Japanese prefectures, 2001100

Japan Center for International Exchange 60 Japan Center for Local Autonomy (Jichi Sōgō Sentaa) 44, 177

Japan-China: Citizens' Fisheries Agreement 75; Model City Plan 100

Japanese government (national and subnational) 40-42, 122; actors, monopoly on foreign affairs 5 ; arms-length approach to soft diplomacy 65 ; conflict 5 ; control on SNGs 45; decentralizing 38, 134; failure to protect local markets 21 ; hands-off approach 65 ; interface 108-09; international affairs departments or sections (kokusai-bu or ka) 8; international affairs, pluralized lineup of actors 39,169 ; international policy (kokusai seisaku) 9; international role (kokusai yakuwari) 9; management of international affairs 167-69; ministries 42-44; monopolistic behaviour 32; national borders and unified national government control over international affairs 14; offices, secondment and transfer of personnel between 55; official aid delivery, SNGs in 112; power structures, erosion of 16 ; principle of seikei fukabun 78; progressive (kakushin) administrations 45; reform 39; relationships $30-32,37,166$; remilitarization 141; reversal in flow of influence 82 ; rivalries between ministries 62 ; security policy intrusion at grassroots level 139; unitary system 30,32 , 62, 114, 140

Japan Exchange and Teaching (JET) programme $10,63,82-86,169,178$, 183; Alumni Association (JETAA) 84-85; budget for 83; Coordinator for International Relations from Shaanxi Province 84; international connections at community level 82 ; literature 84 ; national government 64 ; participants 50, 84; top-down decision-making process 83

Japan External Trade Organization (JETRO) viii, 9, 46-48, 50-51, 57, 128-29, 188; Ehime-Queensland case 136-37; 'Local-to-Local initiative' programme 114,137 ; mission to Okinawa 187; overseas offices 130 ; Press Release 188

Japan Foundation Center for Global Partnership 179, 181-82; surveys 70

Japan Intercultural Academy of Municipalities (JIAM) ix, 46, 51, 57, 178-79

Japan International Cooperation Agency (JICA) ix, 46, 48, 51, 88, 94, 97, 100, 108, 111-12, 183-84; Domestic Partnership and Training Department 185; grassroots technical cooperation projects, with funding from ODA budget 101; in Hyogo Center 47, 177; independent administrative institution 108; international training programmes 57; in Kobe and Kitakyushu 185; Sapporo office 107, 177, 185; Soviet Union/ Russia relationship at subnational level 103, 182; status 46; surveys, SNGs' strengths 107; training programme 93

Japan-Korea Strait Exchange Association of Governors of Coastal

Prefectures 104

Japan Lottery Association 186

Japan Municipal League for International Friendship (JAMLIF) (Kokusai Shinzen Toshi Renmei) 44, 75, 177

Japan Overseas Cooperation Volunteers (JOCV) 43, 184

Japan Research Institute for Local Government 182

Japan-Russia Association of Mayors of Japan Sea Coastal Cities 95

Japan-Russia Coastal Mayors' Association 7, 95, 103

Japan Sea 169; naming of 121; region, importance and potential 121; revival 120; side (including Kyushu, Niigata, Hokkaido) 115; SNGs 95

Japan Sea Coastal Cities Council for Japan-North Korea Friendship and Trade Promotion 105

Japan Sea Economic Group (JSEG) (kan Nihonkai keizaiken) 117, 119-23; 
assessments of 122; concept, bilateral and submicro-regional activities 123

Japan Sea Group Subnational

Governments International Exchange

and Cooperation Summit 104

Japan Sea Rim Zone 82, 184

Japan Silver Volunteers, Inc. (JSV) 183

Japan-Soviet Far East-Hokkaido

Friendship Exchange Conference 125

Japan-Soviet Peace Treaty 80

Japan-US Defence Cooperation guidelines 149,153

Japan-US security relations see United States

JBIC see Japan Bank for International

Cooperation (Kokusai Kyōryoku Ginkō)

JET see Japan Exchange and Teaching programme

JETRO see Japan External Trade

Organization

JIAM see Japan Intercultural Academy of Municipalities

Jiangsu 74

JICA see Japan International Cooperation Agency

JICA Partnership Programme (JPP) 47

Jichitai Kokusaika Kyōkai see Council of Local Authorities for International Relations

Jilin Province 104

Johnson, C. 186, 191

Johnston, E. 163, 190

Joint Standing Committee on Economic Cooperation between Hokkaido Prefecture and the Russian Federation Far East Region 103

'Journey to Sakhalin' programme (1981) 80

JSEG see Japan Sea Economic Group

Kabashima Hideyoshi 177

Kadena 156

Kagawa 163; and Shaanxi, exchanges between 84

Kagoshima, prefectural offices 56

Kaifu Toshiki, Prime Minister 161

Kajimoto Shushi 189-90

Kamimura Naoki 145, 189-91

Kanagawa Ken 133, 173-74, 179

Kanagawa Prefecture 57; Economic Trade office in Dalian 130; Governor Nagasu Kazuji 61, 142, 180

Kanamori Hisao 185

Kanbara Masaru, Professor 182, 190

Kaneyama 45
Kangwon Province 104

Kansai 115, 117, 119; International Airport 118; Science City 118

Kansai Economic Federation 186

Kanto Area Xv, 115

Karnataka 23

Kasumigaseki 97

Katayama Yoshihiro, governor of Tottori 82, 163, 180, 182-83, 186, 192

Katsunuma Town, wine-making in 135

Kawasaki 163, 188

Kazo City assembly 151

Keating, M. 175-76

Keicho Diplomatic Mission 174

Kenmotsu Kanae 180, 183, 192

Keohane, R. O. 6, 15, 174

Kerala 23

Kershaw, D. 181

Khabarovsk 80, 103, 125, 181

Kholmsk 127

Kim Il-Sung 81

Kincaid, J. 175

Kinki Area xv

Kitagawa Masayasu, governor of Mie Prefecture 131

Kitahayashi Mitsuaki 181

Kitakoyama Industrial Estate in Geino 132

Kitakyushu City 93; and Dalian 75, 100, 112; and Inchon City 'Small and Medium Enterprise Technical Traineeship' (2002) 104; technical assistance to Chongqing and Surabaya for waste management 108

Kitakyushu International Techno-cooperative Association (Kitakyushu International Training Association) (KITA) 93-94, 184

Kitami and Polonaisk cities 80

Kitayama Toshiya 173, 177

Knight, J. 184

Kobe City 47, 60, 93, 118-19, 132-33, 149, 163, 184; administration 149; anti-nuclear stance $149,151,153$, 164,171 ; city offices of 57 ; and Foreign Ministry and Defence Agency relationship 150; foreign warships 164, 190; International Department 58, 178; legal basis for resolution 150; and Seattle 67; SNG as 'Best Portal Zone' for business 132; and Tianjin 71, 74-75; top 11 corporate tax-payers and foreign-owned corporations 133 
Kobe Inc. (Kōbe kabushiki kaisha) 118

Kobe International Cooperation Center (KICC) 184

Kobe model (anti-nuclear port) 149, 151, 153, 164, 171

Kochi Prefecture 152-53; attempts to follow 'Kobe model' 164

Koizumi, Prime Minister, structural reform initiatives of 135

Komai Hiroshi 180

Koppel, B. 176

Korea 67, 69, 130, 178, 184; CIRs 178; Peninsula 172; residents in Japan 2; SNGs in 70; see also North Korea; South Korea

Korean Local Authorities Foundation for International Relations (KLAFIR) 104

Korean Society for Cultural Relations with Foreign Countries (Chōsen Taigai

Bunka Renraku Kyōkai) 105

Korsakov 127

Krauss, E. 179

Kumamoto City, sister-city tie with Heidelberg 92

Kumamoto Prefecture: sister linkage with Montana 72; work with Oregon 136

Kume Ikuo 173

Kunashiri island 159

Kuril Islands 160

Kusumoto Toshio 178

Kwan, C. H. 175

Kyongsangnam 104

Kyoto 163; World Historical City summit 95

Kyushu xv, 99

LAL see Local Autonomy Law

Large-scale Retail Stores Law 36

LAT see local allocation tax

Law Concerning Measures to Ensure the Peace and Security of Japan in Situations in Areas Surrounding Japan (Shūhen jitai anzen kakuho-hō) (SASJ law) 151-53

LDP see Liberal Democratic Party

League of Councillors to Promote Friendship Relations between Sakaiminato City and North Korea 81

Liaodong peninsula, SNGs in 22

Liaoning 74

Liberal Democratic Party (LDP) 35; defeat of 199336 local allocation tax (LAT) (chihō kōfuzei) $43,45,54,83,88$

Local Autonomy College (Jichi Diagokkō) 51

Local Autonomy Law (LAL) 41, 45; Article 14190

Local Employees Overseas Dispatch Law (Chihō kōmuin kaigai haken-hō) 53

Local Exchange Group Concept (kyokuchi kōryūken kōzō) 96

Local Government Declaration to the World Summit on Sustainable Development 176

Local Government-JBIC Partnership Promotion Forum 48

local issues: era of slogan 'chihō no jidai' 68; government xiii, 40; local bonds (chihōsai) 43

local ODA see ODA, local; local people (shimin sanka) in public life 143; local public entities (jichitai) 40

London 50

Louisiana 180

Luxembourg administration 54

McConnell, D. L. 52, 84, 177-78

MacDougall, T. 173-74, 177

Maharashtra 23

Maizuru City link with Nakhodka 73

Makuhari 130

Malaysia 93; 'one village, one product' movement 180 ; SNGs in 70

Marshall, A. 16, 175

Massachusetts, Burma Law 25

Mathews, J. T. 16, 174-75

Matsue City 100

Matsuo Takafumi 180

Matsushita Keiichi 57, 173, 179

Mayors for Peace Movement 141, 147-48; and Hiroshima's role 165

Meiji constitution 41

Meisai University 57

Mekata Motoko 34

Menju Toshihiro 60, 70, 174, 176, 180-81, 184

Mercedes-Benz 22

METI see Ministry of Economy, Trade and Industry

Metropolis 28

Mexico 27

micro-regionalism 22, 119, 121, 123

Mie Prefecture: governor of 184; Industrial Site Development Division 132 
Minagawa Shugo, Professor 191

Minamata City 93

Ministry of Agriculture, Forestry and Fisheries (MAFF) 46

Ministry of Economy, Trade and Industry (METI) 33, 42, 136

Ministry of Education (ME, now MEXT) 9

Ministry of Finance 34

Ministry of Foreign Affairs see MOFA

Ministry of Home Affairs see MOHA

Ministry of International Trade and Industry (MITI) 9, 46-47

Ministry of Public Management, Home Affairs, Post and Telecommunications (Sōmushō): responsibility for SNGs 174

Ministry of Transport 122, 135

Minobe Ryōkichi, governor of Tokyo 40, $57,80,153,179$

Minsai Center 94

Misumi Town 94, 112

MITI see Ministry of International Trade and Industry

Miyagi Prefecture 132, 134, 174, 183; see also Sendai City

Miyazaki Prefecture 56, 180; office in Hong Kong 130

Miyazaki Tatsuo, Kobe mayor 149

Mizukami Tetsuo 173

Mochizuki Kiichi 123, 186-87

MOFA viii, 1, 35, 39, 43, 67, 89, 100, 112 , 178; blocking rise of SNGs 52-53; Council on ODA Reforms 107; Diplomatic Bluebook 177; Economic Cooperation Bureau 43, 56, 185; Gaikō Fuoramu 174; Hokkaido's activism, opposition to 159 ; international bureaucratic domain 33 ; international contributions, kokusai kōken 87; Kobe non-nuclear formula 150; and North Korea 163; pluralizing actors and decentralizing to SNGs 40, 167-68; regulating SNGs' 'local' foreign policies $39,52,81,135$; to SNGs from ODA budget 184; see also SNGs, as international actors

MOHA (Sōmushō Home Affairs, SHA) viii, 9, 39, 46, 49, 55, 87, 174; in CLAIR 44; financial control over SNGs 43, 54; international advisory board (kokusai iinkai) 52; international cooperation 178; international section (kokusai shitsu) 44; in JET programme 44; Jichishō 174; LAT mechanism 100; support for slogan 'Kōryū kara kyōryoke e' 90; support for SNGs $42,52,54,81,86,111$; two-way engagement between national and subnational levels 53

Mongolia 70, 108, 120-21, 184; multilateral institutional agreement 105 Morgan, A. 188

Moscow 125

municipalities (shichōson) 41; current prospect of mergers 180,192 ; diplomacy (chihō gaikō) 9; by prefecture xiii

Muramatsu Michio 43, 173, 176-77

Myanmar 26

Nagasaki 56, 76-77, 144, 145, 147, 180, 183; Flag Incident in 1958 76; Itō Itcho, mayor of 148; and St Paul, sister-city relationship 67, 180

Nagasaki Prefecture 56, 75, 136, 148, 183; Chamber of Commerce 75; contacts with China 75, 192; and Fujian Province 75-76; with Fuzhou City 76; port of Deshima 66

Nagasu Kazuji, Governor of Kanagawa Prefecture 61, 142, 174, 179-80

Nago City 128; 1997 referendum in 156; Mayor Kishimoto Tateo 128; as tax-haven 129

Nagoya and Los Angeles linkage 67

Naha City 75

Nakagawa Gun assembly 152

Nakagusuku New Port industrial complex 128

Nakamura Akira ix, 186

Nakasone Yasuhiro, Prime Minister 150; government 146

Nakazono Satoshi 186

Nakhodka 73, 125, 127, 181

Nara Prefecture 18, 108

National Mayors Association of Japan 81 nation state: primacy of 14 ; transformation of system 168 natural economic territories (NET) 119

Negishi Mayumi 131, 188

Nemuro region 80, 161; and Hokkaido Development Agency 191; regional economy 192

Nepal 100; SNGs in 70

Netherlands, the 25 


\section{Index}

Newhouse, J. 22, 175

New York 50

New Zealand 50, 69; SNGs 27

NGOs see nongovernmental organizations

Nicholson, M. 17, 174-75, 187

Nihon Toshi Sentaa 174, 178, 182, 187

Niigata City 60, 67, 71, 95-96, 104-05, 121, 134, 182; authorities 163;

Citizens' Hospital 102; Foreign Affairs Division 58; international office 173; linked formally with Khabarovsk 181; linked with Harbin 74; Mayor Wakasugi Motoki 134; Mayor Watanabe Kōtarō 81, 134; in Russian and North Korean affairs 57,81 ; as strategic operator for ura Nihon 122

Niigata Prefecture 57, 75, 111, 119-20, 123, 134, 164, 184; Cancer Centre 101-02; and China 101; cooperation with RFE 103, 185; in developing Sea of Japan Grouping 58; and Heilongjiang Province 74, 101-02; International Affairs Division 58; major medical institutions 102; SNG 110; University Faculty of Medicine 102 Nikko City 151

NIMBY (not in my backyard): Okinawa 154; Zushi 157

Ninagawa Torazō, governor of Kyoto 179

Nishikawa Jun 183

Nishimura Kunio 183-84

Nomura Securities 128

Nonaka Hiromu 152

nongovernmental organizations (NGOs) 5, 34, 198; educational institutions 92; projects 27; rise of 176; role in Japan's foreign policy 189

'no-nuclear certificate' ordinance 152

North America 69; SNGs in 6, 12,88

Northeast Asia 89; multilateralism 105-06

Northern Regions Centre (Hoppō-ken Sentaa) 124, 184

Northern Territories 162, 164; dispute 80, 161 ; as obstacle to national-level relations 124; Return Movement 161; see also Hokkaido Prefecture; Russia

North Korea (Democratic People's Republic of Korea) 111, 120-21, 164, 171; abductions of Japanese nationals 78; diplomatically sensitive partners 138; emigrants 81 ; Japanese SNGs and ODA 104-05; missiles towards Japan 78; multilateral institutional agreement
105; North Territories 159; nuclear programme 78; for Sakaiminato 182; SNGs taking international action 99

Norway 184

nuclear-equipped warships, protests against $149-50$

Nye, J. S. 6, 15, 174, 179

Oceania 69

ODA (Official Development Assistance): bottom-up policy in projects 100,112 ; budget 35, 98; Charter 1992 107; delivery 167 ; in international engagements 88 ; JICA supported project 94; local (jichitai) 1, 27, 91-92, 97-98, 112, 183; national programme 97-98, 112; policy, developments in 106-07; policy, reports on reform of 96; projects involving SNGs 89, 99, 106; 'soft infrastructure' of 48; technical cooperation 46; training programmes 100; White Paper on role of SNGs 107

Ogata Sadako 176

Oita Prefecture 108, 163, 180; governor Hiramatsu Morihiko 180, 184; 'One Village One Product' (isson ippin) 58; sister city Wuhan 180

Okada Shin'ichi 188

Okayama Prefecture 78; International Affairs Division 58; and San Jose, linkages 67; and South Australia 77

Okimi Town 190

Okinawa 98, 113, 116-17, 154-57, 169; appeal to US authorities and opinion-makers 165; cheap labour costs 128; economic geography 127-29; Governor Öta 154-55, 157, 191; international tourists in 98,187 ; land for US bases 155, 164, 191; against national government in Supreme Court 164; rape incident 154-55; return of sovereignty to Japan 154

Okinawa Prefecture 56, 149, 154; governor Inamine Keiichi 156; link with Fujian Province 75

Okuyama Yutaka 161, 182, 187, 191

Omnibus Decentralization Act 54

Omura City ties with Minhang 76

'one village, one product' movement 58, 101,180

Organization for Economic Cooperation and Development (OECD) 118, 183

Orr, R., Jr 176 
Osaka Building 118

Osaka Business and Investment Centre (O-BIC) 118

Osaka City 118

Osaka Prefecture 118-19, 133, 163;

Bay Area Development Programmes

118; Chamber of Commerce and Industry 118; 'over-concentration' within Kansai 118

Ota City, international academy of 135

Ōta Masahide, Okinawa

Governor 154-55, 191

Otaru City 80, 127, 181

O'Toole, K. 28, 77, 176, 180, 182; study of sister-city relationships 77

Ōtsu Hiroshi 51, 122, 174, 182, 187-88

Outlines for Planning for Local International Exchange Promotion 52

Overseas Dispatch Law 54

Overseas Economic Cooperation Fund (OECF) 177

Pacific Basin Economic Council (PBEC) 30

Pacific Economic Cooperation Council (PECC) 30

Pacific growth corridor (Tokyo, Nagoya and Osaka) 115

Paris 50

Parker, P. 181

peace: advancing global 35 ; and anti-nuclear movements $141,145-48$; constitution 34; SNGs agenda for internationally $141,144-46,164$

Peace Boat (1985) 80

Peace of Westphalia in 164816

People's Republic of China (PRC) see China, People's Republic of

Perkmann, M. 175

Philippines, the 93; 'one village, one product' movement 180

Pierre, J. 174

Plan to Promote Economic Exchange between Hokkaido and Sakhalin 103

pluralism 33, 139; 'complex interdependence' model 17; in ODA policy 92

pluralization (tayōka): diplomacy 33; of foreign policy $5,62,168$

Policy on the Status of Community Groups in Charters Promoting Local Government International Cooperation 53

Pollard, V. K. 191; study detailing Okinawan grievances 191 pollution: control 99; problems 100

Port Law (kōwan-hō) 150

Ports and Harbour Law 188

post-Cold War conditions 116; geo-strategic 116; globalizing environment 137; world 87

Postel-Vinay, K. 102-03, 127, 185,187

post-war: 1947 constitution, chapter on Local Self-government 41; evolution of subnational international cooperation 95-97; industrialization and urbanization 2; Japan Sea area 120

prefectures (to, dō, fu, ken) xv, 41; capitals xiii

Price, R. 175

Primorye 80

Procter and Gamble 132

Pursiainen, C. 20, 23, 175; study of Russian regional SNGs 20

Pusan 104

Quebec 22

Queensland: and Ehime, Memorandum for Economic Cooperation 136; Trade Division of Government 188

Rason city 105

Reagan administration 25, 60

Realpolitik 14

refugees 25,140

regional international associations

(chiiki kokusaika kyōkai) 43

regionalization 21,29

Reid, P. 176

Reilly, A. 173

RFE see Russian Far East

Rio Earth Summit in 199228

Rix, A. 177,185

Road Paving Technology Cooperation Project for Cold Areas of Heilongjiang Province 101

Road Transportation Law 135

Rosenau, J. N. 15, 174; schema 17

Rozman, G. 122, 174-75, 187

Russia 23-25, 34, 67, 69, 89, 159; diplomatically sensitive partners 138 ; entry into APEC 161; Governors meetings 163; and Japanese SNGs 102-04; and Japan, territorial dispute 123, 159-60; marketization and political decentralization 124 ; multilateral institutional agreement 105; and North Korea 78 
Russian Far East (RFE) 61, 86, 103-04, 111, 120, 121-22, 159, 164, 171-72; foreign investment and taxation 126; Japan's share of trade 126; resources 123; Siberia-Japan Association 96

Ryukyu Kingdom 154

\section{Saga 104, 180}

Saitama Prefecture 108, 133; offices 56

Sakaiminato City: commercial links with North Korea 134; Hunchun as sister-city 105; Order of Goodwill Second Class Award from North Korea 105; Wonsan City as sister-city $81,105,134,182$

Sakamoto Yoshikazu 59, 174, 179

Sakhalin (Russia) 80, 93, 103-04, 122-23, 125, 160; disaster prevention measures 159; export of marine products 126; four disputed islands 102; and Hokkaido agreements 127; and Kobe's declaration 164; low self-sufficiency in food 124; oil and gas development projects 124; Trade and Industry Association office 125

Sakhalin-1 and Sakhalin-2 oil and gas development projects 127,161

Samuels, R. J. 173

Sandinista administration 25

Sapporo City 60, 80, 163; City Office 47, 57, 97; Itagaki Takeshi, Mayor of 97; Winter Olympics 80; see also Hokkaido Prefecture

Sasaki Nobuo 184

Sasebo City 75; link with Xiamen City 76

SASJ law see Law Concerning Measures to Ensure the Peace and Security of Japan in Situations in Areas Surrounding Japan

Satō Eisaku, Prime Minister 143, 159

Satō Kōichi 183

Sawaji Osamu 178

Scalapino, R. 119, 186

Schep, G. J. 176, 183

Schirmer, D. B. 190-91

SDF see Self Defence Forces

Sea of Japan, Sea of Peace 120; see also Japan Sea

Second World War, defeat in 173

Segal, G. 31, 176

Self Defence Forces (SDF) 146; facilities to Hokkaido 160; new legal capacity 151
Sendai City 132, 183; international information industrial zone 135

Senkaku Islands 158

Seoul 50

Sergounin, A. 175

Serita Kentarō 184, 186

SHA see MOHA

Shaanxi and Kagawa 84

Shandong China 74; economic connections with South Korea 23, 26; SNGs in 22

Shanghai 180; Club 76; Zhu Rongji, Mayor 26

Shiga Prefecture 51; international conference on water quality and lake management 95

Shikoku Island xv; prefecture on 152

Shikotan island 159, 161

Shindō Muneyuki 173-74, 176-77, 189-90

Shipbuilding Industry Group Corporation in Fujian 173

Shizuoka 56

Shuman, M. H. 27, 173-76, 181; study of German SNGs 189

Siberia 103-04

Siddle, R. 191

Singapore $50,130,181$

Sister Cities International 180

sister cities/partnerships/relationships 7, 10, 27, 63, 66, 79, 86; with Australia 77-78; boom in 72; with China 73-77; combined budget of SNGs 181; commercial arrangements 28,72 ; and cooperative relationships 50 ; diplomatic symbolism of programmes 88; economic motivation 72 ; geographic focus 70-71; Japanese and Australian survey 77; in Japan, roots of 66-67; JET similarities and differences 64-65; links as vehicles for economic ties 133-35; with municipalities in Nicaragua 25; North Korea 80-82; for peaceful international relations 181 ; period of growth in 68-69; with Russia 79-80, 181; SNGs' motivation 73; stages of development, post-war 67-69

Smith, S. A. 174, 191

SNGs (subnational governments) 22, 29; 30 per cent autonomy (sanwari jichi) 21, 45; action against repressive regimes 26; agenda against nuclear weapons 144-45; agenda for international peace $141,144-46$; amalgamating, current trend of 171 ; 
ambiguous status of 14,38 ; anti-apartheid sanctions 25; Anti-Nuclear City Declarations 146; in Asia 166; challenges for international cooperation 109; China, budgetary allocations 74; and CLAIR 84; comparative perspective 19-21; competition among 42, 115; Consortium 147; cooperative arrangements 111 ; diplomatic skills 50 ; diversity 41-42; domestic context 35-37; domestic status as international actors 39,89 ; donor 27 ; as economic actors 113-14, 117; economic diplomacy, weak link in 131-33; engagement, key areas 21-27; in Europe and the United States 20; evolution as international actors 6-9, 167; exchanges, developing 85-86; expenditures on projects 54; features as international actors 17-19; financial shortages 36 ; foreign counterparts, mutual learning with $7,38,88,90$; foreign investment, attracting to localities 131; foreign policy, impact on 5 ; funding $21,54-55,88$; future roles as 172; global network 20 ; hard diplomacy 2, 140; income and direction 4; institutionalizing international cooperation 53 ; interests and motivations for participating 71-73, 89, 92-95; as international actors $13-17,27$, $32,69,170-72$; international capacity, building 56-59; in international cooperation programmes $27,87-88,92$; international sections (kokusai kōryūka) 52, 90; JET programme 83, 85; LAL, international role in 53 ; legal and constitutional power 10 ; local administrators 169-70; location, size and importance 20; mixed line-up in international activities 179 ; motivations for international cooperation 92-95; and national goals and objectives 114; and national security 139; national taxation system, change in 55 ; NGOs in various countries 55, 183; non-state actors 17 ; North Asia, national-level resistance in 122; Okinawa 138, 156; overseas economic linkages 21, 54, 113-14; partnerships with organizations in international cooperation 107-08; policies, legislation, budgets and personnel 36, 51-56; political resistance on 175; politics, significant implications 166; quasi-diplomatic status 17; quest for action 62; reach 4-6; restrictions on 24; sanctions on oppressive foreign regimes 25 ; Sea of Japan, around 45, 99, 113; self-funded cooperation programmes 100; skills at grassroots level 170; 'soft' programmes, role in 63,65 ; technical cooperation and aid activities 184; territorial dispute, views and responses on 159 ; total revenue 45 ; transnational coalition of 91,98 ; transport arrangements 135; types of international activities 55; unilateral assistance by 91 ; utility in international affairs 26, 156

SNGs and ODA 88, 99; delivery, major players in 96-97; formalizing involvement 106; 'local' and national 91, 98-105; projects in 89

SNGs-national government relations 5, 44-46, 89, 167-68, 171; administrative expertise 169; autonomy from 4, 21, 45,169 ; challenging foreign-policy stance 3; comparison with non-government organizations and 18-19; diplomatic issues in hard diplomacy 162; gain for 93; national security and international politics 135 , 140; opposition to stated policy 25 ; in partnership 168; policy and 51-53; reasons for expanding role 109; subset of 18; support of activities 138; see also MOFA; MOHA

Soka University 59

Sōmushō Home Affairs (SHA) see MOHA

South Africa, diplomatic relations with PRC 26

South America 69

South Australia 78; see also Australia South Korea (Republic of Korea) 104, 120-1; economic contacts between Shandong and 23, 26; island SNGs from 98; multilateral institutional agreement 105; overseas branches 181

South Vietnam 189

Soviet Far East 117, 120; see also Russian Far East

Soviet Union 60, 71; break-up 78, 80, 124; invasion of Afghanistan 163; and Japan relationship, thaw in 120 ; see also Russia 
Spain 27

Special Action Committee on Okinawa (SACO) 155

special designated zones (tokku) 135-71; bureaucratic resistance to 135

Spiro, P. J. 26, 28, 176

Sports Exchange Advisors (SEAs) 49, 83

Sridharan, K. 26, 32, 175-76; study, international role of Indian states 23

Sri Lanka 26

Steiner, K. 79, 173-74, 176-77, 182

Stephan, J. J. 191

Stevin 25

Strange, S. 175

subnational governments see SNGs

Sugai, N. 180

Sugioka, A. 60

Sum Ngai-Ling 175

Sumi Kazuo, leading critic of Japan's ODA policy 176

Sumita Kiyoshi 56, 177-78

Summary of Records of Canada-Japan Twinning Forum 182

Summit for International Exchange and Cooperation between Regional Governments in Northeast Asian region 105

Sweden 184

Switzerland 22

Sydney 50

Tabe Yoshihiro 178

Taga Hidetoshi 174

Taiwan 23, 93; inauguration of President Chen Shui-bian 162

Takahashi Masaki 177

Takasaki City, multinational study group of global environmental problems 98

Takeshima islands 158

Takeshita administration 180

Takinoue Town 80

Tamaki Kazuhiko 190

Tamil Nadu 23; chief minister of 26

Tanaka Akihiko 176, 179

Tanaka Kakuei, Prime Minister 119

Tanaka Naoki 60, 97, 184; Northern Region concept (Hoppōken kōsō) 98

Tang, J. T. H. 175-76

territorial issues 158-62; dispute between Japan and Russia 102-03, 121, 123, 126, 141; fragmenting of public policy 12

Thailand 93, 100

third sector organizations (kyōkai) 8
Tiananmen incident 26

Tianjin area, SNGs in 22

Todhunter, M. 180

Tohoku Area xv

Tokdo islands 158

tokku see special designated zones

Tokugawa period 67

Tokushima 163

Tokyo 20, 47, 50; phenomenon 115; public works programmes 120; Rinkai Fukutoshin 130; Wangan 130; World Major City summit 95

Tokyo Metropolis (Tokyo-to) 40-41; Government 95; link with Moscow 79

Tokyo-Nagoya-Osaka Corridor 128

Tokyo-Nagoya-Osaka Pacific belt 113

Tomakomai 127

Tomino Kiichirō, mayor of Zushi City $157,174,179,184,186$

Toshiba 132

Tottori Prefecture 20, 104-05, 111, 123, 164; governor Katayama 61, 105, 134; links with North and South Korea 61; and North Hamgyong Province 182; Sea of Japan Grouping 58; SNGs in 82, 171

Toyama City link with Qinhuangdao City 100

Toyama Prefecture 56, 123; Kangwon Province 'Cutting Edge Biological Agricultural Chemicals Technology Traineeship' 104; tie with Primorsky region 103

Tsujiyama Takanobu 182

Tumen River Area Development Programme (TRADP) 121

Turkey 93

Uchida Kazuo 185

umbrella model of economic growth 117 , 119; of Tokyo 115

UN see United Nations

United Cities and Local Governments (UCLG) 28

United Kingdom 27, 69; CIRs 178; FDI stock 131; 'twin city' concept 66

United Nations: Economic and Social Council, Mayors for Peace Movement (Heiwa Shichō Kaigi) as Category II NGO with 147; General Assembly 148; Independent Commissions on Disarmament and Security Issues 145; to meet Millennium Development goals 28; Office for 
Coordination of Humanitarian Affairs (OCHA) 118; official resistance 145; Second Special Session on Disarmament 147; Special Arms Reductions Conference 145

United States 40, 55, 98, 131, 178, 184; allocation of power to SNGs in 24; bases in Okinawa, local resistance to 156; CIRs 178; exchange activities 181; government nuclear policy 148 ; invasion of Iraq 11, 63; Iran, policies against 25; military bases in Japan 146, 149; nuclear policy 26; nuclear umbrella 146, 149; occupation (Okinawa) 145; 'one village, one product' movement 180 ; response to Japan's mounting trade surplus 64; Seventh Fleet 149; sister-city relationships 28; SNGs 21, 140; South Africa, government policy 25; and Soviet Cold War divide 73; states, offices overseas 22; strategic designs 34 ; troops in Japan 153; trophy connections with cities in 71

United States (US)-Japan Defence Cooperation Guidelines 141, 149; revised 151-3

United States (US)-Japan Local Autonomy Forum 2002177

United States and Japan relations: debate on 162 ; security relationship 32,142 ; Status of Forces Agreement 156

United States (US)-Japan Security Treaty 141, 145, 149-50, 157, 167; manifestation inside Japan 153; site of continued tensions between national and subnational governments 158

Universal Studios Japan 118 ura Nihon (hidden or backdoor Japan) 116, 119-23

US see United States

Utsunomiya Hiroshi, Director-General of Hyogo Prefecture 60, 179, 186

Vassilieva, A. 103, 185

Vietnam 143

Vietnam War 149; campaign against 142; measures against 25

Vladivostok 125; Coastal Trade Fair in 134

Wakayama Prefecture technology link with Florida 58

Wakkanai 125,127 ; and Nevesk 80
Warring States period 66

Watado Ichirō 57, 180

Watanabe Osamu 48

Watanabe Sumio 173

West Bengal 26

WHO see World Health Organization

Willetts, P. 16, 175

Williams, B. 79, 125, 182, 187, 191-2

Wonsan City link with Sakaiminato City $81,105,134,182$

World Bank 23

World Big City Convention 95

World Conference Against Atomic and Hydrogen Bombs 145

World Conference of Mayors for Peace through Inter-City Solidarity 148

World Federation of United Cities (FMCU-UTO) 28

World Health Organization (WHO) 118, 148

World Summit on Sustainable Development in Johannesburg 28

World Trade Organization (WTO) 21

Xiamen City 75-76

Xixia Wang Imperial Mausoleum project 100

Yabuno Yūzō 115, 173, 186

Yamagata Prefecture 45

Yamaguchi Prefecture 104, 122, 188

Yamamoto Tadashi 174-76

Yamato City 135

Yamatotakada City and Lismore 77

Yamazaki Mitsuru 186

Yellow Sea Economic Zone 122

Yinchuan City 100

Yokkaichi City 93, 135; ICETT for international cooperation in environmental management 94

Yokohama City 41, 57, 163; Asukata Ichio, Mayor 7, 57, 142; closure of streets to US army vehicles 171; hosting German, British, Canadian and US trade centres 133; Minato Mirai 130; Second Asian Table Tennis tournament 143; and Shanghai 71,74

Yokomichi Takahiro, Hokkaido Governor 79; Dialogue '92 160

Yokota 112; and Roiet Province 94 
220 Index

Yoshida Hitoshi x, 60, 178-85, 188; study of Japan's local-level international exchanges 67

Yoshida Shinichirō 59

Yoshida Yoshiaki 146

Yuzhno-Sakhalinsk 125, 127, 159;

see also Hokkaido Prefecture

Zhejiang 74

Zheng Yong-Nian 175

Zushi City 149, 154, 157-58; concern for environment and NIMBY

opposition 157; housing complex

issue 157, 165; mayor Tomino

Kiichirō 157, 174, 179, 184, 186 
eBooks - at www.eBookstore.tandf.co.uk

\section{A library at your fingertips!}

eBooks are electronic versions of printed books. You can store them on your PC/laptop or browse them online.

They have advantages for anyone needing rapid access to a wide variety of published, copyright information.

eBooks can help your research by enabling you to bookmark chapters, annotate text and use instant searches to find specific words or phrases. Several eBook files would fit on even a small laptop or PDA.

NEW: Save money by eSubscribing: cheap, online access to any eBook for as long as you need it.

\section{Annual subscription packages}

We now offer special low-cost bulk subscriptions to packages of eBooks in certain subject areas. These are available to libraries or to individuals.

For more information please contact webmaster.ebooks@tandf.co.uk

We're continually developing the eBook concept, so keep up to date by visiting the website. 